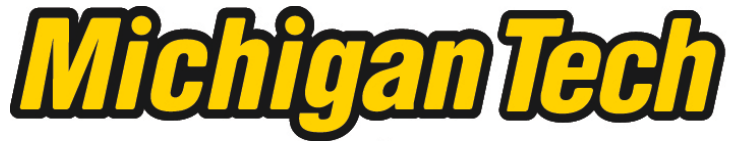 \\ Michigan Technological University Create the Future Digital Commons @ Michigan Tech
}

2011

\section{Evaluation of the performance and cost-effectiveness of pavement sections containing open-graded base courses}

Abdul A. Koroma

Michigan Technological University

Follow this and additional works at: https://digitalcommons.mtu.edu/etds

Part of the Civil and Environmental Engineering Commons

Copyright 2011 Abdul A. Koroma

\section{Recommended Citation}

Koroma, Abdul A., "Evaluation of the performance and cost-effectiveness of pavement sections containing open-graded base courses", Dissertation, Michigan Technological University, 2011.

https://doi.org/10.37099/mtu.dc.etds/247

Follow this and additional works at: https://digitalcommons.mtu.edu/etds

3 Part of the Civil and Environmental Engineering Commons 


\title{
AN EVALUATION OF THE PERFORMANCE AND COST-EFFECTIVENESS OF PAVEMENT SECTIONS CONTAINING OPEN-GRADED BASE COURSES
}

\author{
By \\ Abdul A. Koroma \\ A DISSERTATION \\ Submitted in partial fulfillment of the requirements for the degree of \\ DOCTOR OF PHILOSOPHY \\ (Civil Engineering)
}

MICHIGAN TECHNOLOGICAL UNIVERSITY

2011

(C) 2011 Abdul A. Koroma 
This dissertation, "An Evaluation of the Performance and Cost-Effectiveness of Pavement Sections Containing Open-Graded Base Courses," is hereby approved in partial fulfillment of the requirements for the degree of DOCTOR OF PHILOSOPHY IN CIVIL ENGINEERING

Department of Civil and Environmental Engineering

Signatures:

Dissertation Advisor

Dr. Ralph J. Hodek

Department Chair

Dr. David Hand

Date 


\section{E D I C A T I O N}

To my two deceased younger sisters Salamatu and Isatu whose memories will forever remain with me. 


\section{TABLE OF CONTENTS}

PAGE

LIST OF FIGURES ....................................................................

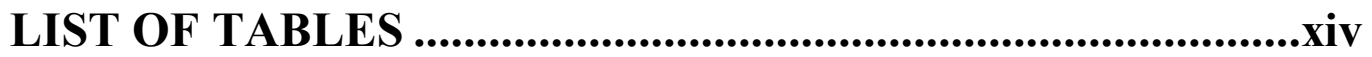

ACKNOWLEDGEMENT .......................................................xvi

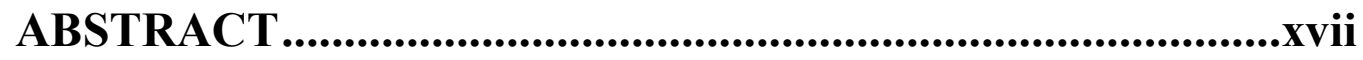

\section{GENERAL INTRODUCTION}

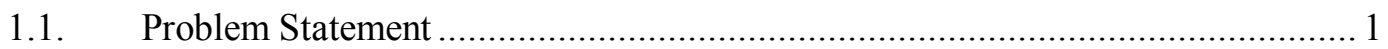

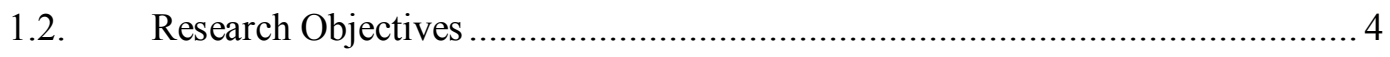

1.3. Working Hypothesis and Research Goals .................................................... 5

1.3.1 Working Hypothesis ............................................ 5

1.3.2 Research Goals ......... ......................................6

1.4. Research Significance.................................................. 6

1.5. Research Methodology and dissertation outline ................................. 7

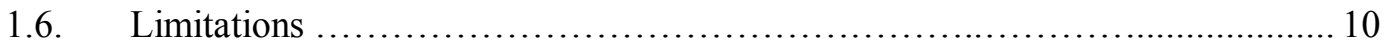

2. WATER IN PAVEMENT STRUCTURES .........................11

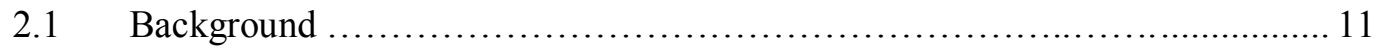

2.2. Moisture Effects in Pavement Systems ................................. 12

2.3. Moisture Related Pavement Distresses ................................. 17

2.4. Ways of minimizing moisture damage in pavements ......................... 20

2.4.1. Surface Drainage Considerations .............................. 21

2.4.2. Subsurface Drainage Considerations ............................ 21

2.5. General Description of Subsurface Technology .................................. 22 
2.5.1. When to include subsurface Drainage Features ................................. 23

2.5.2. Components of a Drainable Pavement ..........................24

2.6. Hydraulic and structural considerations of subsurface drainage .................. 27

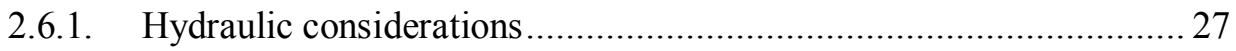

2.6.2. Structural Considerations ...................................... 29

2.7. Evolution of Subsurface considerations in pavement design .................... 31

2.7.1. Incorporating Drainage Factors into the AASHTO

Pavement Design Guides ..................................... 32

2.7.2. The Mechanistic and Empirical Pavement design

Consideration of subsurface drainage ........................................ 36

2.8. Factors Affecting the Efficiency of Subsurface Drainage ................................. 39

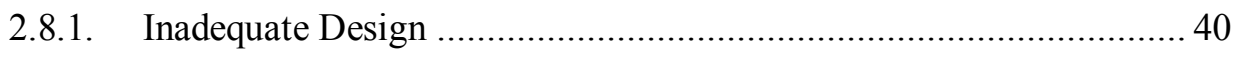

2.8.2. Improper Construction ........................................................... 41

2.8.3. Inadequate Maintenance .................................... 42

2.9. A Summary of Highway Agencies`Experiences with Permeable

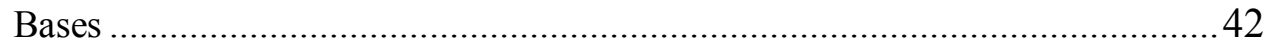

3. EXPERIMENTAL PROGRAM...........................................45

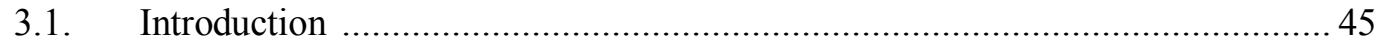

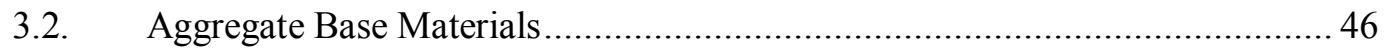

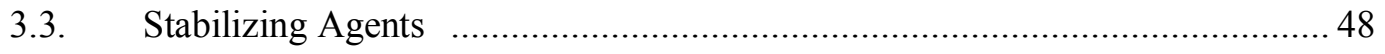

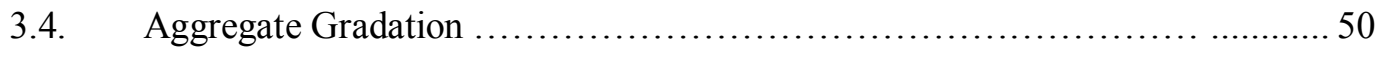

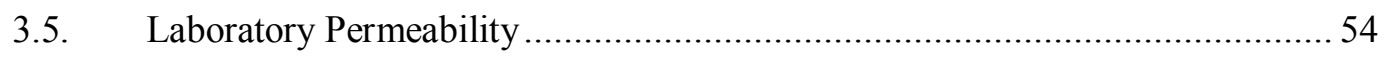

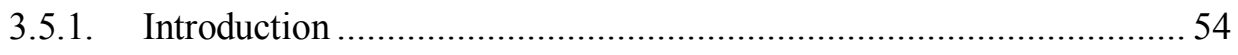

3.5.2. Specimen Preparation and Testing Procedures.............................. 55

3.5.2.1. Mix Design and Testing for CTPBs .................................. 56 
3.5.2.2. Mix Design and Testing Procedures for

Asphalt-treated Permeable Bases (ATPBs)

3.5.2.3. Testing Procedures for Untreated Open-

Graded Aggregate Materials

3.5.3. Test Procedure for Laboratory Permeability 70

3.5.4. Design Considerations in the Measurement of the Coefficient of Hydraulic Conductivity using the Flexwall Permeability 72

3.5.5. Effective Porosity and Post-Compaction Gradation Curves ........... 76

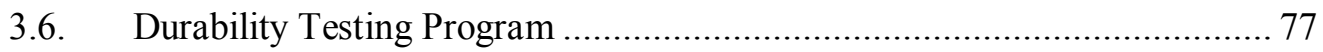

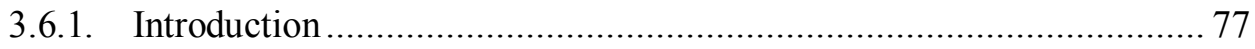

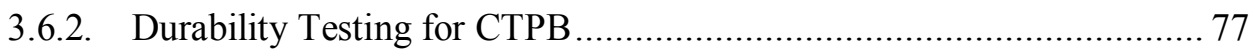

3.6.3. Durability Tests for ATPBs...................................................... 79

\section{EXPERIMENTAL RESULTS AND DISCUSSIONS ...................81}

4.1. Hydraulic Conductivity Test Results for Untreated Open-graded

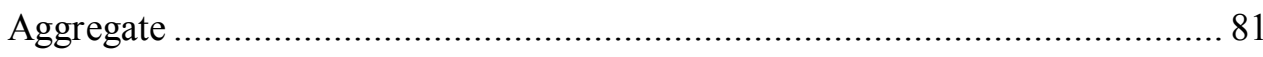

4.1.1. Result Comparison between different Gradation types ..................... 85

4.1.2. Comparison of Hydraulic Conductivity values

Between Materials types

4.1.3. Computing the Drainage Efficiency of Unbound

Open-Graded Drainage Layer

4.2 Results for Treated Permeable Aggregate Bases ....................................... 100

4.2.1. Cement Treated Permeable Base Materials ......................... 100

4.2.1.1. Coefficient of Hydraulic Conductivity

Test Results 100

4.2.1.2. Unconfined Compression and Durability 102 vi 
4.3. Asphalt Treated Permeable Base Materials ............................................. 110

4.3.1. Coefficient of Hydraulic Conductivity Test Results .......................... 112

4.3.2. Results of Moisture Susceptibility Test ....................................... 113

4.4. Discussion of Results of Treated Open-Graded Aggregate Base

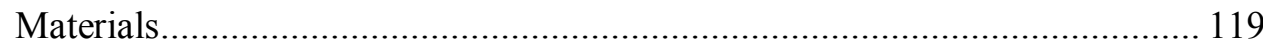

4.4.1. Cement Treated Permeable Base Materials ..................................... 119

4.4.2. Asphalt Treated Permeable Base Specimens ................................. 123

\section{MEPDG PERFORMANCE ANALYSIS OF PAVEMENT STRUCTURES CONTAINING TREATED AND UNTREATED PERMEABLE BASES .........................................................129}

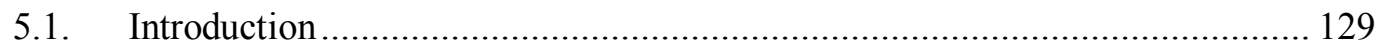

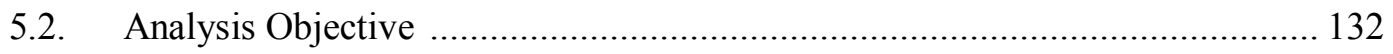

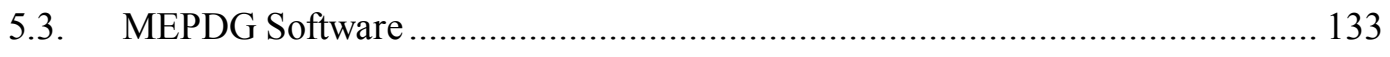

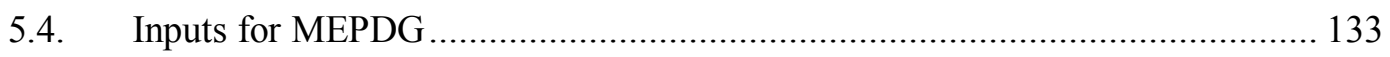

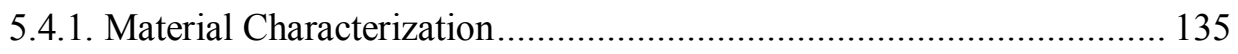

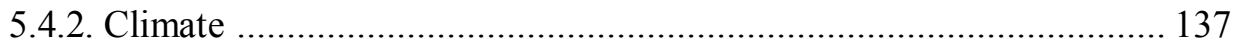

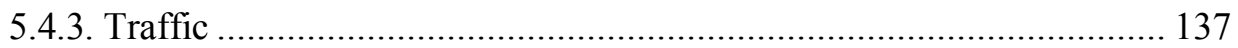

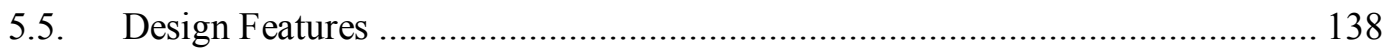

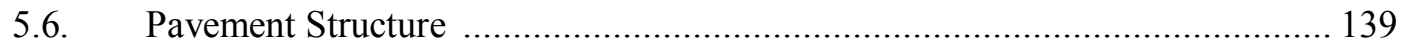

5.7. MEPDG Performance Prediction Models for PCC …............................... 140

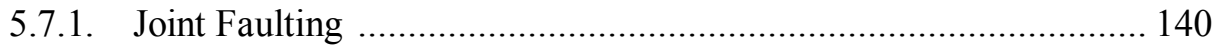

5.7.2. Cracking Model ................................................................. 141

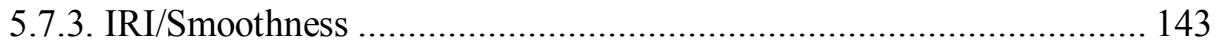

5.8. Selection of Performance Criteria and Reliability Levels ......................... 144

5.8.1. Performance Criteria for Rigid Pavements ............................. 145

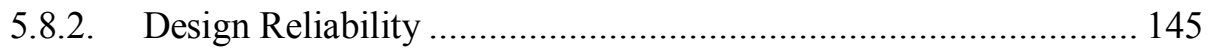


5.9. Procedure for Implementing MEPDG Sensitivity Analysis

5.10. Full Factorial Experimental Design for the sensitivity

Analysis

5.11. Result and Analysis.

5.11.1. Sensitivity of Pavement Performance with Hydraulic

Conductivity 165

5.11.2. Sensitivity Analysis of Permeable Base

Base to the Required Slab Thickness . 168

5.12. Determining the Structural Adequacy of Drainage Layer

Using MEPDG Simulations

5.12.1. Defining an Appropriate Erodibility Factor for Treated

For Treated Open-Graded Bases

5.13. MEPDG Prediction of Flexible Pavement Sections

containing Different Open-graded Base Layers 196

5.14. Calibration of MEPDG Runs with LTPP Performance Database

\section{ECONOMIC ANALYSIS OF PAVEMENT SUBSURFACE DRAINAGE SYSTEMS}

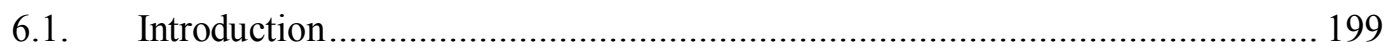

6.2. Life Cycle Cost Analysis for Highway Infrastructure ................................ 205

6.3. Components of a Life Cycle Cost Analysis ........................................... 207

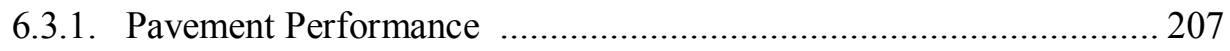

6.3.2. Maintenance and Rehabilitation Strategy ................................... 209

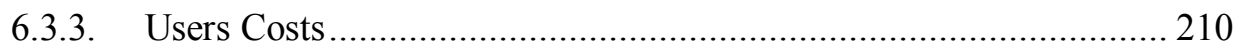

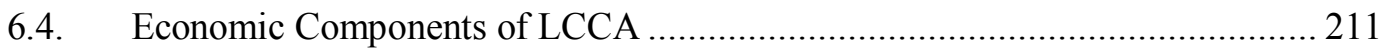

6.5. Developing Life Cycle Analysis for Subsurface Drainage Systems:

Previous Researcher 213 
6.6. Previous Research on the Economic Impact of Subsurface

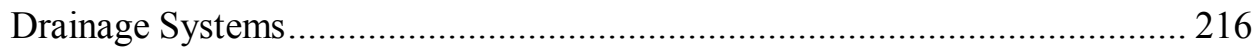

6.7. Calculation of Life Cycle Cost from Performance Prediction Data.................. 221

6.8. Pavement Performance Prediction for LCCA............................................. 222

6.9. Computation of the Economic Benefit of using a Drainage Layer ................... 227

6.10. Discussion of Results from Life Cycle costs Analysis ................................. 234

6.11. Importance of Limitations and Assumptions .......................................... 234

\section{RESEARCH SUMMARY, CONCLUSION,} RECOMMENDATIONS AND TECHNOLOGY

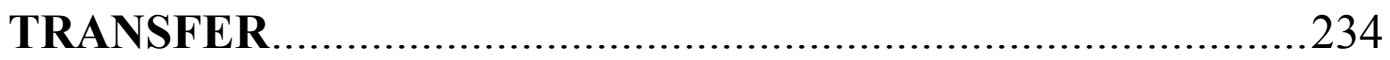

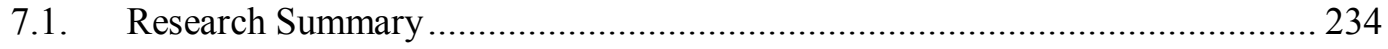

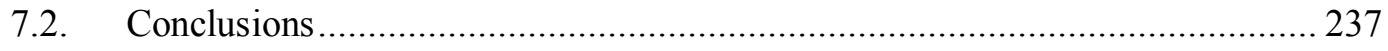

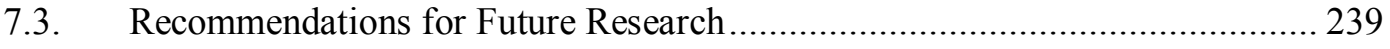

7.4. Technology Transfer: Putting Research into Practice ................................. 242

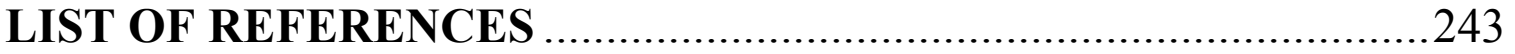

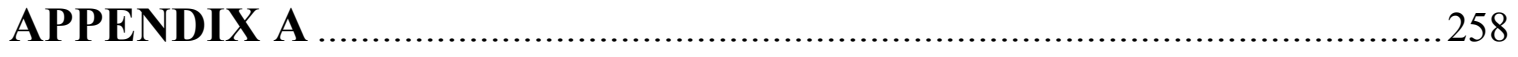

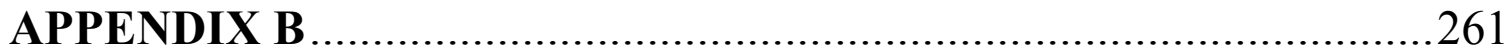




\section{LIST OF FIGURES}

Page

Figure 2.1. Sources of Moisture in Pavement (MEPDG, 2004) ....................................... 13

Figure 2.2. Typical Permeable Base Pavement Section .................................................... 25

Figure 3.1. Photo Showing Crushed Surfaces on the Three Aggregate Types ...................... 47

Figure 3.2. Grain-size Distribution of Michigan 4G Aggregate Gradation ........................... 52

Figure 3.3. Grain-size Distribution of NJ Unstabilized Mix ............................................. 52

Figure 3.4. Grain-size Distribution of AASHTO No. 67 Aggregate Gradation ..................... 53

Figure 3.5. Grain-size Distribution of MDOT 5G Aggregate Gradation ............................ 53

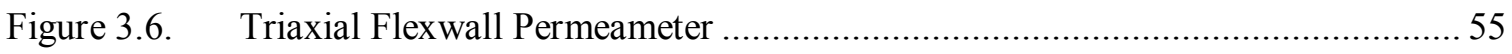

Figure 3.7. Measuring the K of CTPB using a Flexawall Permeameter .............................. 61

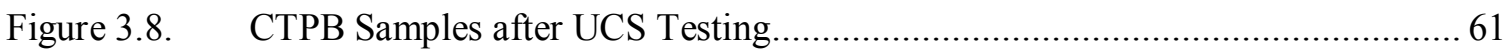

Figure 3.9. ATPB Samples Disintegrating immediately after Gyration Compaction ........... 66

Figure 3.10. Test Apparatus used to measure the K of ATPB Samples .................................. 66

Figure 3.11. Laboratory set up for measuring the $\mathrm{K}$ of Porous stones …........................... 75

Figure 4.1. Moulton's Chart for estimating the K for Unbound Aggregate Materials .......... 83

Figure 4.2. Variation of $\mathrm{K}$ with unit weights for MDOT 4G Gradation ............................ 89

Figure 4.3. Variation of $\mathrm{K}$ with unit weights for NJ Unstabilized Mix Gradation............. 90

Figure 4.4. Effect of Compaction on Crushed Concrete. ................................................ 91

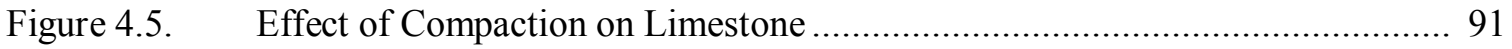

Figure 4.6. Sensitivity of time-to-drain with Permeable Base K....................................... 94

Figure 4.7. Sensitivity of time-to-drain with Permeable Base Thickness ............................ 94

Figure 4.8. Laboratory Coefficient of Hydraulic Conductivity for Natural Gravel ............ 101

Figure 4.9. Laboratory Coefficient of Hydraulic Conductivity for Dolomite ..................... 101

Figure 4.10. Laboratory K for Recycled Concrete Aggregate ........................................ 102 
Figure 4.11. Freeze-Thaw Durability test results on Natural Gravel MDOT 5G................. 103

Figure 4.12. Freeze-Thaw Durability test results on Natural Gravel AA 67 ...................... 104

Figure 4.13. Freeze-Thaw Durability test results on Dolomite MDOT 5G Samples ............ 105

Figure 4.14. Freeze-Thaw Durability test results on Dolomite AASHTO

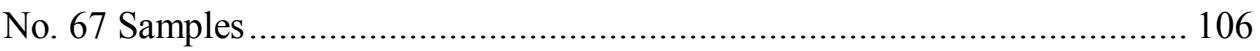

Figure 4.15. Freeze-Thaw Durability test results on Recycled Concrete MDOT 5G

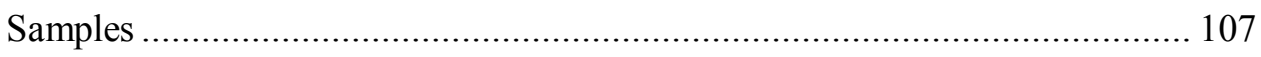

Figure 4.16. Freeze-Thaw Durability test results on Recycled Concrete AASHTO No. 67

Samples .................................................................................... 108

Figure 4.17. Variation of K with \% air void content Natural Gravel Samples .................... 109

Figure 4.18. Variation of $\mathrm{K}$ with \% air void content for Dolomite Samples ..................... 110

Figure 4.19. Average K value for Natural Gravel Specimen ........................................ 112

Figure 4.20. Average K value for Recycled Concrete Specimens .................................. 112

Figure 4.21. Average K value for Dolomite Specimens ............................................... 113

Figure 4.22. Moisture Susceptibility of Dolomite AASHTO No. 67 Samples ...................... 114

Figure 4.23. Moisture Susceptibility of Dolomite MDOT 5G Samples ............................... 115

Figure 4.24. Moisture Susceptibility of Natural Gravel AASHTO No. 67 Samples............. 116

Figure 4.25. Moisture Susceptibility of Natural Gravel MDOT 5G Samples.................... 117

Figure 4.26. Moisture Susceptibility of Recycled Concrete AASHTO \#67 Samples ........... 118

Figure 4.27. Moisture Susceptibility of recycled concrete MDOT 5G

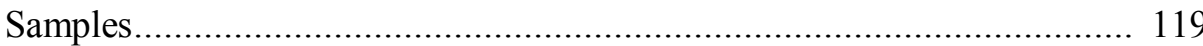

Figure 5.1. Benefits of Design Features in Concrete Pavements .................................... 139

Figure 5.2. Mechanistic-Empirical Design Framework........................................... 149

Figure 5.3. Pavement Sections Containing Treated and Untreated Permeable Bases ......... 155

Figure 5.4. JPCP with Bound Permeable Base place directly on the Subgrade ................. 159

Figure 5.5. "Error" Message for Drainage Analysis in the MEPDG.............................. 161

Figure 5.6. Predicted Pavement Performance for Wet/Freeze, Low Traffic 
Conditions

Figure 5.7. Predicted Pavement Performance for Wet/Freeze, Medium Traffic

Conditions

Figure 5.8. Predicted Pavement Performance for Wet/Freeze, High

Conditions

Figure 5.9. Predicted Pavement Performance for Dry/No Freeze, Low Freeze Conditions 174

Figure 5.10. Predicted Performance for Dry/No Freeze, Medium Traffic

Conditions 175

Figure 5.11. Predicted Pavement for Dry/No Freeze, High Traffic

Conditions 175

Figure 5.12. Differences in Predicted Faulting Performance under Wet/Freeze and Low Traffic Conditions.

Figure 5.13. Differences in Predicted Faulting under Wet/Freeze and Medium Traffic Conditions

Figure 5.14. Differences in Predicted Faulting under Wet/Freeze and High Traffic

Conditions

Figure 5.15. Material Properties of ATPB use in the MEPDG Analysis

Figure 5.16. Material Properties for Untreated Permeable Aggregate used in the MEPDG

Analysis.

Figure 5.17. Variation of Pavement and Performance with Permeable Base

Thickness

Figure 5.18. Predicted Faulting using three Erodibility Levels for Low Traffic

Figure 5.19. Predicted Faulting using three Erodibility Levels for High Traffic

Figure 5.20. Predicted Performance for Low Traffic, Wet/Freeze Region

Figure 5.21. Predicted Performance for Low Traffic, Dry/No-Freeze Region

Figure 5.22. Predicted Performance for Medium Traffic, Wet/Freeze Region 198

Figure 5.23. Predicted Performance for Medium Traffic, Wet/Freeze Region 198 
Figure 6.1. Performance Criteria for two Common Rigid Pavement Distresses................ 209

Figure 6.2. Flowchart showing Comprehensive Life Cycle Cost Analysis ....................... 215

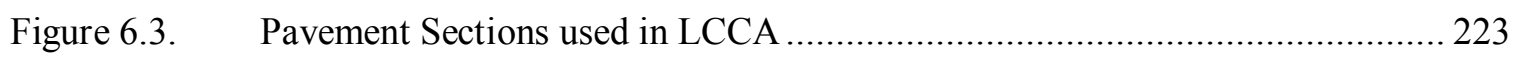


Table 2.1. Permeable Base Quality of Drainage .................................................... 28

Table 3.1. Aggregate Material Properties ..................................................................... 48

Table 3.2. Physical/Mechanical Properties of PG 58-28 _............................................... 49

Table 3.3. Physical Properties of type Cement ............................................................. 49

Table 3.4. Aggregate Gradation Specification Percent Finer by Weight ........................ 51

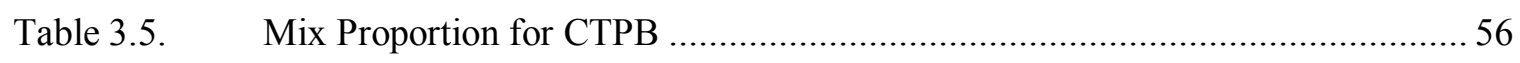

Table 3.6. Physical Properties of Aggregates ............................................................. 57

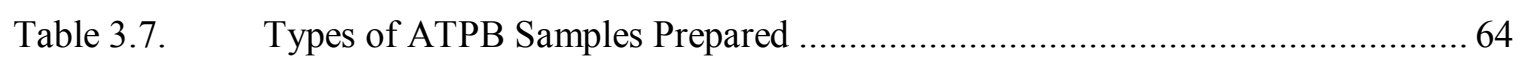

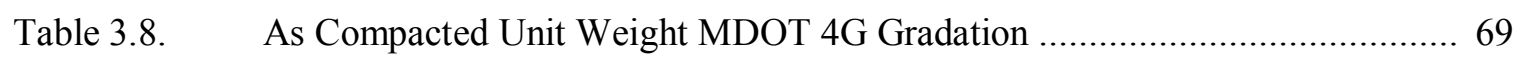

Table 3.9. As Compacted Unit Weight NJ Unstabilized Mix Gradation........................... 69

Table 4.1. K Results for Untreated Open-Graded Aggregate Materials .......................... 82

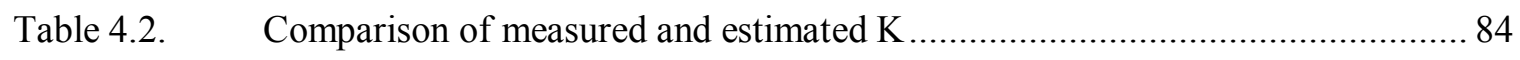

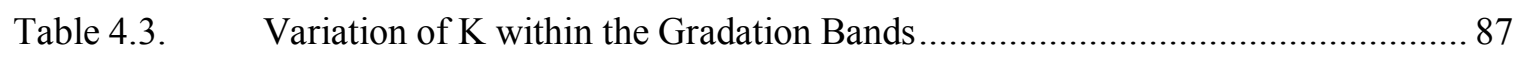

Table 4.4. Minimum K for various Categories of Drainage .......................................... 93

Table 4.5. Average \% air void content and K of ATPB Samples ................................. 111

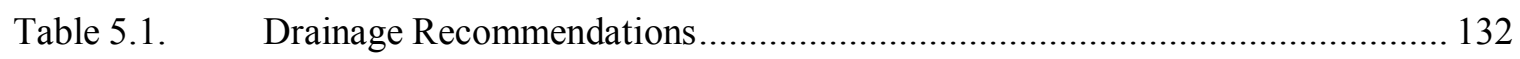

Table 5.2. AASHTO Recommended Performance Criteria for Rigid Pavements ............. 145

Table 5.3. AASHTO Recommended Reliability Level ......................................... 146

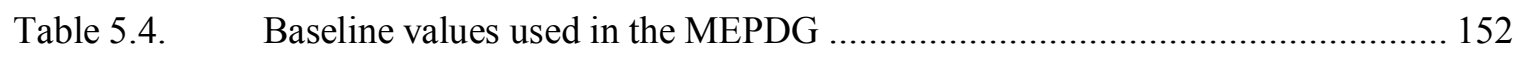

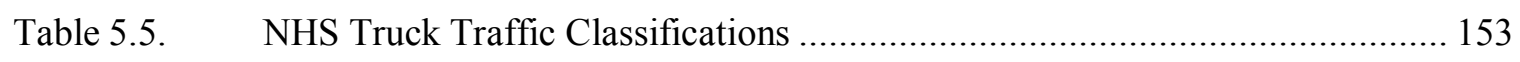

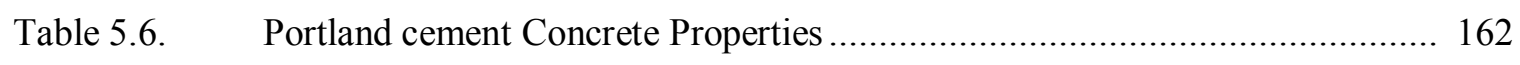

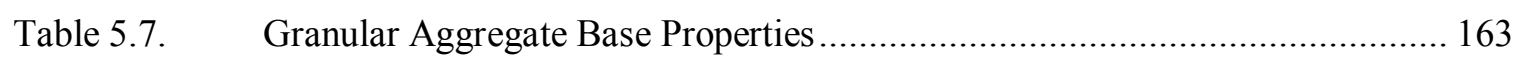

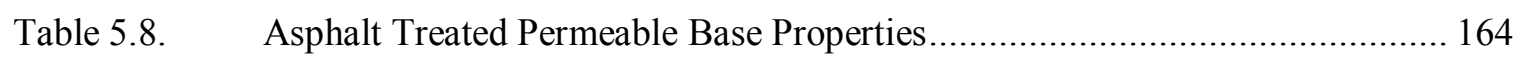

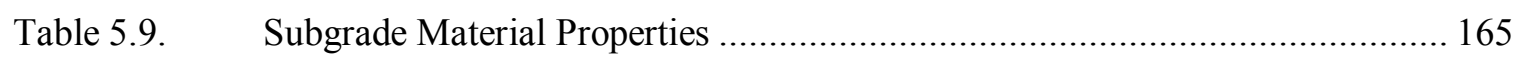

Table 5.10. Sensitivity Analysis of Pavement Performance with K ................................ 167 


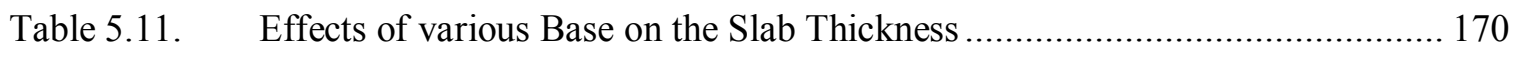

Table 5.12. Variation of Pavement Performance with Percent air void content of Permeable

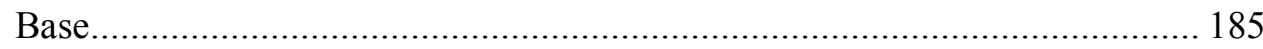

Table 5.13. Variation of Performance with \% binder content

of treated Permeable Base _..................................................................... 186

Table 5.14. Variation of Pavement Performance with Binder type use to treat Permeable

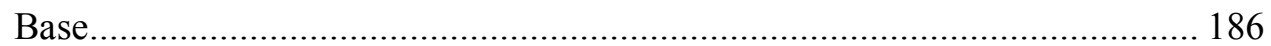

Table 5.15. Variation of Pavement Performance with Permeable Base Thickness ............. 187

Table 5.16. Variation of Pavement Performance with percent air void content of Permeable

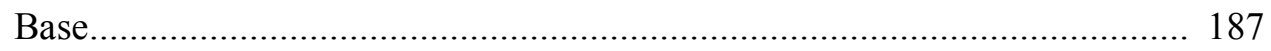

Table 5.17. Variation of Performance with binder content of treated Permeable Base ....... 188

Table 5.18. Variation of Performance with Binder type use to treat Permeable Base ......... 188

Table 5.19. Erodibility Class of Common Pavement Bases ........................................... 192

Table 6.1. Performance Criteria and Reliability Levels used in LCCA …..................... 225

Table 6.2. MEPDG Predicted Design Life for the three Pavement Sections ..................... 226

Table 6.3. MEPDG Predicted Slab Thickness for the three Pavement Sections................ 226

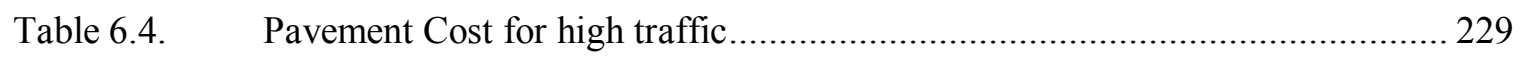

Table 6.5. Pavement Cost for Medium truck Traffic ................................................. 230

Table 6.6. Pavement Cost for High Truck Traffic ...................................................... 231

Table 6.7. Initial Construction Cost of the three Pavement Sections ............................... 232

Table 6.8. Computed Life Cycle Costs for the three Pavement Sections ........................ 233 


\section{A C K N O W L E D G M E N T S}

I want to thank my Lord and Savior Jesus Christ for giving me the resources I needed to go through this course. I would like to express my deepest gratitude and sincere appreciation to my Advisor Dr. Ralph Hodek for his constant help and motivation throughout my studies at Michigan Tech.

I also would like to thank to Dr. Jake Hill, Dr. Zhanping You and Dr. Thomas Oommen for their willingness to serve as committee members and also for their invaluable assistance they have rendered to me throughout these four years.

I want also to express sincere thanks and appreciation to the Fulbright Foundation for giving me this amazing opportunity to do my post-graduate studies in the United States. I want also to greatly appreciate all the members of Light House Pentecostal Church especially Baron and his wife Karen for helping me and my family in ways unimaginable that only the Good Lord will reward you.

My wife has been quite supportive and helpful and I want to say thank you. Finally, I want to thank my 11 month old daughter, Karen Dora for bringing peace and joy to my life again at a time of great personal tragedy. Karen, you are a ,breath of fresh air' and you can always count on daddy's love. 


\begin{abstract}
A B S T R A C T
Moisture induced distresses have been the prevalent distress type affecting the deterioration of both asphalt and concrete pavement sections. While various surface techniques have been employed over the years to minimize the ingress of moisture into the pavement structural sections, subsurface drainage components like open-graded base courses remain the best alternative in minimizing the time the pavement structural sections are exposed to saturated conditions. This research therefore focuses on assessing the performance and cost-effectiveness of pavement sections containing both treated and untreated open-graded aggregate base materials.
\end{abstract}

Three common roadway aggregates comprising of two virgin aggregates and one recycled aggregate were investigated using four open-ended gradations and two binder types. Laboratory tests were conducted to determine the hydraulic, mechanical and durability characteristics of treated and untreated open-graded mixes made from these three aggregate types. Results of the experimental program show that for the same gradation and mix design types, limestone samples have the greatest drainage capacity, stability to traffic loads and resistance to degradation from environmental conditions like freeze-thaw. However, depending on the gradation and mix design used, all three aggregate types namely limestone, natural gravel and recycled concrete can meet the minimum coefficient of hydraulic conductivity required for good drainage in most pavements. Tests results for both asphalt and cement treated open-graded samples indicate that a percent air void content within the range of 15-25 will produce a treated open-graded base course with sufficient drainage capacity and also long term stability under both traffic and environmental loads.

Using the new Mechanistic and Empirical Design Guide software, computer simulations of pavement performance were conducted on pavement sections containing these opengraded base aggregate base materials to determine how the MEPDG predicted pavement performance is sensitive to drainage. Using three truck traffic levels and four climatic regions, results of the computer simulations indicate that the predicted performance was not sensitive to the drainage characteristics of the open-graded base course.

Based on the result of the MEPDG predicted pavement performance, the costeffectiveness of the pavement sections with open-graded base was computed on the assumption that the increase service life experienced by these sections was attributed to the positive effects of subsurface drainage. The two cost analyses used gave two contrasting results with the one indicating that the inclusion of open-graded base courses can lead to substantial savings. 


\section{CHAPTER I}

\section{GENERAL INTRODUCTION}

\subsection{Problem Statement}

The provision of adequate subsurface drainage in pavements in order to prevent or minimize moisture induced distresses is an important design consideration in pavement design. This is largely due to the pioneering work of Cedergren and others. Cedergren, through extensive research had shown that adequate subsurface drainage underneath pavements can drastically reduce the life cycle cost of pavements (Cedergren 1974). Premature failure of the pavement system due to a malfunction of the subsurface drainage feature can be costly, but if the permeability and stability of the drainable bases can be maintained, pavement design life and significant lower life cycle cost would be realized.

An extensive review of the literature on research work conducted has shown that pavements with inadequate subsurface drainage deteriorate much faster than their welldrained counterparts (Cedergren 1989). A pavement with inadequate subsurface drainage will cause the base course within the pavement layer system to be in a perpetual saturated or nearly saturated state. With the base course in this saturated condition, traffic loads can cause water and base materials to be pumped out through joints and cracks and at pavement edges. This will eventually weaken the support layers of the pavement and compromise the functional and structural integrity of the pavement (McEnroe, 1994). This moisture which is trapped within these underlying pavement layers can shorten the service life of even well designed and constructed pavements and can significantly increase life cycle cost of pavements due to high maintenance costs in both the short and long terms.

Even though several surface drainage techniques have been employed with great success to drastically reduce the moisture intrusion into pavement sub-layers, it is virtually 
impossible to keep water from entering pavements through joints and cracks. Even though there are site conditions that may not warrant the use of subsurface drainage systems, it is a design necessity to put in place an effective subsurface drainage mechanism if longer pavement service life is to be realized. Both moisture induced and moisture accelerated distresses in rigid pavements like pumping, faulting and Dcracking can however be drastically minimized by incorporating well-designed subsurface drainage features. A properly designed subsurface drainage system can also mitigate the detrimental effects of frost damage to the pavement structure by keeping the pavement in a continuously drained condition (Hoppe 2000). The need for and importance of subsurface drainage is also an issue that was given due significance in the new pavement design guide, Mechanistic and Empirical Design Guidelines (MEPDG), in which appropriate subsurface drainage parameters are incorporated into the material characterization of the underlying pavement materials (ARA Inc 2004).

Traditionally, subsurface drainage in both flexible and rigid pavements is carried out by the base/subbase layers within the pavement system. In addition to providing structural support to increase the load-carrying capacity of the pavement, these layers are also sometimes designed to facilitate drainage of moisture that infiltrates the pavement structural sections (Christopher et al. 2006). The issue of the base layer being the most dominant subsurface drainage layer becomes even more prevalent in a rigid pavement system, where high strength bases are not required due to the fact that the Portland Cement Concrete (PCC) layer carries most of the applied load. However, even in flexible pavements where the base is primarily a load-supporting layer, there are many site conditions that may dictate the use of a base that can meet the dual requirements of stability and drainage (Hall et al. 2003). In an effort to produce non-erodible and drainable base layer, many state highway agencies have moved from the traditional dense graded base course gradation specifications to more open graded base course specifications that allow for greater drainage in the pavement sub-layers. One major reason for this transition is due to the fact that dense gradations, even though they offer stiffer bases with good constructability have serious long term stability problems as a result of prolonged saturation of the pavement structural section leading to a reduction in 
the stiffness as the pavement ages. As a result of this, open-gradation specifications like the $4 \mathrm{G}$ and $5 \mathrm{G}$ aggregate specifications used in Michigan have been developed in order to allow for greater permeability and lower field saturation levels in subsurface pavement layers (Mayrberger and Hodek 2007). However, one prominent drawback of these open-graded specifications is producing base layers that are difficult to construct and less stable under traffic and environmental loads. In order to overcome these drawbacks, some of these open-graded materials are now being stabilized with either cement or asphalt. (Hansen et al. 2009).

However, studies have found that after years of apparently satisfactory service, distresses have been observed in some pavements with free-draining bases even when they meet open-graded specifications. It has been observed that drainage from these layers is slowing over time and there is now increasing concern as to how long the coefficient of hydraulic conductivity of open-graded base course can be maintained as the pavement ages. Also some base course materials that do meet the required gradation specification for use as free-draining bases have only produced fair to poor drainage. This has led to the observance of premature joint deterioration, faulting and cracks in pavement sections containing these open-graded bases (Bennet et al. 2007). As a result of these problems, concerns have been raised about the durability of free-draining bases and their influence on pavement performance.

There is also now emerging evidence that under certain conditions, rigid pavements constructed over certain stabilized permeable bases have been found to have a higher risk of early age, uncontrolled cracking even when they are built according to standard specifications (Hall et al. 2005). Research conducted also by California Department of Transportation (CalTrans) on pavement sections containing Asphalt Treated Permeable Bases (ATPB) showed extensive stripping of the ATPB layer (Harvey et al. 1999).

There has been a marked increase in the use of open-graded base courses by many highway agencies in an effort to provide an effective and durable subsurface drainage system. This has led to many research opportunities in order to characterize the drainage characteristics of these free draining materials. However, the lack of adequate and 
proper design guidelines concerning the stability and permeability of these free draining materials has been the primary cause of many poor and malfunctioning subsurface drainage features in pavements (Grogan 1994). Despite the best efforts of many highway agencies to incorporate accurate and representative hydraulic and mechanical properties for these free draining materials into design software like the MEPDG, material characterization and construction specification for these materials have largely remained empirical. This has led to the wide and sporadic use of diverse and ad hoc specifications which has raised serious questions on the design adequacy of these subsurface drainage features (Ashford et al. 2007).

Without a properly engineered analysis and design, it is quite probable that most subsurface drainage features are far less optimal and possibly not even cost effective and in some cases they may even be injurious to the pavement when they deliberately introduced water to moisture sensitive pavement sub-layers.

It is therefore the singular aim of this research project to analyze the performance of several free draining aggregates used in base course in both flexible and rigid pavements and to develop an optimal model through a combined experimental and analytical approach that improves the stability and hydraulic features of free draining base course materials over the pavement's life.

\subsection{Research Objective}

The central objective of this research program is to evaluate the performance of unbound and bound permeable aggregate base layers in pavements under varying environmental conditions and in the process determine the cost-effectiveness of various open-graded drainage layers used in asphalt and concrete pavements. 


\subsection{Working Hypothesis and Research Goals}

\subsubsection{Working Hypothesis}

The past two decades have seen a dramatic increase in traffic loads that have led to high incidences of moisture damage in both flexible and rigid pavements. Realizing the danger posed by this emerging trend to the nation's highways, the Federal Highway Administration (FHWA) in the early 1990s encouraged state highway agencies (SHAs) to adopt full subsurface drainage system consisting of permeable/drainage layer directly beneath the concrete or asphaltic surface with edge drains and outlet pipes on the side to minimize the time the pavement's structural sections are exposed to saturated conditions (FHWA 1992). The aggregate materials used for this purpose have different maximum size gradation, binder types and content, and as such are expected to have different hydraulic, mechanical and durability properties. The practical and economic combinations of these materials have resulted in different types of subsurface design options available to pavement designers. Therefore, in order to identify which of these subsurface designs options is best suited to a given project and site condition, the effect on pavement performance and cost for each alternative subsurface drainage systems must be thoroughly evaluated.

This dissertation therefore explores this hypothesis through a literature review of the experiences of highway agencies with treated and untreated open-graded drainage layers, a laboratory testing program to characterized the hydraulic, mechanical and durability properties of these materials, computer simulations of representative pavement structures using results of the laboratory tests and a determination of the cost-effectiveness of pavement sections containing these materials using an appropriate life cycle cost analysis methodology. 


\subsubsection{Research Goals}

The specific goals of this research are:

1. Experimental determination of critical material properties of treated and untreated permeable base aggregate materials for their use in the drainage layer underneath both rigid and flexible pavements.

2. Using results from research goal 1 to develop balance and economic mix designs of permeable aggregate that will meet hydraulic, stability and durability properties of a drainage layer in pavement.

3. Conduct computer simulations of pavement performance of pavement sections containing the open-graded aggregate materials analyze in research goals 1 and 2 using the Mechanistic Empirical Design Guide software.

4. Conduct life cycle cost analysis of pavement structures containing various free draining aggregates bases in order to make a comparative performance evaluation on their cost-effectiveness

5. Determine innovative ways on how results from this research can be use in the development of a pavement subsurface drainage manual for Sierra Leone.

\subsection{Research Significance}

This research project would be able to provide an improved understanding of the engineering and environmental factors affecting the drainage characteristics of in-place base materials under rigid pavements. This knowledge will be of tremendous help to many highway agencies in designing improved subsurface drainage that can minimize moisture induced and moisture accelerated distresses in the future. The research will also lead to findings that will enhance the design process of Portland Cement Concrete (PCC) through an optimal combination of subsurface drainage features and other 
concrete design features that may lead to a pavement with a lower life cycle cost. Some of the deliverables of this research includes:

Determination of the drainage and stability characteristics of both bound and unbound aggregate base materials

Material characterization of both bound and unbound permeable bases for use in MEPDG.

Quantitative analysis of the performance of rigid pavements under different permeable bases.

Provide guidelines for improved design and material selection for both bound and unbound permeable bases materials use in subsurface drainage.

Provide an in-depth understanding on the interaction of the various parameters affecting the process of draianbility in rigid pavements using a numerical simulation approach.

Provide a rational method to determine the cost-effectiveness of pavement sections with open-graded base layers using MEPDG predicted pavement performance.

\subsection{Research Methodology and Dissertation Outline}

Since the key delivery for this research is to develop an optimal drainage layer with hydraulic, stability and durability characteristics for effective subsurface drainage and pavement structural integrity, research methodology will be a combination of both experimental work and numerical simulations. Laboratory testing will focus on investigating the coefficient of hydraulic conductivity of these free draining aggregate materials, its variations within the bands of open-graded specifications and the environmental factors affecting long term flow. Stability analysis of treated open-graded materials was assessed in the form of a laboratory investigation of unconfined compressive strength and tensile strength and how these properties vary under certain environmental conditions such as freeze-thaw. Based on the findings of the experimental 
testing program, the hydraulic, stability and durability of the open-graded mixes will be analyzed and their suitability for use as pavement drainage layer under various site conditions of traffic and climate will be assessed. The new Mechanistic-Empirical Design Guide (MEPDG) software will be used to simulate pavement performance of sections with different open-graded aggregate base layers under different climatic conditions. The performance of these open-graded pavement sections will then be compared to pavement sections having traditional dense-graded bases. A life cycle analysis will be used to determine the cost-effectiveness of pavement sections containing both treated and untreated open-graded aggregate bases. In summary, the research methodology consists of the following:

Laboratory investigation of permeability of both bound and unbound free draining base aggregates using a flexible wall permeameter. Determine also the effective porosities and the variation or permeability within the broad gradation envelopes of these materials.

Investigate the stability and durability of treated open-graded aggregate base materials. Use the moisture characteristics of these materials in order to predict seasonal changes in the stiffness and strength properties for use in the mechanistic-empirical structural design inputs for these materials. .

Use analytical tools and computer simulations to predict the performance of pavement sections containing bound and unbound open graded materials for different climatic conditions and traffic levels.

Determine whether pavement sections having these open-graded bases have the lowest life cycle costs compared to pavement sections with dense-graded bases. 
A schematic outline of the dissertation describing the main ideas and content of each chapter is given below:

\section{Chapter 1: $\quad$ General Introduction}

Present a brief overview of the need for the research, the objective of the research and its scope and limitations. A brief discussion of the research methodology and Dissertation outline is also presented.

\section{Chapter 2: $\quad$ Water in Pavement Structures}

An in-depth literature review of the effects of water on pavement structures including its detrimental effects, various methods employed to combat its adverse effects on pavement performance is presented.

\section{Chapter 3: $\quad$ Experimental Program}

This chapter will discussed the methodology of the various tests use in the research the system operations will also be discussed and the background to each laboratory tests would be presented.

Chapter 4: $\quad$ Presentation and Analysis of Laboratory test results

Presents result of the laboratory test program and make in-depth analyses to interprete test results in light of research objectives and current pavement subsurface drainage design trends.

Chapter 5: $\quad$ MEPDG prediction of pavement performance for pavement sections containing treated and untreated drainage layer.

Carry out computer simulations of pavement performance for pavement sections containing various kinds of open-graded bases. Multi-layered elastic analysis will be used to assess the structural contribution of drainage layer 


\section{Chapter 6: Life Cycle Cost Analysis of Pavement sections Containing}

and untreated drainage layer

Carry out limited life cycle cost analysis on pavement sections containing a permeable base aggregate layer.

\section{Chapter 7:}

$\underline{\text { Summary, discussions, conclusions and recommendation }}$

Present summary of research results, discussions of research findings and recommendations.

\subsection{Limitations}

There are several open-graded specifications used by highway agencies but this research project focuses on four main open-graded specifications namely: AASHTO 67, MDOT 5G, MDOT 4G and NJ open-graded gradations. No resilient modulus tests will be conducted and $\mathrm{M}_{\mathrm{r}}$ values used in the MEPDG simulations are those from literature. No experimental field monitoring program will be conducted to determine the average moisture levels within pavement layers incorporating these free draining base materials. This means that moisture content levels predicted by the finite element program will not be verified by field results. As a result of this, the accuracy of the results from the numerical simulations and computer simulations cannot be verified. Only a limited life cycle cost analysis was done on pavement sections containing free draining bases which exclude the use of user costs. The maintenance and rehabilitation strategies used in computing the life cycle costs were assumed and does not reflect the M\&R strategies of any highway agency. 


\section{CHAPTER 2}

\section{WATER IN PAVEMENT STRUCTURES}

\subsection{Background}

The influence of moisture on the performance of pavements has been a significant consideration in road building over the ages. Road builders have been aware of the importance of not building a road system that holds water underneath the pavement surface because this can lead to poor field performance. As a result, it is safe to say that these ancient road builders did understand the very basics of good drainage and its role in preserving the road structure. It is reported that the Incas placed their carriageways along contours well above water courses and rivers. And where the existing terrain made it impossible to do so, they used culverts and raised embankments (Hindley 1972).

The idea of providing effective drainage was certainly not lost on pioneers of modern road building technology. During the $17^{\text {th }}$ century, Macadam, Telford both from England, and Tresagnet in France were credited with developing road building principles that form the basis of modern road technology. These roads were basically well drained compacted unbound granular materials overlaid by carefully placed paving blocks. Pavement designers of today also do recognized the importance of providing effective drainage and the disastrous consequences of excess moisture flooding pavement sublayers. Leading researchers in the field of pavement subsurface drainage such as Casagrande, Shannon, Barber, Lovering, and Cedergren recognized that a high degree of saturation of pavement sublayers is the dominant cause of premature pavement failures. Cedergren (1974) concluded after a series of extensive investigations that a well drained pavement can have a service life as much as five times that of a conventional poorly drained pavement. These researchers developed charts that can be used in design of subsurface drainage systems. These charts and empirical equations are being used even today to determine the necessary cross falls as well as the thickness and coefficient of hydraulic conductivity of the base course needed to provide effective subsurface drainage. 
Even though the benefits of a well drained base were glaringly evident to road builders over the ages, drainage considerations have not been at the forefront of pavement design. Two of the most important experimental road tests that provided the necessary design inputs for modern pavement design, namely the Western Association of State Highway Official (WASHO) in Idaho in 1954, and the American Association of State Highways Officials (AASHO) in Illinois in 1958-1960, were conducted with drainage as an afterthought. Drainage was not considered as a viable option for increasing pavement performance at little or no added original cost (Cedregren 1989). However, concerted efforts by early researchers like Cedergren to promote the need for subsurface drainage has led to the situation wherein current pavement design practice has a strong drainage component with almost 1 in 3 pavements now being designed with subsurface drainage features (ERES 1999).

\subsection{Moisture Effects in Pavement Systems}

Excessive moisture in pavement layers has been shown to lead to early structural and/or functional failures of pavement, if adequate subsurface measures are not taken to address the detrimental issues of moisture conditions in pavement systems. Water can enter a pavement system from many sources which can all contribute to make the pavement sublayers to be in a saturated condition at different times of the year. According to Low and Lovell (1959), moisture in pavement systems can come from the following sources:

i. Precipitation which infiltrates pavement through surface discontinuities like joints and cracks.

ii. Seasonal rise in water table especially in the winter and spring seasons.

iii. Water may move vertically by capillary action or interconnected water films.

iv. Water may move laterally

v. Moisture may move in vapor form depending upon adequate temperature gradient and air void spaces. 
The moisture sources highlighted above are shown graphically in Fig 2.1

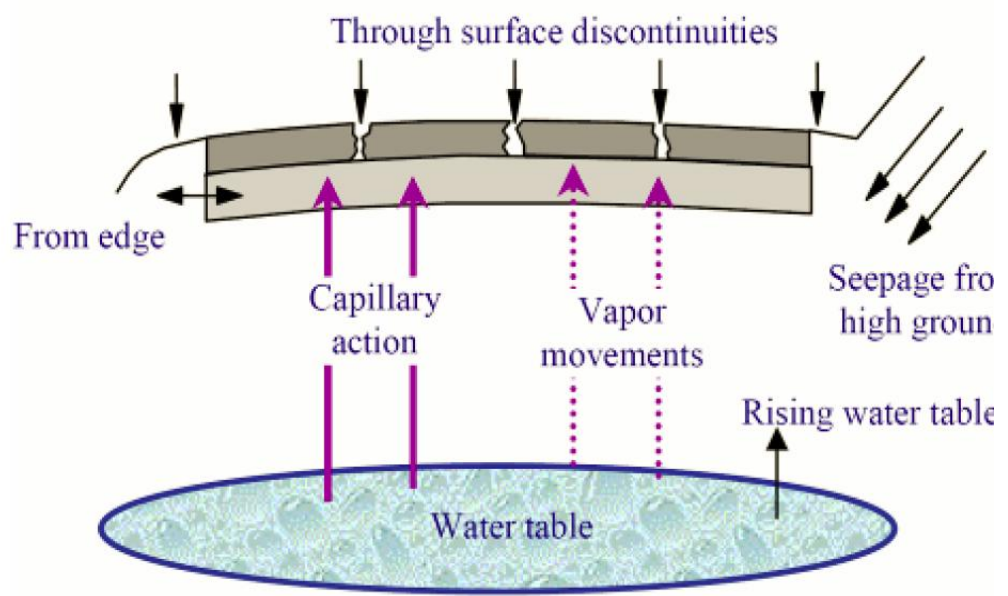

Figure 2.1 Sources of Moisture in pavement (ARA Inc, 2004).

Early highway investigators were of the opinion that the primary sources of water infiltrating pavement system are due to a high water table and capillary water (Elsayed et al. 1996). However, Cedergren (1974) explained that the main source of water was precipitation which infiltrates pavement sublayers through surface discontinuities like cracks, longitudinal and transverse joints. Other researchers have since verified Cedergren's explanation. Van Sambeek (1989) also showed that surface water infiltration accounts for as much as $90-95 \%$ of the total moisture in a pavement. Field studies carried by Ahmed et al. (1997) also found that pavement-shoulder joints are the major water infiltration entry points for surface moisture into the pavement system. Another major source of water in pavement systems is water that may rise from an underlying water level by capillary action. This is primarily due to seasonal fluctuations of ground water table especially in the winter and spring seasons when the ground water table rises. This high ground water table may cause capillary water and water vapor to move towards the ground surface thereby increasing the moisture content of the pavement sublayers especially the subgrade. According to Yoder et al. (1975), ground water conditions may be the major factor influencing the moisture content of the subgrade if the ground water table is within approximately $20 \mathrm{ft}$ from the pavement surface. 
From extensive field work on twenty pavement sections in North Carolina, Hicks (1948) observed that the moisture content for bases, subbasses and subgrades were highest during late winter or early spring. Other investigators have reported lower moisture levels in pavement sublayers corresponding to a lower ground water table with frost action also having been shown to increase the moisture content of pavement sublayers by up to $3 \%$ (Russam 1967).

From the discussion above on the various sources of moisture in pavement system, it can be shown that moisture conditions in pavement is thus a function of geographical location, pavement type, season and material characterization for pavement sublayers. From an extensive review of literature, Low and Lovell (1959) concluded that moisture content in pavement systems showed a continuous variation with seasons, even though these variations may be small at times. Experimental field work conducted by Chu et al. (1971) on pavement in South Carolina observed that moisture contents varied with season, soil type, and location in the pavement system and the height of water table influence subgrade moisture content. Moisture variations within pavement sections have also been observed by several investigators, who concluded that pavement edges generally have higher moisture contents than interior locations. Turner and Jumikis (1956) however observed that changes in moisture regime within pavement sublayers like subgrade moisture content and depth of water table were sensitive to the type of precipitation. They observed that more water from melting snow precipitation infiltrated into the ground than if the precipitation was in the form of rain. Benkelman (1959) who carried out a deflection analysis on the WASHO road test observed that pavement edges experienced adverse moisture conditions more than at interior locations. Guinnee et al. (1955) pointed out that water enters the pavement more easily and in greater volumes at the pavement edges. In their investigations on Australian pavements, Atchison et al. (1965) also noted greater moisture fluctuations at the pavement edges.

So with precipitation having been highlighted as the major source of percolating water in pavement sublayers, it should be a foregone conclusion that pavements built in areas with high precipitation should experience higher moisture variations within their sublayers. In 
other words, precipitation was also the major influencing factor in moisture variation within pavement sections since most of the water that infiltrates pavement systems is from precipitation. This seems to be the view held by many researchers. In their studies on highways in Virginia, Steven et al. (1949) observed that spring break-up can be related to the amount of precipitation and the length of the freezing period. They observed that subgrade and bases underneath highways are highly saturated during the months of October, November, and December due to the large amounts of precipitation experienced in those months. Straub et al. (1969) reported high moisture increases beneath snow covered shoulders during spring thaw due to gravitational flow of snow bank melt water. However, not all investigators were in agreement on this positive correlation between the amount of precipitation and moisture variation in underlying pavement underlying pavement layers. Kubler (1963) analyzed subgrade moisture content variation and precipitation for pavements in West Germany, but was unable to find any relationship between precipitation and the change in subgrade moisture content. Precipitation tends to have a greater influence on cyclic moisture variations of pavement sublayers in areas where pavements are poor (i.e. pavements having greater number of cracks, joints and perviousness in pavement surface). However, cyclic moisture changes would not be correlated with precipitation for pavements with high surface rating (i.e. those with few cracks and excellent surface conditions. Moisture content variations for those higher rated pavements were found to be mainly due to temperature effects. Moulton (1980) concluded from the results of field investigation that the moisture content in granular pavement layers would be more dependent upon the drainage characteristics of the materials and the site than upon precipitation.

The variation of moisture content within pavement sublayers was also found to be dependent on the type of pavement. An evaluation of moisture regime underneath both flexible and rigid pavements showed a marked difference in moisture condition of the underlying granular layers. Kersten (1945) conducted extensive investigations of moisture conditions in both flexible and rigid pavements and observed that for similar soils beneath rigid and flexible pavements on airfields, concrete pavements have on average a higher degree of saturation by as much as $10 \%$ than those of flexible 
pavements. Redus (1952) also conducted similar investigation on moisture condition in flexible pavements and made the following observations:

The moisture regime in pavement sublayers is highly dependent upon the percentage of fines.

Base courses and subgrades moisture content were always found to be below the liquid limit. This however may not be entirely true due to winter frost action.

The degree of saturation was found to be related to the plasticity of the material but has no correlation to the annual precipitation/rainfall.

Another important consideration of moisture condition in pavement reported in the literature is that of moisture movement in pavement systems due to a temperature gradient (Guthrie et al. 2006). Pavements are for the most part subjected to cyclic temperature variations as a result of daily and seasonal changes in air temperature. Many investigators have conducted research on the mechanics of water vapor flow in response to temperature gradient within a pavement. Field studies conducted by Eigenbrid and Knuttson (1992) on an asphalt parking lot observed that post winter water content on pavement underlying granular layers was $6 \%$ higher at a location just below the asphalt concrete surface than at a location which is $3 \mathrm{~m}$ below. However with earlier observations that frost action can also increase the moisture content of pavement layers by an average of $3 \%$, it does not completely make sense to ascribe that $6 \%$ moisture difference to vapor movement only. A practical explanation for that $6 \%$ difference in moisture content can be attributed to the moisture contributed by vapor and melt water from thawing snowbank. There is however a very distinct possibility that this 3\% increase in the moisture content of the pavement underlying layers due to thawing is small. Some estimates have put it as high as 30\% considering the fact that some thawing events are almost equivalent to major a precipitation event. Several factors have been found to influence the flow of water vapor within a pavement structure due to a temperature gradient. According to Guthrie (2006) these factors are the availability of subsurface water, properties of base material and the magnitude of the temperature gradient. The direction of this vapor flow is from a 
region of higher temperature to lower temperature regions. However, temperature variations within the depth of pavement underlying granular layers have been shown to follow changes in the ambient temperature. Field studies conducted by Vaswani (1974) on recording subgrade temperatures showed that the upper part of the subgrade have higher temperatures during the spring and summer seasons, while the reverse is true during the autumn and winter months. If this holds true, then water vapor will flow from the upper part to the lower part of the subgrade during the spring and summer seasons and reverse its movement during the autumn and winter seasons.

\subsection{Moisture Related Pavement Distresses}

Excessive moisture in pavement underlying layers has been shown to lead to several distresses which can significantly affect the performance of the pavement. There are numerous pavement distresses which have been identified to affect the performance of both flexible and rigid pavements. Some of these distresses can directly be attributed to the prolonged exposure of underlying pavement sublayers to excessive moisture. Some of the other pavement distresses, even though they may not be directly attributed to the prolonged presence of excess moisture, but their rate of deterioration can be accelerated in the presence of excess moisture (Dempsey et al. 1975). Research on experimental road sections like WASHO and AASHO road test have indicated that the presence of excess moisture in pavement sublayers can aggravate most of the distresses in pavements (Christopher et al. 2006). Some of the major distresses in concrete pavements that are associated with moisture are summarized below (ERES 1999):

* Pumping: This is the ejection of free moisture and fine materials from the base layers resulting in large voids beneath the pavement. The way this works is that water will infiltrate the pavement structural section through the joints and is collected in the voids in the aggregate layer. As wheel loads approach the joint, the approach slab will deflect downwards and in the process sends a pressure wave towards the leave slab. As the wheel load crosses the joint, the approach slab rebounds sending the leave slab downwards. This back and forth action results in the erosion of the material under the leave slab with some material being deposited under the approach slab. Some material is 
also being pumped through the pavement joint. According to the FHWA (1992), the four conditions that must exist beneath the pavement slab for pumping to occur are free water in the pavement section, heavy wheel loads, erodible bases and voids. The absence of any one of these four conditions has the potential to significantly eliminate pumping in concrete pavements.

* Faulting: This is a natural consequence of pumping. Fine materials been pumped from the pavement section is usually visible as stains on the pavement and its shoulders. As the material builds up under the approach slab, the difference in elevation between the approach slab and the leave slab is called faulting.

* Corner Breaks: This distress can also be considered as a natural consequence of pumping. The relocated material that has been pumped under the approach slab is normally in a very loose state and as such these corners are areas of structural weakness underneath the approach slab. This will eventually lead to a triangular corner break as traffic loads passed through those sections of the pavement.As pumping continues and the pavement continues to lose support, additional corner breaks will develop until the pavement will have completely failed and be in need of rehabilitation.

- D-cracking: D cracking of rigid pavements is also a moisture induced distress cause by the freezing and thawing of moisture in saturated aggregate which causes the aggregate to fracture.

* Punchouts: This is a pavement distress that is common to Continuously Reinforced Concrete Pavements (CRCPs). Punchouts are sections of CRCP that become surrounded by cracks that completely separate the punchout face piece from the concrete slab. 
It is obvious that pumping and subsequent faulting is the predominant moisture induced distress in concrete pavements. As a result most of subsurface drainage systems in concrete pavements are therefore gear towards combating the pumping problem. The short and long term effects of having prolonged excess moisture within pavement sublayers, which can eventually manifested as pavement distresses can be related to one of the following (Christopher et al. 1990):

i. Effects on the engineering properties of sublayers resulting in a reduction modulus in a saturated condition, thus affecting the structural capacity of these layers since moisture content has pronounced effects on these granular materials. Changes in material properties can likewise also affect the response of the pavement to external loads. Thus, the pavement system becomes unstable when the underlying granular layers reached high levels of saturation.

ii. Prolonged interaction of material with moisture can degrade the quality thus leading to its rapid disintegration and rendering it incapable of functioning well within the pavement system.

iii. Presence of excessive moisture can also lead to a loss of bond between the structural elements of the pavement system, thus reducing the interface friction between these layers and making them very susceptible to damage.

iv. Moisture induced volume changes: Volume changes in pavement sublayers caused by moisture and temperature variations are the prevalent causes of some of the moisture induced pavement distresses previously highlighted. Some of the major effects of volume changes on the performance of pavement systems have been summarized by Dempsey et al (1975) as follows: 
- Can induce cracks on concrete slabs

- Can induce warping stresses on the concrete which can affect the stress state of the pavement slab.

○ Some underlying granular layers, mostly stabilized layers will undergo drying shrinkage and the associated cracks can be reflected in asphalt concrete surface layer.

- Moisture induced volume changes in the subgrade can lead to differential heave which can result in increased roughness of the pavement surface.

$\circ \quad$ Volume changes in the base course layer can produce tensile cracks in the base layer leading to a pavement distress called reflective cracking, wherein these cracks in the base layer can be reflected through the asphalt concrete layer.

It has also been reported in the literature that the detrimental effects of moisture on pavements is more pronounced during the spring thaw than in other seasons. From investigations of deflection testing on the flexible pavement sections on the AASHO road test, Benkelman (1962) stated that there is more structural deterioration taking place during the spring thaw than during the summer months. He also observed that deflection increases as the moisture content increased except during the winter when the deflection was observed to be constant due to the frozen condition of the pavement sublayers. Other investigators have conducted similar research at the AASHO road test and observed that all the failures in the rigid pavements sections of the AASHO test track were preceded by pumping of underlying materials beneath the concrete slabs due to excess moisture (Christopher et al. 2006).

\subsection{Ways of Minimizing Moisture Damage in Pavements}

As highlighted in the previous section, the prolonged presence of excessive moisture within pavement underlying layers can lead to distresses which can affect both the structural and functional performance of the pavement. Several design considerations have been employed in an effort to mitigate the detrimental effects of excessive moisture in pavement systems. These methods are designed to ensure that the entire pavement structure is kept relatively dried and not expose to high levels of moisture during the 
course of the pavement's design life. The methods generally employed can be categorized into two broad categories namely surface drainage considerations and subsurface drainage considerations.

\subsubsection{Surface Drainage Considerations}

Surface drainage methods are measures designed to prevent moisture from entering the pavement. These measures are generally employed to reduce the amount of surface infiltration include the use of impervious surface courses, sealing joints and cracks, providing longitudinal and transverse slopes so as to be able to rapidly drain water off from the pavement surface (ERES 1999). The rationale behind these surface drainage measures is that the lesser the time water stays on the pavement surface, the less likely it would enter the pavement.

However, regardless of how excellent these surface measures are in design, they cannot completely stop moisture from infiltrating the pavement system. Furthermore, these surface drainage methods become expensive as the pavement age due to the large number of surface cracks and joints (Christopher et al. 2006).

\subsubsection{Subsurface Drainage Considerations}

In an effort therefore to provide more workable and comprehensive solutions to the moisture problem in pavement systems, subsurface drainage features are employed. These subsurface drainage features make use of moisture insensitive materials that can drain any excess water that enters the pavement within a reasonable period of time. The current state of the practice among transportation agencies is to incorporate subsurface drainage features as the most effective way of drastically minimizing the adverse effects of moisture on pavements (Hall et al. 2003). The key to the success of these subsurface drainage features is the provision of moisture insensitive granular pavement sublayers that have the requisite gradation in order to provide enough permeability to drain excess

moisture that infiltrates the pavement system. In so doing, the underlying pavement layers are kept from being continuously in a saturated condition, thus reducing the adverse development of excess pore pressures and the subsequent rapid deterioration of 
materials properties. These various features of subsurface drainage are discussed in the following section (ERES 1996).

\subsection{General Description of Subsurface Technology}

As was highlighted in the previous section, the practical limitations of surface drainage methods used in preventing moisture from infiltrating the pavement system has made subsurface drainage features the only long term remedial technique for mitigating the deteriorating and costly effects of having a prolonged moisture condition in pavement underlying layers. A drained pavement is now considered as a pavement system that comprises of subsurface drainage features which can remove infiltrated water from the pavement sublayers within a reasonable period of time (FHWA 1992). The three subsurface drainage components that makeup what is now refers to as a drainable pavement system are defined by $\mathrm{Yu}$ et al. (1999) as:

1. Permeable Base/subbase

2. Separator layer

3. Edge drain system

The inclusion of subsurface drainage has been considered as the most recent significant change in pavement design philosophy (Mallela et al. 2000). This has seen most highway agencies adopting this emerging trend of dealing with the moisture problems in pavements in their design of new and reconstructed pavements. The permeable base layer, which is the core of these subsurface drainage features, is designed in such a way so as to be able to do the following (Rabab'ah 2007):

- Pervious enough to allow the transmission of infiltrated moisture under both saturated and unsaturated flow conditions.

○ Drastically reduced the time during which the pavement's sublayers remain saturated.

○ Offer structural support to construction traffic. 


\subsubsection{When to Include Subsurface Drainage Features}

As with all aspects of designing a pavement, the inclusion of subsurface drainage features must provide economic benefits that warrant their inclusion in the design process (Arika, et al. 2009). Even though some investigators like Cedergren et al. (1974) have quantified the benefits of including subsurface drainage features in pavement systems, uncertainties still remain as to the actual benefits of incorporating such features in pavements. A plausible question worth answering before making the decision to incorporate subsurface drainage features is "does the inclusion lead to a reduction in life-cycle cost of the pavement?" A reduction in life-cycle cost now seems to be the benchmark for incorporating subsurface drainage features since a reduction in life-cycle cost should ultimately lead to an increase in the service life of the pavement (FHWA 1992). A study done by the Federal Highways Administration (FHWA) on pavements with subsurface drainage features showed that the inclusion of subsurface drainage features can increase the service life by $33 \%$ and $50 \%$ in asphalt and concrete pavements respectively. A similar study by the National Asphalt Pavement Association (NAPA) also provide evidence that despite having a higher initial cost, drainable pavements have a lower lifecycle cost than conventional dense-graded pavements (FHWA 1992).

However, it seems the criteria on which the decision to include subsurface drainage features varies among highway agencies. For instance, the California Department of Transportation (Caltrans) recommend the inclusion of permeable bases under all pavements except in areas where the mean annual rainfall is less than 5 inches and the subgrade soil has a permeability greater than $100 \mathrm{ft} /$ day (ERES 1999). Results from a national survey conducted by Christopher et al. (1997) regarding the inclusion of subsurface drainage features showed that the criteria for including these features vary from agency to agency. From this survey, it can be seen that while some highway agencies like Caltrans have developed a set of stringent guidelines as to when to include subsurface drainage elements, most agencies used as a criterion the level of traffic. When the level of anticipated traffic on the pavement is high, the need to incorporate subsurface drainage elements in the design becomes greater. The FHWA however had recommended the following criteria for the use of Open Graded Base Courses (OGBC) (FHWA 1992): 
A. Concrete Pavements

- Interstate highways use OGBC $100 \%$ of the time

$\circ \quad$ For rural major arterials and minor roadways :

- Daily Esals $>500$, use OGBC

- $250<$ Daily Esals $<500$, investigate the use of OGBC

- Daily Esals $<250$, do not use OGBC.

B. Asphalt Pavements

Evaluate the use of OGBC on a project by project basis

Other noteworthy considerations for including subsurface drainage features into concrete pavements is the prevailing site considerations like low permeability of the subgrade, freezing and thawing conditions and pavements located in cut sections (ERES 1999).

\subsubsection{Components of a Drainable Pavement}

A typical well designed subsurface drainage system should consist of the following design components:

- A full-width and non-erodible permeable base underneath the asphalt and concrete surface

- A separator layer between the permeable base and the subgrade.

- $\quad$ Edge drains and outlet pipes

These three component are shown schematically on a pavement section in Fig 2.2 


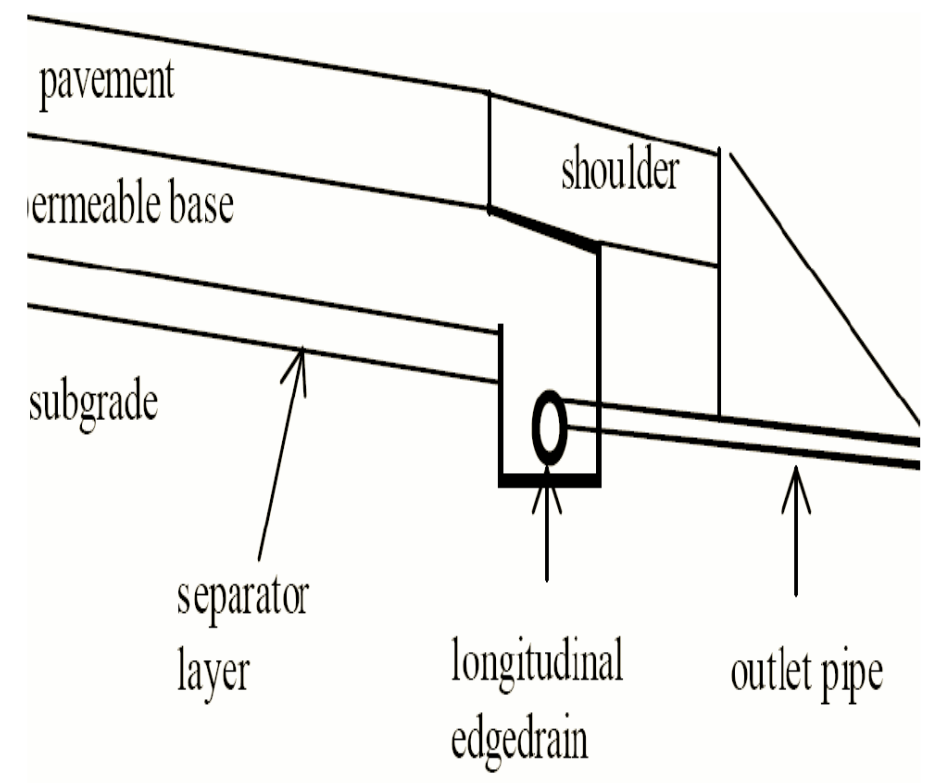

\section{Figure 2.2: Typical Permeable base pavement sections (adapted after ARA Inc 2004)}

A brief description of these components as outlined by the new Mechanistic Empirical Design Guide (MEPDG) is discussed below (ARA Inc 2004):

PERMEABLE BASE: This is normally an open-graded drainage layer consisting of crushed and wear resistant aggregate. Its main function is to collect the water that infiltrates the pavement system and move it within an acceptable time period to the edge drains for subsequent disposal to the side ditches. The permeable base can consist of either bound or unbound aggregate materials depending on the structural stability requirement. Since the critical function of the permeable base is to keep the pavement underlying layers relatively dry, a critical material property for this layer is its permeability. Open-graded materials gradations that provide higher perviousness are normally employed so as to reduce the time require moving the excess water from the pavement sublayers to the edge drains.

In other to provide good drainability, the FHWA recommends a minimum laboratory permeability of $1000 \mathrm{ft} / \mathrm{day}$. Studies have shown that the thickness of the permeable base has no significant effect on the drainage capacity of the permeable and the FHWA has 
therefore recommended a design thickness of 4 inches for the permeable base. Some of the factors which influence the construction and performance of permeable bases include type of materials used i.e. bound and unbound, gradation of aggregate, capacity of edge drains, pavement cross slopes. When it is well designed and constructed, a permeable base can function as a traditional dense graded base supporting the pavement by distributing traffic loads.

SEPARATOR LAYER: This is a layer that separates the permeable base course and the subgrade layer. There is always a likelihood of subgrade fines migrating and clogging the pores of the permeable base thereby reducing its strength and permeability. So the function of the separator layer is to keep these two layers separated and to act as an impermeable barrier that can deflect water from the permeable base horizontally toward the edge drains. The material most commonly used for a separator layer is a geotextile.

EDGE DRAINS: These are longitudinal pipes that are located beneath the pavement shoulder that are designed to collect and move water that drains laterally from the permeable base. The prevailing edge drain design consist of a trench dug on the side of the pavement adjacent to the lane-shoulder joint, along with a pipe, which can either be a perforated plastic pipe or a prefabricated geocomposite edge drain.

OUTLET PIPE: These are normally short, unperforated pipes that are designed to carry water from the edge drains to side ditches. These outlet pipes should be design in such a way as to have adequate capacity to transport all the expected moisture flow from the edge drains.

SIDE DITCHES: Side ditches are provided to carry the flow from the outlet pipes. In order to be effective, such ditches should have a minimum longitudinal grade of $0.005 \mathrm{~m} / \mathrm{m}$ and adequate free board.

DAYLIGHTED BASES: The use of a day-lighted pavement section excludes the inclusion of edge drains and outlet pipes. So a day-lighted pavement section has a permeable base layer that is exposed to allow the trapped water to flow directly into the side ditches rather than having to go through edge drains and outlet pipes. They are normally suited 
for highways with flat grades and shallow ditches where it is extremely difficult to outlet drainage pipes at an adequate height above the side ditch.

\subsection{Hydraulic and Structural Considerations of Subsurface Drainage}

The principal objective of incorporating subsurface drainage features into pavement systems as noted in previous discussion of this literature review is to keep the pavement sublayers relatively dry by draining any excess infiltrating moisture within a reasonable time period. As a result, these subsurface drainage features should be designed in such a way that they can carry the expected flows that infiltrate the pavement. Since the permeable base should also be able to support construction traffic and in some special cases provide structural support to the pavement, the structural contribution to the overall stability of the pavement is also a significant design consideration. In a nutshell therefore, the subsurface drainage system must be designed to have adequate hydraulic capacity for the expected flows and also be stable enough under traffic loads (Wyatt and Macari 2000).

\subsubsection{Hydraulic Considerations}

Adequate hydraulic considerations are required for the effective design of subsurface drainage components like permeable bases, edge drains, outlet pipes and side ditches to be able to effectively drain any excess moisture that may infiltrate the pavement sublayers. The current state-of-practice for evaluating hydraulic design of subsurface drainage features under saturated flow conditions consist of the following two approaches namely Steady state flow and Time to drain (ARA Inc 2004).

The "steady state flow" approach assumes uniform flow conditions for all the moisture infiltrating the pavement. In this method, subsurface drainage features are designed to remove this flow without allowing the base to become saturated. However, the difficulties of computing a design flow from the various multiple sources from where moisture can infiltrate the pavement makes this approach practically undesirable. 
The "time to drain" approach is now the recommended approach by the FHWA and it is based upon the following assumptions:

1) The base course becomes saturated after a rain event.

2) After the base has become saturated, excess runoff would no longer enter the pavement section

3) After base course saturation, water is drained to the side ditches through edge drains or by day-lighting.

The parameter of interest in this approach which is the time required to drain $50 \%$ of the drainable pavement within the permeable base. This time is called the „Time to drain' and it has been used to characterize the efficiency of subsurface drainage system as shown in Table 2.1 below (ARA Inc 2004):

Table 2.1

\section{Permeable base quality of drainage rating based on time taken to drain $50 \%$ of permeable of the permeable water (NCHRP, 2004).}

\begin{tabular}{|l|l|}
\hline \multicolumn{1}{|c|}{ Quality of drainage } & \multicolumn{1}{c|}{ Time to drain } \\
\hline Excellent & 2 hours \\
\hline Good & 1 day \\
\hline Fair & 7 days \\
\hline Poor & 1 month \\
\hline Very Poor & Does not drain \\
\hline
\end{tabular}

From Table 2.1, it can be seen that for a subsurface drainage system to be described as ,excellent', it must be able to drain $50 \%$ of drainable water within 2 hours after the rain event. So the higher the permeability of the permeable base layer, the shorter the ,time to drain' but in order to provide cost-effective subsurface drainage features, FHWA had recommended a minimum laboratory permeability of $1000 \mathrm{ft} /$ day. 
Other investigators have also recognized the importance of „time to drain’ in describing the effectiveness of subsurface drainage systems. In a study of airfield pavements, Berdach et al. (1997) proposed a ,time-to-drain' of 2-6 hours for removing 50\% of drainable water from airfield pavements. Considering that airfield pavements received heavier wheel loads than highway pavements, one can make a suggestion based on these research results that the ,time to drain” is a function of the wheel loads per hour acting on the pavements. The heavier the wheel loads that are expected to act on the pavements at any given time, the shorter will be the "time to drain" requirement. This is very important considering that the action of heavy loads on a saturated pavement section is the primary cause of moisture related distresses like pumping in rigid pavements. Carpenter (1990) however considered a ,time to drain' of 5 hours to drain $85 \%$ of drainable water as acceptable, while Feng et al. (1999) also reported ,time-to-drain’ between 4-7 hours. As stipulated by the FHWA guideline of minimum coefficient of, it is good to note that the various ,time-to-drain' given in Table 2.1 should just serve as a guideline and that the main objective of subsurface drainage to remove all drainable water within a reasonable period of time.

Rather than focusing exclusively on the ,time to drain', McEnroe and Zon (1994) stipulated that the extent of drainage is more of an important parameter than the ,time to drain'. McEnroe correlated the extent of drainage to permeability of the permeable base and found that the ,time to drain' approach recommended by the FHWA of 1000ft/day greatly overestimated the drainability of base courses with hydraulic conductivities in the normal range. He observed that granular bases material with hydraulic conductivity of less than $0.017 \mathrm{~cm} / \mathrm{s}$ do not drain at all.

\subsubsection{Structural Considerations}

The structural contribution of subsurface drainage features like the permeable base has been the topic of much debate. As a result, even though the hydraulic aspect of subsurface design has been well detailed and generally accepted within the discipline of pavement design, the structural aspect subsurface design components have not received the same level of acceptance (Mallela et al. 2000). Researchers are generally divided on 
what is the expected structural contribution of the permeable base to the overall structural integrity of the pavement system. On one hand, there are those researchers who hold the view that permeable base offers no structural contribution and as such its strength should not be included in the thickness calculations of the pavement layers. This view can of course lead to a very conservative cost estimate especially if bound permeable bases are used. On the other hand, some researchers however believe that the permeable base do contribute to the structural capacity of the pavement. However, even proponents of this second view are still divided on just how much structural contribution gives towards pavement strength and performance (Wyatt and Macari 2000). Some researchers are even of the opinion the inclusion of an unbound open-graded permeable base introduces a plane of weakness in the pavement structure because of its lower modulus and its high void content (Smith and Diefenederfer 2005). However, the use of bound permeable bases like asphalt treated permeable bases(ATPB) and cement treated permeable bases(CTPB) have shifted the debate towards ascribing some sort of structural number to the permeable base. Some researchers have now showed that bound permeable base like ATPB do make significant structural contribution which has led to some meaningful reduction in the thickness of the pavement surface (FHWA 1990).

Since the principal function of subsurface drainage features is to quickly remove any infiltrating water from the pavement system, it is therefore logical to say that the more open-graded the permeable base, the more effective the subsurface drainage system is in meeting its primary objective. However, a highly open-graded layer can serve as an unstable section within the pavement system that could greatly affect the structural capacity of the pavement. Hall et al. (2005) stated that even though the permeable base layer can mitigate durability related distresses in Portland Cement Concrete (PCC) like D-cracking, its structural contribution is ignored in the design process since it is relatively weak. So it can be seen from the previous discussion that the construction of a permeable base within a pavement system involves a compromise between permeability and stability. According to Kohn et al. (2003) the compromise should always be made towards stability. They noted that "a balance between the need for stability and the need for porosity must be considered in the design with stability taking precedence. The 
thickness of the drainage layer is typically 100-150mm (4-6in). The use of unbound open-graded aggregate drainage layer is not recommended for pavements used by wide bodied aircraft. These layers do not provide the necessary stability and construction related problems (rutting due to construction traffic, etc) are common. If unbound opengraded layer is necessary, it should be placed deeper in the pavement structure to reduce stresses on the layer". Therefore, in order to compensate for the poor stability of opengraded permeable base aggregate materials, it is often recommended to add small doses of asphalt or Portland cement as binders. This will result to a permeable base of lower permeability than those of open-graded but much more stable under traffic loads (Mallela et al. 2000).

\subsection{Evolution of Subsurface Considerations in Pavement Design.}

As was discussed in previous sections of this literature review, subsurface drainage was not explicitly considered even though the benefits of providing a quick and effective internal drainage has been well documented over the years. According to Cedergren (1989) "Most modern designers erroneously believe that if they make pavement strong, there is no need for fast internal drainage. This belief evolved during two major experimental road tests conducted by WASHO in Idaho in 1954 and that by AASHO in Illinois in 1958-1960. Though hundreds of combinations of pavement and base were tested, not a single test pavement was well drained. The members of the task overseeing these tests were thinking only in terms of strength, not at all of drainage as a viable option that could greatly extend pavement life at little or no added original cost, thereby saving billions of dollars a year for those paying for pavement systems". In other words, these modern designers are assuming that a sufficiently thick pavement section could mitigate or offset any detrimental effects of having prolonged excessive moisture in the pavement layers. These designers would have done well had they take heed to what John McAdam wrote as early as 1820 "The erroneous opinion so long acted upon and so tenaciously adhered to, that by placing a large quantity of stone under the roads, a remedy will be found for the sinking into wet clay, or other soft soils, or in other words, that a road may be made sufficiently strong artificially, to carry heavy carriages, though the subsoil be in 
a wet state, and by such means to avoid inconveniences of the natural soil receiving water from rain or other sources, has produced most of the defects of the roads of Great Britain" (Christopher et al. 2006).

As of now the issue of subsurface drainage has been brought to the forefront of pavement design as the detrimental effects of excess moisture combined with heavy traffic loads becomes prevalent. The American Association of State Highways and Transportation Officials (AASHTO) had since summarized the detrimental effects of water in pavement as follows (Christopher et al. 1997):

- Water in the hot mix asphalt (HMA) surface can lead to disintegration of the asphalt concrete mix, modulus reduction and loss of tensile strength. Saturated conditions can reduce the dry modulus of the asphalt by as much as $30 \%$ or more.

- Unbound aggregate bases and subbases in a fully saturated state can experience loss of stiffness on the order of $50 \%$ or more.

○ A significant modulus reduction of up to $30 \%$ can be expected for asphalttreated bases and an increase in the erosion susceptibility of cements or lime treated bases.

- Subgrades especially fine-grained soils, when they are exposed to saturated conditions could experience modulus reduction of over $50 \%$.

As a result of these findings, AASHTO has been making periodic adjustments to its Design Guides over the years in order to appreciably account for these changes of material properties due to saturated conditions in the design process.

\subsubsection{Incorporating Drainage Factors into the AASHTO Pavement Design Guides}

The AASHTO Pavement Design Guides have been the used as the primary documents for the design of new and rehabilitated highway pavements. These Design Guides have now appeared in several versions ad new findings and modifications are been made to previous versions. However, all the versions of the Design Guides are empirically based 
on results of field performance of pavement sections at the AASHO Road Test (Christopher et al. 2006).

The first version of the Design Guide which appeared in 1961 contained the original empirical equations obtained directly from the AASHO Road test data. These empirical equations relate traffic; pavement structure and pavement performance based upon field performance data obtained from both the flexible and rigid pavement sections of the AASHO road test sections. The empirical design equations contained in the AASHTO 1961 Design Guide for flexible and rigid pavements are given in equations 2.1 and 2.1 respectively:

$$
\begin{gathered}
\log W_{18}=7.35 * \log D+1-0.06+\log \frac{\left[\frac{4.5-P_{t}}{4.5-1.5}\right]}{\left[\frac{0.4+1094}{S N+1^{5.6}}\right]} \text { Equation 2-1 } \\
\log W_{18}=7.35 \log D+1-0.06+\log \left[\frac{\frac{4.5-P_{t}}{4.5-1.5}}{\frac{1+1624^{*} 10^{7}}{D+1^{8.46}}}\right] \text { Equation 2-2 }
\end{gathered}
$$

Where

$$
\begin{aligned}
& \mathrm{W} 18=\text { number of } 18 \text { kip equivalent single axle loads (ESALs) } \\
& \mathrm{Pt}=\text { Terminal serviceability at the end of the pavement design } \\
& \mathrm{SN}=\text { Structural number } \\
& \mathrm{D}=\text { slab thickness }
\end{aligned}
$$

A closer look at the two equations would show that there are no explicit drainage terms in them, thus confirming earlier statements made that pavement designers working on this road test were primarily concern with the structural strength of the pavement layers only.

The AASHTO 1972 Design Guide was a modified version of the 1961 Design Guide and was intended to extrapolate the findings from the AASHO Road Test to other different 
site conditions. The design Esals empirical equations for flexible and rigid pavement sections are given in equations 2.3 and 2.4 respectively

$\log W_{18}=9.36 * \log S N+1-0.20+\log \left[\frac{\frac{4.5-P_{t}}{4.5-1.5}}{\left(0.4+\frac{1094}{S N+1}+\log \frac{1}{R}+0.372 * S_{i}-3.0\right)}\right]$

Equation 2.3

$\log W_{18}=7.3 * \log D+1-0.06+\log \left[\frac{\frac{4.5-P_{t}}{4.5-1.5}}{1+1.624 * 10^{7}}+4.22-0.33 P_{t}\left(\log \left(\frac{S_{c}}{215.63 J}\right)\right)\right]$

Equation 2.4

Where

$\mathrm{R}=$ the regional factor

$\mathrm{Si}=$ soil support value

$\mathrm{Sc}=$ Modulus of rupture

$\mathrm{Ec}=$ Modulus of Elasticity of concrete (psi)

$\mathrm{J}=$ empirical joint load transfer coefficient

$\mathrm{k}=$ Modulus of subgrade reaction

It was only in the AASHTO 1986 Design Guide that an explicit mention of the importance of subsurface drainage on pavement performance was made. For flexible pavement design, the benefit of drainage was factored into the Structural Number using empirical drainage coefficients as shown in equation 2.5:

$$
S N=a_{1} D_{1}+a_{2} m_{2} D_{2}+a_{3} m_{3} D_{3} \text { Equation } 2.5
$$

Where $\mathrm{m} 2, \mathrm{~m} 3=$ empirical drainage coefficients. 
For rigid pavement design, a drainage factor $\mathrm{Cd}$ was also introduced to equation 2-4 to give a modified version of equation 2-4 as:

$$
\log W_{18}=Z R * S_{o}+7.35 \log D+1+\log \left[\frac{\Delta P S I / 4.5-1.5}{1+6.47 * 10^{7} / D+1^{8.46}}\right]+4.22-0.33 P_{t} * \log S_{c} * C_{d} * D^{0.75}-1.132
$$

\section{Equation 2.6}

Where

$$
\mathrm{ZR}=\text { function of design reliability }
$$

$\mathrm{So}=$ measure of overall uncertainty

$\Delta \mathrm{PSI}=$ change in serviceability

$\mathrm{Cd}=$ empirical drainage coefficient

All the other terms are previously defined.

These empirical drainage coefficients are normally in the range of $0.4-1$ for flexible pavements and 0.7-1.25 for rigid pavements. They are determined empirically from such determinants as the quality of drainage provided by the drainage layer and the estimated percentage of time that the pavement structure would be in a near saturation condition (Christopher et al. 2006).

From equations 2-4 and 2-5, it is very clear that the design axles (Esals) for both flexible and rigid pavements are sensitive to the drainage coefficients $M_{i}$ and $C_{d}$ for flexible and rigid pavements respectively. For instance, if $m_{i}$ is reduced from its maximum value of 1 to its minimum value of 0.4 , there will be a three-fold increase in the thickness of the base. Similarly, a $10 \%$ change in $\mathrm{C}_{\mathrm{d}}$ could result in a $12.5 \mathrm{~mm}$ change in the thickness of the slab (Mallela et al. 2000). What these two instances showed is that the selection of drainage coefficients to be used in the design is very important in the design of economic pavement sections using this AASHTO Guide. However, the AASHTO Guide does not provide stringent guidelines for the selection of these coefficients.

The percentage of time the pavement structure is subjected to saturated conditions, which is one of the criterions stipulated by the Guide to determine these drainage coefficients is 
difficult to quantify. As a result the selection of these drainage coefficients has largely remained empirical for the most part.

The AASHTO 1993 and 1998 Design Guides did not contained any significant modifications to the drainage coefficients. However, the 1998 version of the Design Guide recommended that drainage coefficients for rigid pavement $\mathrm{C}_{\mathrm{d}}$ should no longer be used in the structural design equations (Christopher et al. 2006). What necessitated this change was that some researchers who became increasingly skeptical of the structural contribution of these drainage coefficients and the subsequent long term performance on the pavement. These researchers argued that issues of drainage should be implicitly considered in the design equations. In a supplementary note to the AASHTO Design Guides, some researchers provided the following consideration with regards to drainage coefficients (FHWA 1997): The AASHTO drainage coefficients contained in the Design Guides are not recommended strictly for use in structural design. It was however recommended that the design process should take into consideration modulus reduction in unbound pavement layers due to saturated conditions.

Despite the aforementioned, the inclusion of these empirical drainage coefficients in recent AASHTO Design Guides did however succeed in raising the awareness of the significance of subsurface drainage and as a result encouraged the design and construction of pavements with subsurface drainage features like permeable bases and edge drains (Christopher et al. 1997).

\subsubsection{The Mechanistic and Empirical Pavement Design Guide Consideration of Subsurface Drainage}

The AASHTO Design Guides as was discussed in previous sections of this literature review were all based on the performance data from the AASHO Road Test. These designs equations are widely empirical and since then, they have been extrapolated to cover other material, traffic and climatic conditions different from those used in the original AASHO Road Test (Christopher et al. 2006). In an effort to minimize the empiricism that has characterized pavement design philosophy for several decades, the Mechanistic Empirical Design Guide (MEPDG) was introduced in 2002 as a product of 
the Strategic Highway Research Project (SHRP). It was hoped that the MEPDG will usher in a new design philosophy wherein mechanistic tools will become a part of pavement design and in so overcome some of the limitations of the previous pavement design philosophy that was solely based on the AASHO Road Test of the 60s (ARA Inc 2004).

Whereas previous AASHTO Design Guides explicitly developed a drainage coefficient for use in computing the structural sections for both asphalt and concrete pavement, the MEPDG developed a rather sophisticated but practical method for dealing with pavement structural sections that are subjected to saturated conditions through the Enhanced Integrated Climatic Model (EICM) and the Drainage Requirement in Pavement (DRIP 2.0). Even though the AASHTO Design Guides developed a set of guidelines for selecting the drainage coefficients, they are at best arbitrary and as such their use can lead to conservative designs.

EICM is a one dimensional model for predicting heat, moisture and frost depth penetration. The MEPDG approach to handling the effect of excess moisture in pavement structural section is to consider the change of moisture profiles in the pavement structure and subgrade over the entire service life of the pavement through the EICM model. The EICM model can simulates changes in material behavior and properties of pavement sublayers due to changing environmental condition. This is accomplished through a set of adjusted factors for unbound material layers to account for the effect of environmental conditions like moisture content changes, freezing and thawing (ARA Inc 2004). Within the EICM model is the ID module, which through a numerical technique can compute the degree of drainage versus time of an initially saturated base with lateral drainage overlaid on a permeable or impermeable subgrade. In making this analysis, the ID module assumes that the base course is a free draining material. The ID module evaluates the relative adequacy of the base course design in terms of the time required to reach a critical degree of saturation. The outputs of the ID module are degree of saturation of the base course, degree of drainage of consecutive dry days and the probability if a dry/wet base exists (Quintero 2007). 
The EICM predicts the moisture content in the base and subgrade layer due to changing environmental conditions throughout the pavement design. It then uses these predicted moisture content to compute changes in the resilient modulus of the pavement sublayers which can then be used to compute seasonal changes in the modulus of the unbound pavement layers. The predicted seasonal modulus of the unbound pavement layers are then used in pavement performance prediction models (Rabab'ah 2007). Thus in following this mechanistic-based design procedure the MEPDG improves the design practice over that of the AASHTO Design Guides to properly account for the actual material and seasonal changes in unbound pavement sublayers.

The MEPDG software is also equipped with a user-friendly microcomputer program called the Drainage Requirement in Pavement (DRIP). DRIP can perform all the necessary hydraulic design computations of any kind of pavement and environmental conditions and it is based on the FHWA design manual on guidance for handling excess moisture within the pavement structural system (ARA Inc 2004). DRIP has the following capabilities:

* Roadway Geometry Calculations: This feature can compute the length and slope of the actual drainage path as a function of the longitudinal and transverse grade of the roadway, and the width of the underlying base for both crowned and superelevated roadway cross-sections.

- Sieve Analysis Calculations: For each gradation, this feature can calculate the effective grain sizes, total and effective porosities, coefficient of uniformity and gradation, and the coefficient of permeability.

* Inflow Calculations: This program feature uses two options namely the Infiltration Ratio approach and the Crack Infiltration approach to compute the amount of moisture entering the pavement structure precipitation and meltwater. 
* Permeable Base Design: Using results from the inflow calculations module, this feature can design an open-graded base course that can handle the compute inflow entering the pavement using both depth-of-flow and time-to-drain approaches.

* Separator Layer Design: This feature can determine the need for a separator layer based on the gradations of proposed permeable base and the subgrade under consideration. If calculations pint to the need of a separator layer, this feature can then design either a geotextile or aggregate separator layer as the designer may select.

* Edge Drains: This program feature can calculate edge drain capacity and the outlet spacing required. The two types of edge drains that can be designed using this feature are pipe edge drains and geocomposite fin drains.

\subsection{Factors Affecting the Efficiency of Subsurface Drainage}

The presence of subsurface drainage features like permeable bases and edge drains in a pavement structure is no guarantee that all moisture related pavement distresses have been addressed or minimized. Recent studies have raised doubt that concerning the effectiveness of subsurface drainage systems for certain types of pavement structures. Using pavements sections from the Long Term Pavement Performance (LTPP), Wyatt and Macari (2000) showed that subsurface drainage features did not significantly mitigate faulting of doweled jointed concrete pavements, and that edge drains may have a negative effect on the performance of flexible pavements. The research findings from this NHCRP Project 1-34 can be summarized as follows (Yu et al. 1998):

- The presence of a permeable base does not significantly improve joint faulting of a doweled JPCP.

$\circ \quad$ Edge drains have little or no effect on the rutting performance of a flexible pavement on a dense graded base. 
Due to the limited performance data used in the above studies and the different designs used on the sections under consideration, it would be difficult to make any sweeping generalizations from these studies about the performance of subsurface drainage features. It would be prudent to determine firsthand whether these subsurface drainage features are adequately designed and constructed before making any definitive conclusions about their effectiveness. Using similar data from the LTPP database, Wyatt and Macari (2000) showed that most of the subsurface drainage features are not adequately designed to carry the expected flows, thus limiting their contribution to effectively keep the pavement system relatively dried. The study showed that subsurface drainage features like the permeable base and edge drains may not have sufficient hydraulic conductivity to carry the moisture inflow out of the pavement structure. In one instance, the study found that the permeable base has a very low hydraulic conductivity and as such flows into the edge drain are almost negligible. In such a scenario, the edge drains becomes of no practical importance in the pavement structure and as such invalidate any conclusion that edge drains can adversely impact such a pavement structure.

It is difficult to quantify the relative effectiveness of subsurface drainage systems as this will necessitate the construction of control pavement sections with properly designed drainage systems that can drain all of the expected moisture infiltration into the pavement within an appreciable period of time (Christopher et al. 2006). Most highway practitioners however believed that the reasons why many subsurface drainage features have not always produced the desired impact on pavement performance are inadequate design, improper construction and inadequate maintenance (Hall et al. 2003). These three factors are discussed in the following sections:

\subsubsection{Inadequate Design}

As was discussed in previous sections, the primary function of incorporating subsurface drainage features in pavement structure is to remove the excess moisture infiltrating the pavement structure. As a result subsurface drainage elements like the permeable base and edge drains should be adequately design to be able to carry the expected flows (ERES 1999). The challenge facing designers of subsurface drainage components is how 
to adequate quantify the design moisture inflow entering the pavement structure from multiple sources ( $\mathrm{Yu}$ et al. 1998). In their study of some LTPP sections, Wyatt and Macari (2000) discovered that most of the subsurface drainage elements did not have the requisite hydraulic capacity which limits their effectiveness. The permeable base should be designed to adequately carry the estimated moisture inflow and likewise both the edge drain and outlet pipes should be designed to have the needed hydraulic capacity to carry the discharge from the permeable base.

Therefore, a well designed subsurface drainage system should have a permeable base that is pervious enough to carry the expected inflow and also stable under construction traffic, edge drains with adequate capacity to receive the flow from the permeable base and finally, outlet pipes and side ditches that have the capacity to carry the outflow from the edge drains. Furthermore, all these subsurface drainage components must be functioning effectively throughout the design life of the pavement (Wyatt and Macari 2000).

\subsubsection{Improper Construction}

When carefully designed, constructed and regularly maintained, subsurface drainage features can have the expected impact on pavement performance. However, recent field studies on some LTPP SPS-1 and SPS-2 test sections have discovered major discrepancies between the "as-designed" and ,as-built" subsurface drainage designs (Hall et al. 2003). These discrepancies point to the fact that regardless of how well subsurface drainage features are designed, if careful construction practices are not employed in their construction, then this subsurface drainage elements may never have the desired longterm positive effects on the pavement performance.

The construction specifications for subsurface drainage features like the ATPB and CTPB were developed by modifying existing dense-graded base specifications. But since these layers are open-graded and have no standard construction acceptance testing, applying conventional techniques to construct them pose some practical difficulties (Delatte 2007). 
In a survey of subsurface drainage practices across the U.S. conducted by Christopher et al. (2000) most highway practitioners affirmed that construction control is one of the vital keys to the long term performance of pavement subsurface systems. Some of the unacceptable construction practices include the following:

$\begin{array}{ll}\circ & \text { Drains not connected to outlets } \\ \circ & \text { Drains crushed by equipments } \\ \circ & \text { Drains going uphill } \\ \circ & \text { No compaction of permeable base } \\ \circ & \text { No outlet pipes }\end{array}$

\subsubsection{Inadequate Maintenance}

Regular maintenance of subsurface drainage features is needed if they are to provide the desire long term effects on pavement performance. Drainage features like permeable base, edge drains outlet pipes and side ditches should be constantly maintained so as to prevent any undesirable circumstances from limiting or restricting their capacity to carry the expected moisture inflow into the pavement (Ceran et al. 1992). Some of these maintenance practices include the following:

\section{- Erosion control of side ditches \\ - Repair of eroded and scoured outlet areas \\ - Repair of damage due to frost and clogging}

Subsurface drainage features just like any other components of a pavement systems, if not properly and regularly maintained can be more detrimental to a pavement. Hall et al. (2003) rightly noted that neglecting regular maintenance of drainage outlets or daylighted drainage layers may lead to more premature failure of the pavement. The report concluded by stating that the installation of subsurface drainage carries the inherent risks that the drainage systems may not function as designed and that a firm commitment by the highway agency to maintenance should be made before contemplating on including one. Maintenance of subsurface drainage features can be substantial and can account for a significant portion of an agency's maintenance budgets. This is further evidence why 
the selection, design and construction of subsurface drainage systems must be given due importance.

\subsection{A Summary of Highway Agencies' Experiences with Permeable Bases}

From the foregoing discussion, many research results have pointed to the immense benefit of including a permeable base layer in the pavement as a means of mitigating moisture induced distresses. As a result many highway agencies have experimented with the inclusion of a drainage layer in the construction of new and rehabilitated pavements. Their experiences are well documented in the literature. From the literature it is very clear that the design and construction of permeable bases varies from one highway agency to the other. What many highway agencies did was to modify their existing dense-graded aggregate base gradation by lowering the percentage of fines. Even though stability was compromised, such efforts resulted in a gradation that can produce the required coefficient of permeability needed to classify the base as permeable. State highway agencies like the Michigan Department of Transportation (MDOT) have made structural improvement to its $3 \mathrm{G}$ dense-graded aggregate base to develop a new gradation specification for its unbound aggregate base course that can provide better pavement drainage. The Michigan 4G as the new gradation is called has a lower and upper bound fines content of $0 \%$ and 6\% respectively (Mayrberger and Hodek 2007). Similar efforts have also been undertaken by other highway agencies.

While these modified gradations specifications for the unbound aggregate materials have fulfill the agencies' need of providing a pavement with a drainage layer, they have also posed significant construction challenges because of their open structure. As a result of these construction and stability issues of open-graded unbound permeable bases, some highway agencies are using bound permeable bases like Asphalt Treated Permeable Bases (ATPB) and the Cement Stabilized Permeable Bases (CTPBs). These lightly stabilized open-graded materials with asphalt content in the range of $2-3 \%$ and cement content of 100-150 pounds per cubic yard. Since stability is achieve by the action of the stabilizing agent, a much more open gradation can be use for bound permeable bases. 
MDOT used recycled concrete aggregate for its stabilized 5G permeable base aggregate. Even though the performance of pavements containing this $5 \mathrm{G}$ permeable base has been good, a recent finding by Bennet et al. (2007) found that poor sub-surface drainage condition was found to promote permanent joint settlement in some of the pavements with stabilized open-graded base courses.

The California Department of Transportation (Caltrans) has experimented with ATPB as a drainage layer for over three decades. Since 1983 Caltrans has recommended the use of ATPB as a standard design component in new and rehabilitated pavement. However, recent findings have shown that the ATPB is highly susceptible to moisture damage and observations from cores taken from pavement with ATPB have shown progressive stripping of the asphalt from the aggregate. This has forced Caltrans to rethink its design philosophy and in 1993 issued a monotorium to discontinue the use of ATPB except in cases where additional steps are taking to increase its resistance to moisture degradation (Harvey et al. 1999). Similar stripping problems have been reported by other highway agencies and some have even introduced the use of anti-stripping agents in the mix design of ATPB (Elfino et al. 2007). 


\section{CHAPTER 3}

\section{EXPERIMENTAL PROGRAM}

\subsection{Introduction}

A key objective of this research work is to conduct computer simulations of pavement performance in order to properly determine the relative contribution of a treated and untreated permeable base layer on the performance of pavements. In order to successfully carry out these computer simulations of pavement performance that are representative of average field pavement conditions, certain design inputs like coefficient of permeability and resilient modulus and/or strength properties of the stabilized aggregate material are needed. The granular materials which comprise both treated and untreated drainage layers have varying physical, chemical, mechanical, and durability properties. The effectiveness of a drainage layer and its resulting impact on pavement performance is to a very large extent related to a combination of these aggregate properties. It was therefore the aim of this laboratory experimental program to investigate how these properties combine to define the hydraulic, structural and durability properties of open-graded drainage layers comprised of these aggregates.

The experimental program was designed to determine these input design parameters for each aggregate type and how these parameters vary within certain gradation limits and under varying environmental constraints. The experimental program consisted of the following:

1. A permeability testing program

2. A stability/strength testing program

3. A durability testing program

All three laboratory test programs were conducted on both treated and untreated opengraded aggregate base materials. Three types of aggregates that are commonly used as pavement base materials and four gradation types were used in this experimental program. 


\subsection{Aggregate Base Materials}

Three aggregate base materials were investigated consisting of two natural aggregates and one recycled aggregate. The natural aggregates were Natural Gravel and Dolomite while the recycled material was Recycled Crushed Concrete. With the move towards designing and constructing sustainable highway infrastructure with the use of alternative construction materials, the recycled concrete aggregate investigated in this laboratory experimental program was intended to determine the effectiveness of these alternative pavement materials in subsurface drainage structures relative to the performance of natural or virgin materials.

The natural gravel used in the research was produced by crushing and screening gravel. It is predominantly quartzic and has numerous textures and colors due to many mineral types contained in the rock. The particles are relatively equidimensional in shape with very few flaky particles. The limestone is a carbonate rock which was quarried and then crushed. It is light to dull gray in color, angular, and has a relatively smooth surface. The recycled concrete aggregate contains hydrated Portland cement and both fine and coarse natural aggregate materials such as sand and gravel. All the three aggregate types under investigation were crushed stones, which complies with the specification requiring all aggregate base materials to be $100 \%$ crushed aggregate (FHWA 1992). The number of crushed surfaces for each aggregate type was not determined but a closer look at each aggregate type as shown in Fig 3.1 would show that all the aggregate types are 100\% crushed. 

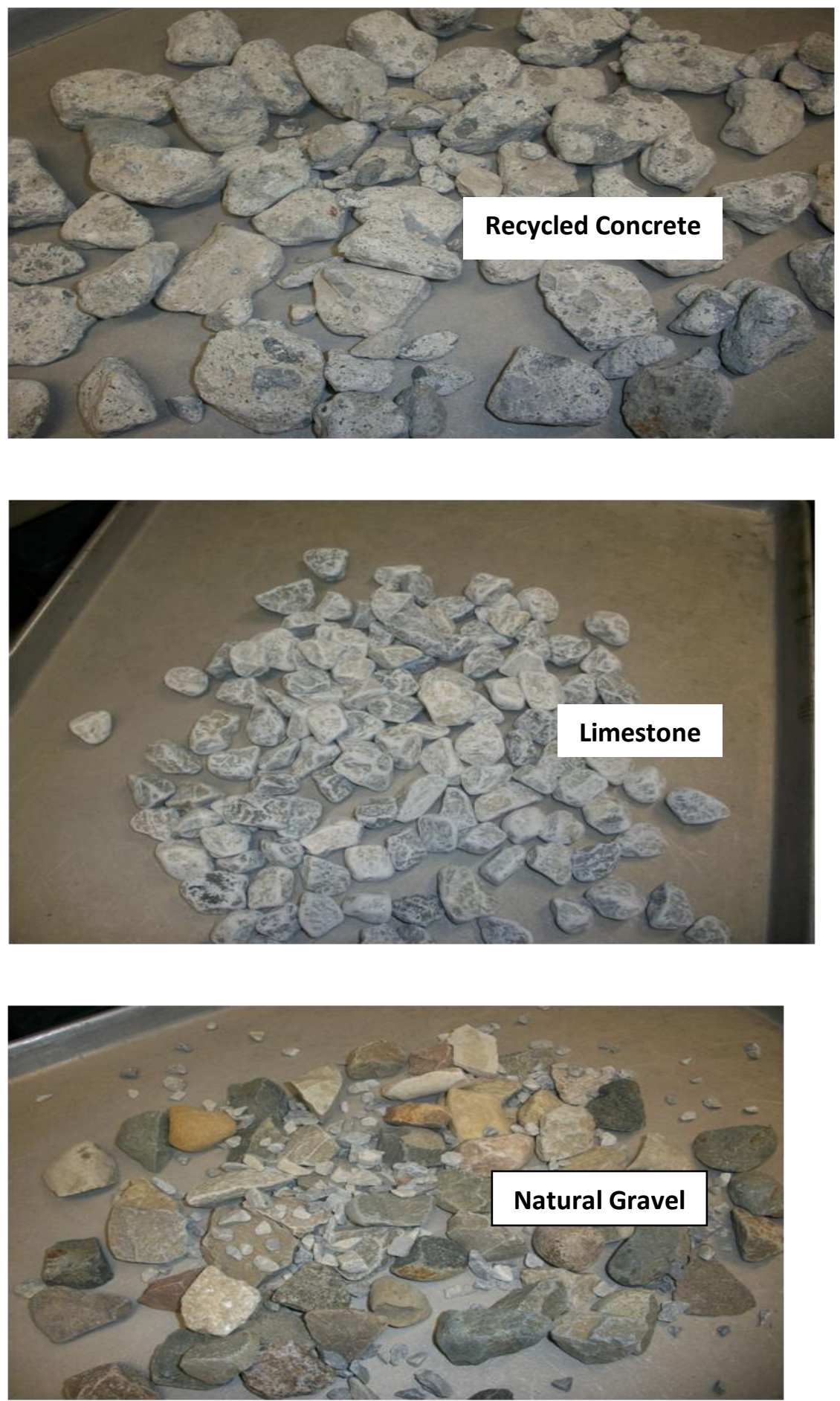

Figure 3.1: Photo showing crushed surfaces of the three aggregate types 
Since this research was focused on stabilized drainage bases, both the specific gravity and absorption of the aggregate types were needed for mix design purposes. The specific gravity and absorption were determined according to AASHTO T85. Table 3.1 shows values of specific gravity and absorption for the three aggregate types:

Table 3. 1

Aggregate material properties

\begin{tabular}{|c|c|c|}
\hline Material type & $\begin{array}{c}\text { SSD, specific } \\
\text { gravity }\end{array}$ & Absorption (\%) \\
\hline Natural gravel & 2.65 & 2.62 \\
\hline Limestone & 2.60 & 2.8 \\
\hline $\begin{array}{c}\text { Recycled Portland } \\
\text { cement concrete }\end{array}$ & 2.63 & 5.3 \\
\hline
\end{tabular}

\subsection{Stabilizing Agents}

In general, the two binding agents used to stabilize drainable bases are Portland cement and asphalt but many highway transportation agencies leave the choice of binder selection to the contractor (FHWA 1992). In an effort to provide answers as to which binder can provide an efficient and economical treated open-graded drainage layer, this research utilized both binders. For this research program Type 1 cement was utilized for the cement treated open-graded samples and an asphalt grade of PG grade of 58-28 was used for the asphalt treated open-graded samples. Physical properties of these stabilizing agents were those supplied by the manufacturer and are listed in Table 3.2 and Table 3.3 for the asphalt binder and cement respectively. 


\section{Table 3.2}

Physical /Mechanical properties of PG 58-28 (You et al. 2009)

\begin{tabular}{|l|l|}
\hline \multicolumn{1}{|c|}{ Property } & \multicolumn{1}{|c|}{ Value } \\
\hline $\begin{array}{l}\text { Rolling Thin-Film Oven } \\
\text { (RTFO) }\end{array}$ & $1.507037 \mathrm{e}+03$ \\
\hline Complex Modulus & $8.642802 \mathrm{e}+01$ \\
\hline Phase Angle & \\
\hline
\end{tabular}

Table 3.3

Physical Properties of Type 1 cement (culled from Manufacturer's specification)

\begin{tabular}{|l|l|}
\hline \multicolumn{1}{|c|}{ Property } & \multicolumn{1}{|c|}{ Value } \\
\hline Specific gravity & 3.15 \\
\hline Blaine Fineness $\left(\mathrm{m}^{\wedge} 2 / \mathrm{kg}\right)$ & $325 \mathrm{~m}^{\wedge} 2 / \mathrm{kg}$ \\
\hline Heat of hydration & $82 \mathrm{cal} / \mathrm{g}$ \\
\hline Compressive Strength (7-day) & $2800 \mathrm{psi}$ \\
\hline $\begin{array}{l}\text { Initial setting time (Hours: } \\
\text { Minutes) }\end{array}$ & $3.25-4.50$ \\
\hline Soundness & $<0.80 \%$ \\
\hline Loss on Ignition & $1 \%$ \\
\hline
\end{tabular}




\subsection{Aggregate Gradation}

Four gradation types were employed, two for the untreated open-graded drainage layer and two for the treated open-graded drainage layer. Both the MDOT $4 \mathrm{G}$ and the NJ unstabilized Mix were used for the untreated aggregate materials while the AASHTO \#67 and MDOT 5G gradations were used for the treated open-graded aggregate materials.

Considering the very open nature of these gradation specifications, three gradations bands were established in order to adequately determine the variations of material properties within the gradation bands. These gradation bands were a lower bound, which leans toward coarser size particles, an upper bound which represent a finer gradation and a middle gradation which is the average of the lower and upper bound gradations. In order to obtain aggregate samples for each of these gradation bands, the bulk materials were sieved and then grouped into different particle sizes and then recombined according to the gradation specification into the three targeted gradation bands. The sampled gradations and specification limits are shown in Table 3.4. The gradations plots showing lower and upper bounds are shown from Fig 3.2 through Fig 3.5. 
Table 3.4:

Aggregate gradation specifications-percent finer by weight

\begin{tabular}{|c|c|c|c|c|}
\hline $\begin{array}{l}\text { Sieve Size } \\
\text { (inches) }\end{array}$ & AASHTO'S NO.67 & New Jersey Mix & Michigan 4G & $\begin{array}{l}\text { Michigan } \\
5 \mathrm{G}\end{array}$ \\
\hline \multicolumn{5}{|l|}{$21 / 2$} \\
\hline \multicolumn{5}{|l|}{2} \\
\hline $11 / 2$ & & 100 & 100 & 100 \\
\hline 1 & 100 & $95-100$ & & \\
\hline $3 / 4$ & $90-100$ & & $60-80$ & \\
\hline $1 / 2$ & & $60-80$ & $35-65$ & $0-90$ \\
\hline $3 / 8$ & $20-55$ & & & \\
\hline$\# 4$ & $0-10$ & $40-55$ & & $0-8$ \\
\hline$\# 8$ & $0-5$ & $5-25$ & $10-25$ & \\
\hline$\# 16$ & & $0-8$ & & \\
\hline$\# 30$ & & & $5-8$ & \\
\hline \multicolumn{5}{|l|}{$\# 40$} \\
\hline$\# 50$ & & $0-5$ & & \\
\hline$\# 200$ & & 0 & $0-6$ & $0-3$ \\
\hline & & & & \\
\hline
\end{tabular}




\section{Grain-size Distribution - Base Course}

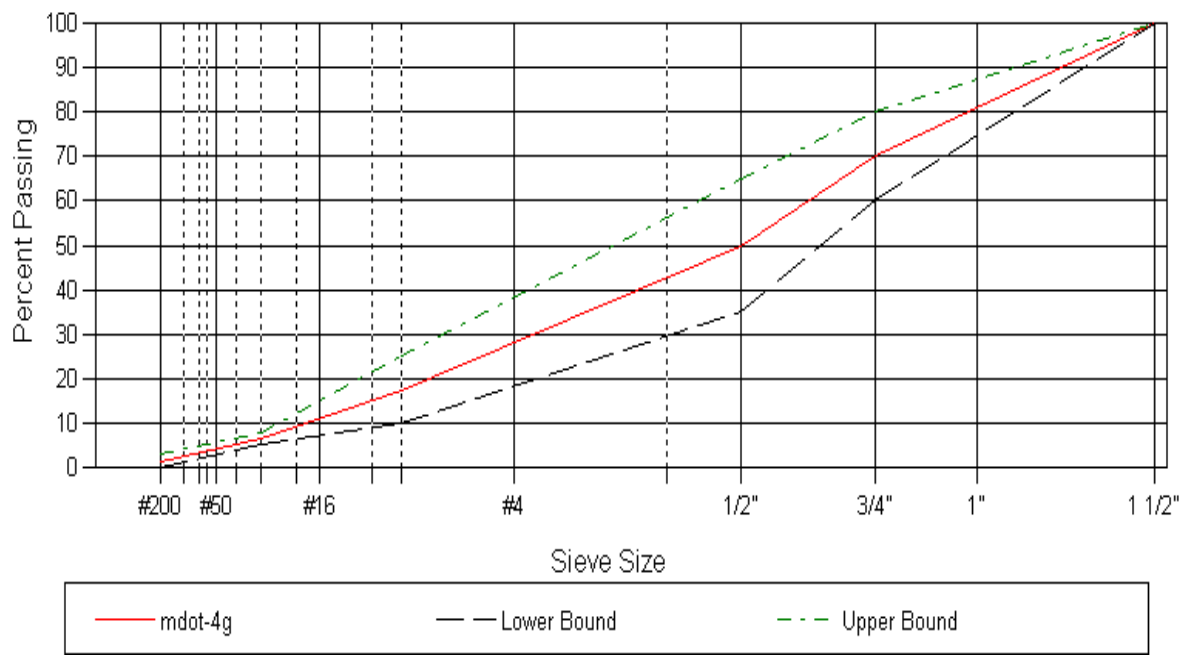

Figure 3.2: Grain-size distribution of Michigan 4G aggregate

\section{gradation}

Grain-size Distribution - Base Course

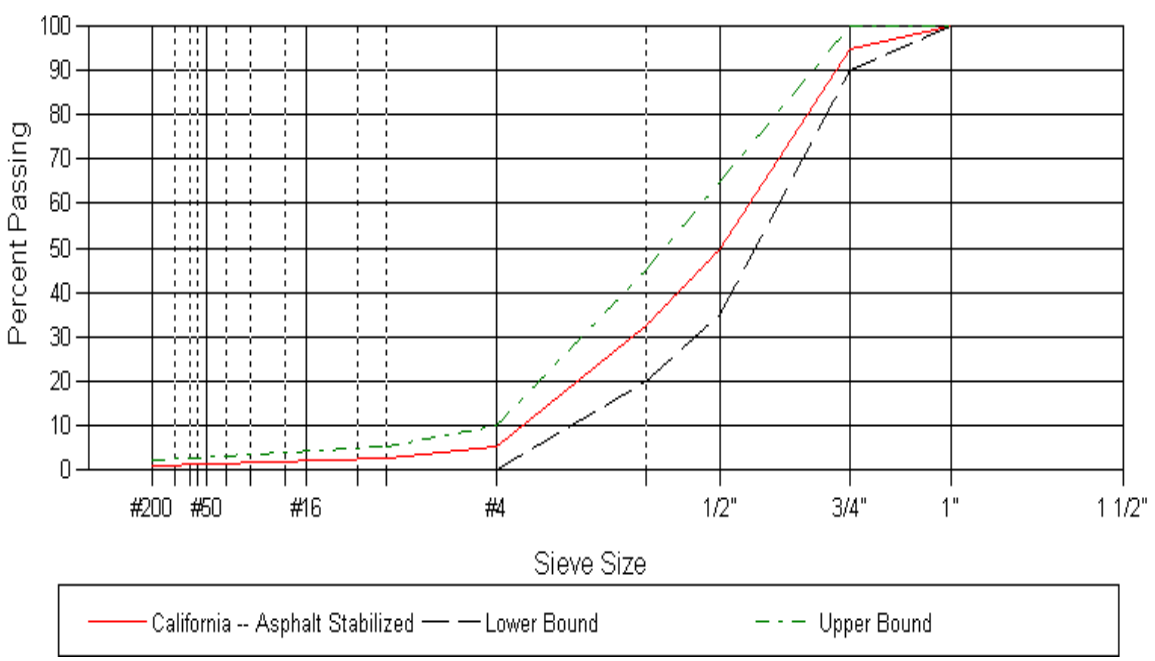

Figure 3.3: Grain-size distribution of NJ unstabilized mix 


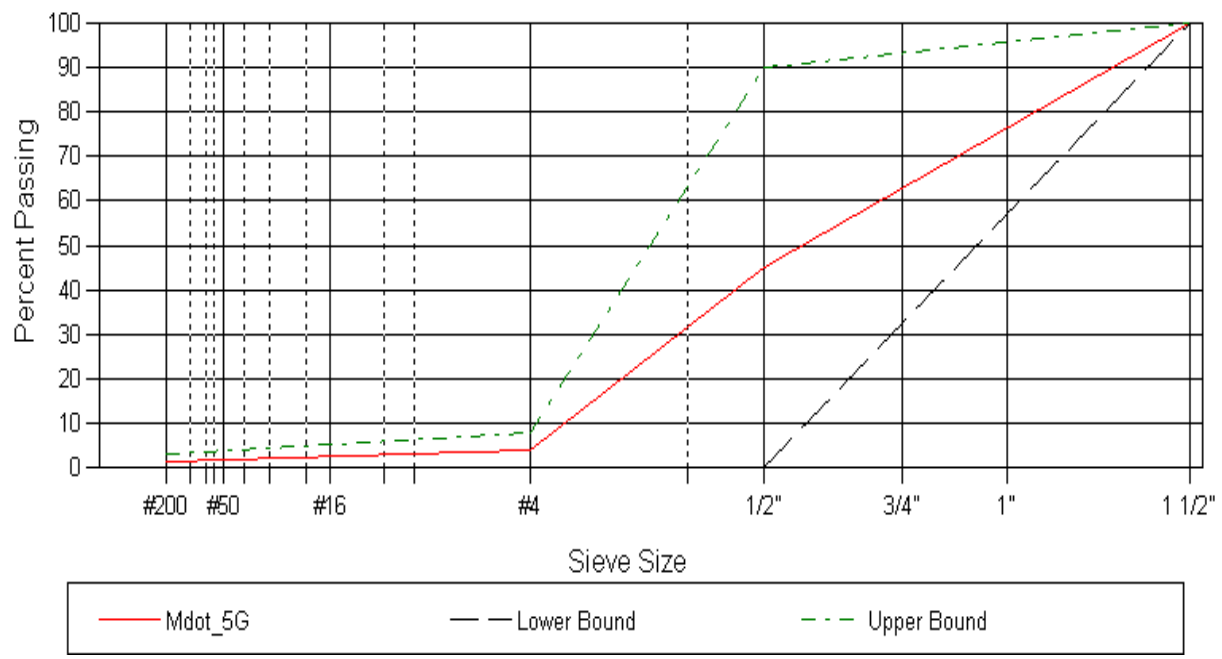

Figure 3.4: Grain-size distribution of Michigan stabilized 5G aggregate gradation

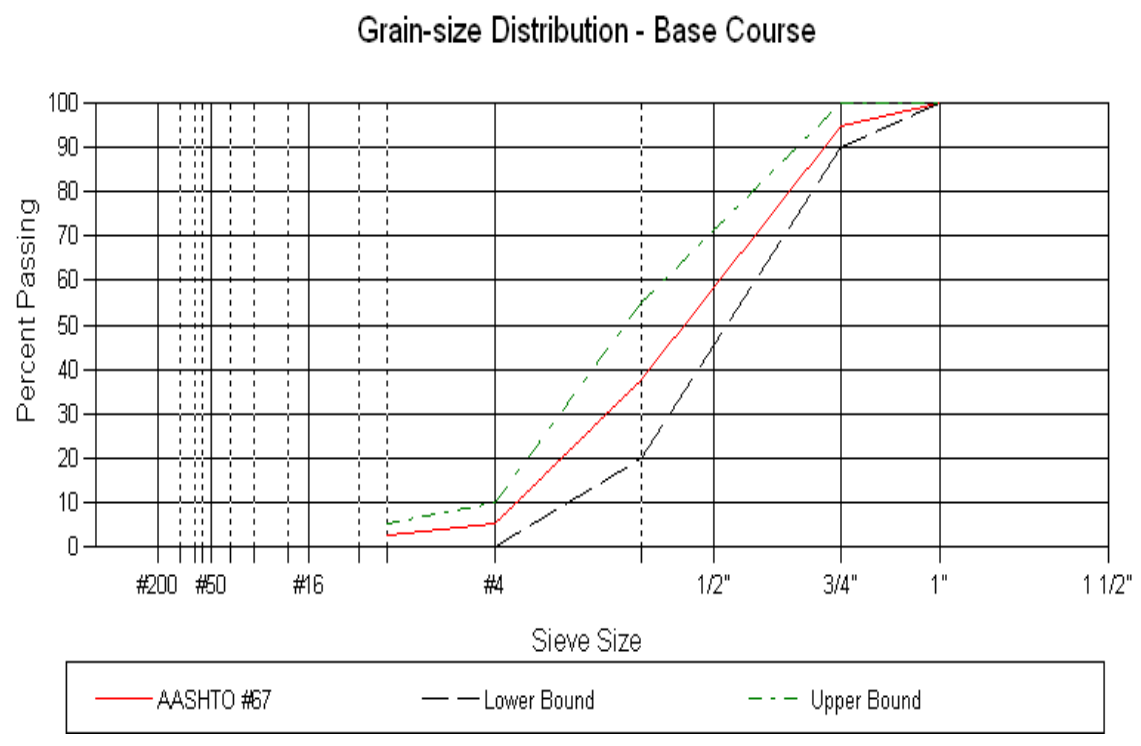

Figure 3.5: Grain-size distribution of AASHTO \#67 aggregate gradation 


\subsection{Laboratory Permeability Test Program}

\subsubsection{Introduction}

The test procedures contained in ASTM D5084-03 titled "Measurement of Hydraulic Conductivity of Saturated Porous Materials Using a Flexible Wall Permeameter" was used to measure the coefficient of hydraulic conductivity of the untreated open-graded samples and the cement treated open-graded samples. For the asphalt treated open-graded samples, a provisional ASTM standard was used measured the coefficient of hydraulic conductivity. The provisional standard is however a based on the test procedures contain in ASTM D5084-03. ASTM D5084 contained various procedures by which the coefficient of hydraulic conductivity can be measured such as the constant head method, falling head method and the falling head and rising tailwater method. The provisional standard only employed the falling head approach. Method C which is the Falling head and Rising tailwater was employed to measure the coefficient of hydraulic conductivity of the samples by ASTM D5048 test procedure. Most of the models currently in use to simulate subsurface flow in pavements are based on the validity of Darcy's law and assume that no turbulence occurs in the system. However, the assumption of laminar flow may not hold true for coarse natural formations and coarse open-graded aggregates in subsurface drainage systems (Cedergren 1989). In such open-graded formations, some degree of turbulence may be expected and several methods have been developed to modify Darcy's law in order to deal with such flows. For this research though, no correction of turbulence was made since it was deemed that such corrections may not significantly affect the value of the measured coefficient of hydraulic conductivity. Fig 3.6 shows the test set up of the flexwall permeameter used in this research. 


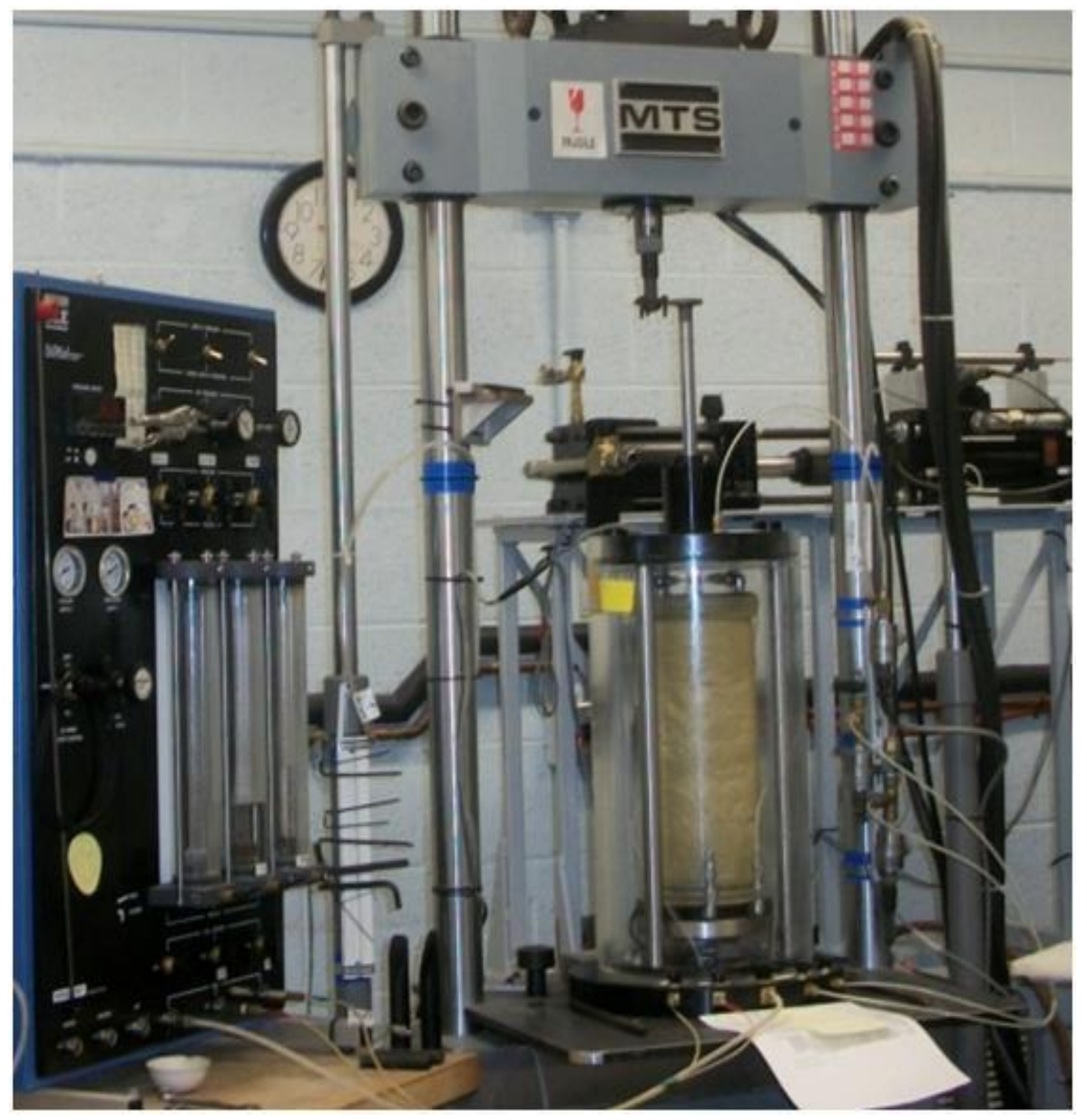

Figure 3.6: Triaxial Flexwall permeameter use to measure the coefficient of permeability of untreated OGM

\subsubsection{Specimen Preparation and Testing Procedures}

The primary objective of this test program was to evaluate the permeability of both treated and untreated open-graded aggregate materials. Bulk materials from various bins were sieved and then grouped into different size particles. The different particle sizes are then recombined to produce the targeted gradations bands shown on Table 3.4. However, for the treated open-graded aggregate materials, a mix design was prepared in order to obtain the design mixes required for the experimental program. The mix design process for the two treated permeable bases is outlined in the following sections 


\subsubsection{Mix Design and testing procedure for Cement Treated Permeable Bases (CTPBs)}

In order to make the testing program for the laboratory hydraulic conductivity yield representative results, the mix design used in this research was made as far as possible to be practically identical to that use in actual construction projects. For this research project, only one cement contents i.e. $200 \mathrm{lb} / \mathrm{yd}^{3}$ was used and three target air voids content of $35 \%, 25 \%$ and $15 \%$. A constant water/cement ratio of 0.36 was used for all the mixes. Table 3.5 gives the mix proportions for the CTPB. Example of mix design calculations for the $35 \%$ air void content is shown in Appendix 3A.

\section{Table 3.5}

\section{Mix Proportion for CTPB}

\begin{tabular}{|c|c|c|}
\hline Mixture ID. & $\begin{array}{c}\text { Cement } \\
\text { Content } \\
\left(\mathrm{lb} / \mathrm{yd}^{3}\right)\end{array}$ & $\begin{array}{c}\text { Design air void content } \\
(\%)\end{array}$ \\
\hline 1 & 200 & 15 \\
\hline 2 & 200 & 25 \\
\hline 3 & 200 & 35 \\
\hline
\end{tabular}

Based on this design mix, 1 cubic yard of cement treated open-graded material with a design percent air void of 35\% will contain $200 \mathrm{lbs}$ of cement, $72 \mathrm{lbs}$ of water and 2250 lbs of coarse aggregate. For a $6 " * 12 "$ concrete mold and batch mix for four samples, the appropriate quantities of cement, water and coarse aggregate were determined. The absorption capacity of the coarse aggregate factions was taking into consideration in arriving at the final amount of water to be added. The purpose of doing three mix types was to find a mix design that will meet minimum acceptable stability and drainability criteria. All the preliminary testing on the aggregates was done in accordance with the ASTM standards of the respective tests. Table 3.6 gives the physical characteristics of the three open-graded aggregate materials used in this research project. 
Table 3.6

Physical properties of aggregates

\begin{tabular}{|c|c|c|c|c|}
\hline $\begin{array}{c}\text { Aggregate } \\
\text { type }\end{array}$ & $\begin{array}{c}\text { Absorption } \\
(\%)\end{array}$ & $\begin{array}{c}\text { SSD } \\
\text { (specif } \\
\text { ic } \\
\text { graivt } \\
\text { y) }\end{array}$ & $\begin{array}{c}\text { SSD } \\
(\text { density) } \\
(\mathrm{lbs} / \mathrm{ft3})\end{array}$ & $\begin{array}{c}\text { Uncompacted air } \\
\text { void } \\
(\%)\end{array}$ \\
\hline Limestone & 2.8 & 2.8 & 112.4 & 43.6 \\
\hline $\begin{array}{c}\text { Natural } \\
\text { Gravel }\end{array}$ & 2.62 & 2.65 & 96.4 & 40.2 \\
\hline $\begin{array}{c}\text { Recycled } \\
\text { concrete }\end{array}$ & 5.3 & 2.53 & 107.4 & 38.7 \\
\hline
\end{tabular}

Four samples for each mix type were prepared leading to a total of 72 cement treated open-graded materials. The samples were tested as follows:

- All four specimens for each mix type were tested for hydraulic conductivity after 1 day curing period. The specimens were returned to the curing after the hydraulic conductivity testing.

○ Two samples were tested for the 7-day unconfined compressive strength (UCS)

- Two samples were subjected for 10 Freeze/Thaw cycles after the 7 day curing period.

- After the Freeze/Thaw procedure, the specimens were weighed to determine any weight loss and then tested for UCS to determine any strength loss as a result of the $\mathrm{F} / \mathrm{T}$ process. 


\section{Specimen Compaction}

Since three design air voids content were targeted, different compaction efforts were employed in order to produce samples of the required percent air void content. As a result many trial mixes were made with different compaction efforts and the corresponding percent air void content measured. The procedure was continued until a compaction effort that produced the closest percent air void content to that of the design air void content was reached. After achieving the desired degree of compaction, the compacted CTPB specimens were then tested for four key performance characteristics that are in the estimation of this researcher paramount to the characterization of cement treated drainage layers. These are the unit weight, coefficient of hydraulic conductivity, unconfined compressive strength for both control and condition specimens and the effective air void content.

After making several the trial compaction runs, the following level of compactive efforts were developed:

1. CTPB mixes with air voids content of $15 \%$ - 3 layers, 25 Marshall Hammer blows per layer and rodded 25 times per layer.

2. CTPB mixes Air voids content of 25\%- 2 layers, rodded 25 times per layer, 20 Marshall Hammer blows per layer.

3. CTPB mixes with air voids content of 35\%- 2 layers, no rodding, 2 Marshall hammer blows per layer

After compaction, the samples were allowed to set for a day and then removed from the molds, marked, weighed, tested for the coefficient of hydraulic conductivity and then wet cure for a period of 7 days.

A. Determination of unit weights and effective air voids content of compacted CTPB samples: There are currently no standard testing procedures for measuring the four performance characteristics of compacted open-graded concrete materials. However, a procedure 
developed by Crouch et al (2003) to measure similar material properties for pervious concrete was used in this research to determine the compacted unit weight and the effective air voids content of the compacted CTPB samples. A summary of the procedure is outlined below:

i. Cast 6 in. $* 12$ in. cylindrical specimens using the degree of compaction outline in the previous section for the targeted air voids.

ii. After moist curing the specimen for 7 days, one of the samples for each mix category was oven dried to a constant mass for a period of 24 hours.

iii. The mass of the dry sample was then determined. The sample was then placed in a plastic bag and put into a Corelok device for vacuum saturation and sealing of the bag.

iv. The sealed sample was then submerged in water and the weight of the sample submerged in water was then determined.

v. The bag was then cut to allow water to enter the bag and saturate the specimen for a period of about 8 minutes. Determine the mass of the submerged, water-saturated sample.

vi. Calculate the bulk specific gravity of the sample using equation 3.1

$$
G_{b}=A /\left[B-E-B-A / F_{t}\right] \text { Equation 3-1 }
$$

Where:

$\mathrm{A}=$ mass of dry sample in air before sealing

$\mathrm{B}=$ mass of dry sealed sample, $\mathrm{g}$

$E=$ mass of the sealed sample in water 
$\mathrm{C}=$ final mass specimen after removal from bag, $\mathrm{g}$

$\mathrm{Ft}=$ apparent specific gravity of the plastic sealing material at $77^{\circ} \mathrm{F}$ when sealed.

The final step was to calculate the effective air voids content of each mix type. Even though air voids content of $15 \%, 25 \%$ and $35 \%$ were used in the mix design calculations, the effective air voids of the compacted samples is the parameter of interest. The effective air voids content represents the pore spaces that are available for drainage. It is calculated from the equation 3.2:

$$
A_{\text {void }} \%=100 *\left(1-G_{m b} / G m m\right) \text { Equation } 3.2
$$

Where:

$\mathrm{Gmb}=$ bulk specific gravity of the CTPB sample

$G_{m m}=A /[A-C-B] \quad$ Equation 3.3

vii. Measuring the hydraulic conductivity of CTPB samples. After curing and the determination of unit weight and effective air void percentage, the hydraulic conductivity of two of the CTPB samples was measured using the flexwall permeameter according to ASTM D5048 as shown in Fig 3.7.

viii. Measuring the Unconfined Compressive Strength. After 7-day curing period, two specimens were tested for UCS. The other two specimens were allowed to undergo the freeze/thaw conditioning and afterwards tested for UCS. Samples of CTPBs after UCS testing are shown in Fig 3.8. 


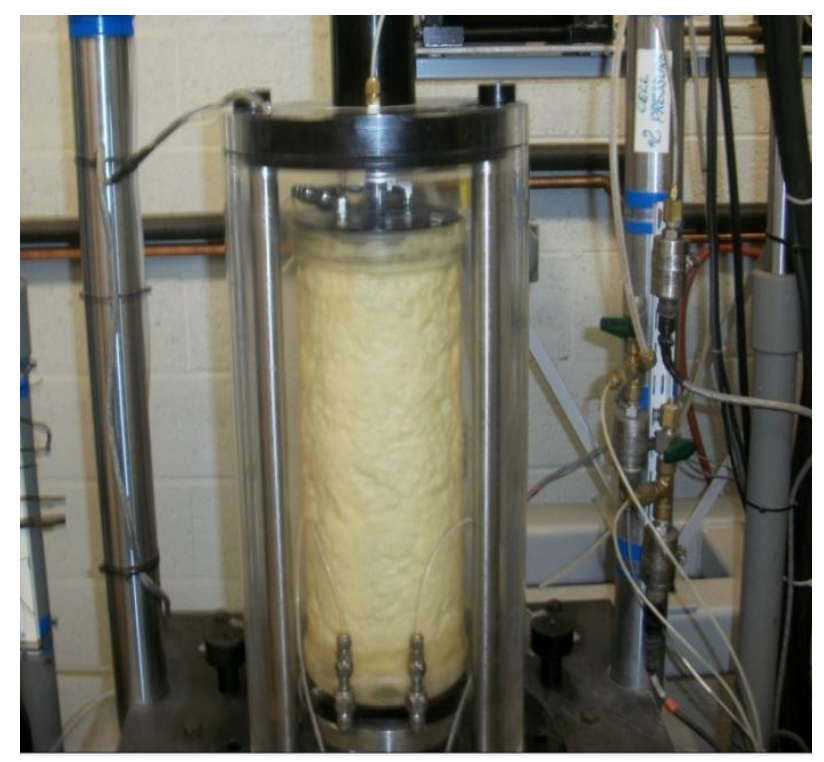

Figure 3. 7: Measuring the $\mathrm{K}$ of CTPB

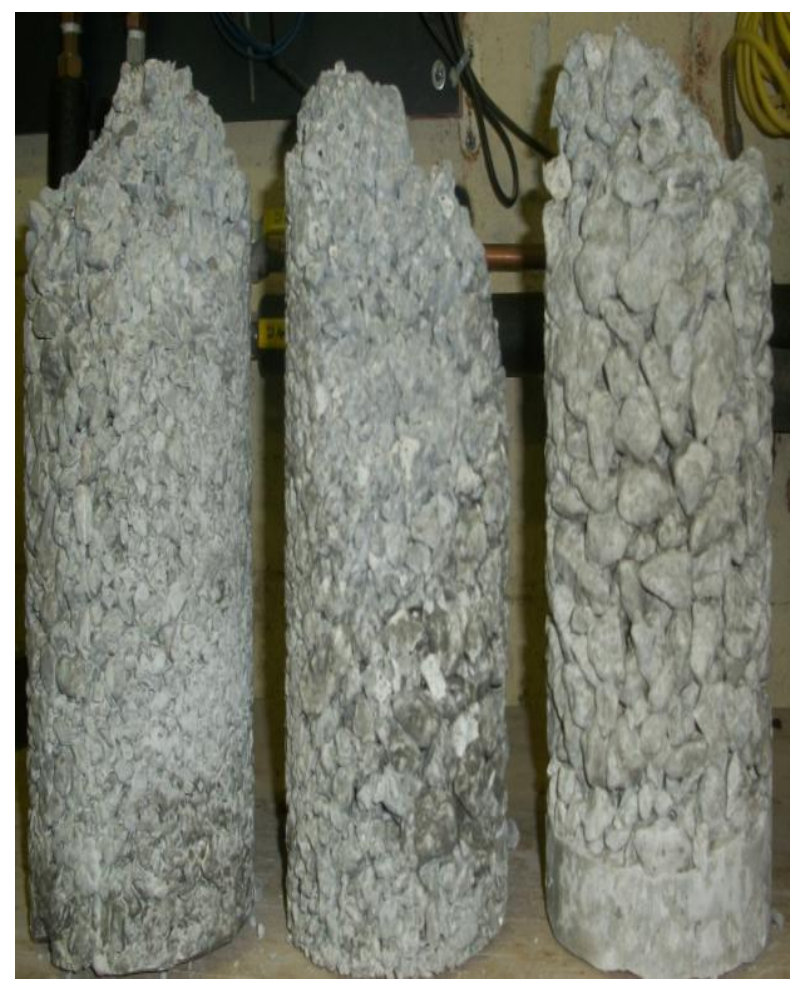

Figure 3. 8: CTPB samples after UCS testing 


\subsection{Mix Design and Testing procedures for Asphalt Treated Permeable Base}

An asphalt content of $3 \%$ by weight of the dry weight of the aggregate was used in this research project. Earlier attempts to use binder content less than 3\% resulted in many of the samples disintegrating due to the insufficient asphalt binder to hold the aggregate particles together as shown in Fig 3.9. A PG 58-28 grade asphalt binder provided by the Pavement Research Group of Michigan Technological University (MTU) was used to make the asphalt treated open-graded samples.

As was the case with the CTPBs, three air voids contents were targeted in this experimental program: air voids content of $15 \%, 25 \%$ and $35 \%$ respectively. The aim here also was to determine how the variations in the volumetric properties of the ATPB mix affect its hydraulic, mechanical and durability properties. Two major concerns with regard to preparing laboratory mixes of the aforementioned percent air voids content is the kind of compaction procedure to employ and the process of determining the percent air voids of the compacted permeable specimen. The gyratory compaction procedure was used to compact the asphalt treated open-graded mixes. The challenge of using the gyratory compaction method is to determine the number of gyrations to be applied in order to achieve the targeted percent air voids content. It was also required that the number of gyrations applied should produce a sample height that meets the requirement for sample height for both the permeability and indirect tensile strength test procedures. In order to achieve this, several trial mixes using different numbers of gyrations and computing the corresponding percent air voids content were carried out. After the trial runs, the following mixes and number of gyrations were arrived at:

- $15 \%$ air voids content: total weight of sample $3500 \mathrm{~g}$ and 40 gyrations

- $25 \%$ air voids content: total weight of sample $2500 \mathrm{~g}$ and 25 gyrations

- $\quad 35 \%$ air voids content: total weight of sample $4200 \mathrm{~g}$ and 20 gyrations

After each trial mix, the corresponding percent air voids content was calculated according the equation 3.2: 
The Maximum Theoretical Rice specific gravity was calculated according to AASHTO T209 in the same manner as is done with compacted asphalt specimen. The only variation was with the procedure used to measure the bulk specific gravity of the compacted treated permeable base material. AASHTO T166 is the testing procedure mostly used to determine the bulk specific gravity of compacted asphalt specimen. However, this procedure requires that the specimen be in a saturated surface dry state. Due to the porous nature of the materials under investigation, a SSD state was impossible to attain and as such an alternative testing procedure was used to measure the bulk specific gravity of the ATPB samples. As a result therefore the Corelok was used to measure the bulk specific gravity of the compacted ATPB specimens in this research.

The determination of the bulk specific gravity of the ATPB sample using the Corelok device was done in strict accordance with ASTM D 6752. A summary of the test procedure is as follows:

- Weighed the sealed ATPB sample and then submerged in water.

- $\quad$ Record the submerged weight

- Remove the sample and then record its weight. Compare this weight to the initial reading. The test is repeated if the difference between the two weight recordings exceeds $5 \%$ as this is an indication of a punctured bag.

- $\quad$ calculate the bulk specific gravity bulk specific gravity using appropriate equation

For each aggregate and gradation type, a separate mix was prepared and used to measure the maximum rice specific gravity. Therefore for each trial mix and trial number of gyrations, the percent air voids content was measured according to the procedure outlined above. The process was continued until a mix with a certain number of gyrations that produced the desired percent air voids contents and sample height was arrived at. The type and number of ATPB samples prepared and tested are shown in Table 3.7: 
Table 3.7

Types of ATPB samples prepared

\begin{tabular}{|l|l|l|l|}
\hline Material type & \multicolumn{1}{|c|}{$15 \%$} & $25 \%$ & $35 \%$ \\
\hline Recycled & RC_5G_15 & RC_5G_15 & RC_5G_15 \\
Concrete & RC_67_15 & RC_67_15 & RC_67_15 \\
\hline Natural & NG_5G_15 & NG_5G_15 & NG_5G_15 \\
Gravel & NG_67_15 & NG_67_15 & NG_67_15 \\
\hline Dolomite & DL_5G_15 & DL_5G_15 & DL_5G_15 \\
& DL_67_15 & DL_67_15 & DL_67_15 \\
\hline
\end{tabular}

Legend:

RC: Recycled Concrete aggregate

NG: Natural gravel

DL: Dolomite

5G: MDOT 5G aggregate gradation

67: AASHTO \#67 aggregate gradation

For each material, percent air voids content and gradation type, four samples were prepared and tested. This resulted in a total of 72 samples.

After preparing the compacted samples, the following tests were performed on the compacted samples:

1. Determine the effective air voids content: This was done to verify that subsequent testing was done on specimen with percent air void content in very close proximity to the design percent air void content. 
2. Hydraulic Conductivity: Hydraulic conductivity was done in accordance with the AASHTO provisional procedure P-125 titled: "Determination of Saturated Hydraulic Conductivity using a Flexwall Permeameter." The apparatus set up is shown in Fig 3.10 and the procedure employed a falling head approach. The test procedure however requires that the height of the test specimen to be about $80 \mathrm{~mm}$. Therefore some of compacted samples with height greater than $80 \mathrm{~mm}$ were cut while some within $+/-5$ were not cut.

3. Stability testing: For this research, the tensile strength was used as a measure of the stability of the asphalt treated open-graded specimens.

Durability testing: Moisture susceptibility using the indirect tensile strength ratio was used as the durability criterion and testing was done in accordance with AASHTO T283 "Standard Method of Test for Resistance of Compacted Hot Mix Asphalt (HMA) to Moisture-Induced Damage". The test was conducted on compacted ATPB specimen at a given air void content. Two control specimens were selected and tested without any moisture condition whatsoever. Two other ATPB specimens were conditioned by saturating with water. The specimen was allowed to undergo a freeze cycle and then a warm-water soaking cycle. The specimens were then tested for indirect tensile strength by loading the specimens at a constant rate. The force required to break the specimen was measured for each specimen (both the control and conditioned specimens). The tensile strength of the conditioned specimens was compared to that of the control specimens in order to determine the Tensile Strength Ratio (TSR). The value of TSR obtained was then compared with established criterion found in the literature. 


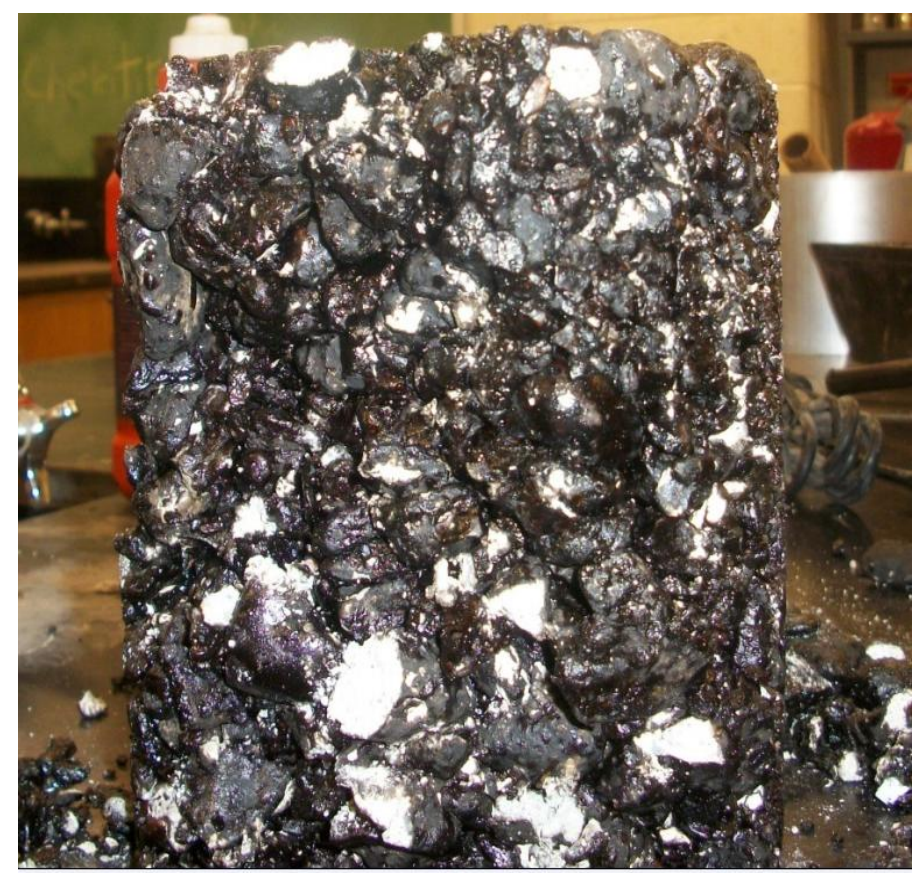

Figure 3. 9: ATPB samples disintegrating

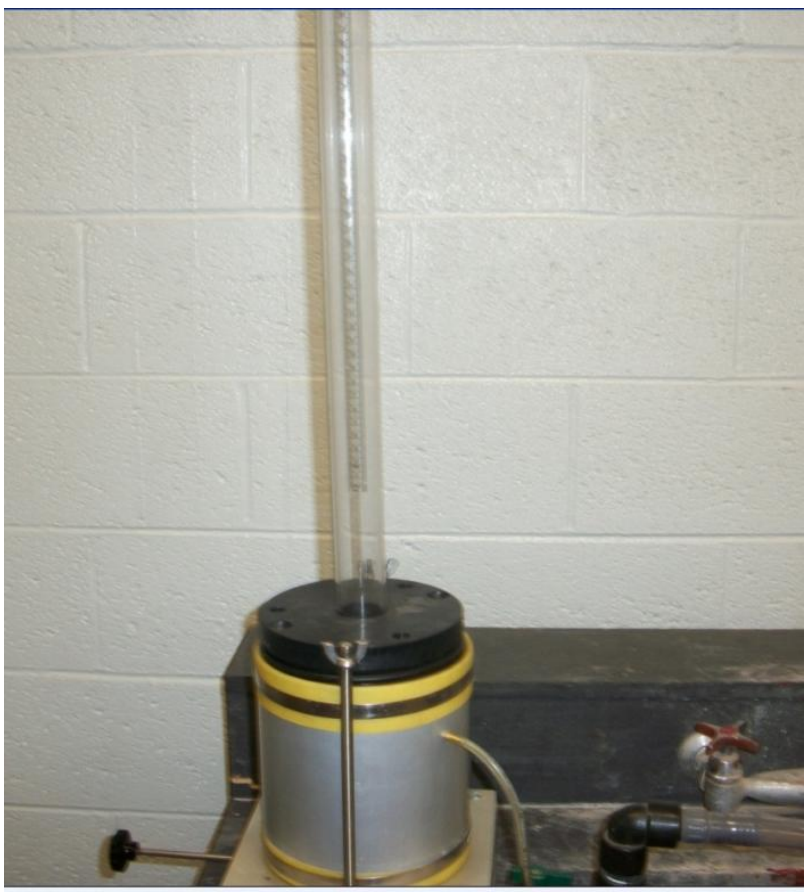

Figure 3. 10: Test apparatus used to measure the $K$ of ATPB samples 


\subsubsection{Testing procedure for Untreated Open-Graded \\ Aggregate Materials}

For the untreated open-graded aggregate materials, the two gradation types investigated were that of Michigan Department of Transportation (MDOT) 4G gradation and the New Jersey (NJ) open-graded gradations which are shown in Fig 3.2 and Fig. 3.3 respectively. Only hydraulic conductivity tests were conducted on the untreated open-graded aggregate specimens. However, discussions on the structural stability and durability of pavement layers containing these untreated aggregate base materials will be based on experimental data from other researchers. Unlike the case with the treated open-graded materials wherein only the middle gradation was investigated, the hydraulic conductivity tests were performed on three gradation bands of the two gradations under investigation:

- A lower band representing the coarser limit of the gradation curve. This gradation has no fines and as such is expected to provide the high limit hydraulic conductivity value.

- An Upper band which is represents the finer gradation limit of the gradation band and has about $7-10 \%$ fines. This gradation is expected to provide the lower limit of hydraulic conductivity value.

- A middle gradation band which is the average of the upper and lower gradation bands.

Mayberger and Hodek (2007) carried out a research work on determining the variation of resilient modulus within the gradation limits of MDOT $4 \mathrm{G}$ aggregate gradations using the three aggregate types investigated in this research. Experimental results from that research will be referenced in the discussions on the suitability of these materials for subsurface drainage. However the as-tested unit weights and compaction moisture contents obtained from their research were used for the $4 \mathrm{G}$ gradation and are shown on Table 3.8. The as-tested unit weights and compaction moisture content for the NJ Mix for the various gradation bands and material type were obtained using AASHTO T99 
"Standard Method of Test for Moisture-Density Relations of Soils Using a 2.5-kg (5.5-lb) Rammer and a 305-mm (12-in.) Drop" with slight modifications to make for particle breakage. The as-tested unit weight for the NJ Mix was set at 98\% of Maximum Dry Density (MDD) which was the same criterion used by Mayberger and Hodek (2007) in their research with $4 \mathrm{G}$ gradation. This was done in order to facilitate comparisons between the two open-graded gradations. The as-tested unit weights and compaction moisture content for the NJ mix are shown on Table 3.9:

Compaction of the various untreated open-graded aggregate specimens was accomplished by means of a servo-hydraulic vibrator which is capable of exerting a maximum load of $200 \mathrm{psi}$. The size of the specimens used for this portion of this research was a $6 * 12$ " inches and the specimens were compacted in six equal lifts. Each lift was compacted to the desired density and appropriate precaution was taken to ensure that each lift was scarified before placement of the subsequent lift. For all the specimen effort was made to ensure that compaction was achieved at moisture content very close to the optimum. A total number of eighteen specimens were prepared for the hydraulic conductivity test. Experimental procedure for conducting the hydraulic conductivity test was done strictly in accordance with ASTM D5068 "Determination of Hydraulic Conductivity of Porous Stone Using a Flexwall Permeameter". For each specimen, five hydraulic conductivity measurements were made and then averaged. Standard practice also requires that the coefficient of hydraulic conductivity be reported to a base temperature of 20 degrees Celsius, the temperature for each test was recorded and correction to the hydraulic conductivity value was made using the appropriate formula. 
Table 3.8

As compacted unit weight MDOT 4G gradation

\begin{tabular}{|c|c|c|c|}
\hline \multirow{4}{*}{ Material type } & Gradation band & $\begin{array}{c}\text { Unit } \\
\text { weight } \\
(\mathrm{pcf})\end{array}$ & $\begin{array}{c}\text { Omc } \\
(\%)\end{array}$ \\
\hline \multirow{4}{*}{ Limestone } & lower & 128 & 2.6 \\
\cline { 2 - 4 } & Middle & 144 & 3.5 \\
\hline \multirow{3}{*}{$\begin{array}{c}\text { Recycled } \\
\text { Concrete }\end{array}$} & Upper & 148 & 3.2 \\
\cline { 2 - 4 } & Lower & 102 & 6 \\
\hline \multirow{3}{*}{$\begin{array}{c}\text { Natural } \\
\text { gravel }\end{array}$} & Middle & 115 & 5.5 \\
\cline { 2 - 4 } & Upper & 119 & 7 \\
\cline { 2 - 4 } & lower & 122 & 3.5 \\
\hline \multirow{2}{*}{} & Middle & 137 & 4.2 \\
\hline
\end{tabular}

Table 3.9

As compacted unit weight $\mathbf{N J}$ unstabilized Mix

\begin{tabular}{|c|c|c|c|}
\hline \multirow{4}{*}{ Material type } & Gradation band & $\begin{array}{c}\text { Unit } \\
\text { weight } \\
\text { (pcf) }\end{array}$ & $\begin{array}{c}\text { OMC } \\
(\%)\end{array}$ \\
\hline \multirow{4}{*}{ Limestone } & lower & 120 & 2.1 \\
\cline { 2 - 4 } & Middle & 138 & 4.2 \\
\hline \multirow{3}{*}{$\begin{array}{c}\text { Recycled } \\
\text { Concrete }\end{array}$} & Upper & 143 & 3.4 \\
\cline { 2 - 4 } & Lower & 93 & 6.3 \\
\hline \multirow{2}{*}{$\begin{array}{c}\text { Natural } \\
\text { gravel }\end{array}$} & Middle & 98 & 5.2 \\
\cline { 2 - 4 } & Upper & 102 & 6.4 \\
\cline { 2 - 4 } & Middle & 108 & 3.0 \\
\cline { 2 - 4 } & Upper & 120 & 4.5 \\
\hline
\end{tabular}

After the hydraulic conductivity tests were conducted, the specimens were allowed to drain and a sample for moisture content determination was taken. 


\subsubsection{Test Procedure for Laboratory Permeability Test}

The following is a summary of the procedures used for the laboratory permeability test:

$\circ \quad$ Sieve analysis

- Recombined the various aggregate sizes to get the targeted gradations

- Carefully and properly mix the mixture's ingredient according to the mix designs for each type of material

- Compaction of the specimen

$\circ \quad$ Curing of the specimen

- Saturating the specimen to the required degree of saturation

- Measuring the head differences and flow rates under a range of hydraulic gradients.

- Draining of the sample in order to get the effective porosity

Boil the two porous stones in order to clean and saturate them. One of the porous stones was placed on the bottom pedestal and a thin coat of vacuum grease applied to the sides of the bottom pedestal. A flexible membrane was the fitted over the lower end and the membrane to the pedestal sealed with two O-rings. The membrane was then fitted into a membrane expander.

Vacuum was applied to the membrane expander in order to stretch the membrane to its walls. The sample was then compacted to its maximum density using a servo-hydraulic vibrator mounted on a rigid frame. The equipment can apply various degrees of pressure on the specimen but to avoid excessive particle breakage, the pressure was limited to a maximum of 150 psi. The specimen was compacted in six layers with each layer scarified before the next layer was built in order to avoid shear planes. After compaction of the specimen, the second porous stone was then placed on top of the sample and sealed by the top cap. Vacuum grease was also applied to the sides of the top cap and the membrane fitted onto the cap with two O-rings. The vacuum applied to the membrane expander was discontinued after the sample has been well seated inside the membrane. A vacuum pressure of 5 psi was applied inside the sample through the venting valve in 
order to keep the sample together while the membrane expander was been removed. Sample heights an diameter were measured for use in volume and dry density calculations. The cell pressure valve was attached to the pressuremeter and filled with deaired water. Upon filling the reservoir the vacuum that was applied to the sample was discontinued and a confining pressure of 5 psi applied to the specimen. De-aired water at $2.5 \mathrm{psi}$ pressure was then run through the sample in order to saturate the sample by washing out entrapped air bubbles inside the sample and flow lines.

Backsaturation was used to saturate the entire specimen to a given degree of saturation. The degree of saturation of the sample is very important in the measurement of hydraulic conductivity. Air bubbles within the sample can block seepage channels between particles thereby reducing the $\mathrm{k}$ value. Head (1986) noted that if the degree of saturation of a specimen is less than $80 \%$, air bubbles in the sample may likely not be interconnected thereby forming continuous air streams that can greatly reduced the hydraulic conductivity. In backsaturation both the confining pressure and backsaturation pressure were increased in 5 psi intervals and for each stage adequate time was allowed for the air bubbles to dissolve.

Pore volumes of de-aired water were continually run through the specimen until the air bubbles became smaller as they dissolved into the surrounding de-aired water. ASTM D5084 recommended a method of verifying sample saturation as follows:

"The test specimen shall be considered to be adequately saturated if the $B>=0.95$ or for relatively incompressible materials if the $B$ value remains unchanged with application of larger values of back pressure”.

The B coefficient approach was used in this research project. After back-pressure saturation of the specimen for a while, the , $\mathrm{B}$ ' parameter was calculated to determine what degree of saturation has been reached. The , $\mathrm{B}$ ' coefficient is defined for this type of test as the change in pore-water pressure in porous material divided by the change in confining pressure". Mathematically, it is expressed as: 
$B=\Delta u / \Delta \sigma$ Equation 3.4

Where $\Delta \sigma=$ change in confining pressure

$\Delta \mathrm{u}=$ change in pore pressure

$\mathrm{A}, \mathrm{B}^{\prime}$ parameter in the range of $0.95-1$ is normally taken to mean a degree of saturation close to $100 \%$. The process to get a "B" value of 0.95 can sometimes be very lengthy and daunting and can range between several hours to a couple of days depending on the mixture type. Permeability testing was conducted as soon as an acceptable B parameter has been reached.

Before running the hydraulic conductivity test on the actual specimens, a makeshift hydraulic conductivity test was first conducted on the apparatus in order to account for the head loss in the apparatus. This head loss in the apparatus can be significant for opengraded aggregates which are under investigation in this research project due to the high velocities of flow. In order to make corrections for the head loss in the apparatus at various velocities, the permeability of the apparatus was measured under different hydraulic gradients. These corrections corresponded to the respective velocities of flow were then applied to account for the head loss in the apparatus.

\subsubsection{Design Considerations in the measurement of the coefficient of hydraulic conductivity using the flexwall permeability}

Two major factors were taken into consideration to make sure that reasonable laboratory coefficients of hydraulic test results were obtained. Firstly, the laboratory set up for measuring the hydraulic conductivity of porous aggregate materials using a flexwall permeameter consists of two porous stones at the bottom and top of the specimen. This set up is similar to a stratification of three different soil layers with vertical flow. As a result therefore the measured hydraulic conductivity is actually the composite hydraulic conductivity of the two porous stones and that of the specimen. In order therefore to get the actual hydraulic conductivity of the specimen, attempts was made to measure the hydraulic conductivity of the ceramic porous stones used. The hydraulic conductivity of 
the porous stone was measured by setting up the flexwall permeameter using the two porous stones without with no specimen in it. Fig 3.11 shows the equipment set up for measuring the coefficient of hydraulic conductivity of the porous stones.

The second factor that was taken into was the issue of the actual head loss across the specimen. Head losses across the instrument can significantly affect the value of measured hydraulic conductivity of specimen if appropriate corrections are not put in place (Crouch et al, 2003). In the standard permeability test methods, notably the constant head and falling head tests, piezometers are normally installed on the sample chamber to enable the true head differential across the specimen to be measured from the piezometer levels. This represents therefore the true head differential across the sample between the points at which the piezometers are installed. But for the flexwall permeameter, the hydraulic conductivity set up is enclosed within the pressure chamber thus making it impossible to measure directly the head differential at the bottom and top of the test specimen. For the flexwall permeamter the head differential measured between the upper and lower burettes includes head losses occurring in the pipeline connections, valves, screen and perforated plates. If this head loss is taken as the actual head loss across the specimen, it introduces significant error especially if the flow rate is high. In order to get correct hydraulic conductivity values, this head difference must be corrected for head losses in the system. The corrected hydraulic gradient can then be calculated from equation 3.5:

$$
i=\Delta h-h_{l} / L \quad \text { Equation } 3.5
$$

Where

$\mathrm{i}=$ hydraulic gradient across the specimen

$\Delta \mathrm{h}=$ head loss in the system as measured by the differences in pressure between the upper and lower burette readings

$\mathrm{h}_{1}=$ head loss in the system 
In order to measure the head loss on the system, the procedure employed by Smith (2004) was employed. A dummy sample of similar dimension as the actual specimen made of cast steel was fitted in the laboratory set up using identical procedures was used for the actual specimen. For this case it was assumed that the head loss across the dummy sample is negligible so that head loss measured will be attributed only to that of the system. The permeameter was filled with water and the head difference between the upper and lower burettes at different flow rates was measured. Since no specimen was included the test set up, this head differential was assumed to represent the actual head losses due to the system at different flow rate. A plot was then made between system head loss versus flow rates. The system head loss was found to be proportional to the flow rate.

$$
\begin{aligned}
& h_{l=} 0.000579 Q(\mathrm{~cm}) \text { Equation } 3.6 \\
& \text { where } \\
& \mathrm{Q}=\text { flow rate in } \mathrm{cm} 3 / \mathrm{s}
\end{aligned}
$$

Corrections for the system head loss can be then be made once the flow rate under which each hydraulic conductivity tests was measured and the subsequent system head loss calculated from equation 3.7. The net head difference $((\Delta \mathrm{h}-\mathrm{hl})$ across the specimen is caused by the resistance from the specimen only and as such was used to calculate the hydraulic conductivity of the sample. Errors of up to an order of magnitude can be realized if the head loss correction was not taken into consideration. 


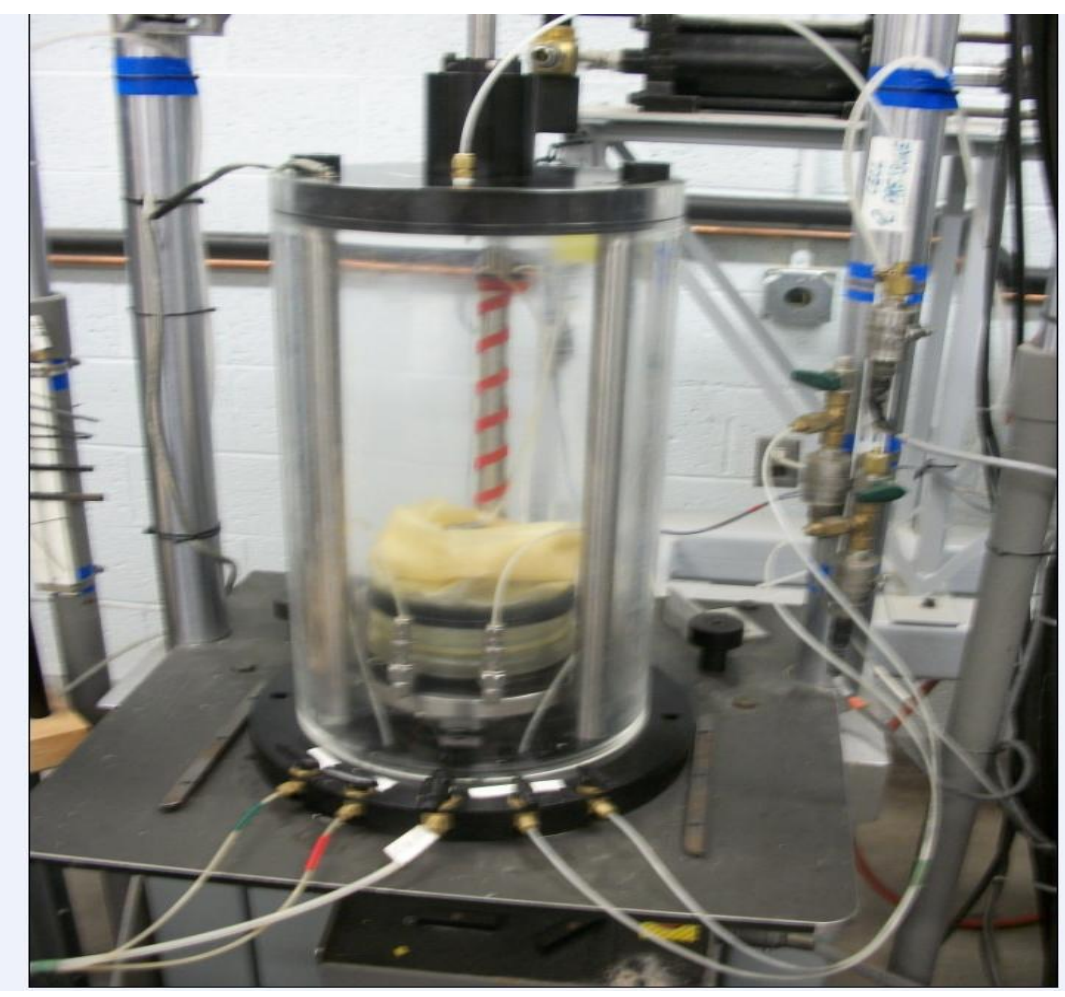

Figure 3.11: Set up for measuring the $K$ of porous stones

The coefficient of permeability of the specimen was then calculated using Equation 3.8 by measuring the time a given flow of de-aired water flow through the specimen (MTS Laboratory manual).

$$
k \mathrm{~cm} / \mathrm{s}=2.303 *[(a)(L) / 2 *(A)(t)] * \log P b+h_{1} / \mathrm{Pb}_{h_{2}} \quad \text { Equation } 3.7
$$

Where

$$
\begin{aligned}
h_{1} & =\left[\begin{array}{llll}
V_{u} & t_{1} & -V_{l} & t_{2} / a
\end{array}\right] \\
h_{2} &
\end{aligned}
$$




$$
\begin{aligned}
& \mathrm{t}=\text { time recorded, } \mathrm{t}_{2}-\mathrm{t}_{1}(\mathrm{sec}) \\
& \mathrm{h}_{1}=\text { initial head at time } \mathrm{t}_{1}(\mathrm{~cm}) \\
& \mathrm{h}_{2}=\text { final head at } \mathrm{t}_{2}(\mathrm{~cm}) \\
& \mathrm{PB}=\text { Bias Pressure }=70.37 \mathrm{psi} \\
& \mathrm{V}_{\mathrm{u}}\left(\mathrm{t}_{\mathrm{i}}\right)=\text { Volume reading of burette at } \mathrm{t}\left(\mathrm{cm}^{3}\right) \\
& \mathrm{V}_{\mathrm{L}}\left(\mathrm{t}_{\mathrm{i}}\right)=\text { Volume reading of lower burette at } \mathrm{t}_{\mathrm{i}}\left(\mathrm{cm}^{3}\right)
\end{aligned}
$$

A graduated cylinder was used to catch the outflow and the elapsed time was measured using a stopwatch. For each sample three permeability values were measured and then averaged to give the permeability value for that particular gradation.

\subsubsection{Effective Porosity and Post-Compaction Gradation Curves}

After completion of the laboratory hydraulic conductivity tests, the specimen was allowed to drain by depressurizing it in order to determine the effective porosity of the sample. This was to determine the amount of water retained after the sample had been permitted to drain. The importance of effective porosity is that it represents the capacity of a free draining base to accept new inflows when it becomes available.

After determining the effective porosity of the materials, efforts were directed towards analyzing the impact of the Servo-hydraulic vibrator on the material and gradation types. The sample was allowed to drain to a constant mass and then dried in the oven for $24 \mathrm{hrs}$. After oven drying, the material was then re-sieved and an after-compaction gradation chat was plotted. This gradation chart was then compared with the original gradation plots to see which of the material and gradation types experienced the most particle breakage. This was not however intended to be a detailed experimental study on particle breakage and subsequent internal rearrangement of these particles as they affect the hydraulic conductivity value of the tested specimen. Post-compaction analyses were done only for the MDOT $4 \mathrm{G}$ gradation and the middle gradation band specimens for the three material types. 


\subsection{Durability Testing Program}

\subsubsection{Introduction}

Tests were carried out top determine the resistance to durability of both the cement treated and asphalt treated open-graded bases. This was done to determine which of the mix designs has the highest resistance to certain environmental variables like freezethaw. In this case the resistance to freeze-thaw was selected for the cement treated materials while moisture damage was chosen for the asphalt treated open-graded materials.

\subsubsection{Durability Testing For CTPBs}

ASTM D559 and ASTM D560 are the two standards normally used to determine the durability of cement treated materials. These two durability tests were designed to reproduce the effects of field moisture and temperature variations on the material in the laboratory. Freeze-thaw durability testing are normally recommended to be done in areas that experienced at least one freeze-thaw cycle in a year but the wetting /drying durability test should be conducted in all geographic areas (FHWA 1992). One useful parameter that can be obtained from these two durability tests is the minimum amount of cement required to produce a structural material that would not undergo volume changes due to moisture and temperature variations. The durability testing was therefore conducted to develop an appropriate Freeze/Thaw durability criterion for treated permeable bases that are based on results of durability test and other supplemental data from the literature. The durability of the drainage layer is very important because if it is not, substantial distress may develop just after it is subjected to limited number of freeze/thaw and/or wetting/drying cycles. Currently, the durability criterion used for base layer is based on mass loss after subjecting the specimen to several cycles of freeze/thaw cycles.

The freeze-thaw durability testing was performed in accordance with the procedures outlined in ASTM D560. The criterion used to measure the resistance to freeze-thaw is the total weight loss after completion of the prescribed freeze-thaw cycles. This percentage weight loss was then compared to established criterion in the literature. For 
stabilized permeable bases underneath concrete pavement the weight loss should be $<5 \%$ (Fang 1990).

Two notable modifications were made to ASTM D 560 with regards to the method of compaction and the number of freeze/thaw cycles. Since the focus of this research was on stabilized open graded aggregate material, the compaction method was geared towards ensuring that this open-graded structure was maintained and that no excessive particle breakage occurred. Another factor that was also taken into consideration was using a compactive effort that will meet the targeted design air void contents of the three mixes and also the thickness of the cement treated permeable base. The thickness of the CTPB normally varies between 3-6 inches, with 4 inches being the most common. The consensus behind the selection of a 4 inch CTPB is that a 4 inch thick drainage layer provides adequate drainage capacity that is appropriate for most highway pavements. Furthermore, these open-graded layers are considered by some pavement designers to be areas of weakness within the pavement structure and as such limiting their thickness are considered a sensible design decision (Hall et al. 2005).

For this research however, a thickness of 12 inches was selected as this height was deem adequate to achieve the three targeted range of air void content. Therefore the prescribed standard proctor compaction method was not employed since it would have lead to excessive particle breakage that may have lead to erroneous tests results which are not representative of the open-graded nature of these specimens.

Furthermore, in accordance with ASTM specification for the freeze/thaw test 12 freeze/thaw cycles was specified. However, $10 \mathrm{~F} / \mathrm{T}$ cycles were used for this testing program because according to Dempsey (1972) the number of F/T cycles chosen for the durability test should be related to geographical location, climatic conditions and position of the stabilized layer in the pavement. Since the drainage layer for most part is located just underneath the pavement surface, it is not subjected to the same freeze/thaw cycles as the subgrade and as such a less severe F/T cycles may be appropriate for the drainage layer. The number of $\mathrm{F} / \mathrm{T}$ cycles was also reduced to 10 in order to reduce the time for the 
experimental program with the assumption being that $10 \mathrm{~F} / \mathrm{T}$ cycles can give a meaningful value of the resistance of these materials to freeze-thaw.

For each material, gradation and mix type, a total number of 4 samples were prepared and then tested as indicated in section 3.5.2.1

\subsubsection{Durability Tests for ATPBs}

The durability of the ATPB samples was given a high priority in this research considering the fact only a small percentage of binder by weight of aggregate is normally use. This low binder content makes ATPBs highly susceptible to moisture damage. The resistance to moisture damage in asphalt treated open-graded samples is a direct function of both the aggregate type, binder type and percent binder content by weight of dry aggregate. However, since only one type of binder and one type of binder content was used in this research, the results of durability tests on ATPBs can give a fair assessment of the moisture susceptibility of both the aggregate and gradation types that are investigated in this research project. As a result, the durability testing portion of the experimental program was geared towards determining the moisture susceptibility of the various ATPB mixes. Durability test on the asphalt treated open-graded samples was done in strict accordance to AASHTO T283 "Standard Method of Test for Resistance of Compacted Hot Mix Asphalt to Moisture-Induced Damage." Durability tests were conducted on each of the asphalt treated open-graded mix types. Test protocols contained in AASHTO T283 "Standard Method of Test for Resistance of Compacted Hot Mix Asphalt (HMA) to Moisture-Induced Damage" were used to determine the moisture susceptibility of ATPBs. Specimen preparation and testing procedures were in accordance with AASHTO T283. The test was conducted on compacted ATPB specimens at a given air void content. The four ATPB samples for each mix type was divided into two groups labeled „control' group and ,conditioned' group. The two control specimens were then tested for tensile strength after the bulk specific gravity and coefficient of hydraulic conductivity tests. Two other ATPB specimens were conditioned by saturating with water and following the conditioning procedure outline in the standard. The specimen was allowed to undergo a freeze cycle and then a warm-water soaking cycle. The specimens were then tested for 
indirect tensile strength by loading the specimens at a constant rate. The force required to break the specimen was measured for each specimen (both the control and conditioned specimens). The tensile strength of the conditioned specimens was compared to that of the control specimens in order to determine the Tensile Strength Ratio (TSR). The value of TSR obtained was then compared with established criterion found in the literature. 


\section{CHAPTER 4}

\section{EXPERIMENTAL RESULTS AND DISCUSSIONS}

\subsection{Hydraulic Conductivity Test Results for Untreated Open- graded Aggregate}

Three types of aggregates, two gradation types and three gradation bands were used to developed samples for hydraulic conductivity testing. This combination produced a total of 18 samples which were tested for the hydraulic conductivity and effective porosity of the untreated open-graded aggregate Results of the laboratory coefficient of hydraulic conductivity are shown in Table 4.1 .

The measured coefficients of hydraulic conductivity results in Table 4.1 were then compared to Moulton's chart used for estimating the coefficient of hydraulic conductivity. Moulton's chart is the analytical expression used in the MEPDG software to predict the saturated coefficient of hydraulic conductivity. Moulton's chart and the accompanying expression is shown in Fig 4.1. Results of the estimated coefficient of hydraulic conductivity using these two analytical methods are shown in Table 4.2: 
Table 4.1:

Coefficient of hydraulic conductivity results for untreated open-graded aggregate materials

\begin{tabular}{|c|c|c|c|}
\hline Sample ID & $\begin{array}{c}\text { Dry unit weight } \\
(\mathrm{lb} / \mathrm{ft} 3)\end{array}$ & Void Ratio & $\mathrm{K}_{20}(\mathrm{~cm} / \mathrm{s})$ \\
\hline RC_4G_L & 102 & 0.312 & 0.13 \\
\hline RC_4G_U & 119 & 0.232 & 0.04 \\
\hline RC_4G_M & 113.4 & 0.273 & 0.05 \\
\hline RC_NJ_L & 93.4 & 0.554 & 0.23 \\
\hline RC_NJ_U & 102.4 & 0.423 & 0.08 \\
\hline RC_NJ_M & 98.3 & 0.487 & 0.11 \\
\hline NG_4G_L & 122 & 0.347 & 0.15 \\
\hline NG_4G_U & 140 & 0.248 & 0.06 \\
\hline NG_4G_M & 133.2 & 0.308 & 0.12 \\
\hline NG_NJ_L & 108.4 & 0.324 & 0.18 \\
\hline NG_NJ_U & 120.2 & 0.228 & 0.09 \\
\hline NG_NJ_M & 115 & 0.297 & 0.13 \\
\hline LS_4G_L & 128 & 0.426 & 0.24 \\
\hline LS_4G_U & 148 & 0.385 & 0.06 \\
\hline LS_4G_M & 140.4 & 0.402 & 0.15 \\
\hline LS_NJ_L & 130.2 & 0.525 & 0.27 \\
\hline LS_NJ_U & 142.3 & 0.407 & 0.07 \\
\hline LS_NJ_M & 136.4 & 0.433 & 0.18 \\
\hline
\end{tabular}

Legend:

$\mathrm{RC}$ : recycled concrete aggregate

NG: natural gravel gradation

LS: limestone/dolomite
4G: MDOT 4G aggregate gradation

NJ: NJ unstabilized aggregate gr L, U\&M: lower, upper and middle Gradation bands respectively. 


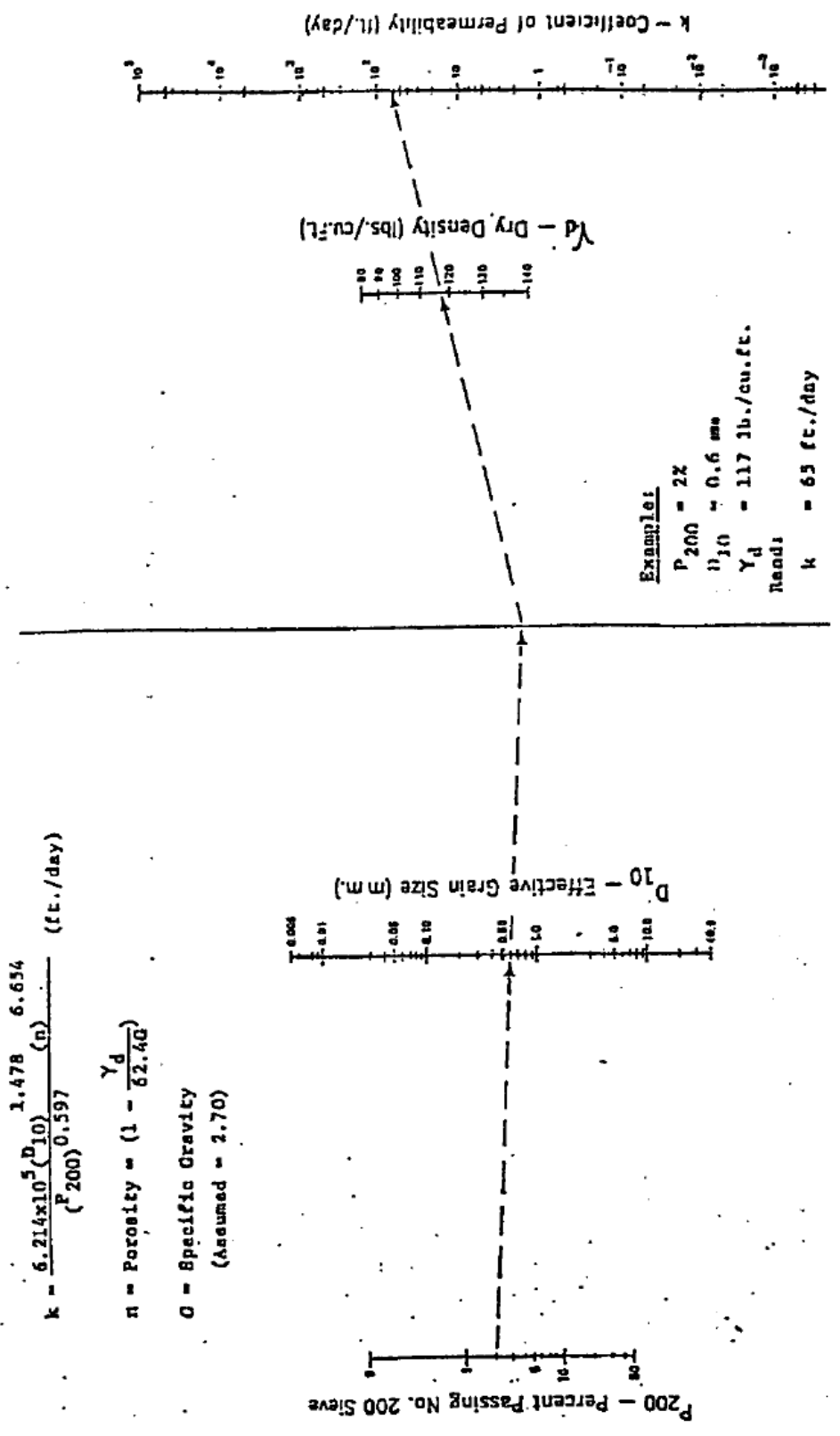

Figure 4.1: Moulton's chart for estimating the $k$ for unbound aggregate Materials (Moulton 1980) 
Table 4.2:

Comparison of measured and estimated coefficient of hydraulic conductivity

\begin{tabular}{|c|l|c|}
\hline Sample ID & $\begin{array}{l}\text { Moulton's } \\
\text { (ft/day) }\end{array}$ & $\begin{array}{l}\text { Measured k } \\
\text { (ft/day) }\end{array}$ \\
\hline RC_4G_L & 1200 & 369 \\
\hline RC_4G_U & 5.3 & 113 \\
\hline RC_4G_M & 41.0 & 552 \\
\hline RC_NJ_L & 3500 & 227 \\
\hline RC_NJ_U & 620.0 & 312 \\
\hline RC_NJ_M & 1460.0 & 410 \\
\hline NG_4G_L & 150.0 & 170 \\
\hline NG_4G_U & 0.13 & 340 \\
\hline NG_4G_M & 2.11 & 610 \\
\hline NG_NJ_L & 2400 & 185 \\
\hline NG_NJ_U & 76.8 & 311 \\
\hline NG_NJ_M & 239.5 & 680 \\
\hline LS_4G_L & 100 & 170 \\
\hline LS_4G_U & 0.01 & 325 \\
\hline LS_4G_M & 0.46 & 785 \\
\hline LS_NJ_L & 146.0 & 1.30 \\
\hline LS_NJ_U & 1.30 \\
\hline LS_NJ_M & 8.00 & \\
\hline
\end{tabular}

The nomograph shown in Fig 4.1 developed by Moulton (1980) which has been adopted into by the new MEPDG software was developed from tests data of granular bases and 
subbases. This means that it is only applicable to those materials and gradations used in the experimental program. As with all ,localized' experimental program, it produces inconsistent results when extrapolated to different materials and gradation types. From Table 4.2, it can be seen that for all the gradation unbound aggregate samples, the coefficient of hydraulic conductivity for the various samples predicted by Moulton's monograph is higher than the test results in some cases For some samples notably the limestone samples the measured coefficient of hydraulic conductivity values are higher than those predicted by Moulton. An explanation for this discrepancy may be attributed to the wide variations in dry unit weight of the samples. Besides the limitations of Moulton's monograph to predict the coefficient of hydraulic conductivity for the materials tested in this research project, another reason for the wide discrepancies between the predicted and measured $\mathrm{K}$ values will be the test procedures employed. There are several methods for measuring the $\mathrm{K}$ of granular material in the laboratory and each of these methods will yield different results. Since the materials tested here are open-graded, there is also a possibility of turbulence, which may invalidate Darcy's law which was assumed for the testing procedure used in this research. This is very critical when it comes to the design for subsurface drainage systems for critical highway projects considering the fact that some highway agencies have the tendency to resort to these analytical expressions to estimate the $\mathrm{k}$ for use in hydraulic analysis of drainage structures. Every effort should therefore be made to ensure that the correct coefficient of hydraulic conductivity of materials use in subsurface drainage systems be determined in the laboratory using the appropriate ASTM standards and instrumentation.

\subsubsection{Result Comparison between Different Gradation types}

The specimens tested for hydraulic conductivity two gradation types namely the MDOT $4 \mathrm{G}$ and NJ unstabilized mix gradations were used to prepare the specimens and as such it is important to know how the measured hydraulic conductivity value varies between the two gradation types. Furthermore, it is also paramount to determine the extent of the variation of $\mathrm{k}$ within the gradation bands of these two open-ended gradations. Mayberger and Hodek (2007) in their work on the resilient modulus of unbound aggregate materials discovered that the resilient modulus can vary as high as $50 \%$ within the $4 \mathrm{G}$ aggregate 
specification. In a similar way, the intention here is to determine how the coefficient of hydraulic conductivity varies within wide gradations like the MDOT 4G and NJ unstabilized gradation.

Since the middle gradation band represents average of the lower and upper gradation bands, it was used to make comparison between the two gradation types. For subsequent analysis of the measured laboratory hydraulic conductivity values, the $\mathrm{K}$ value of the middle gradation was assumed to be the representative $\mathrm{K}$ value for each gradation band. Even though the $\mathrm{K}$ value of the middle gradation is not the average of the $\mathrm{K}$ value of the lower and upper gradation bands, this assumption does help in facilitating the comparison of hydraulic conductivity values between different gradation types. A closer examination of the measured laboratory $\mathrm{K}$ values of the various aggregate samples will show that the gradation parameter $\mathrm{D}_{10}$ is directly proportional to the $\mathrm{K}$ value. Samples with higher $\mathrm{D}_{10}$ values also have higher $K$ values. Based on this relationship between $K$ and $D_{10}$, the $\mathrm{NJ}$ unstabilized gradation with the higher $\mathrm{D}_{10}$ value has the higher measured coefficient of hydraulic conductivity. For the NJ unstabilized Mix samples, the variation of between two gradation bands like that between the lower and upper bands can be as high as 109\% for some materials, while that of the MDOT $4 \mathrm{G}$ gradation can be as high as $52 \%$. However, the difference in the measured value of $\mathrm{K}$ between the two gradations is less than an order of magnitude for all the samples. Also, the differences in $\mathrm{K}$ among the gradation bands even though they can be as high as $100 \%$ in some cases, are still less than an order of magnitude. One can therefore concluded that o the basis of coefficient of hydraulic conductivity alone, there is not much to choose between the two gradations. Furthermore, choosing any of the gradation bands within those two gradations for drainage consideration is justifiable since there was no significant difference in measured $\mathrm{K}$ values among the three gradation bands.

Table 4.3 shows the $\mathrm{D}_{10}$ values for the samples tested and their corresponding coefficient of hydraulic conductivity. 
Table 4.3:

Variation of $\mathrm{K}$ within the gradation bands for unbound open-graded materials

\begin{tabular}{|c|c|c|c|c|}
\hline $\begin{array}{c}\text { Sample } \\
\text { ID }\end{array}$ & $\begin{array}{c}\text { Dry unit } \\
\text { weight } \\
\text { (pcf) }\end{array}$ & $\begin{array}{c}\mathrm{D}_{10} \\
\text { (in) }\end{array}$ & $\mathrm{Cu}$ & $\begin{array}{c}\text { K20 } \\
(\mathrm{cm} / \mathrm{s})\end{array}$ \\
\hline RC_4G_L & 102 & 0.0929 & 8.05 & 0.13 \\
\hline RC_4G_M & 105 & 0.0184 & 33.38 & 0.05 \\
\hline RC_4G_U & 119 & 0.0074 & 55.24 & 0.04 \\
\hline NG_4G_L & 128 & 0.0929 & 8.05 & 0.15 \\
\hline NG_4G_M & 133.2 & 0.0184 & 33.38 & 0.12 \\
\hline NG_4G_U & 140 & 0.0074 & 55.24 & 0.06 \\
\hline LS_4G_L & 128 & 0.0929 & 8.05 & 0.24 \\
\hline LS_4G_M & 135 & 0.0184 & 33.38 & 0.15 \\
\hline LS_4G_U & 148 & 0.0074 & 55.24 & 0.06 \\
\hline RC_NJ_L & 103.2 & 0.1042 & & 0.23 \\
\hline RC_NJ_M & 107.7 & 0.0696 & 4.84 & 0.11 \\
\hline RC_NJ_U & 110.5 & 0.051 & & 0.08 \\
\hline NG_NJ_L & 108.4 & 0.1042 & & 0.18 \\
\hline NG_NJ_M & 109.4 & 0.0696 & 4.84 & 0.13 \\
\hline NG_NJ_U & 120.2 & 0.051 & & 0.09 \\
\hline LS_NJ_L & 108.3 & 0.1042 & & 0.27 \\
\hline LS_NJ_M & 116 & 0.0696 & 4.84 & 0.18 \\
\hline LS_NJ_U & 134 & 0.051 & & 0.07 \\
\hline
\end{tabular}

\subsubsection{Comparison of Hydraulic conductivity values between material types}

Three material types were investigated in this research. Two natural or virgin aggregates namely Natural Gravel and Limestone and one recycled material namely Recycled Concrete. The aim for using these two categories of material types was to determine the drainage efficiency of drainage layers that are made up of recycled aggregates as against those consisting of virgin aggregates. With the recent discussions on the move towards designing and building sustainable transportation infrastructures, such a comparison will be helpful in the selection of appropriate and cost-effective aggregate material for use as a drainage layer. 
From the measured laboratory hydraulic conductivity listed on Table 4.3, one can observed that for the same gradation, the general trend was that limestone samples have the highest $\mathrm{K}$ value and the recycled concrete samples have the least measured $\mathrm{K}$ value. However there are a couple of test results where the coefficient of hydraulic conductivity of recycled concrete was higher than that of natural gravel. A likely reason for that deviation from the general trend may be due to testing errors. The variation of hydraulic conductivity values between different material types can be attributed to the particle shape, texture and void ratio of the various aggregate types. As was discussed in the literature review, the hydraulic conductivity value of a material is a function of both the soil matrix and fluid properties. However, for this research all the hydraulic conductivity tests were done using the same fluid type i.e. distilled water and as a result differences in the $\mathrm{K}$ value between material types could be attributed solely to that of the aggregate matrix. On the basis of particle shape and texture, theoretically one should expect particles of a rounded shape and of a smooth texture to provide smooth path for moisture flow and hence a higher $\mathrm{K}$ value than angular shape particles with rough surfaces that make the flow paths more tortuous and create frictional resistance to flow.

A detailed examination of the particle shapes and texture of the four material types showed that natural gravel have relatively round shape particles with smooth surfaces. The shapes of the dolomite particles are angular and they have more smooth surfaces than $\mathrm{n}$ the natural gravel and crushed concrete. From the preceding explanation, if variation of hydraulic conductivity between material types is solely due to particle shape and texture, then one should expect that the $\mathrm{K}$ values of recycled concrete samples are the ones likely to be adversely affected by the effect of particle shape and texture. So considering only the effect of particle shape and texture, gravel should provide the highest $\mathrm{K}$ values, followed by dolomite, and then recycled concrete. But the experimental results however did not match this theoretical explanation, which means that other factors besides particle shape and texture may also have had a significant effect on the variation of $\mathrm{K}$ between material types. 
One likely parameter that should also affect this variation of $\mathrm{K}$ between material types is the void ratio. Void ratio is a function of the unit weight of the material and the compactive efforts use to compact the various samples. The void ratio of the various samples depends on the compaction effort use to compact the specimens. The dry unit weight is often used as an indication of the efficiency of the compaction process and as such it was deemed necessary to determine the variation of the coefficient of hydraulic conductivity with the unit weight of the aggregate material. Of the three aggregate types, for both gradation types, limestone has the highest as-compacted unit weight, second by recycled concrete aggregate with natural gravel being the least.

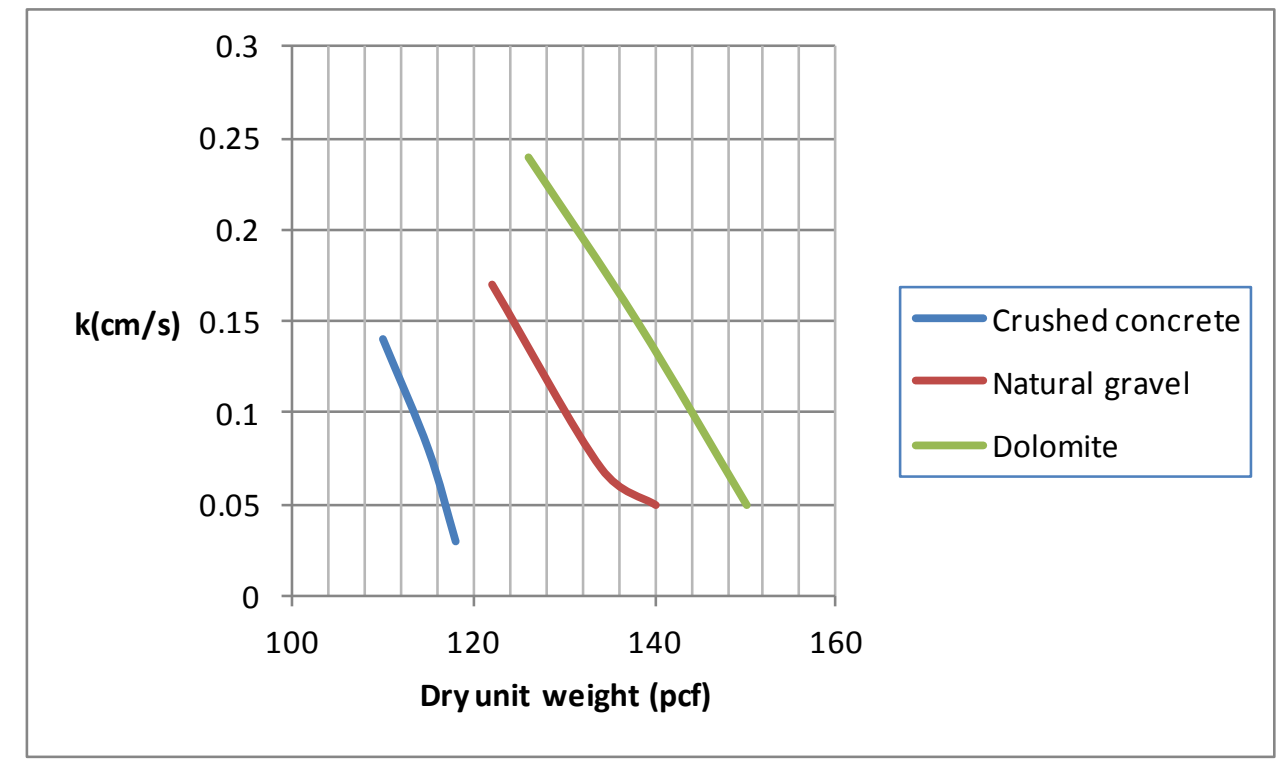

Figure 4.2: Variation of $k$ with unit weight $s$ for MDOT 4G gradation 


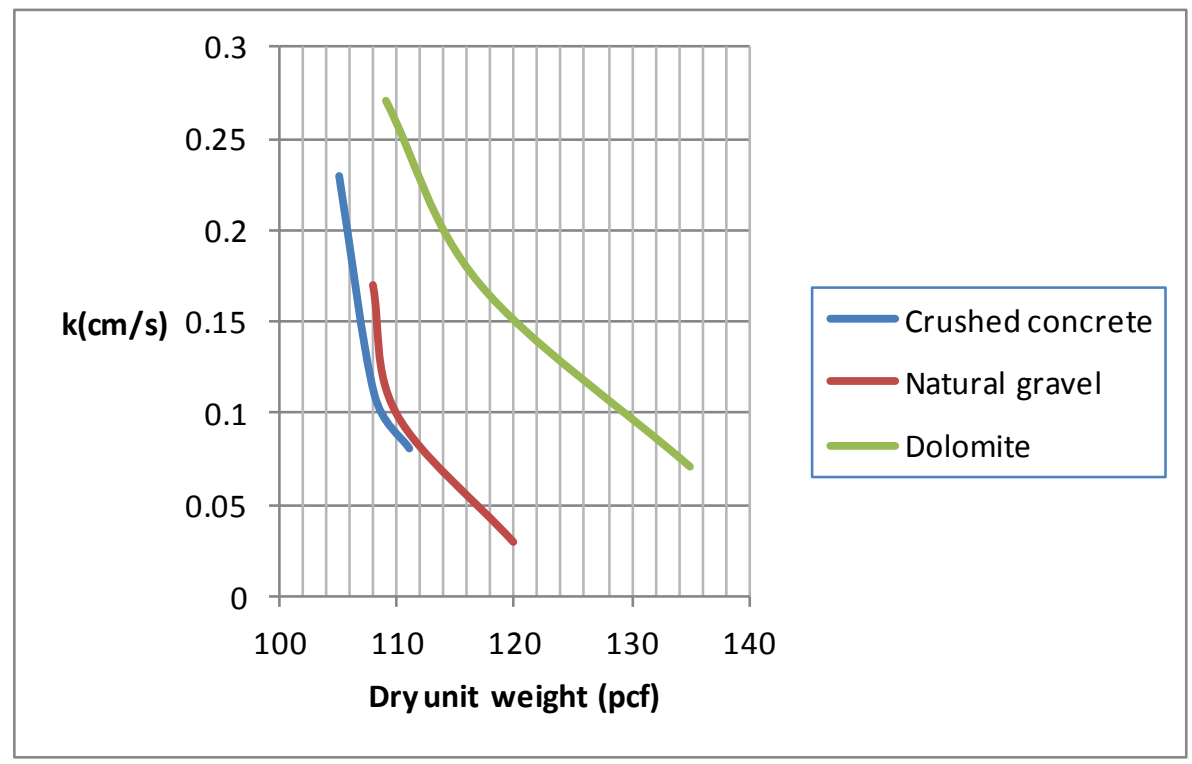

Figure 4.3: Variation of $k$ with unit weights for $\mathrm{NJ}$ unstabilized Mix gradation

From both Figures 4.2 and 4.3, the general trend is that the $\mathrm{K}$ values decrease with increasing unit weight. This is to be expected since higher unit weight are due to higher compaction efficiency which resulted in reduced air void space that is available to serve as conduit for water flow. This is however not a generalization especially when different material types having different specific gravities are taken into consideration.

As was highlighted in the literature review, the level of compaction effort used affects the void ratio considerably, which in turn have a very profound effect of the measured coefficient of hydraulic conductivity. To this end it was deemed necessary to determine what effect the compaction method used on the gradation of the unbound material. The aim here was to determine if there was any significant difference in the post-compaction gradation curves of the three aggregate types. Only the MDOT 4G gradation and the middle gradation band were used for this illustration. Figs 4.4 through 4.5 shows the pre and post compaction gradation curves recycled concrete and limestone samples: 


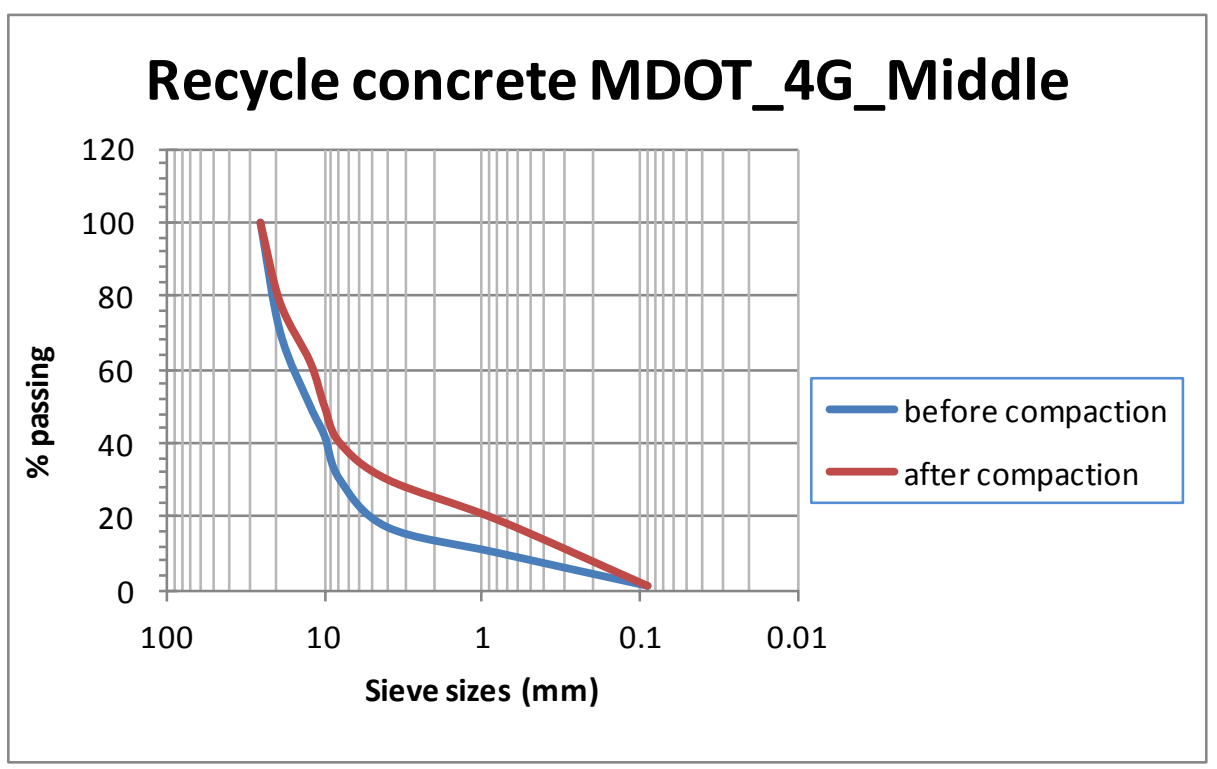

Figure 4.4: Effect of compaction on crushed concrete

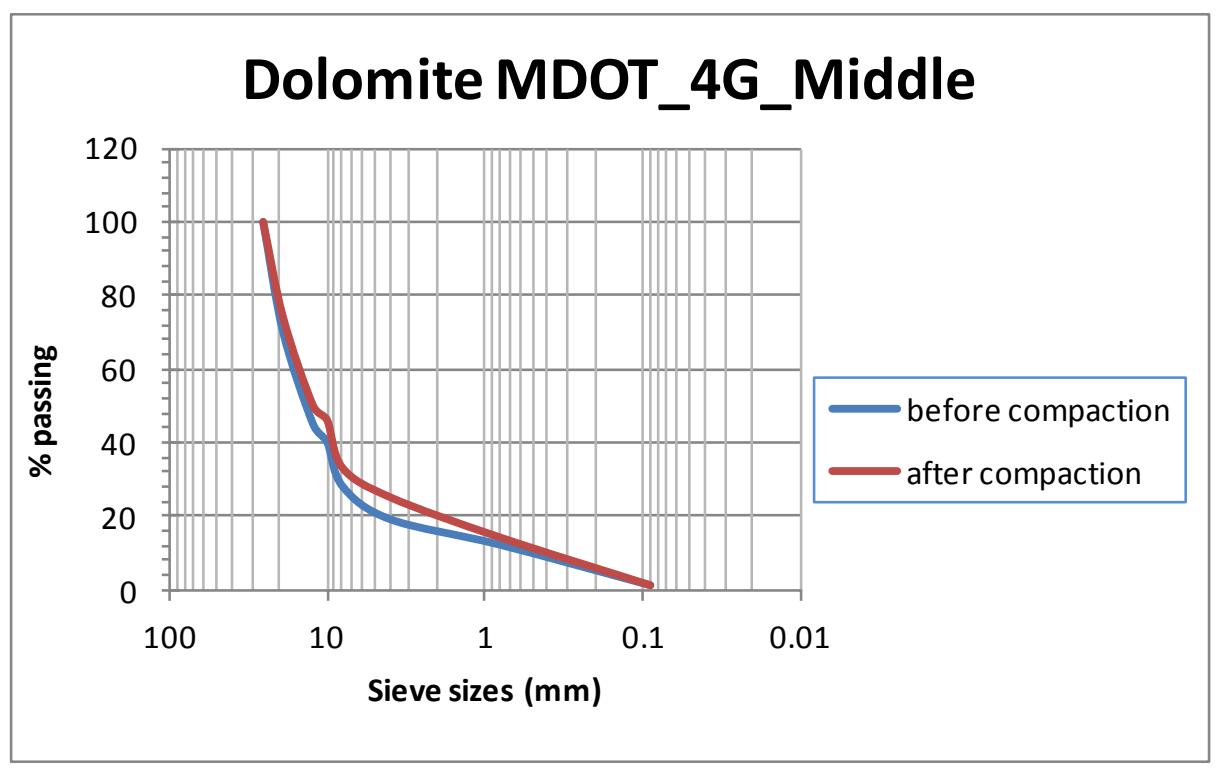

Figure 4.5: Effect of compaction on Limestone

In order to determine which material and gradation types underwent the greater degradation as a result of the compaction, the difference between the „before' and ,after' compaction \% passing on each of the sieve was computed and then summed. 
From Fig 4.4 and Fig 4.5, it can be seen that for a particular gradation, recycled concrete aggregate samples underwent the greater degradation than the limestone. Also comparing the gradation curve parameter $\mathrm{D}_{10}$ shows that the after-compaction curve has a lower $\mathrm{D}_{10}$ value than the pre-compaction gradation curve. Since $\mathrm{D}_{10}$ is directly proportional to the value of $\mathrm{K}$, it can be established that the measured hydraulic conductivity may not be representative of the actual starting gradation. This is very significant as it calls in to question the validity of estimating hydraulic conductivity based on gradation curve parameters rather than actual measurement. It also emphasized the importance of using a laboratory compaction effort that is representative to that employed in actual field situations.

\subsubsection{Computing the Drainage Efficiency of Unbound Open- Graded Drainage Layer}

So based on the preceding discussions on the variation of hydraulic conductivity for different aggregate types and different gradation envelopes, the next step is to determine the drainage efficiency of a pavement drainage layer made up of these three aggregate types based on the measured coefficient of hydraulic conductivity values. The FHWA recommended a minimum $\mathrm{K}$ value of $1000 \mathrm{ft} / \mathrm{day}$ for a drainage layer and from the hydraulic conductivity values listed on Table 4.1 none of the samples tested satisfied the minimum hydraulic conductivity criterion. However, this does not mean that the tested materials and gradations may not be appropriate as effective drainage materials. Using the AASHTO recommended time-to-drain values in Table 2.1 and assuming the following pavement parameters:

$$
\begin{aligned}
& \circ \text { resultant pavement length (LR) of } 7.6 \mathrm{~m} \\
& \circ \quad \text { Resultant slope (SR) of } 0.02 \mathrm{~m} / \mathrm{m}
\end{aligned}
$$

The minimum hydraulic conductivity for each category of ,quality of drainage' was computed for each of the time-to-drain values using Equation 4.1 and the results shown in Table 4.4: 
$t_{50}=N e^{* L R^{2}} / 2 k S R L H+H$ Equation 4.1

Where: hours

$\mathrm{t}_{50}=$ time-to-drain $50 \%$ of drainable water infiltrating the pavement in

$\mathrm{Ne}=$ effective porosity

$\mathrm{L}_{\mathrm{R}}=$ resultant pavement length in $\mathrm{m}$

$\mathrm{S}_{\mathrm{R}}=$ resultant pavement slope

$\mathrm{H}=$ thickness of permeable base in $\mathrm{m}$

$\mathrm{K}=$ hydraulic conductivity in $\mathrm{m} /$ day

Table 4.4

Minimum hydraulic conductivity for various categories of drainage

\begin{tabular}{|c|c|c|}
\hline Quality of drainage & Time-to-drain & Minimum saturated k $(\mathrm{cm} / \mathrm{s})$ \\
\hline Excellent & 2 hours & 0.4011 \\
\hline Good & 1 day & 0.0669 \\
\hline Fair & 7 days & 0.009550 \\
\hline Poor & 1 month & 0.002228 \\
\hline Very Poor & Does not drain & - \\
\hline
\end{tabular}

From Table 4.4 the measured hydraulic conductivity values for all the tested materials fall within the good drainage category. This by interpretation means that a pavement base that is made up of any one of the unbound open-graded samples tested can drain $50 \%$ of drainable water within the pavement structural section within a day.

Since the ,time-to-drain' is the primary criterion used to judge the efficiency of drainage, DRIP 2.0 has an in-built capacity that plots the sensitivity of the ,time-to-drain' to other parameters like hydraulic conductivity, thickness of permeable base layer and effective 
porosity of the drainage aggregate material (NCHRP 2004). The sensitivity analyses of time-to-drain versus $\mathrm{k}$ and $\mathrm{H}$ for sample ID DL_4G_U using the pavement parameters in the previous section was carried out and the results displayed in Figs 4.6 and Fig 4.7 respectively.

Time to Drain vs. Base Course Permeability

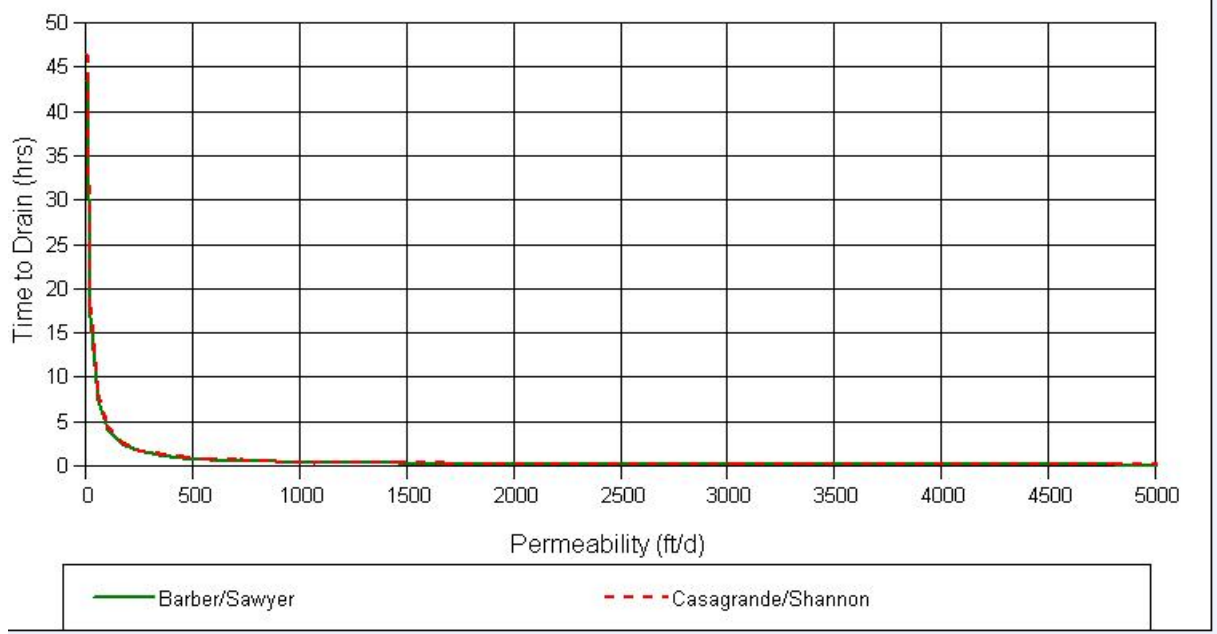

Figure 4.6: Sensitivity of time-to-drain with permeable base $\mathrm{K}$

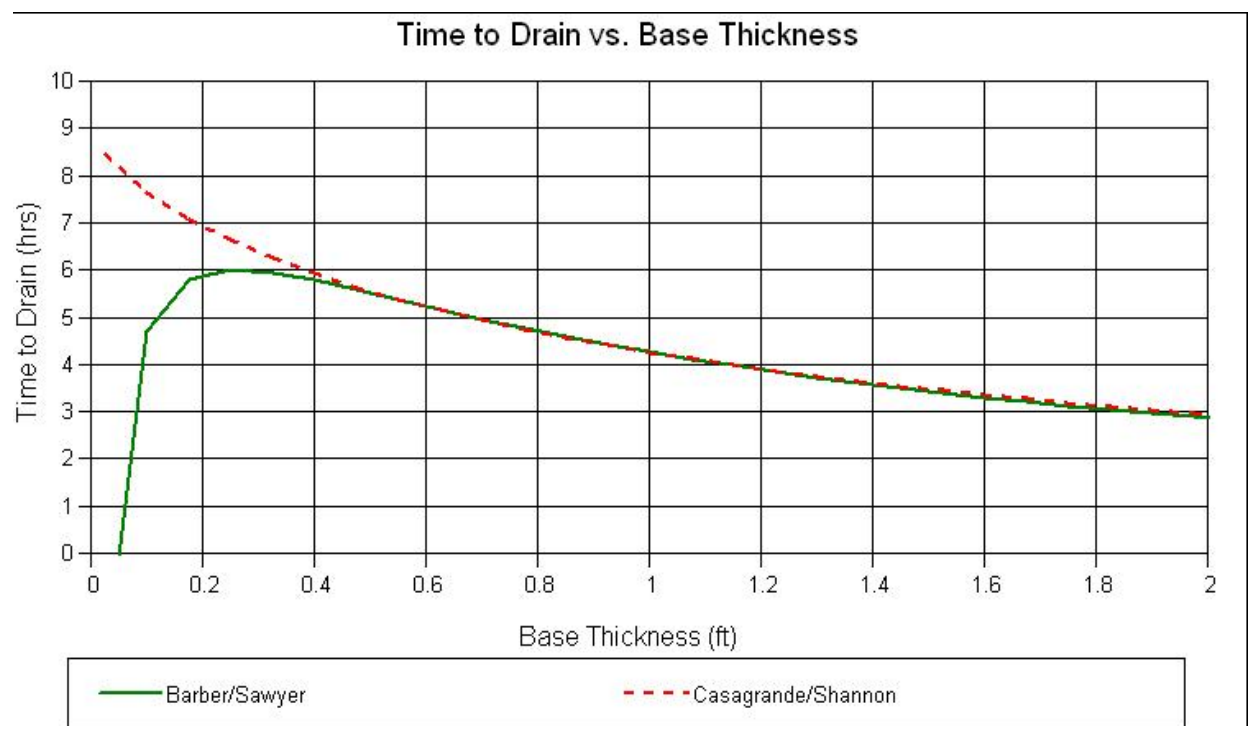

Figure 4.7: Sensitivity of time-to-drain with thickness of base 
From both figs 4.6 and Fig 4.7, it can be established that the „time-to-drain’ is not highly sensitive to both the base thickness and base permeability.

The time-to-drain is almost constant beyond a base $\mathrm{K}$ value of $1000 \mathrm{ft} / \mathrm{day}$ and a base thickness of 1 foot. This means that increasing the base thickness and base permeability beyond these values have an insignificant effect on the time-to-drain. In other words what this means is that getting a thicker base layer of highly permeable base layer does not significantly improve the pavement's ability to drain all infiltrating water. This is because the time-to-drain concept is based on the principle of saturated flow which assumes that the permeable base is completely saturated prior to drainage. As a result selecting a material and gradation type that produces a hydraulic conductivity in excess of 1000 $\mathrm{ft} /$ day will bring no added improvement to the drainage efficiency of the drainage layer. In this regard therefore the FHWA has established a minimum $\mathrm{k}$ value of $1000 \mathrm{ft} / \mathrm{day}$ and many highway agencies have limited the thickness of the permeable layer within 3-4 inches range. Therefore if the time-to-drain is a better parameter for characterizing the efficiency of pavement subsurface drainage, then one has to call in question the wisdom behind the design decision to use permeable bases with high $\mathrm{K}$ values as those recommended by Cedergren (Cederegren 1989). It should however be pointed out here that analysis that calls for the use of a drainage layer with such high $\mathrm{K}$ values and thickness are based on the assumption of steady flow where the sole aim was to keep the drainage layer from reaching saturated condition. Such a design analysis even though they may produce a pavement section that has the capability of preventing saturation within the structural section may not produce an economic design. The use of the timeto-drain as a valid criterion for quantifying the effect of drainage stems from research showing that high pore pressure will develop within pavement materials when the degree of saturation exceeds $80 \%$. Research results further show that stability of unbound pavement materials tends to increase greatly when they are at a degree of saturation between $70 \%-60 \%$ percent in the case of very moisture sensitive materials. Also it was noted that no excess porewater pressure was developed for a degree of saturation of up to $85 \%$ (Thom and Brown 1987). This means that the design priority is to provide a 
drainage layer that can keep the degree of saturation of the pavement structural section to a desired minimum at the very shortest time possible.

This has a major consequence on the process of selecting which types of material and gradations are most suitable for use in pavement bases. According to Hoffman (1982) three reasons for selecting aggregate base gradation specifications are:

i. Necessary strength and stability to support construction traffic, pavement and subsequent traffic

ii. Drainage

iii. Material that can be produced with adequate quality control at reasonable cost

It is therefore very quite obvious from the above description that any aggregate specification developed for use as pavement bases and subbases is a compromise to achieve the aforementioned criteria. As much it is important to get a $\mathrm{k}$ value that will ensure that the permeable base offers greater drainability for the pavement, it is also very important that these open-graded pavement layers are stable under construction and actual traffic loads. Even though the primary purpose of the open-graded aggregate specifications under investigation in this research is to facilitate the rapid draining of any excess moisture that infiltrate the pavement underlying sublayers, this should not be done at the detriment of the other two criteria. For the untreated permeable bases, the coefficient of uniformity $\left(\mathrm{C}_{\mathrm{u}}\right)$ has often been used as a measure of stability. A minimum $\mathrm{C}_{\mathrm{u}}$ value of 4 is considered an appropriate threshold in which untreated permeable bases are stable enough to accommodate some construction traffic (FHWA 1992). Based on this value and the $C_{u}$ values given in Table 4.3 one can conclude that all the untreated samples meet this stability requirement with the MDOT 4G specimens having the greater stability. However, to get an indication of which of the three aggregate types offer the greatest stability under the combine action of traffic and environmental forces, results from the work of Mayrberger and Hodek (2007) were used. 
Mayrberger and Hodek (2007) conducted a research on characterizing the variation of resilient modulus within the MDOT 4G gradation under the following environmental constraints:

1. As-compacted moisture content which simulates construction process in the field and is represented by the compaction moisture content (OMC).

2. The wetting curve which simulates the movement of water through the base course by capillary action.

3. The drying curve simulates moisture drainage after a rain event.

4. Fully saturated moisture content simulates $100 \%$ saturation of the base layer as a result of a non-draining or slow draining base layer.

Environmental conditions 3 and 4 above are of prime importance to pavement subsurface drainage. Environmental condition 2 represent the changes to the resilient modulus of the base layer due to it serving its drainage function while environmental condition 4 represents the worst case scenario of the changes in resilient modulus of a base not been able to properly serve its drainage function. This can also represent the long term case of a drainage layer that can no longer maintain high level drainage efficiency as result of it been clogged or degradation of its constituent aggregate particles. The conclusion from their research work was that limestone is stiffer than recycled crushed concrete by a margin of $7-15 \%$ which in turn is stiffer than natural gravel by $15-20 \%$. For the four environmental conditions simulated in this research program, they discovered that for all three gradation bands and four material types the drying curves which represent the subsurface drainage process caused a marginal or no response to the stiffness of the material. However, for the fully saturated environmental case which is representative of the case of "no drainage' or a permeable base with a high time-to-drain, all three gradation bands and four material types experienced marginal softening in some materials and considerable softening in others with some materials experiencing up to $50 \%$ reduction in stiffness. This is to be expected since in a fully saturated and undrained condition the pavement material will experience a drastic increase in porewater pressures 
which will eventually reduce the stiffness and load-carrying capacity of the layer comprised of that material. The new pavement design philosophy i.e. Mechanistic Empirical Pavement Design Guide (MEPDG) has characterized stiffness to be the dominant geotechnical parameter that controls the distress of pavement layers made up of unbound material. The longer therefore an unbound pavement layer remains in fully saturated conditions, the higher the resulting damage on the pavement due to a combination of high porewater pressure and heavy vehicle loads (ARA Inc, 2004). However, even though the stresses acting on in-service pavement layers comprising of unbound granular materials are in reality well below the failure strength of these materials, these research findings further emphasized the importance of effective pavement subsurface drainage systems in minimizing the times the pavement experienced saturated conditions. One design question that has been the subject of research in the past is what significance if any in terms of improved pavement performance that can be achieved with the use of highly permeable bases and subbases. In other words, what is the difference in pavement performance between pavements having a drainage layer with a $\mathrm{K}$ value of $1000 \mathrm{ft} /$ day to a similar pavement having a drainage layer with a $\mathrm{K}$ value of $10000 \mathrm{ft} /$ day? In order to answer questions of this nature, Markow (1982) conducted a study of pavement performance in which he used the computer software program EUROMAR to simulate pavement performance under various moisture conditions. He used the following quantitative description of drainage:

$\begin{array}{ll}\circ & \text { Good: } 10000 \mathrm{ft} / \text { day } \\ \circ & \text { Fair: } 100 \mathrm{ft} / \text { day } \\ \circ & \text { Poor: } 0.1 \mathrm{ft} / \text { day }\end{array}$

Results of the computer simulations showed that pavement performance under good and fair drainage conditions was practically identical and that under poor drainage condition the rate of deterioration increases rapidly. Markow (1982) concluded that if the findings of these computer simulations are true, then it means that a minimum acceptable value of base permeability lies between the poor and fair drainage classification i.e. $0.1-100$ $\mathrm{ft} /$ day. Although this minimum acceptable K value is considerable less than the FHWA's recommended minimum value of $1000 \mathrm{ft} / \mathrm{day}$, the concept was however investigated in 
this research using the new MEPDG software and details of that analysis can be found in Chapter 5. Because the MEPDG is highly sensitive to the resilient modulus of the pavement layer, the pavement sections selected to determine the effect of moisture variations only differ in gradation type and the subsequent $\mathrm{K}$ value. What the findings from the results of simulations conducted by Markow (1982) using EUROMAR and that obtain using the MEPDG is that the current pavement prediction performances can't be used to give a realistic assessment of the effect of drainage on the performance of pavements.

So based on these findings and those of other past researchers, it is therefore very reasonable to question the selection of material and gradation types that produce hydraulic conductivity in excess of $1000 \mathrm{ft} / \mathrm{day}$. It also calls into question the use of stabilized open-graded bases with very high $\mathrm{K}$ values, some even in the excess of 10000 $\mathrm{ft} /$ day. One likely reason for the use of these permeable bases with high $\mathrm{K}$ values is concerns about long term changes in the value of $\mathrm{K}$ as the pavement ages. Since these bases are usually subjected to cyclic environmental factors when in service, questions still abound as to whether these unbound open-graded bases will continue to perform favorably over the life of the pavement. The possibility therefore exist that as these bases become degraded over time due to load and other environmental conditions, their gradation will change drastically as the pavement ages and this will significantly reduced the measured laboratory hydraulic conductivity value upon which the design drainage capacity was based. This will present a situation where in the drainage capabilities of the open-graded base is severely reduced.

In summary therefore, combining research results from the hydraulic and stability analyses, the following conclusions can be drawn about the suitability and effectiveness of open-graded base courses:

i. All three materials and two gradations types investigated will provide good effective subsurface drainage layer by rapidly removing moisture from the pavement's structural sections. 
ii. Selecting the appropriate gradation to balance the hydraulic and stability requirements is a very important to the long term performance of opengraded unbound drainage layers. Even though NJ unstabilized Mix samples did produced a higher coefficient of permeability than the MDOT $4 \mathrm{G}$ samples the difference is less than one order of magnitude. This difference is too insignificant to override the greater stability provided of MDOT 4G samples.

iii. Of the three material types investigated limestone offers the best aggregate for use in subsurface drainage layer in terms of both hydraulic and stability properties, followed by recycled crushed concrete and the least is natural gravel.

iv. The degree of compaction used is very critical as it affects both the hydraulic and stability properties of the subsurface drainage materials.

\subsection{Results for Treated Permeable Aggregate Bases}

For both the cement and asphalt treated open-graded specimens, three mix types were prepared and tested. These are designated as Mix_15, Mix_25 and Mix_35 wherein the numbers 15, 25 and 35 represent the design percent air void content of the mixes.

\subsubsection{Cement Treated Permeable Base Materials}

\subsubsection{Coefficient of hydraulic conductivity test results}

Coefficients of hydraulic conductivity test results for the three materials are shown in Figs 4.8 to $4-.10$. 


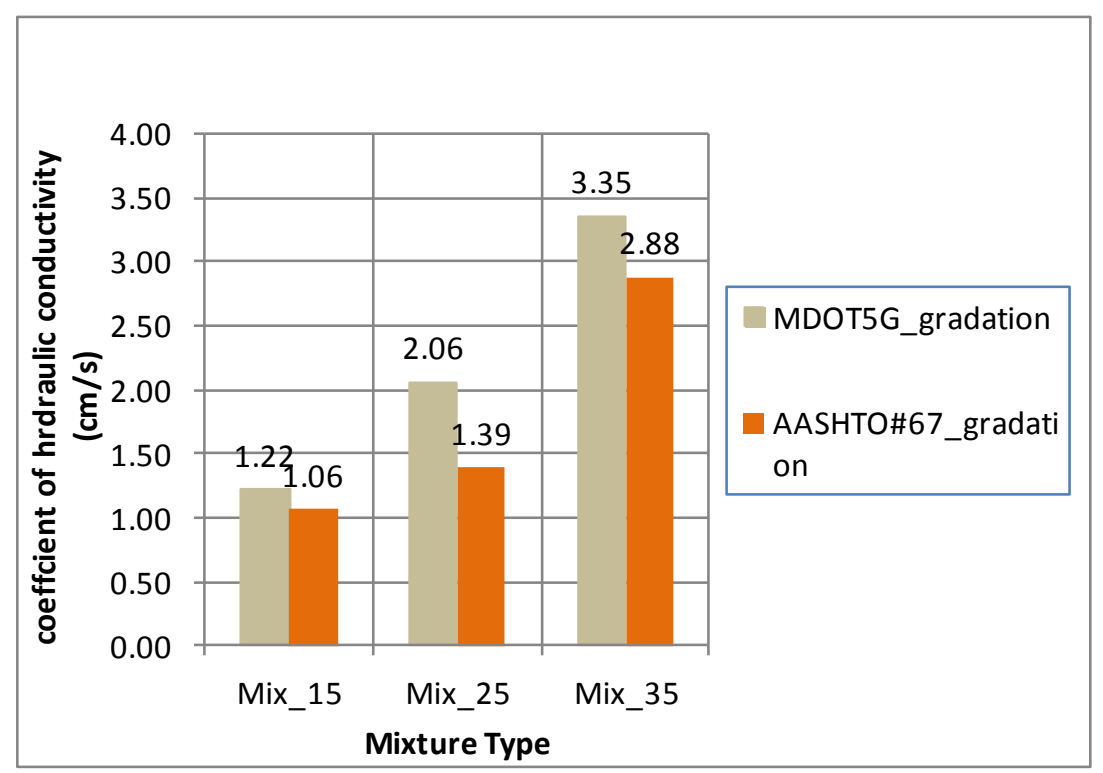

Figure 4.8: K of Cement-Treated Natural Gravel samples

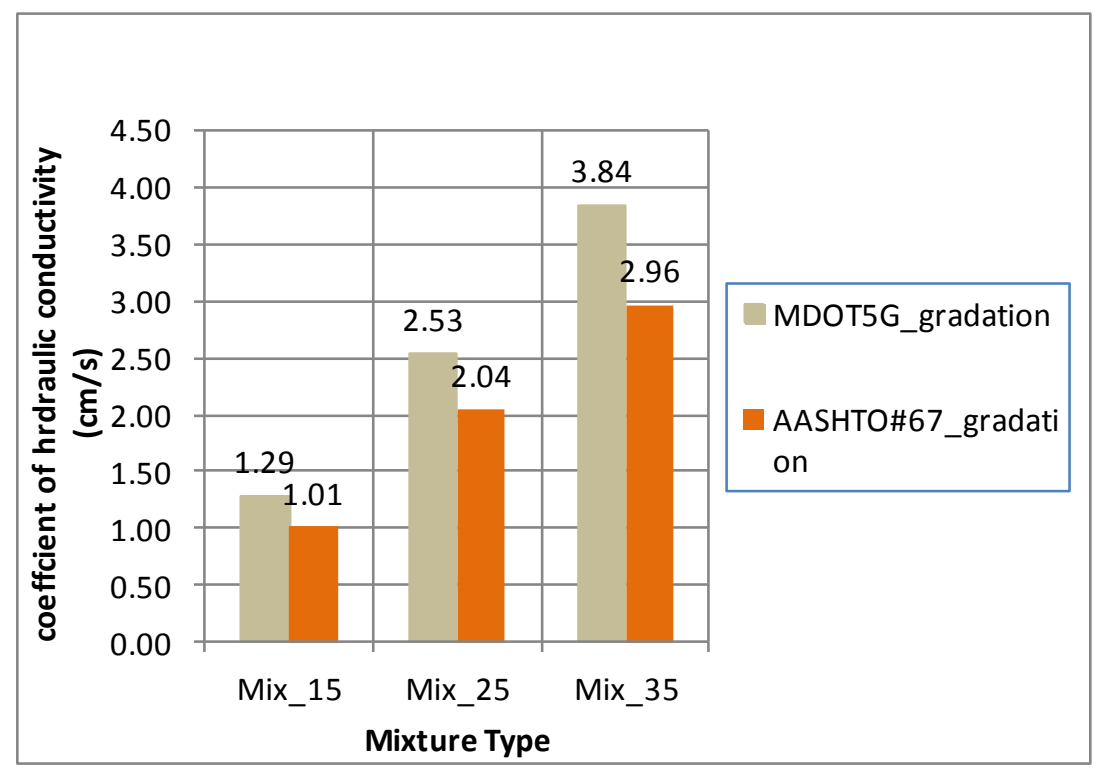

Figure 4.9: $\mathrm{K}$ of Dolomite samples 


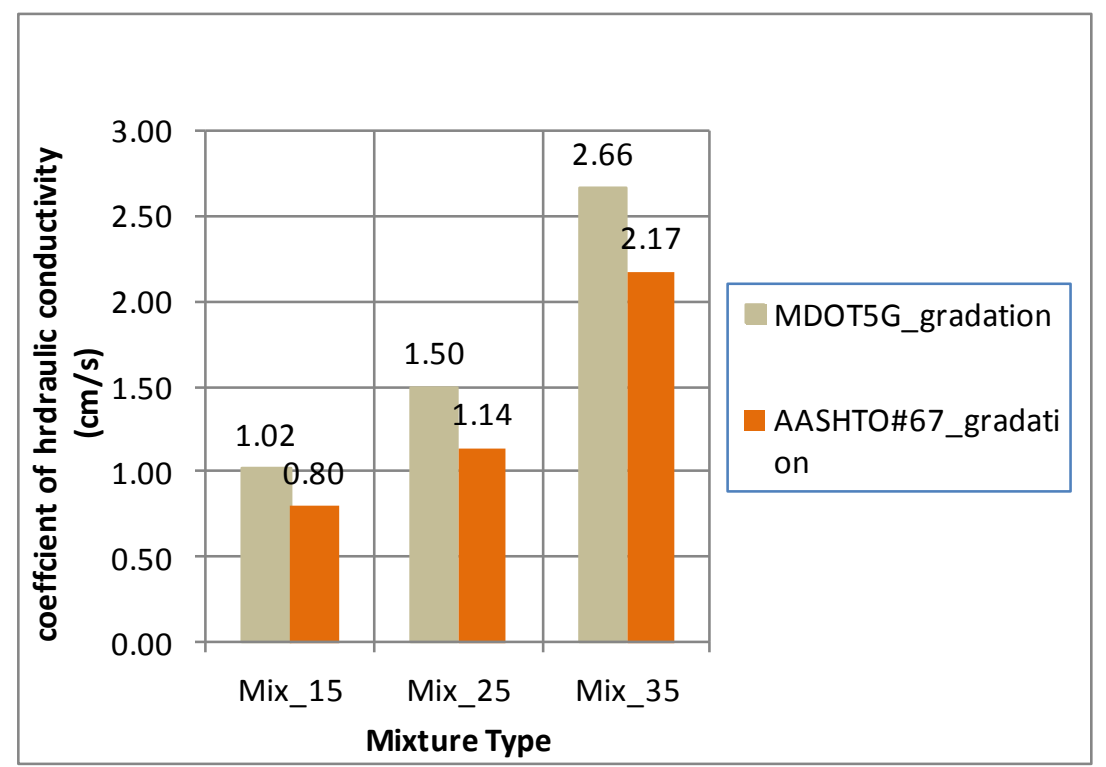

Figure 4.10. K of Recycled Concrete Aggregate samples

4.2.1.2. $\quad$ Unconfined Compression and Durability $\underline{\text { Test Results }}$

Results for the unconfined compression test and Freeze/Thaw durability tests results for the three material types and three design mixes for both the MDOT 5G and AASHTO \#67 gradations are shown in Figs 4.11 through Fig4.16. The variation of K with both the percent air void content and dry unit weights are for both the natural gravel and limestone samples are also shown in Fig 4.17 and Fig4.18 respectively 


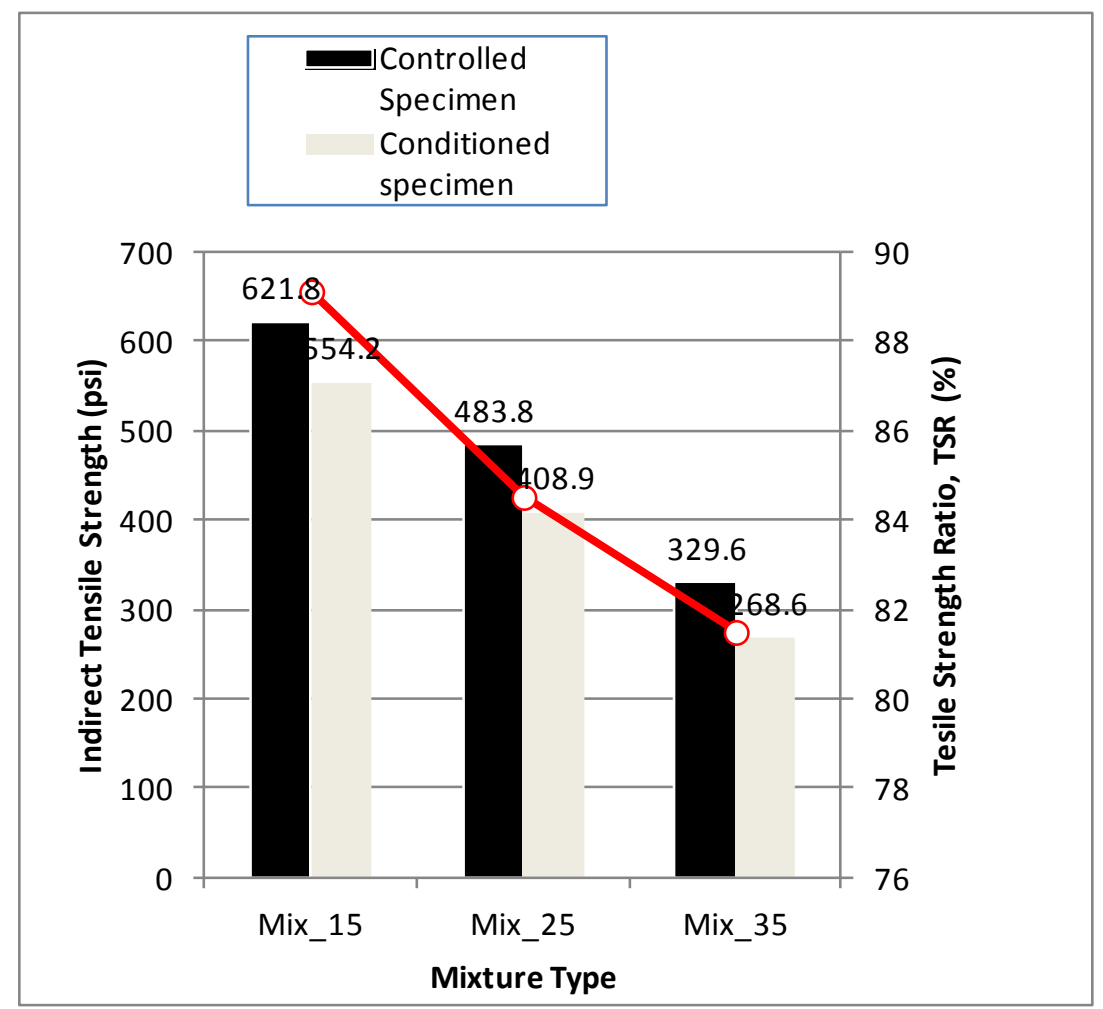

Figure 4.11: Freeze-Thaw durability test results of natural gravel MDOT 5G 


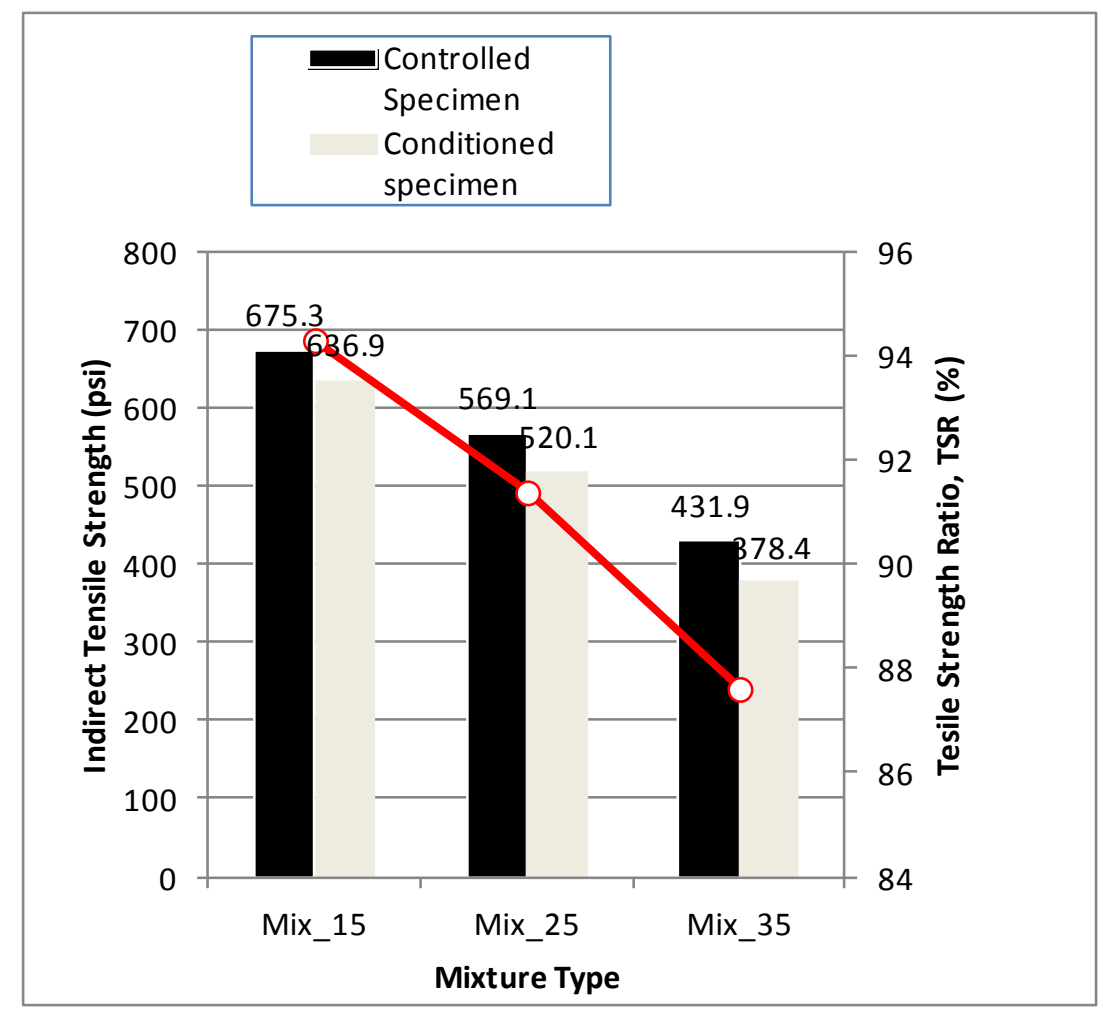

Figure 4.12: Freeze-Thaw durability test results of natural gravel

AASHTO \#67 samples 


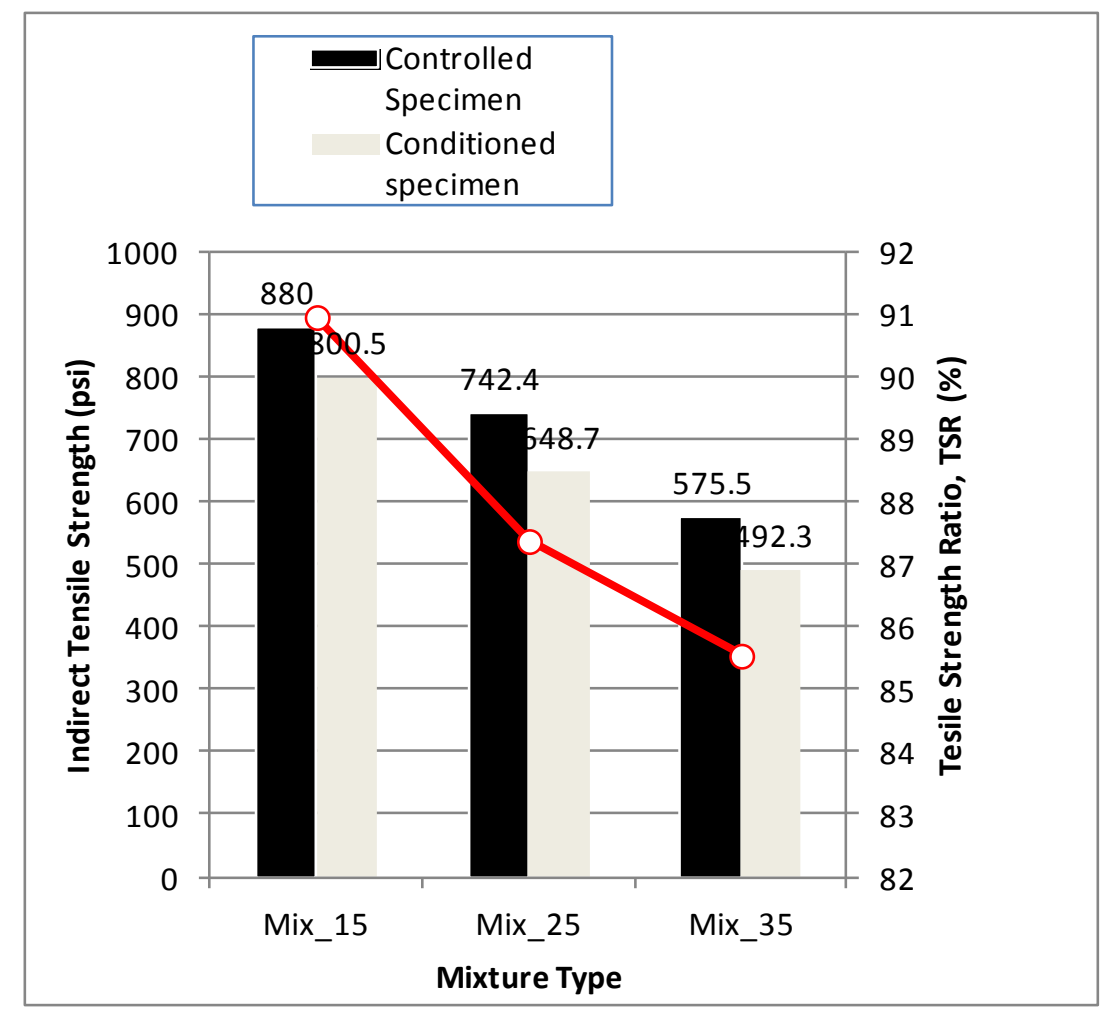

Figure 4.13 Freeze-Thaw durability test results of dolomite MDOT 5G samples 


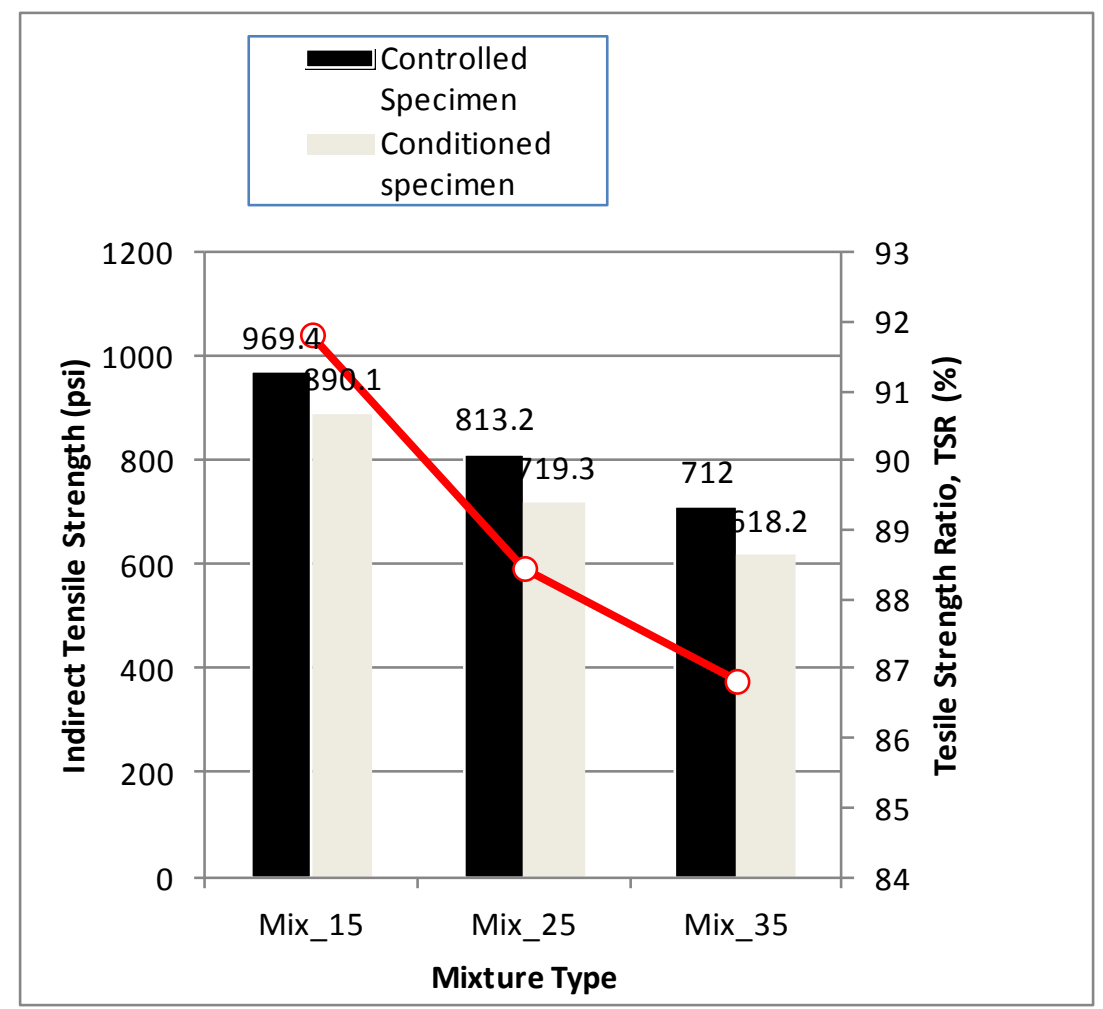

Figure 4.14: Freeze-Thaw durability test results of dolomite AASHTO \#67 


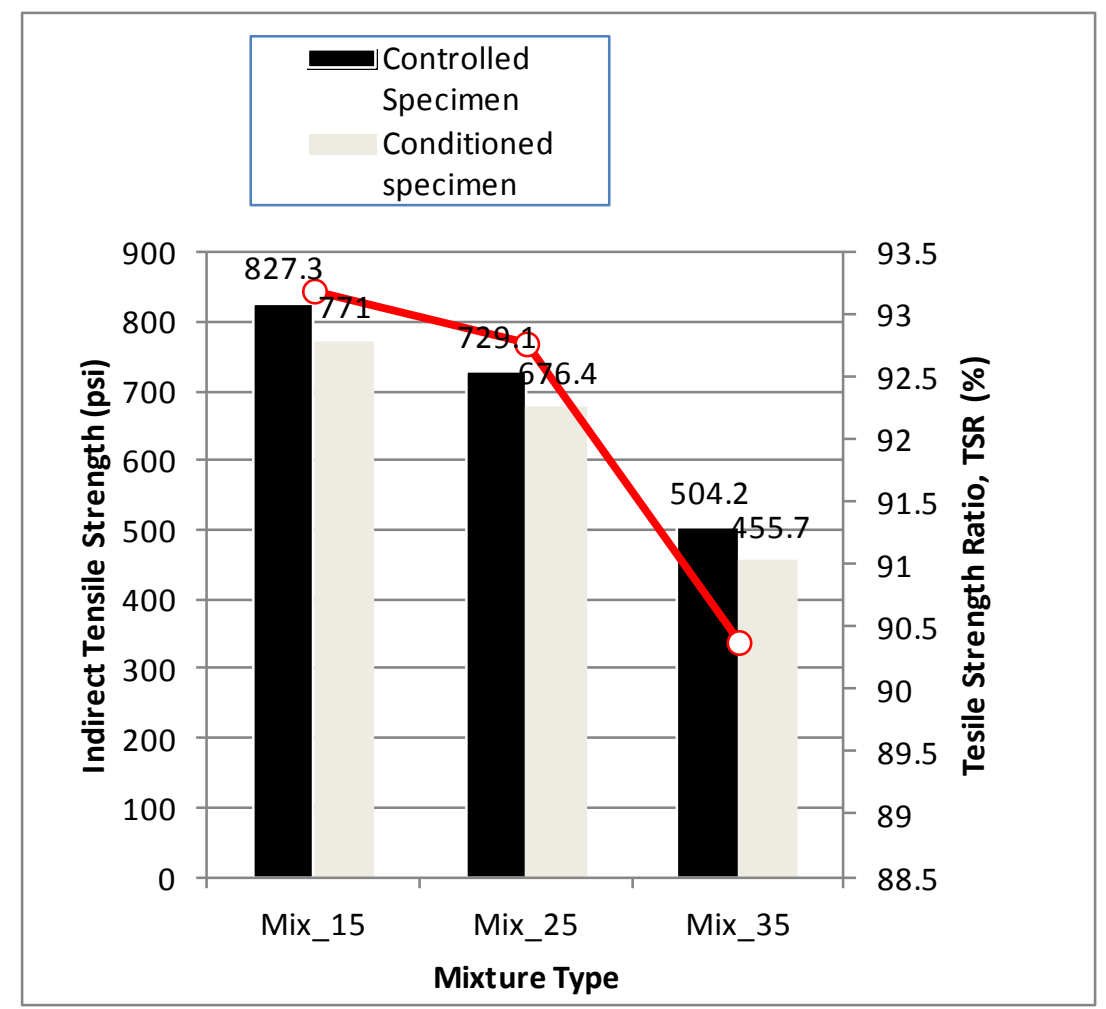

Figure 4.15: Freeze-Thaw durability test results of recycled concrete MDOT 5G 


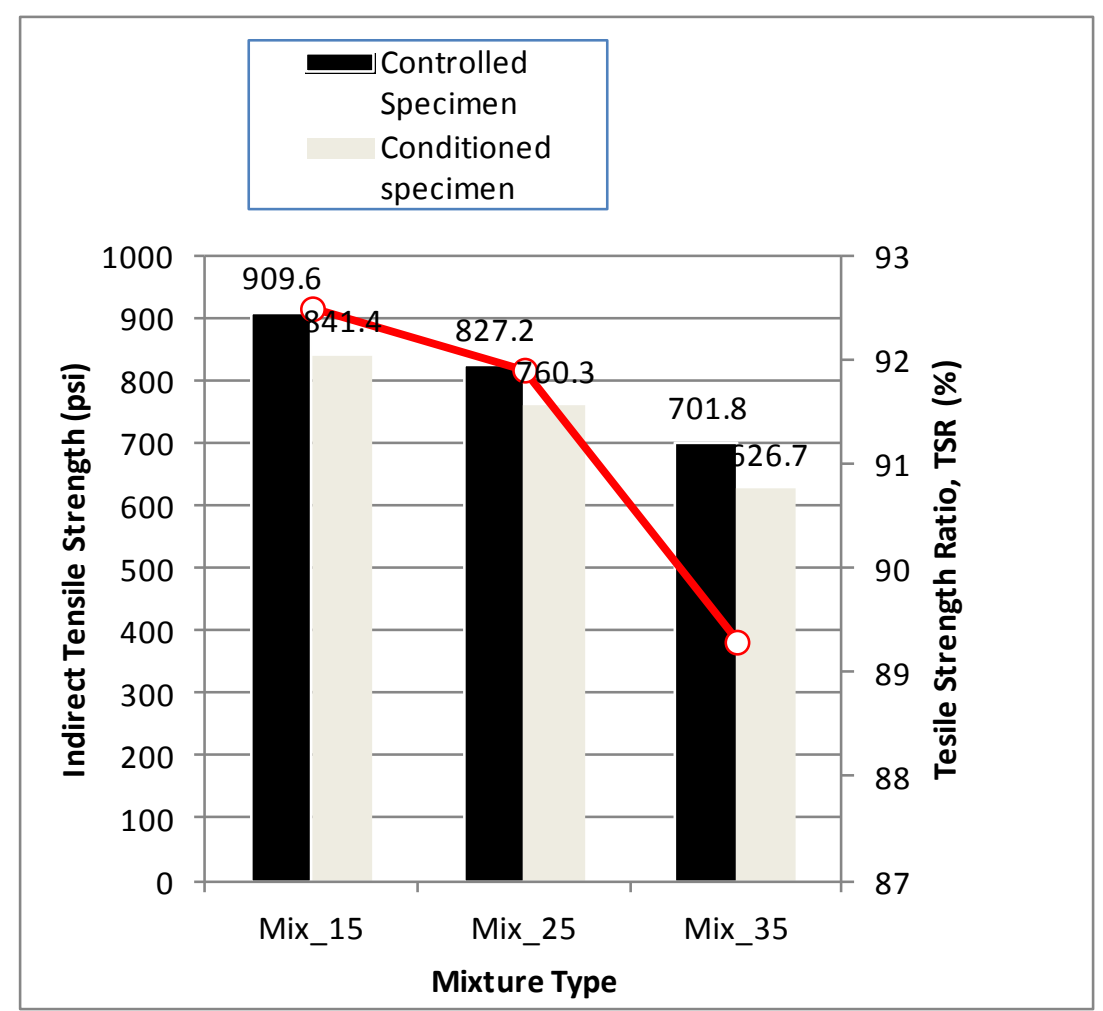

Figure 4.16: Freeze-Thaw durability test results of recycled concrete AASHTO \#67 samples 


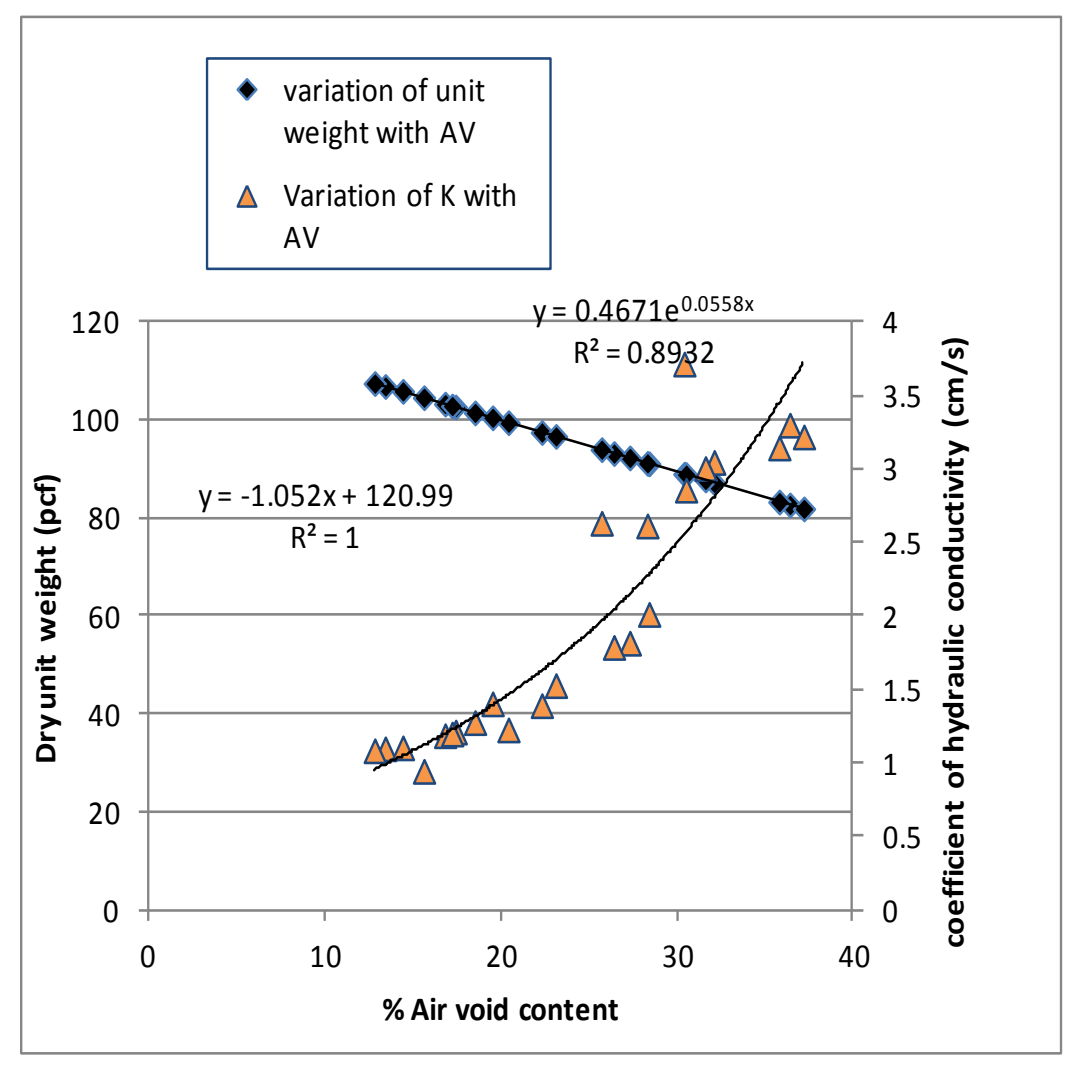

Figure 4.17: Variation of $K$ with $\%$ air void content Natural gravel samples 


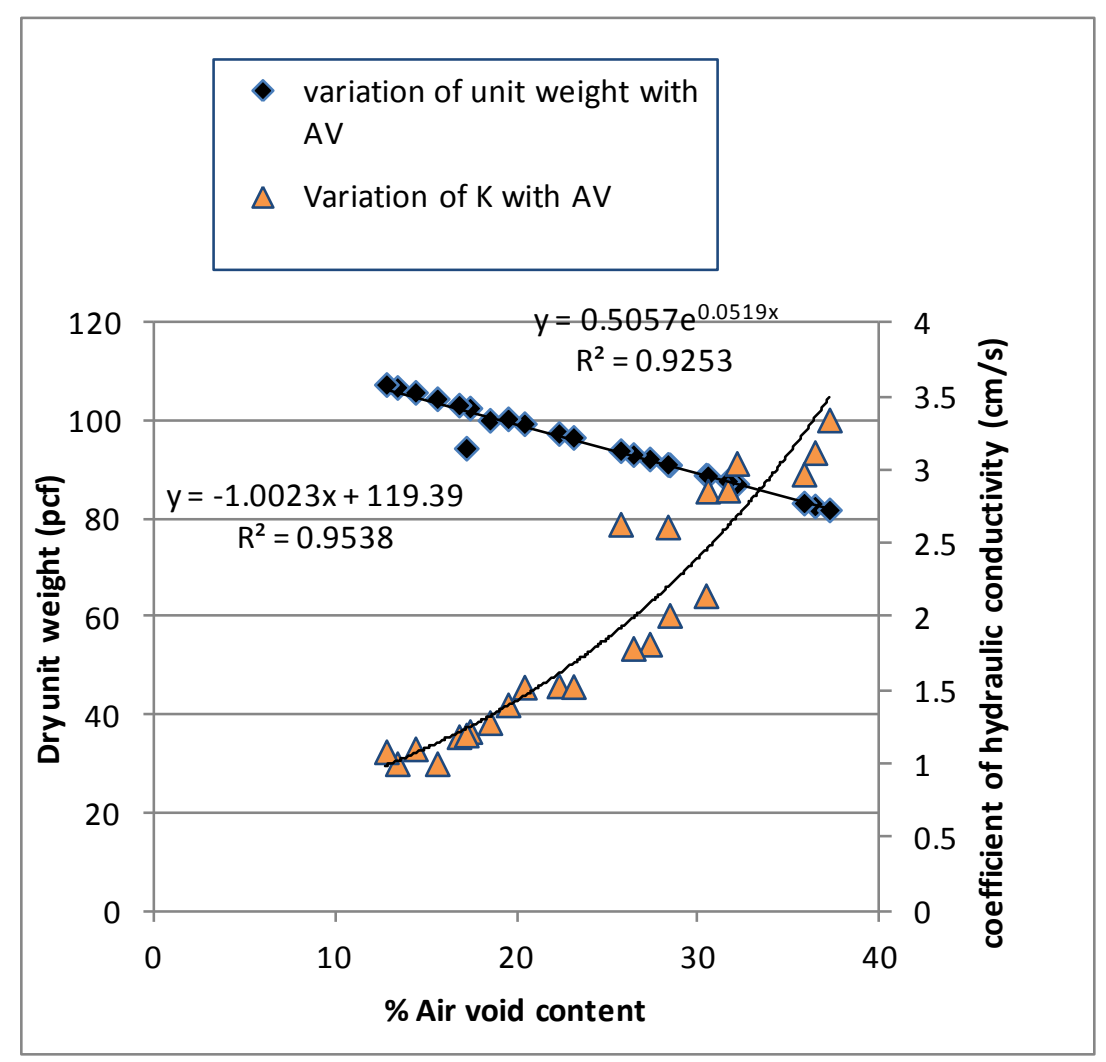

Figure 4.18: Variation of $K$ with $\%$ air void content for Dolomite samples

\subsection{Asphalt Treated Permeable Base Materials}

For each material and gradation type, a batch of four ATPB samples was prepared to produce the specimens for a given mix type. Both the asphalt binder and the aggregate were heated at $160^{\circ} \mathrm{C}$ for two hours and the two constituents were then mixed at that temperature. After mixing, the batch material was then allowed to cool for a minimum of 2 hours and then reheated at the compaction temperature of $125^{\circ} \mathrm{c}$ as required (Faghri et al. 2002). The batch material was then compacted in the gyratory compactor using the appropriate number of gyrations that has been determined earlier for a given air void content range. The compacted specimens were left in the compaction mold for several hours to cool down before being extruded. Table 4.5 gives the average air voids percent of ATPB samples from both the control and conditioned groups and the corresponding average coefficient of hydraulic conductivity. 
Table 4.5:

Average percent air void content and coefficient of hydraulic conductivity of ATPB samples

\begin{tabular}{|c|c|c|c|c|c|c|}
\hline Specimen & $\begin{array}{c}\text { Number of } \\
\text { samples }\end{array}$ & $\begin{array}{c}\text { Rice } \\
\text { Specific } \\
\text { gravity }\end{array}$ & $\begin{array}{c}\text { Nominal } \\
\text { Asphalt } \\
\text { content } \\
(\%)\end{array}$ & \begin{tabular}{|c|} 
Avg. Air \\
void \\
content \\
for \\
control \\
group \\
$(\%)$
\end{tabular} & \begin{tabular}{|c|} 
Average \\
Air void \\
content, for \\
conditioned \\
group \\
$(\%)$
\end{tabular} & $\begin{array}{c}K \\
(\mathrm{~cm} / \mathrm{s})\end{array}$ \\
\hline RC_15_5G & 4 & 2.426 & 3 & 16.2 & 15.8 & 2.73 \\
\hline $\mathrm{RC} \_25 \_5 \mathrm{G}$ & 4 & 2.426 & 3 & 20.4 & 21.4 & 3.50 \\
\hline RC_35_5G & 4 & 2.426 & 3 & 29.6 & 30.8 & 5.13 \\
\hline $\mathrm{RC}$ 15_67 & 4 & 2.44 & 3 & 15.3 & 15.1 & 2.58 \\
\hline RC_25_67 & 4 & 2.44 & 3 & 19.2 & 19.7 & 3.30 \\
\hline RC_35_67 & 4 & 2.44 & 3 & 29.1 & 29.3 & 4.96 \\
\hline NG_15_5G & 4 & 2.65 & 3 & 17.7 & 17.2 & 2.96 \\
\hline NG_25_5G & 4 & 2.65 & 3 & 22.4 & 21.2 & 3.70 \\
\hline NG_35_5G & 4 & 2.65 & 3 & 33.2 & 33.6 & 5.67 \\
\hline NG_15_67 & 4 & 2.62 & 3 & 16.4 & 16.8 & 2.82 \\
\hline NG_25_67 & 4 & 2.62 & 3 & 20.7 & 21.4 & 3.58 \\
\hline NG_35_67 & 4 & 2.62 & 3 & 30.1 & 31.4 & 5.22 \\
\hline DL_15_5G & 4 & 2.744 & 3 & 18.4 & 18.7 & 3.15 \\
\hline DL_25_5G & 4 & 2.744 & 3 & 24.3 & 25.2 & 4.20 \\
\hline DL_35_5G & 4 & 2.744 & 3 & 35.4 & 36.3 & 6.09 \\
\hline DL_15_67 & 4 & 2.722 & 3 & 17.2 & 17.6 & 2.96 \\
\hline DL_25_67 & 4 & 2.722 & 3 & 22.4 & 23.1 & 3.92 \\
\hline DL_35_67 & 4 & 2.722 & 3 & 31.4 & 32.6 & 5.44 \\
\hline
\end{tabular}




\subsubsection{Coefficient of Hydraulic Conductivity Test Results}

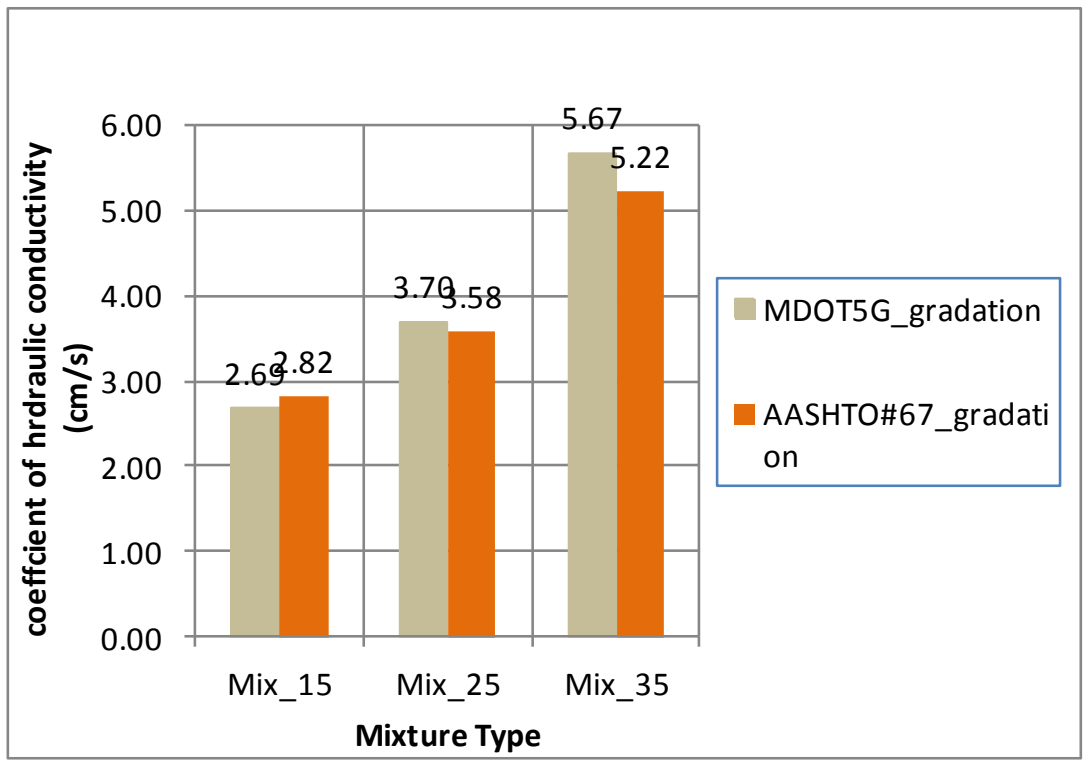

Figure 4.19: Average K for Asphalt-Treated Natural gravel Specimen

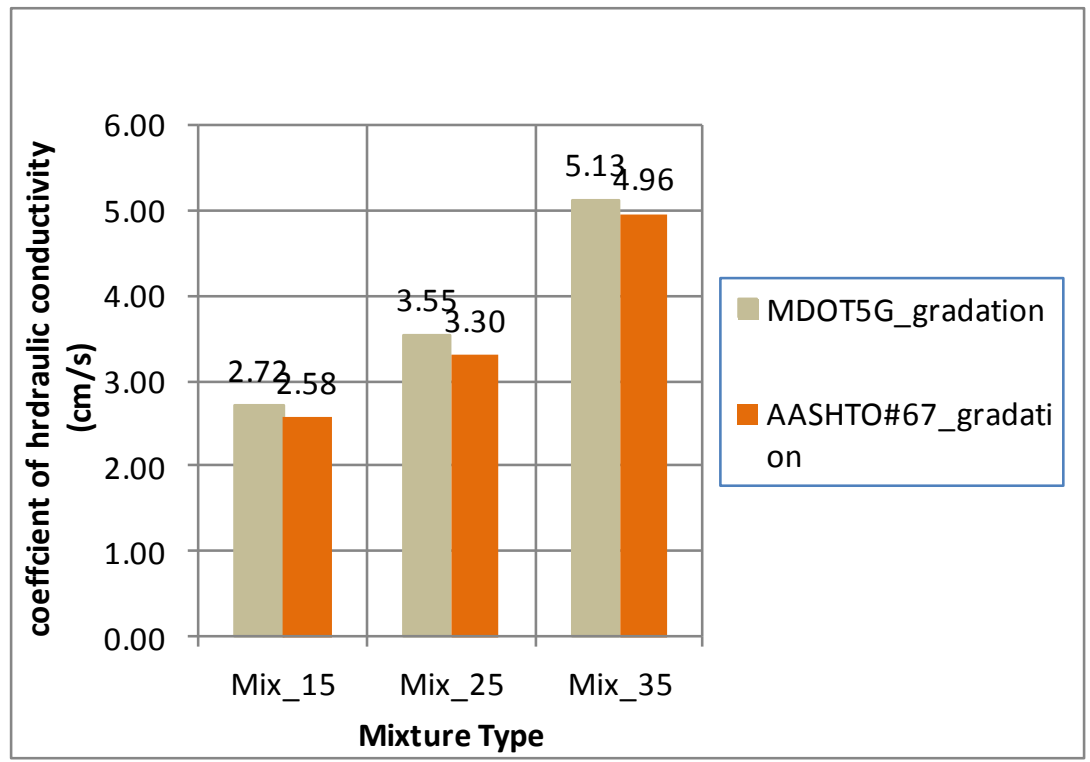

Figure 4.20: Average K for Asphalt-Treated Recycled Concrete 


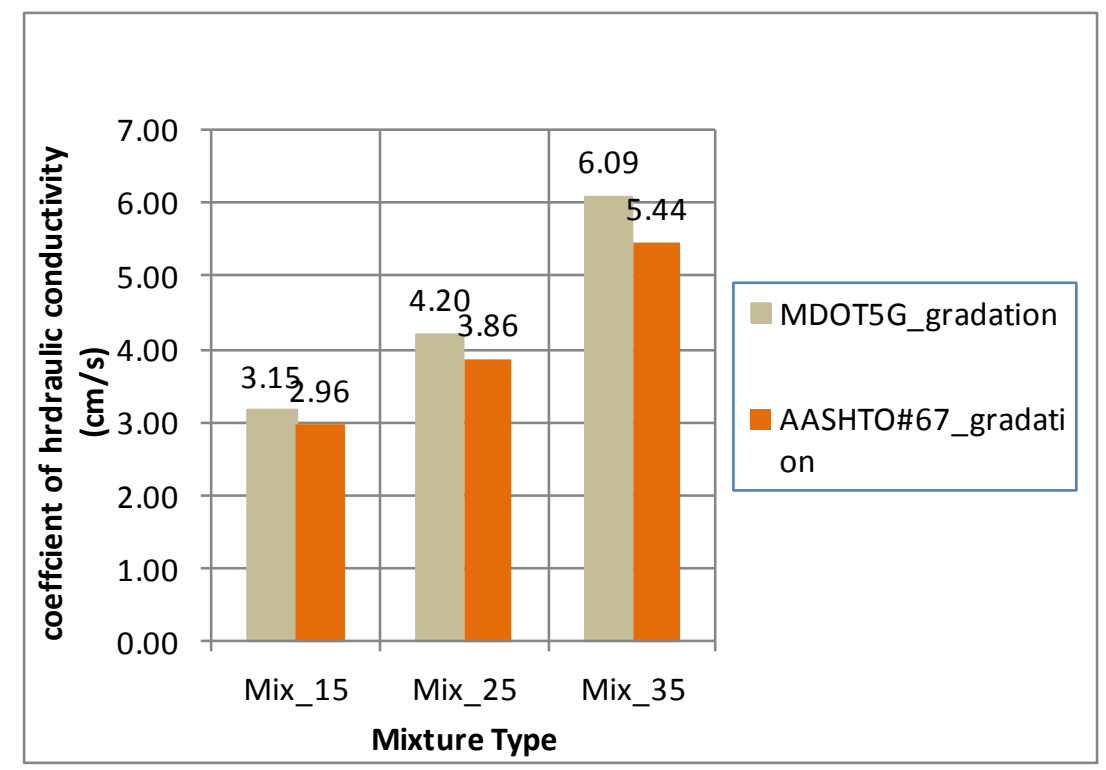

Figure 4.21: Average K for Asphalt-treated dolomite specimens

\subsubsection{Results of Moisture Susceptibility Test}

After completing the coefficient of hydraulic conductivity testing, indirect tensile strength testing was carried out on both control and conditioned specimens as described in Chapter 3 of this dissertation. For each specimen, tensile strength was calculated as follows:

$$
S t=2 * \frac{P \max }{\pi t D} \text { Equation } 4.2
$$

Where

$$
\begin{aligned}
& \mathrm{S}_{\mathrm{t}}=\text { tensile strength (psi) } \\
& \mathrm{P}_{\max }=\text { Maximum load (lbs) } \\
& \mathrm{t}=\text { height of specimen (in) } \\
& \mathrm{D}=\text { specimen diameter (in) }
\end{aligned}
$$

For each material and gradation type four indirect tensile strength tests were conducted on 3 control specimens and 3 conditioned specimens. The results of these six tests were 
then averaged for both the control and conditioned to give average tensile strength for the control specimen and average tensile strength for conditioned specimens. The tensile strength Ratio (TSR) was then computed as follows:

TSR $=$ (Avg. Tensile strength of conditioned specimens)/ (Avg. tensile strength of control specimens)*100

Tensile strength for control and conditioned specimens for each material and gradation types are shown in Figs 4.22- 4.27. The figures also show the associated TSR.

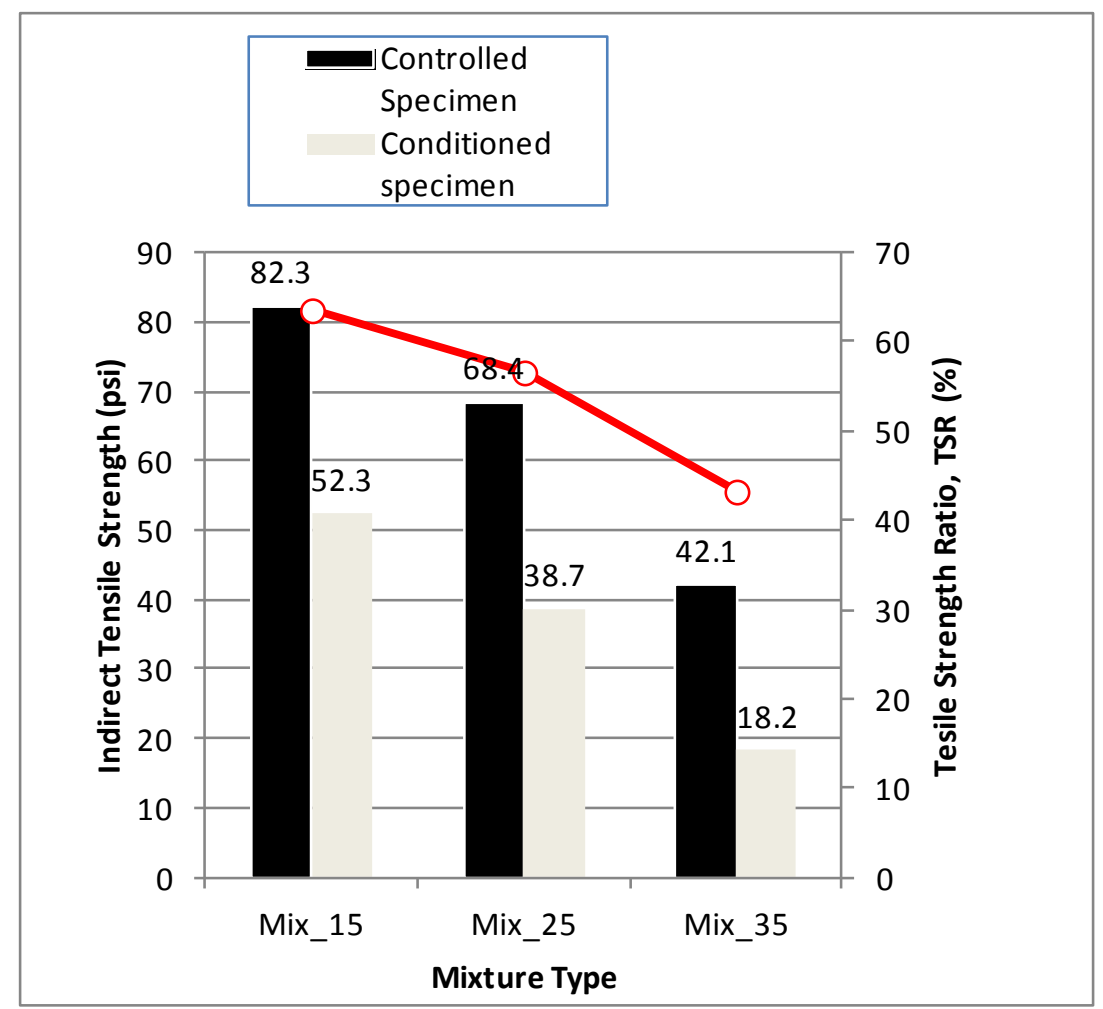

Figure 4.22: Asphalt-treated dolomite AASHTO \# 67 samples 


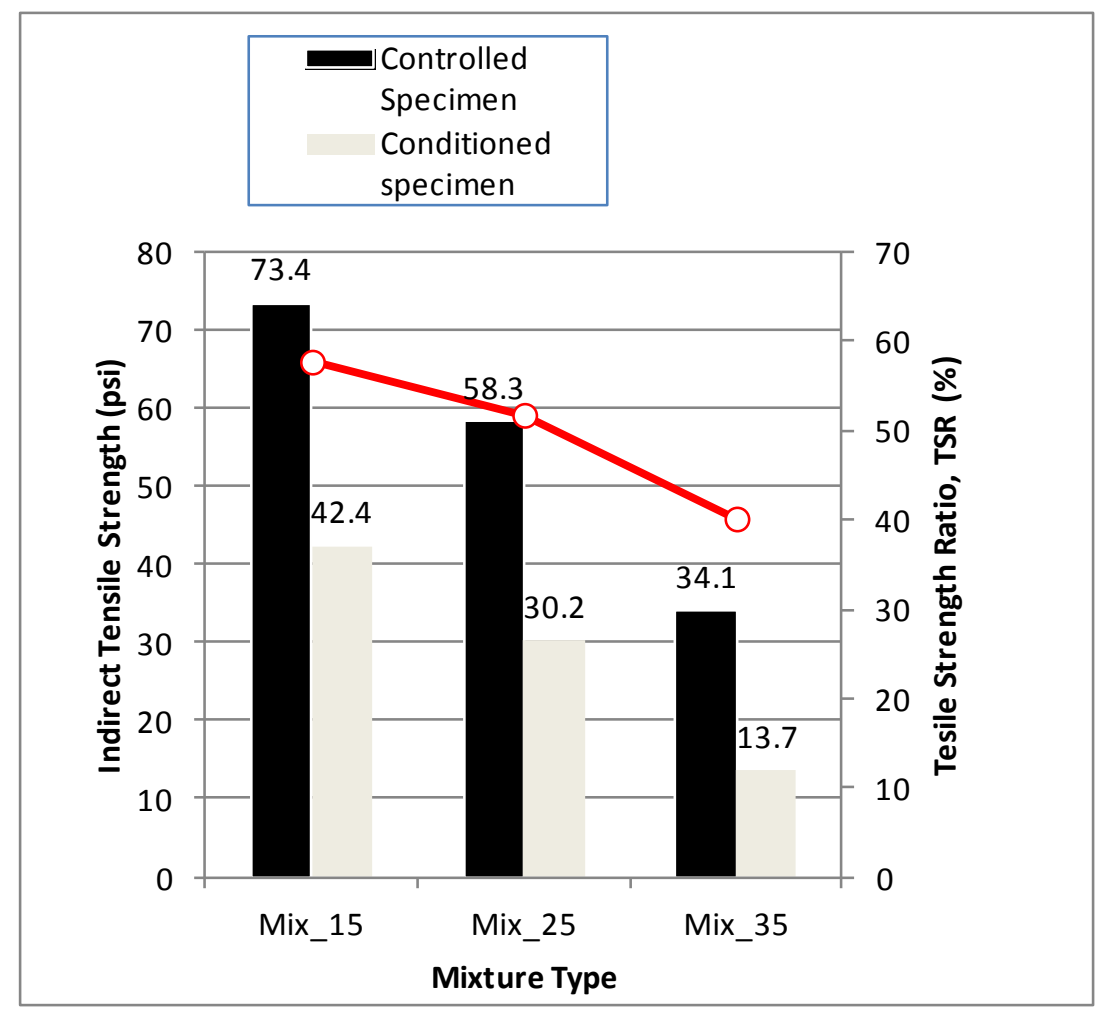

Figure 4.23: Asphalt-treated dolomite MDOT 5G samples 


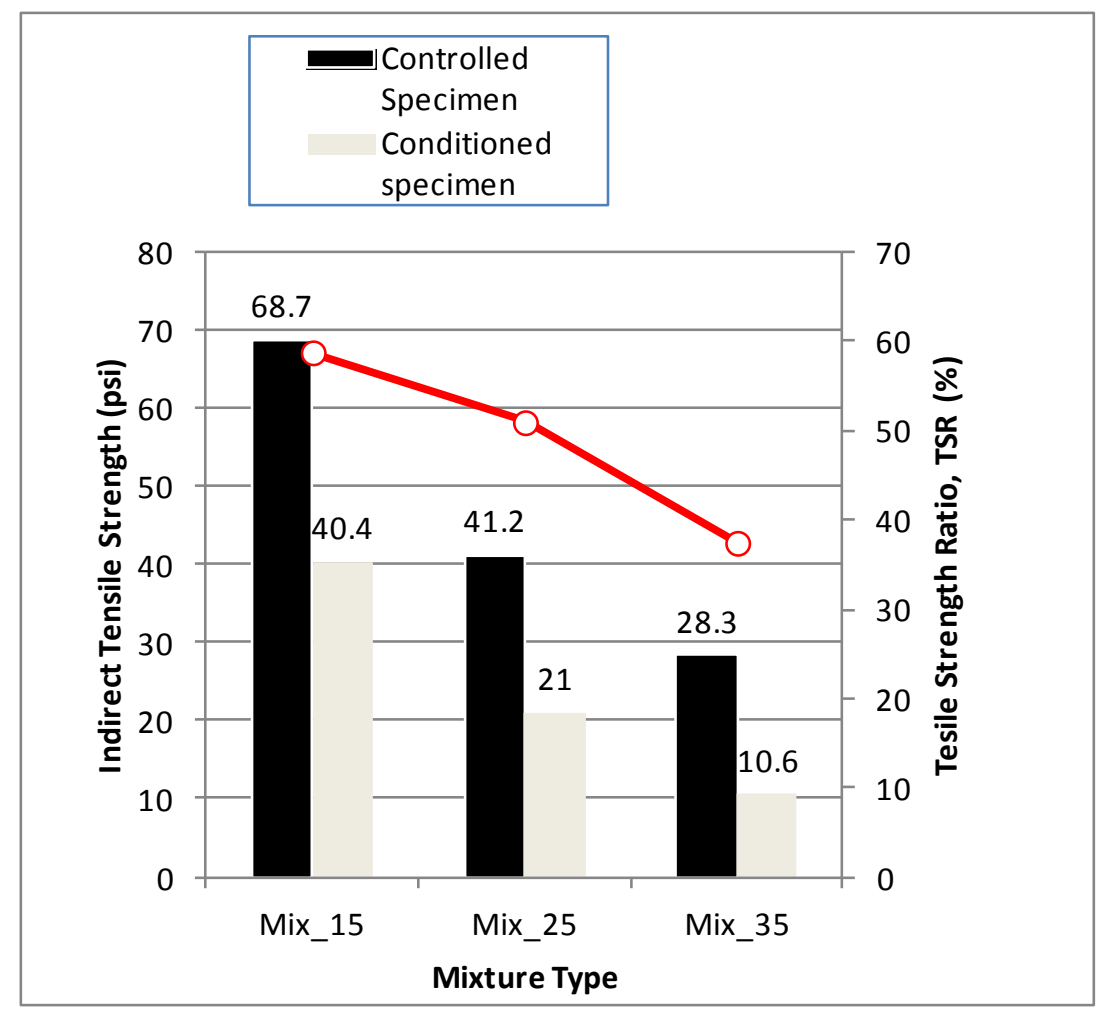

Figure 4.24: Asphalt-treated natural gravel AASHTO \#67 samples 


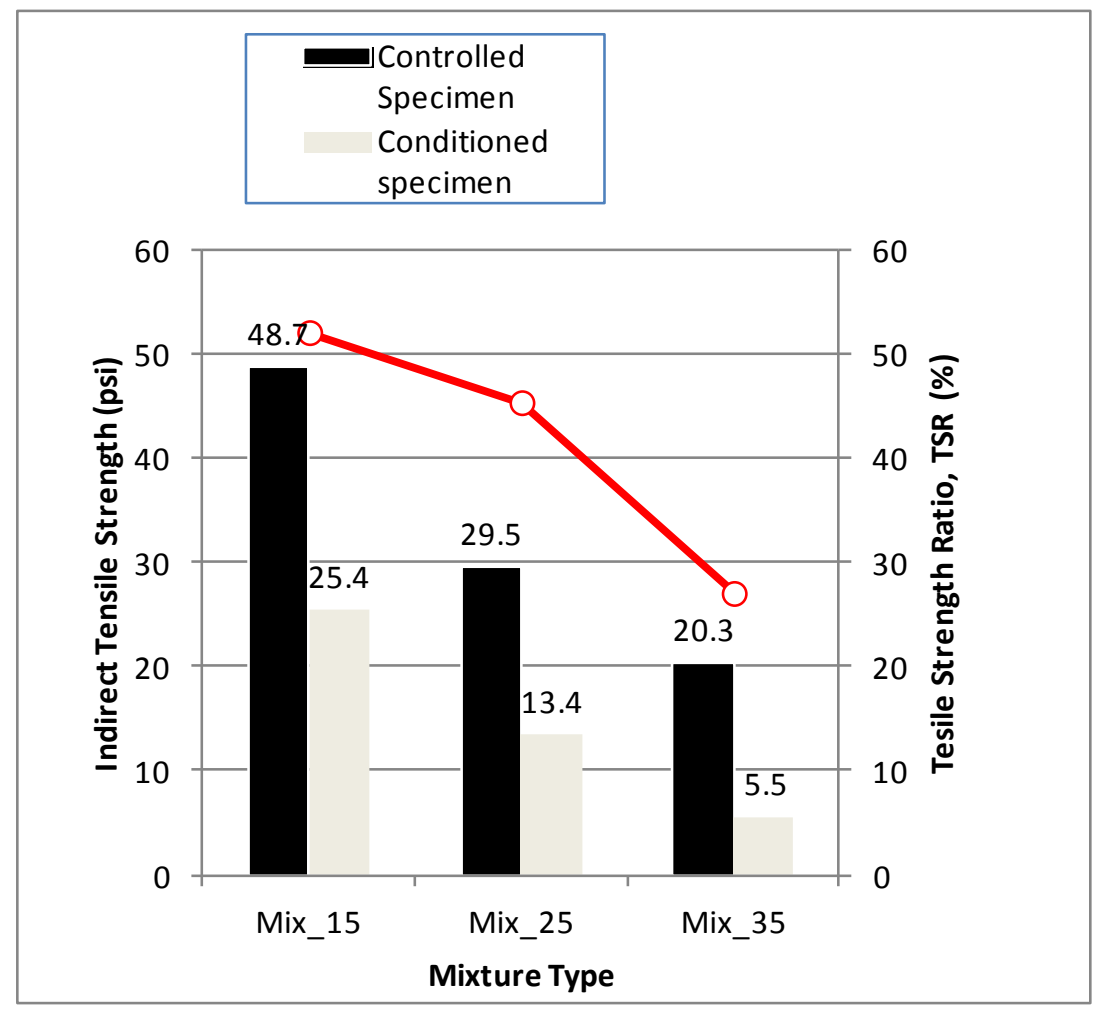

Figure 4.25: Asphalt-treated natural gravel MDOT 5G samples 


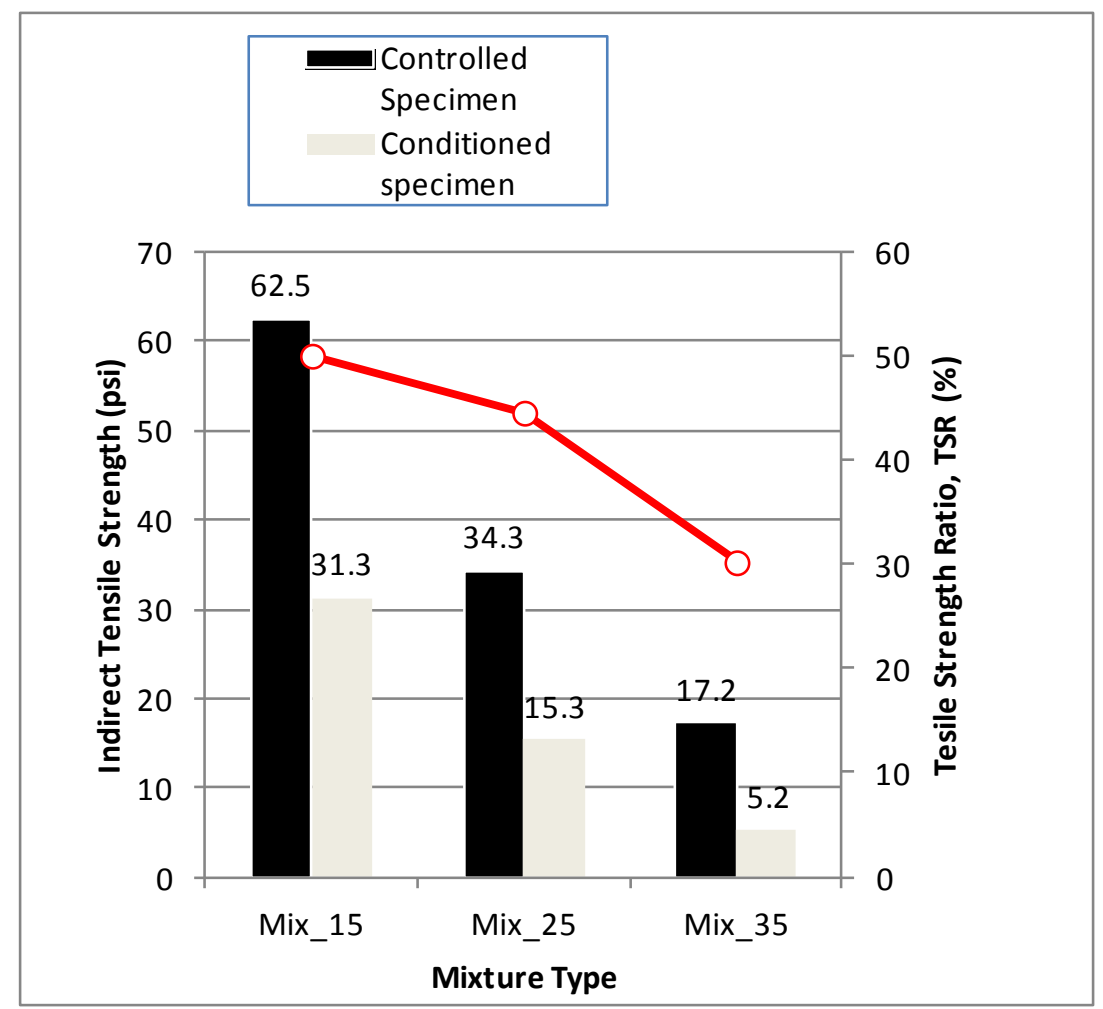

Figure 4.26: Asphalt-treated recycled concrete AASHTO \#67 samples 


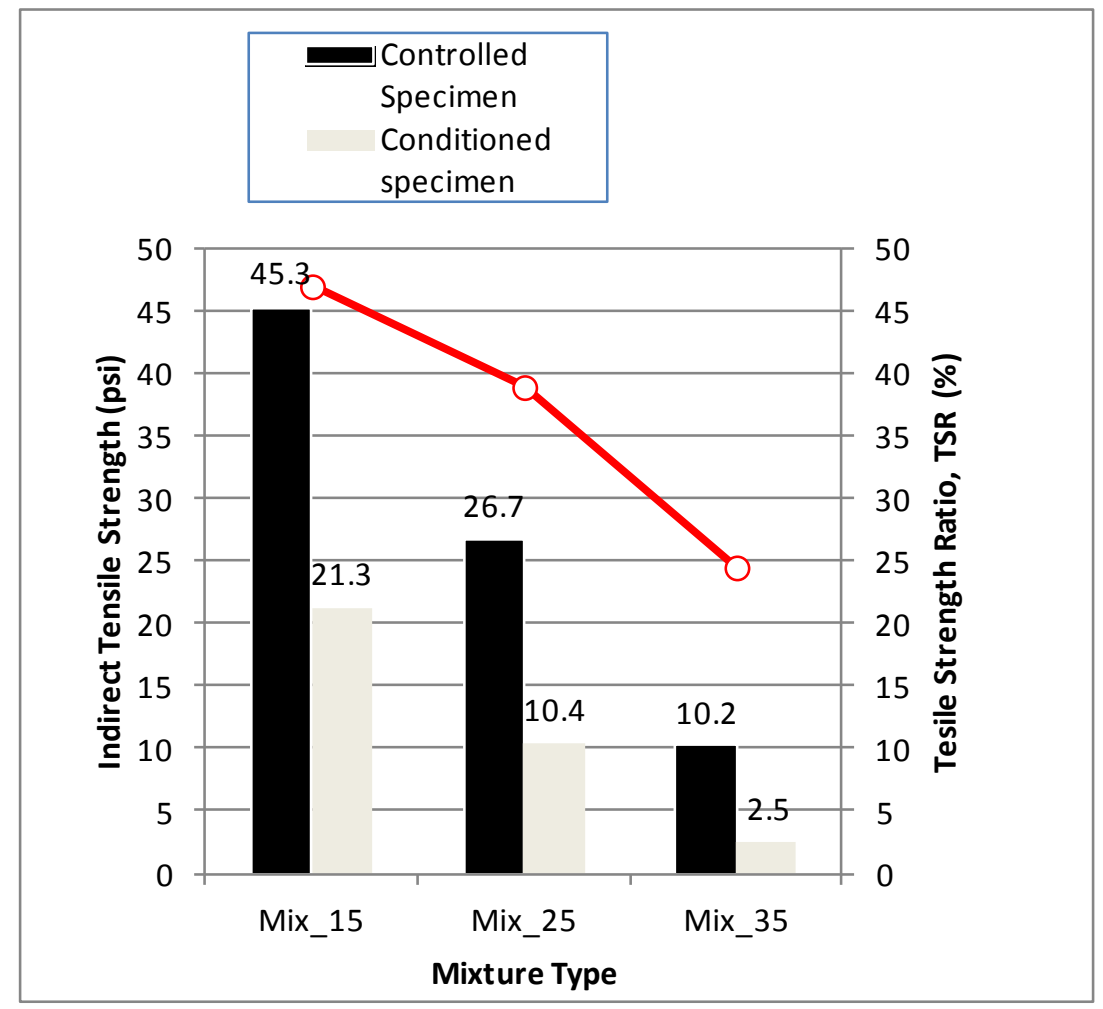

Figure 4.27: Asphalt-treated recycled concrete MDOT 5G samples

\subsection{Discussion of Results of Treated Open-graded Aggregate Base Material}

\subsubsection{Cement Treated Permeable Base Materials}

From the results of laboratory testing to determine the hydraulic, mechanical and durability characteristics of cement treated open-graded aggregate base materials as displayed in Figs 4.8 through Fig 4.18 , the following trends were observed:

1. All three mix types with target $\%$ air voids of 15,25 and 35 produced coefficient of hydraulic conductivity that satisfied AASHTO minimum K value of $1000 \mathrm{ft} / \mathrm{day}$ for good drainage. This means that all three design mixes can be used to provide a drainage layer that can drain within 2 hours $50 \%$ of infiltrating moisture within the pavement structural system. 
2. From a material perspective, limestone mixes have the highest $\mathrm{K}$ values followed by those of recycled concrete aggregate and natural gravel being the least. However the differences in $\mathrm{K}$ value between the $\mathrm{K}$ values of limestone mixes and those of natural gravel is less that an order of magnitude. Since all mix types meet the minimum accepted $\mathrm{K}$ value, these differences in $\mathrm{K}$ values between the materials is not significant enough as to warrant the selection of one material over the other on the basis of hydraulic conductivity alone.

3. From a gradation perspective, MDOT $5 \mathrm{G}$ gradation samples containing the larger size fractions produced higher $\mathrm{K}$ values for all the mix types than mixes made from AASHTO \# 67 gradation. Again the difference in $\mathrm{K}$ value here is less than an order of magnitude even though the MDOT gradation is more open-graded gradation with a $\mathrm{D}_{10}$ value almost 1.5 times that of AASHTO \#67 gradation. One possible explanation for this is that MDOT 5G samples because of their larger size fractions require small amount of aggregates than the AASHTO \#67 for the same volume. As a result the MDOT 5G samples will contain larger pore spaces between the aggregate particles which leads to a higher void ratio and subsequently higher measured coefficient of hydraulic conductivity than the AASHTO \#67 samples.

4. Unconfined Compressive strength (UCS) results as expected are a direct function of the $\%$ air void content. For all mix types, the lower $\%$ air void content samples provided the highest UCS values. One noticeable trend though is that the difference in UCS values between a $15 \%$ and $35 \%$ air void content sample of the same material and gradation is about $25 \%$. This is quite a significant amount especially when considering the stability of the drainage layer under the combined action of traffic and environmental loads. However according to Marks (2008) compressive strength is not used as an acceptance criterion for pervious concrete materials like CTPBs 
because UCS is highly dependent on \% air void content and also very difficult to reproduce during field compaction.

5. Selection of the appropriate compaction method use to compact CTPB samples is very critical since most of the hydraulic, mechanical and durability characteristics are dependent on the compacted sample. Since the aim is not to achieve a maximum dry density as with traditional dense bases, determining the degree of compaction to meet a certain degree of porosity was quite challenging especially for the 25 and $35 \%$ air void contents.

6. Results from the durability testing showed that degradation of the compressive strength due to the environmental forces of Freeze/Thaw increases as the \% air void content increases. Samples with 35\% air void content experienced $10 \%$ reduction more in strength than samples with air void content of $25 \%$. This is very critical in terms of determining the degree of openness needed since the more open-graded the drainage layer the greater degree of strength loss will be due to freeze/thaw action. This is quite different from the behavior of normal concrete wherein a small amount of entrained air is normally included in the mix design to increase the resistance of the cement mixture to the action of cyclic freeze/thaw. However, according to Nagi et al. (2007) these microscopic entrained air voids are different from the large voids which form the porous structure of treated permeable bases. However, research on the freeze/thaw durability resistance of pervious concrete, a material with similar porous structure as CTPBs, showed that resistance to $\mathrm{F} / \mathrm{T}$ is more a function of the saturation levels within the porous structure at the time of freezing rather than on the number and size of the voids (NRMCA 2008). Therefore if this research results hold true, then one would expect problems associated with cyclic $\mathrm{F} / \mathrm{T}$ will not be critical in impairing the performance of CTPBs due to the 
high coefficients of hydraulic conductivity of these bases which basically minimize the potential of saturation.

7. Results for the 7-day UCS are well within the values reported in the literature for the given cement content used. 7 -day UCS results range from 880-320 psi. 7-day UCS values reported by Hall et al (2005) for mixes with a $200 \mathrm{lbs} / \mathrm{yd}^{3}$ cement content, cement stabilized open-graded base ranges from 600 psi for the $15 \%$ dolomite sample to 150 psi for the $35 \%$ natural gravel specimen. Results for the coefficient of hydraulic conductivity were however lower than some of the values reported in the literature. K values reported by Rabab'ah (2007) are in the range of 3000 $\mathrm{ft} /$ day to $15000 \mathrm{ft} /$ day. A likely reason for this wide discrepancy may be due to the testing procedures and equipment employed to run the permeability tests. Due to the large aggregate size particles, conventional testing equipment like the one use in this research may be unsuitable for producing correct and repeatable test results. Gupta et al. (2000) built a special flexwall permeameter for measuring the hydraulic of open-graded cement treated aggregate bases and reported $\mathrm{K}$ values in the range of $21000 \mathrm{ft} /$ day to $38000 \mathrm{ft} /$ day.

The challenge from a construction quality control point of view will be to determine an appropriate quality acceptance criterion for CTPBs. For pervious concrete use in low volume roads, the acceptance criteria used are percent air void structure and unit weight. While unit weight is easily measurable in the field, measuring the air void structure in the compacted CTPBs is quite a challenge. From the previous analyses, it can be seen that most of the hydraulic, mechanically and durability characteristics of CTPBs are in a good measure directly connected to the \% air void content. From the graphs of Fig 4.17 to Fig 4.18, the percent air void content is well related to the coefficient of hydraulic conductivity, Unconfined Compressive Strength and the strength reduction due to the environmental forces of cyclic freeze/thaw. For instance the percent air void content has a very strong relation with the wet unit weight with an $\mathrm{R}^{2}$ value of 0.94 . The wet unit 
weight of a constructed СТРB layer is easily measurable in the field than the percent air void content of the in situ CTPB layer. The wet unit weight is also easily measurable in the field compare to the percent air void content. So the question depends on what constitutes an acceptable wet unit weight for CTPB for a given pavement site conditions. For dense graded bases, depending on the level of traffic expected on the given pavement, acceptance criterion is normally expressed as some percentage of Maximum Dry Density (MDD), which for most highway pavements ranges between 90-105\% (Holtz and Kovac 1981). From the results of this limited testing program, reasonable K and UCS values that meet specification requirement for the hydraulic and mechanical stability of a drainage layer are within the 15-25\% air void content. Plugging this range of percent air void content into the trendline equations of Figs 4-15 and 4-16 will yield a dry unit weight in the range of 95-105 pcf.

Therefore based on this analysis, a quality control acceptance criterion for cement treated drainage layer will be within the range of 95-105 pcf for most pavement site conditions.

\subsubsection{Asphalt Treated Permeable Base Specimens}

Based on the results of permeability, tensile strength and durability of asphalt treated permeable specimens, the following trends was observed:

1. All the samples have a $\mathrm{K}$ value well in excess of FHWA minimum of $1000 \mathrm{ft} /$ day. The Recycled concrete samples made from the AASHTO \#67 gradation have the least $\mathrm{K}$ with an average $\mathrm{K}$ of $7314 \mathrm{ft} / \mathrm{day}$. The Dolomite MDOT 5G gradation samples have the highest $\mathrm{K}$ with an average value of $17263 \mathrm{ft} /$ day.

2. For the same gradation and mix type, dolomite samples have the highest coefficient of hydraulic conductivity. On average dolomites sample s have a $\mathrm{K}$ value about $7 \%$ greater than that of natural gravel samples. Recycled concrete aggregate samples shave the least $\mathrm{K}$ value. A likely reason for this can be attributed to the greater degradation of recycled concrete 
aggregate particles as a result of the gyratory compaction. This degradation leads to breakdown of particles which produces smaller size fractions which can block flow channels thus reducing the $\mathrm{K}$ value in the process.

3. For the same material type, MDOT 5G samples have higher coefficient of hydraulic conductivity than AASHTO \#67 samples. However, the AASHTO \#67 samples have higher tensile strength values and TSR. This was expected since the MDOT $5 \mathrm{G}$ gradation is a more open gradation than the AASHTO \#67. As a result of this more open-graded matrix, MDOT $5 \mathrm{G}$ samples will have higher $\mathrm{K}$ values but there will also be less contact between the aggregate particles giving its lower tensile strength values.

4. Compaction becomes more of a problem for lower percent air void content since the many number of gyrations caused some particle breakage. This was more evident at the surface of the samples where debris of the broken particles can be seen.

5. The $\mathrm{K}$ values of asphalt treated specimens are much higher than the cement treated samples but this is due to the method used to determine the $\mathrm{K}$ value for each material type. The flexwall permeameter used to measure the $\mathrm{K}$ value of the cement treated samples was not designed to measure the $\mathrm{K}$ of highly porous specimens like CTPBs and as result this limitation of the testing equipment may have placed a limit on the measured $\mathrm{K}$ values of cement treated samples.

6. Another important deduction that can be made from the test results is the critical importance of material and gradation selection for asphalt treated permeable material. Limestone samples have the highest tensile strength followed by those of natural gravel and the least being recycled concrete aggregate. Limestone samples also showed the least tensile strength reduction i.e. highest TSR value. For each material and gradation type, the indirect tensile strength (ITS) decreases as the percent air void content 
increases due to reduced contact between the aggregate particles. Since only a small percent by weight of binder was used in these mixes, it is probable to consider that stability of these mixes is due mainly to the interparticle contacts between the aggregate particles. As a result high quality aggregates are needed to produce a porous and stable mix. Even though no quality control tests were done on the aggregates, the limestone aggregate which is deemed to be of superior quality than the other two did produce the most porous and stable mixes. The tensile strength of the asphalt mix has been shown to be dependent on the absorption capacity of the aggregate use in the mix (Barksdale 1978). Aggregates with high absorption capacity tend to have lower tensile strength values as they absorb more binder into their skeleton and in the process there is too little binder available to hold the aggregate particles together. Recycled concrete has the highest absorption of the three aggregate with 5.3\% which is almost twice that of limestone aggregate at $2.2 \%$. Results of tensile strength on mixes containing these aggregates indeed show that recycled concrete aggregate mixes have the lowest tensile strength followed by those natural gravel and dolomite samples having the highest tensile strength. Another point worth mentioning is the resistance to degradation of mixes containing these aggregates. Mixes containing recycled concrete aggregate have the lowest resistance to degradation and the impact of this was evident in the mixes with lower percent air void content since they require higher number of gyrations to compact them to that desired percent air void content. Degradation is very important especially for drainage layer which are poorly compacted layers within the pavement structure since the applied stresses on the layer can cause the layer to fail structurally or changes the original gradation of the aggregate thereby altering the hydraulic and mechanical properties of the drainage layer. These changes in the material properties of the asphalt treated drainage layer as a result of the degradation of the aggregate particles can 
impair the performance of the drainage layer and can lead to premature failure of the pavement.

7. Even though one binder type and content was used in this research, it is worthwhile to note the impact of these two parameters on the hydraulic and mechanical properties of ATPBs. A binder content of $3 \%$ was used in this research but earlier attempts to use a binder content of $3.5 \%$ results in a mix having too much asphalt binder and as a result was deemed not workable. This is due to the porosity of these mixes and the fact that they have no fines. From stability point of view having higher binder content will have produced a thicker binder film that will not stiffen with age compared to thin binder films of these low binder asphalt mixes. From a hydraulic perspective, increasing the binder content will lower the percent air void content leading to reduced coefficient of hydraulic conductivity of the mix. This is because increasing the binder content of the mix will seal off some of the interconnected air voids within the porous matrix of the asphalt mix. For ATPBs therefore, there must be an optimal binder content that can satisfy both the requirement of stability and drainability. From the results of this limited testing and based on the quality of aggregates an asphalt binder content in the range of $2.5-3 \%$ will provide that optimal mix.

8. The Tensile Strength Ratio (TSR) which is a measure of the moisture susceptibility of the asphalt mix also reduces with increasing percent air void content for all the samples. For most dense Hot Mix Asphalt (HMA) and open-graded asphalt materials used as surface course in asphalt pavement, a TSR of $80-85 \%$ is normally specified. A TSR value less than that specified is normally interpreted to mean that the mix may have long term durability problems. A pavement layer containing such a mix is therefore expected to be susceptible to moisture damage leading to premature failure of the pavement structure (Zaniewski and Srinivasan 
2004). All the samples under investigation in this project have TSR values lower than that which was specified. The highest TSR value was that of DL_15_AA67 samples with a value of $64.7 \%$ and the least being $27.4 \%$ for a RC_35_5G samples. These low TSR values will mean that these mixes have very low resistance to moisture damage. The question however is whether the same TSR specification used for the surface course can be used for the asphalt treated drainage layer or whether the TSR is an appropriate performance criterion for asphalt treated permeable bases considering their high percent air void content. In the estimation of this researcher since the TSR can be related to both fatigue and rutting of asphalt pavement, it seems only appropriate to use it to determine the moisture susceptibility of asphalt treated drainage layer. Furthermore, another concern is how this reduced tensile strength will affect the value of the vertical tensile strength at the bottom of the HMA layer. One of the important performance criterions of asphalt pavement is the vertical tensile strain at the bottom of the HMA which governs the fatigue life of the pavement. For the most part, the drainage layer is located just underneath the surface course and even though some designs may not assign any structural significance to the drainage layer, its position will no doubt affect the magnitude of the vertical tensile strain at the bottom of the HMA layer.

9. What the results of this limited testing program did show was the wide range of mixes, composition and performance of various types of asphalt treated permeable base materials. The delicate balance of providing a mixture that has sufficient permeability for pavement subsurface drainage while at the same time providing a long term stable layer within the pavement structure was quite evident from the results. These test results further reinforced recent findings by Mallela et al. (2000) that the mere presence of permeable base layer does not guarantee the effectiveness of subsurface drainage. What these test results show is that issues with 
material and gradation type selection and mix design are very critical to the overall performance of asphalt treated drainage layer. However, obtaining an optimal mix with sound hydraulic and mechanical properties is dependent on the requirement of the asphalt treated drainage layer. Since treated permeable bases are normally expected to provide some measure of stability for construction traffic as minimum requirement for stability, performance of asphalt treated permeable material should not be assess only by its hydraulic properties. From the results, it can be seen that the stability of ATPBs decreases as the percent air void content increases. It was also evident from the test results that even the most inferior material at its lowest percent air void content i.e. the RC_5G_15 samples have $\mathrm{K}$ values well in excess of the minimum $1000 \mathrm{ft} /$ day set by the FHWA but at the same time also such a mix offered the most unstable mix. Therefore an optimal ATPB mix based on this limited testing program that will meet both hydraulic and stability requirements will therefore be a mix with a percent air void content within the range of 15 $20 \%$. However, concerns with regard to the long term variation of the coefficient of hydraulic conductivity with age of the pavement will need to be addressed. Even though pavement containing these drainage layers are by specification required to have a separator layer in order to prevent clogging of the pore spaces within the drainage layer, questions still remain as to whether these permeable layers do undergo internal compression from the effects of load and environmental forces, subsequently leading to a reduction in the percent air void content and ultimately the $\mathrm{K}$ value. 


\section{CHAPTER 5}

\section{MEPDG PERFORMANCE ANALYSIS OF PAVEMENT STRUCTURES CONTAINING TREATED AND UNTREATED PERMEABLE BASES}

\subsection{Introduction}

In an effort to provide subsurface drainage in rigid pavement structure various types of bases ranging from unbound open-graded bases like the Michigan $4 \mathrm{G}$ to bound base types like ATPB and CTPB are available. According to Sargand et al. (2006), the following factors determine which base type can be used for a given pavement section:

- $\quad$ Pavement type

- $\quad$ Environmental conditions

- $\quad$ Traffic

- $\quad$ Subgrade type

Even though the inclusion of subsurface drainage features in the pavement structure have been demonstrated to improve the performance of the pavement, it has also been shown that this will increased the initial bid cost by as much as $24 \%$ when stabilized permeable bases are used (Cole and Hall 1997). The provision of subsurface drainage will increase the overall initial construction cost of the pavement and as such it is expected that the increased cost would be offset by improved pavement performance and reduction in the pavement's life cycle cost. The focus of this chapter is therefore to present result of a sensitivity analysis using the Mechanistic Empirical Pavement Design Guide (MEPDG) software on key parameters that characterized both treated and untreated permeable bases. Permeable bases are made up of materials that have different properties i.e. aggregate type, maximum aggregate size, gradation and binder content.

The underlying assumption is that pavement layers constructed with these materials have different hydraulic characteristics and as a result will have different drainage behavior 
and subsequently the impact on pavement performance will be different for each material type and subsurface drainage system. Since the focus of this research project is based on both treated and untreated permeable bases, these mechanistic performance evaluations were used in the economic evaluation of pavement systems containing these bases so as to determine various scenarios for which the use of these bases is practically desirable and cost-effective. Analyses of pavement sections containing traditional bases like densegraded aggregate base and asphalt/cement stabilized bases were also carried out in order to help in the selection of most cost-effective alternative pavement section.

In an effort to properly capture the various scenarios for which the use of permeable bases is deemed appropriate and desirable from a cost and performance perspective, a full factorial experimental design wherein several design inputs such as traffic volume, axle load spectra, climate and PCC thicknesses were varied. The mechanistic performance evaluation was designed in such a way that results of the computer simulation analysis are interpreted to mean the contribution of permeable bases to the performance of Jointed Plain Concrete Pavement (JCPC). A limited number of performance simulations runs were also done on flexible pavement sections in order to determine the contribution of the permeable drainage layer to the performance of flexible pavement relative to that of rigid pavements.

There have been several quantitative descriptions of the quality of pavement subsurface drainage. AASHTO uses the time-to-drain a fully saturated base to $50 \%$ saturation as the basis of quantifying the effectiveness of subsurface drainage (ARA Inc, 2004). A subsurface drainage system that has a time-to-drain of $2 \mathrm{hrs}$ is considered excellent and one that has a time-to-drain of 7 days is considered to be of poor drainage. Other quantitative descriptions use the permeability of the base as the basis of quantifying the effect of subsurface drainage as shown in Table 5.1 (Markow 1982). 
Table 5. 1

Drainage Recommendations (Markow, 1982)

\begin{tabular}{|c|c|}
\hline Quality of drainage & $\begin{array}{c}\mathrm{K} \\
(\mathrm{ft} / \mathrm{day})\end{array}$ \\
\hline Good & 10,000 \\
\hline Fair & 100 \\
\hline Poor & 0.1 \\
\hline
\end{tabular}

Markow (1982) conducted simulations of pavement performance under various moisture conditions using the EUROMAR software. Results of these simulations showed that pavement performance under good and fair drainage conditions as outlined in Table 5.1 were virtually identical. So if these findings hold true, then it means that a minimal acceptable value of base permeability lies between the poor and fair i.e. (0.1-100 ft/day). AASHTO however recommended a minimum permeability of $1000 \mathrm{ft} / \mathrm{day}$ which for a standard pavement section containing 4 inches of permeable base will produce a time-todrain of about 2 hours, which will classify the pavement as one with excellent drainage. The basis on which AASHTO arrived at this minimum hydraulic conductivity is not clear in the literature and this value seems to be far greater that the minimum required hydraulic conductivity value obtained by Markow's research.

\subsection{Analysis Objective}

The primary objective of this portion of the research project was to perform computer simulations of pavement performance using the MEPDG software in order to develop a sound basis of the various scenarios for which the use of a treated permeable base is costeffective. This analysis is therefore intended as a means of quantifying the impact permeable bases have on pavement performance as predicted by the MEPDG. 


\subsection{MEPDG Software}

The MEPDG Software, which is a product of the Strategic Highway Research Project (SHRP), is the new pavement design software that incorporates mechanistic principles into the design and analysis of pavement structures. It was developed to overcome the limitations of the AASHTO 1993 Design Guide and its earlier versions which are based entirely on empirical methods. An outline of some of the essential improvements which makes the MEPDG a standout pavement analysis tool and makes it superior to the AASHTO pavement Design Guides are (Coree 2005):

- $\quad$ Employed mechanistic approach/models to pavement analysis and evaluation

- Integration of detailed climatic inputs

- Better characterization of traffic

- $\quad$ Advanced structural modeling capabilities

- Is able to model changes in material properties

This new design software has built-in sophistication that better capture the complex interaction of traffic, climate, material properties and pavement structure over the design life of the pavement than previous design guides. This makes the MEPDG a very apt pavement analysis tool to predict the performance of the pavement over time. Another thing which makes the MEPDG a very versatile pavement analysis tool compare to the AASHTO Design Guides is that unlike the AASHTO Design Guides which were based on the AASHO Road Test, the mechanistic models in the MEPDG are calibrated with data from the Long Term Pavement Performance (LTPP) sections from across the different climatic regions of the United States. This capability makes the MEPDG easily adaptable to a wide range of pavement types, pavement structure, material properties and climatic regions (Gulcu and Ceylan 2009).

\subsection{Inputs for MEPDG}

One of the challenges of using the MEPDG is the large number of inputs needed to run the analysis. Unlike the AASHTO Design Guides that require very few inputs such as the 
number of Equivalent Standard Axles (ESALS), structural layer coefficient, drainage coefficient, the MEPDG as a mechanistic tool of pavement analysis required a far greater number of inputs to run pavement performance models that can accurately reflect the complex interaction between pavement structure, material properties and environmental constraints (Rabab'ah 2007). As a result of this, implementing the MEPDG for any given pavement design is a time consuming and costly exercise since it requires running a large amount of laboratory and field testing in order to determine these inputs. However, in an effort to provide pavement designer greater flexibility in the choice of design inputs, the MEPDG uses a hierarchical approach that is base on the significance of the project and the data that is available. The MEPDG incorporates three levels of inputs as follows (McCracken et al. 2008):

1. Level 1 input is the highest quality of input data and is mostly used for highly prioritized projects where there is an economic consequence of early failure. This level of inputs requires that all the input data should be obtained from direct testing on the actual material in question e.g. the resilient modulus testing of the subgrade.

2. Level 2 is the intermediate level and is used when direct tests are not available or too expensive to carry out. Input values under this category are obtained from empirical relationships with other test result e.g. the resilient modulus of the subgrade can be obtained from other standard tests like the California Bearing Ratio (CBR) using the empirical relationship of $\mathrm{M}_{\mathrm{r}}=2555^{*} \mathrm{CBR}^{0.64}$

3. Level 3 inputs has the lowest rating in terms of accuracy and are normally employed for low volume roads wherein it is not economical feasible to do a level design analysis. At this level, it is normally wise to just use the default material properties that are found in the software.

Therefore, whatever the category of the project and the amount of information available, these three levels of design inputs do offer pavement designers a lot of flexibility in using 133 
the software as a tool of pavement analysis by mixing the levels of inputs for any given project and design (Coree 2005).In order to compare the pavement performance predicted by the MEPDG software using three hierarchical inputs, McCracken et al. (2008) conducted a study on the effect of the MEPDG hierarchical levels on the predicted performance of a Jointed Plain Concrete Pavement (JPCP). With regard to the thickness of the slab, they concluded that regardless of the level of input used, dowel slabs will have the same predicted thickness. For undoweled slabs they found out that the predicted thickness is increased by one-half of an inch.

\subsubsection{Material Characterization}

A pavement consists of several layers and each of these layers is made up of different material type since each pavement layer performs a very distinct role within the pavement system. Characterizing these materials is a key to understanding the long term behavior and performance of any given pavement structure. It is therefore a worthwhile exercise to characterize the materials used to construct each layer, their properties and behavior under both traffic and environmental loads. The MEPDG characterizes pavement materials in terms of elastic properties so that pavement responses such as deflections, strains and stresses due to traffic and environmental factors can be computed using appropriate mechanistic methods. Even though some pavement materials like Portland cement concrete, permeable concrete base and lean concrete exhibit perfectly linear elastic stress-strain relationships at working stress levels, it is also quite apparent that some of these pavement materials like the subgrade may not exhibit elastic behavior. Elastic behavior is however assumed when modeling these materials since most of the deformations under repeated traffic loads are recoverable to some extent (Abdallah et al. 2004).

For rigid pavement the materials that made up of the pavement structure are:

- Portland Cement Concrete

○ Stabilized Granular materials

- Unstabilized granular materials 
Below is a summary of material characterization for each of the above layers as extracted from the MEPDG software (ARA Inc 2004):

The Portland cement concrete (PCC) is characterized in the MEPDG by the 28-day flexural strength of concrete which is the primary input parameter. Other relevant PCC material properties needed for the analysis of the performance of rigid pavement for all the three hierarchical levels includes unit weight, Poisson's ratio, coefficient of thermal expansion and drying shrinkage.

The MEPDG covered a wide range of chemically stabilized materials consisting of the following:

Cement Treated Base, Asphalt Treated Base, Asphalt Treated Permeable Base, Cement Treated Permeable Base, soil cement, lime cement and flyash treated materials. The elastic modulus is the primary input property of these chemically stabilized materials. The Design Guide then uses empirical elastic relationships to calculate the compressive strength from the input elastic modulus values for each stabilized material.

For the unbound granular materials and subgrade materials the Design Guide uses the AASHTO soil classification system. The Design Guide characterized unbound materials by grain size distribution, liquid limit and plasticity index. The primary input parameter used for analysis is the resilient modulus. The resilient modulus values for these unbound materials are obtained from triaxial tests for level 1 design inputs. However, for level 2 design inputs correlation equations with more commonly used test protocols like the CBR have been developed o estimate the resilient modulus of the unbound materials. For the level 3 design inputs, the resilient modulus of unbound materials is selected based on the AASHTO/USCS material classification of the unbound material. The design guide provides a general range of typical modulus for each material classification at their optimum moisture content. 


\subsubsection{Climate}

The MEPDG requires detailed characterization of climatic variables of the environment where the pavement section is located. Climate changes hourly and seasonally all year round and this in many ways affects the performance of the pavement layers in quite different ways. The climate model within the MEPDG is called the Enhanced Climatic Integrated Model (EICM) and was designed to account for these variations that naturally occur throughout the design life of the pavement. The primary input climatic data includes the following (Zapata et al. 2008):

i. Hourly air temperature

ii. Hourly wind speed

iii. Hourly \% sunshine

iv. Hourly precipitation

v. Daily maximum solar radiation

vi. Monthly humidity

The climate data are obtained from historic records of weather stations across the U.S. The current version of the Design Guide has more than ten years of climate data. In order to provide climate data for a pavement with a design life of thirty years, the software used the ten year climate data and then repeats the climate data up to the number of pavement performance years desired, in this case three times (Corre 2005).

\subsubsection{Traffic}

Traffic data represents one of the layers of input data needed in the MEPDG pavement analysis software. While the traffic input data for the AASHTO design guide were based solely on the number of Equivalent standard axles (ESALS), the traffic input data for the MEPDG are intended to capture the wide variability of vehicles using the pavement including the number of axles, types of axles and their distribution, hourly and monthly traffic distribution. The MEPDG list the following traffic inputs (Smith and Diefenderfer 2010): 
i. Axle load spectra

ii. Gear/axle configuration

iii. Axle/tire spacing

iv. Tire pressure

v. Truck volume distribution and speed

vi. Number of axles per truck

vii. Monthly and hourly distribution factors

viii. Traffic wander

The above traffic data are obtained from Weigh-in-motion (WIM) traffic database.

\subsection{Design Features}

Rigid pavement design does not simply involve the determination of slab thickness but other features of the PCC pavement system have a significant contribution to the performance of the pavement and a such must be given due consideration in the structural design process. These components are collectively called Design Features and include such things as transverse joint design, joint spacing, base type, drainage design and shoulder type. These design features are grouped into the following (Hoerner et al. 2004):

i. Joint details

ii. Type of edge supports

iii. Base properties.

Many studies have shown that the careful selection of these design features based on the environment and traffic loading conditions to which a particular rigid pavement is exposed play a major role in the overall design of rigid pavement (Hoerner et al. 2004). Figure 5.1 shows how selecting the appropriate design features can extend the useful life of the pavement. 


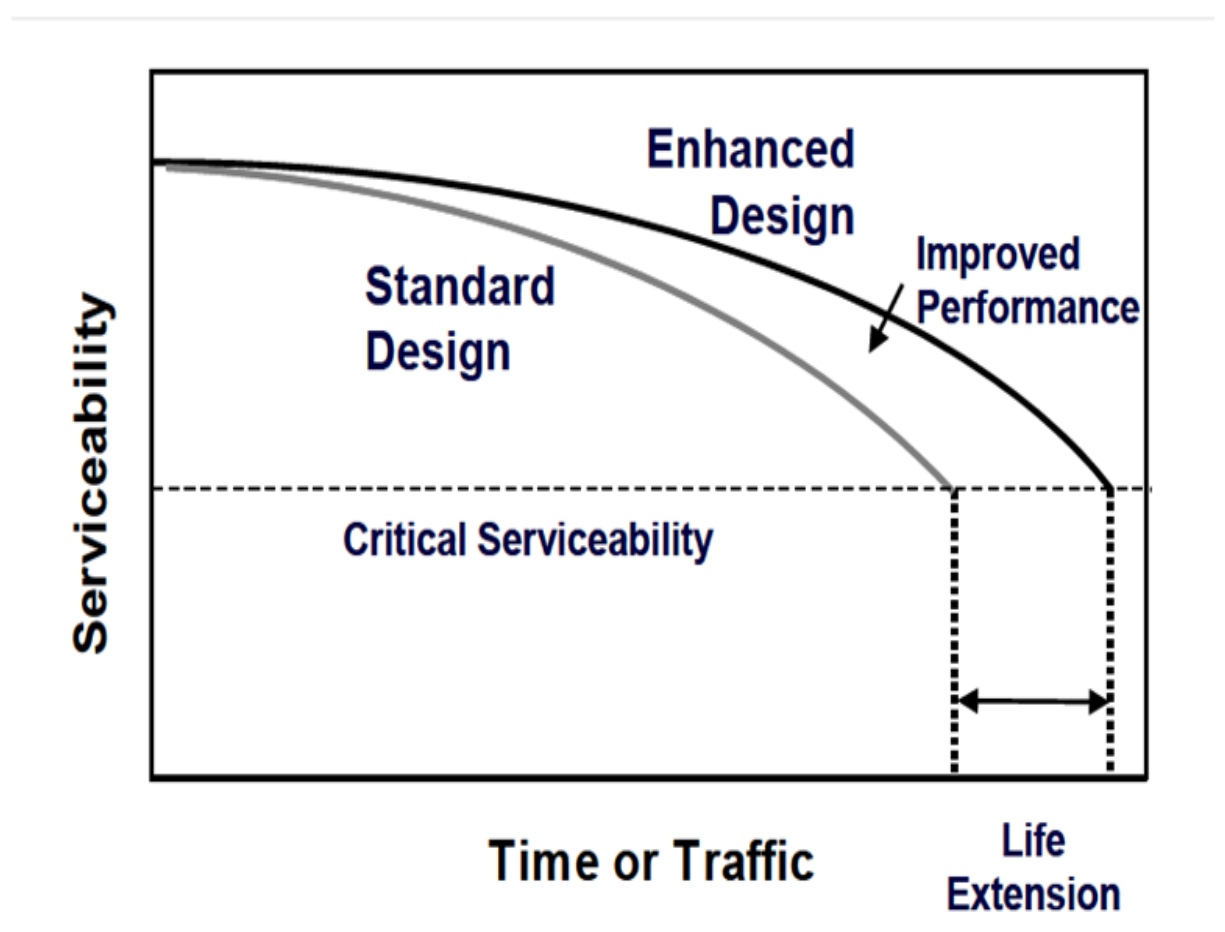

Figure 5.1: Benefits of design features in concrete pavements (Hoerner et al. 2004)

Even though design features have a positive effect on pavement performance, they however also increase the overall cost of the pavement structure. So the inclusion of any combination of design features in the pavement structure should be done on the basis of cost effectiveness rather than over-designing PCC pavement by incorporating multiple design features that are in essence playing identical functions within the pavement structure. According to Rodden (2010), design features like permeable bases are only considered to be cost-effective if they extend pavement service life between 8 and 15 years.

\subsection{Pavement Structure}

The MEPDG is not a tool for pavement design and so does not contain thickness as an output. It is however a tool of pavement analysis wherein a given pavement structure containing different thicknesses of PCC slab, stabilized bases and unbound granular layers are input into the software and then analysis using various performance models to ascertain how that particular pavement structure will perform during its design life. The 
design thickness can then be predicted by modifying design inputs and obtaining the best performance with an iterative procedure (Velasquez et al, 2009).

\subsection{MEPDG Performance Prediction Models for PCC}

Both the functional and structural performances of pavements are considered in the MEPDG. The functional performance deals with how well the pavement serves the user while the structural performance relates to the pavement's physical condition that would reduce its load carrying capabilities. The MEPDG considers three primary mechanistic performance models for JPCP, which are namely (ARA Inc 2004):

1. Faulting

2. Transverse/Longitudinal cracking

3. International Roughness Index (IRI)

\subsubsection{Joint Faulting}

Faulting is as a result of pumping under the slab which results in a difference in the elevation across a joint. It is a common feature of undoweled JCPC and provides an indication of the condition of the joint as well as that of the underlying pavement layers. The MEPDG model for predicting transverse joint faulting uses an incremental approach wherein a fault increment is determined for each month and the faulting during each month is determined as the sum of the faulting increments from all previous months during the life of the pavement (NCHRP 2004). This faulting increment is determined by the PCC slab upward deflection due to curling and warping. The curling and warping behavior is determined by the curl/warp effective temperature difference and the PCC coefficient of thermal expansion. These parameters are also believed to influence the predicted faulting (Guclu et al. 2009).The mechanistic model for joint faulting in the MEPDG is express as follows:

$$
\begin{aligned}
& \text { Faultm }=\sum_{i}^{m} \text { Faulti } \text { Equation } 5.1 \\
& \Delta \text { Faulti }=C 34^{*} \text { FAULT } \max i-\text { Faulti } 1^{2} * D E i
\end{aligned}
$$


FAULT max $i=$ FAULTMAX $0+C 7 * \sum_{j=1}^{m} D E j X * \log 1+C 5 * E R O D$

\author{
C6FAULTMAX $0=C 12 *$ dcurling $*\left[\log 1+C 5 * 5.0\right.$ EROD $* \log P 200 *$ Wetdays $\left.{ }^{C 6}\right]$ \\ $\mathrm{R}^{2}=0.71, \mathrm{SEE}=0.029, \mathrm{~N}=564$ \\ Where \\ Faultm $=$ mean joint faulting at the end of month $\mathrm{m}$. \\ $\delta$ Faulti $=$ Incremental change in mean transverse joint faulting in month $\mathrm{i}, \mathrm{j}$. \\ FAULTmaxi= Maximum mean transverse joint faulting for month i,m. \\ FAULTMAXo= Initial maximum mean transverse joint faulting \\ $\mathrm{EROD}=$ Base-subbase erodobility factor \\ $\mathrm{DE} i=$ Differential deformation energy accumulated during month $\mathrm{i}$ \\ $\Delta$ curling= Maximum mean monthly slab cover upward deflection of PCC \\ Ps $=$ Overburden on Subgrade, lbs \\ $\mathrm{P} 200=\%$ subgrade material passing the $\# 200$ sieve \\ WetDays $=$ Average annual \# of wet days $(>0.1$ in rainfall $)$ \\ $\mathrm{C} 1$ through $\mathrm{C} 8, \mathrm{C} 12$ and $\mathrm{C} 34$ are material calibration constants.
}

\title{
5.7.2. Cracking Model
}

Fatigue damage is considered the primary component of the cracking model in the MEPDG. Fatigue damage is defined as the ratio of the applied number of load applications to the allowable number of load applications. The equation of allowable number of load applications in the MEPDG includes the PCC modulus of rupture at age and the applied stress at the condition. Therefore the input design parameters that have an influence on the PCC strength and stress should also be influencing the predicted 
cracking in the MEPDG. The MEPDG considered both bottom-up and top-down modes of cracking for JCPC transverse cracking. The percentage of slabs with transverse cracks in a given traffic lane is used as the measure of transverse cracking and is predicted using the following model (Guclu et al. 2009):

$$
\begin{aligned}
& \begin{array}{l}
C R K=1 /(1+\sqrt[-1.68]{F D}) \text { Equation } 5.2 \\
\mathrm{R}^{2}=0.68, \mathrm{~N}=52 \text { and } \mathrm{SEE}=5.4 \% \\
\text { Where } \\
\mathrm{CRK}=\text { Predicted amount of bottom-up or top-down cracking } \\
\mathrm{FD}=\text { Calculated fatigue damage }
\end{array}
\end{aligned}
$$

The general expression for Fatigue Damage is given below;

$$
F D=\sum(n i, j, k, l, m, /(N i, j, k, l, m, n) \text { Equation 5-3 }
$$

Where

$\mathrm{Ni}, \mathrm{j}, \mathrm{k}, \mathrm{l}, \mathrm{m}=$ applied \# of load application at condition i,j,k,l,m,n.

$\mathrm{Ni}, \mathrm{j}, \mathrm{k}, \mathrm{l}, \mathrm{m}, \mathrm{n}=$ Allowable \# of load applications at condition $\mathrm{i}, \mathrm{j}, \mathrm{k}, \mathrm{l}, \mathrm{m}, \mathrm{n}$

The allowable number of load applications is determined using the following fatigue model:

$\log N i, j, k, l, m, n=C 1 * M R i /(\partial i,, k, l, m, n)+0.437$

Where

$\mathrm{Ni}, \mathrm{j}, \mathrm{k}, 1, \mathrm{~m}, \mathrm{n}=$ Allowable number of load applications at condition $\mathrm{i}, \mathrm{j}, \mathrm{k}, \mathrm{l}, \mathrm{m}, \mathrm{n}$

$\mathrm{MRi}=\mathrm{PCC}$ modulus of rupture at age $\mathrm{i}, \mathrm{psi}$

$$
\Delta \mathrm{i}, \mathrm{j}, \mathrm{k}, 1, \mathrm{~m}, \mathrm{n}=\text { Applied stress at condition } \mathrm{i}, \mathrm{j}, \mathrm{k}, 1, \mathrm{~m}, \mathrm{n} .
$$




\section{$\mathrm{C} 1 \& \mathrm{C} 2=$ Calibration constants}

\subsubsection{IRI/Smoothness}

The MEPDG procedure uses faulting and cracking to predict the smoothness of a rigid pavement structure at any given point in the pavement's life. So once both faulting and cracking has been predicted, the MEPDG then uses empirical relationships to determine the IRI from these two performance criteria. As a result the variables/design inputs that affects the IRI are mostly the same factors that affect significantly affect cracking and faulting. These variables are the presence of dowels, traffic volume, joint spacing, PCC thickness, climate zone and shoulder type. However, according to mechanistic model, subgrade type, base type and PCC strength have very little effect on the IRI (Kannekanti et al. 2006).

Users of highways value smoothness of the pavement as the most important pavement characteristics. The IRI model as with all the mechanistic models in the MEPDG were calibrated and validated using LTTP data. The final calibrated IRI model for JPCP is as follows:

$$
\begin{aligned}
& I R I=I R I 1+C 1 * C R K * S P A L L+C 3 * T F A U L T+C 4 * S F \text { Equation } 5.4 \\
& \mathrm{R}^{2}=0.60, \text { see }=27.3, \mathrm{~N}=183
\end{aligned}
$$

Where

$\mathrm{IRI}=$ Predicted IRI, in in $/ \mathrm{mi}$

IRI1= Initial smoothness

$\mathrm{CRK}=\%$ slabs with cracks

SPALL $=\%$ of joint with spalls

TFAULT $=$ Total joint Faulting

$S F=$ sitefactor $=A G E(1+0.5556 * F 1)(1+P 200) * 10$

Where

$$
\begin{aligned}
& \text { AGE }=\text { Pavement age }, y r \\
& F 1=\text { Freezing index, }{ }^{\circ} \text { f-day }
\end{aligned}
$$




\section{C1,C2,C3 \&C4= Calibration constant}

Various LTPP sites across the United States were used to calibrate the above models. Some states may not have sites that were used in the calibration process of these mechanistic models used in the MEPDG and as such it is incumbent upon the various states' department of transportation (DOTs) to calibrate these models using the existing pavement conditions and materials prevailing in their respective States (Von Quintus et al. 2009).

\subsection{Selection of Performance Criteria and Reliability Levels}

It is very important that if the MEPDG simulations of pavement performance should be use in determining the cost-effectiveness of pavement subsurface drainage features, the appropriate design criteria and reliability levels should be selected since both these parameters can greatly affect the performance and construction costs. For example selecting a low level of distress in conjunction with a high level of reliability may make it impossible or very costly to obtain an adequate design. As a result AASHTO recommended that both the design criteria and design reliability levels should be selected in balance with each other so as to arrive at a cost-effective and adequate design (NCHRP 2008).

\subsubsection{Performance Criteria for Rigid Pavements}

Performance criteria are used in pavement design to ensure that a given design will perform satisfactorily over its design life (ARA Inc 2004). For each trial design, the MEPDG software gives the designer the option of selecting critical limits or thresholds values upon which he/she can judge the adequacy of any given trial design. Comparing to the old AASHTO Design Guides, these performance criteria are similar to the initial and final serviceability indices. The selection of these design criteria is normally based on a highway agency's design philosophy based on its maintenance and rehabilitation policies. Some of the factors normally taken into consideration in the selection of appropriate design criteria are the pavement condition and its impact on safety, maintenance needs, 
ability to rehabilitate the pavement in that existing condition and the level of design reliability used (NHCRP 2008).

AASHTO has provided recommended values of design criteria for use in trial designs based on the functional classification of the highway pavement which are given in Table 5.2:

Table 5. 2:

AASHTO recommended performance criteria for rigid pavements

\begin{tabular}{|l|l|l|}
\hline \multicolumn{1}{|c|}{$\begin{array}{c}\text { Performance } \\
\text { criteria }\end{array}$} & \multicolumn{1}{c|}{$\begin{array}{c}\text { Functional } \\
\text { classification }\end{array}$} & $\begin{array}{c}\text { Maximum value } \\
\text { at the end of } \\
\text { design life }\end{array}$ \\
\hline Mean Joint & Interstate & $0.15 \mathrm{in}$ \\
Faulting & Primary & $0.20 \mathrm{in}$ \\
Secondary & $0.25 \mathrm{in}$ \\
\hline Percent & Interstate & $10 \%$ \\
transverse slab & Primary & $15 \%$ \\
cracking & Secondary & $20 \%$ \\
\hline IRI (smoothness) & Interstate & $160 \mathrm{in} . / \mathrm{mi}$ \\
& Primary & $200 \mathrm{in} . / \mathrm{mi}$ \\
& Secondary & $200 \mathrm{in} / \mathrm{mi}$ \\
\hline
\end{tabular}

\subsubsection{Design Reliability}

Reliability as it pertains to pavement design is defined by AASHTO (1993) as "The reliability of the pavement design process is the probability that a pavement section designed using the process will perform satisfactorily over the traffic and environmental conditions for the design period." In other words, the design reliability is the probability that the predicted distress will be less than the critical levels shown in Table 5.2 at the end of the pavement's design life. The selection of design reliability for any given project will therefore have to be based on the general consequence of reaching those critical levels earlier than the pavement's design life (NCHRP 2008). Each distress type can have a unique design reliability assigned to it during the trial design but AASHTO recommended that the same design reliability be applied for all the performance criteria used in the trial design. The key factor that influences the selection of design reliability is the risk of a particular project to failure, which carries with it the implication that the 
more important the project is in terms of consequences of failure, the higher the design reliability. For instance one would expect an interstate highway to have a higher design reliability that a secondary arterial road. In this vein some state highway agencies have typically used the Average Annual Daily Truck Traffic (AADTT) as the sole parameter for selecting design reliability (NCHRP 2008). AASHTO's recommended design reliability levels for the various functional classes of highways are shown in Table 5.3:

Table 5.3

\section{AASHTO recommended reliability level}

\begin{tabular}{|l|c|}
\hline \multicolumn{1}{|c|}{$\begin{array}{c}\text { Functional } \\
\text { classification }\end{array}$} & $\begin{array}{c}\text { Level of reliability } \\
(\%)\end{array}$ \\
\hline Interstate & $90-95$ \\
Principal Arterials & $90-85$ \\
Collectors & $80-75$ \\
Local & $75-70$ \\
\hline
\end{tabular}

Currently many state highway agencies are in the process of calibrating the MEPDG software in order to better reflect local site conditions and some have use design reliability levels that are quite different from those recommended in Table 5.3. A local calibration research effort by the Center for Transportation Research and Education (CTRE) at Iowa State University has shown that the reliability levels recommended by AASHTO are too high and that their use in the design analysis may lead to an overestimation of the distresses and hence higher pavement thicknesses and higher initial construction costs. The CTRE therefore recommended the use of a reliability level of $50 \%$ as opposed to the $90 \%$ recommended by AASHTO for Iowa conditions (Coree 2005). This further emphasizes the need for local calibration of the MEPDG software in order to get appropriate reliability levels that do match with their local pavement design settings. For this research project, three reliability levels were used to represent the three 
levels of truck traffic used for the MEPDG simulations namely 50\%, 75\% and 90\% for low trafficked, medium trafficked and for heavy trafficked pavements respectively.

\subsection{Procedure for Implementing MEPDG Sensitivity Analysis}

The MEPDG Software was used in this dissertation to conduct computer simulations to predict the performance of pavement sections containing treated permeable bases and unbound granular bases. The object of these computer simulations is to perform a sensitivity analysis on the effect of permeable bases on the predicted pavement performance and also to determine the differences in performance between pavement sections containing these base types. The pavement performance simulation was conducted under comparative climate; subgrade soil and traffic conditions in order to determine appropriate conditions for which the use of stabilized permeable bases may provide reduced life cycle costs. As was highlighted earlier, the MEPDG as a tool of pavement analysis does not produce a thickness design as was the case with AASHTO Design Guides but rather analyzes a trial design to see if it meets specified structural and functional criteria. The NHRCP (2004) put forward a design framework for using the MEPDG software which is shown in Fig 5.2 and can be summarized as follows (Taamneh 2009):

- Select a trial design for specific site conditions of traffic, subgrade support, material properties and climatic conditions.

- Define pavement performance criteria at the end of the design period

- Choose a reliability factor for each of the distress considered in the analysis

- Computation of monthly traffic volumes and seasonal climate conditions

- Modify materials properties with respect to environmental conditions

- Compute structural responses for each type of axle and loads acting on the pavement during its design life

- Calculate the predicted life of the pavement with respect to each of the distress considered in the analysis 
- Evaluate the predicted performance of the trial design as against the specified performance criteria that were set earlier in the analysis.

- Modify the trial design and other material properties if the predicted performance does not measure to the performance that was specified and repeat the entire process until a suitable design is reached that meet performance expectations. 


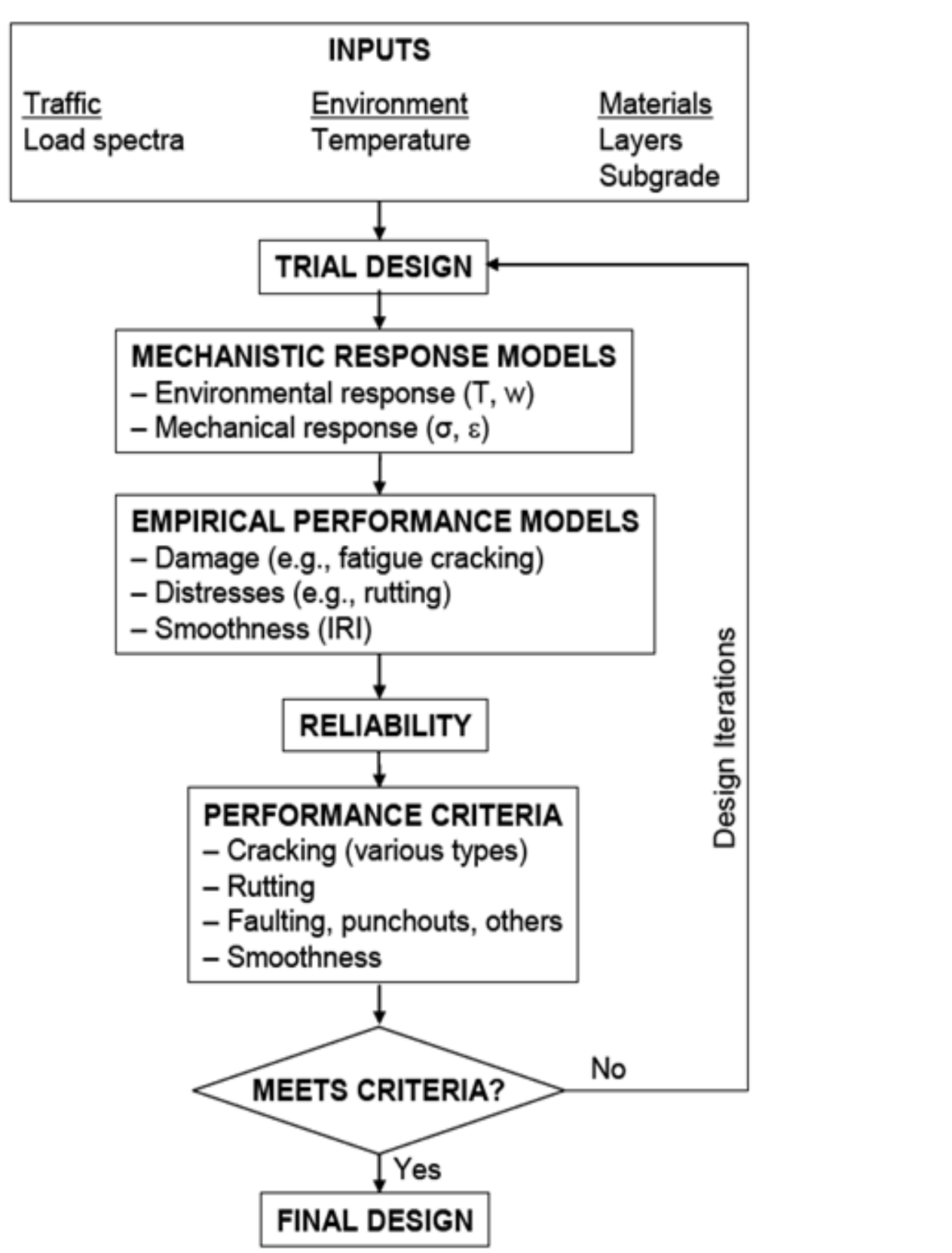

Figure 5.2: Mechanistic-Empirical Design Framework (ARA Inc 2004)

1. The pavement performance simulations were done for the following four base courses:

2. With unbound open-graded base courses(unbound permeable bases)

3. With Asphalt Treated Permeable Bases (ATPB)

4. With Cement Treated Permeable Bases (CTPB) 
As was discussed in the review of the literature, it is appropriate that subsurface drainage features are included in the design only when site conditions warrant their inclusion. As a result therefore, a prime target of this pavement performance simulations exercise was geared towards determining what conditions of traffic, climate, subgrade, design features require the use of open-graded base courses. As a result, a full factorial experimental design containing different combinations of traffic, climate, pavement structure, design features was employed in the pavement simulation in order to correctly develop a sound basis of the relative merits of using stabilized permeable bases.

The following section discusses some of the variables used in the full factorial experimental design:

- $\quad$ Climate: The Long Term Pavement Performance (LTPP) program sponsored by the FHWA has identified four distinct climatic regions in the U.S. These regions are (ARA Inc, 2004):

i. Wet No-Freeze

ii. Wet Freeze

iii. Dry Freeze

iv. Dry No-Freeze

The LTTP defined Wet/Dry regions in terms of annual precipitation of 20 inches per year i.e. a region with a precipitation of 20 inches per year or greater is a wet region; otherwise it is a dry region. The freeze/No-freeze regions are defined in terms of the Freezing Index (FI) with a freeze region having an FI of $83.8^{\circ} \mathrm{c}$-days or greater (ARA Inc 2004). It should be quite obvious that subsurface drainage may not be a critical design need for the Dry/Freeze and Dry/No-freeze climatic regions. Nevertheless, pavement performance simulations were conducted for all four climatic regions highlighted above in order to test the predictive accuracy of the MEPDG software. The states that were selected to represent each of these climatic regions are as follows:

\section{- Wet No-Freeze (Florida) \\ $\circ \quad$ Wet Freeze (Michigan)}




\section{$\circ \quad$ Dry Freeze (Texas) \\ ○ Dry No-Freeze (California)}

While it is understandable that the four States selected may have other climactic regions besides those designated above, only climate stations within the climatic regions outlined above were used in the MEPDG simulations. Each one of the four States has a different pavement design philosophy. However, since the objective of the pavement performance simulations was geared towards identifying a range of traffic and climatic conditions under which it is cost-effective to use permeable bases, a constant baseline material property was used for all the four climatic regions. In doing so therefore it was possible to capture the effect on the predicted pavement performance that can be directly attributed only to differences in permeable bases and not due to the differences in pavement design philosophies of the different states. As a result of this a summary of baseline values for pavement used in the MEPDG simulations of pavement performance is given in Table 5.4 
Table 5. 4

\section{A summary of baseline values used in the MEPDG Performance Simulations}

\begin{tabular}{|c|c|}
\hline Design life & $30 \mathrm{yrs}$ \\
\hline Cement & 660 lbs type 1 \\
\hline $\begin{array}{c}\text { Concrete flexural } \\
\text { strength }\end{array}$ & 650 psi \\
\hline Curing & Curing compound \\
\hline shoulder & Tied \\
\hline JPCP dowel diameter & 1.5 inches \\
\hline Pavement opening & Spring \\
\hline Base layers & $\begin{array}{l}\text { 4" ATPB/CTPB } \\
\text { 6" granular base } \\
\text { 6" chemically } \\
\text { stabilized base }\end{array}$ \\
\hline Subgrade & $5000 \mathrm{psi}$ \\
\hline Depth to ground water & $12^{\prime}$ \\
\hline $\begin{array}{c}\text { 28-day PCC } \\
\text { compressive strength }\end{array}$ & $4200 \mathrm{psi}$ \\
\hline Water/cement ratio & 0.48 \\
\hline
\end{tabular}

- Traffic: The level and type of truck traffic expected on any given highway facility is one of the critical factor in deciding the use of subsurface drainage systems in pavements. One of the three requirements for pumping to take place in JPCP is the application of heavy wheel loads during the time the pavement layers are subjected to high positive porewater pressures (FHWA 2002). As a result various truck traffic levels ranging from heavily-trafficked urban concrete pavements to moderatelytrafficked rural concrete pavements were used in the MEPDG 
performance simulations in order to determine minimum threshold of truck level for which the use of treated permeable bases are cost-effective. According to data from the National Highway System (NHS) $40 \%$ of interstate and arterial road sites had less than 200 trucks on average per day. This represent a light truck trafficked based upon the truck traffic volume classification of Table 5.1 (Alam et al. 2007). A breakdown of current and projected truck traffic of the NHS bases upon Table 5-6 is given below:

i. $\quad 82 \%$ of NHS miles in the year 2002 are less than 5000 AADTT.

ii. $66 \%$ of NHS miles in 2035 will be less than 5000 AADTT.

iii. Only $6.44 \%$ of NHS miles in 2002 experienced heavy truck traffic

iv. $\quad 20 \%$ of NHS miles in 2035 will experienced heavy truck traffic.

In the light of this current and projected national truck traffic, three truck traffic volumes representing low (AADTT $=500)$, moderate $(\mathrm{AADTT}=5000)$ and heavy trafficked $(\mathrm{AADTT}=10000)$ pavement sections were used in the MEPDG performance simulations.

Table 5. 5:

NHS truck traffic classification (Alam et al, 2007)

\begin{tabular}{|c|c|}
\hline Truck traffic classification & Truck traffic level (AADTT) \\
\hline Very Low & $0-480$ \\
\hline Low & $480-960$ \\
\hline Medium & $960-2880$ \\
\hline Medium High & $2880-5760$ \\
\hline High & $5760-11,520$ \\
\hline Very High & $>>11,520$ \\
\hline
\end{tabular}


Traffic data are mostly obtained from weigh-in-motion (WIM) stations that are dispersed across the various states in both rural and urban locations. The WIM stations record not only the traffic volume but also the different axle types and distributions of the various vehicle classes using the pavement facility. According to Kannekami et al. (2006) urban locations in this context are defined as freeway segments that have more class 5 trucks than class 9 trucks, whereas rural locations are those with more class 9 trucks. AASHTO (2009) defined class 5 trucks as trucks that are typically use for short hauls and consist of short trailers whereas class 9 trucks have longer trailers and are typically use for long hauls. Both these classes of trucks will produce different axle load distributions and since axle load distributions played a dominant role in pavement performance, so categorizing the traffic inputs in this manner will capture the desired effects. However, according to an MEPDG calibration study conducted by the Wisconsin Department of Transportation (WSDOT), the MEPDG Design Guide is moderately sensitive to axle load spectrum for typical WSDOT pavement designs. The study concluded that one type of axle load spectrum can represent the load characteristics for all WSDOT MEPDG analyses (Li et al. 2009). Therefore based on this WSDOT studies only the urban load spectrum which has more class 9 trucks was used for the entire MEPDG sensitivity analyses.

Default values were used for the following traffic inputs factors: Hourly truck distribution factor, vehicle class distribution factor and monthly adjustment factors. In order to simplify the performance simulation, a zero traffic growth was assumed. According to Kannekami et al. (2006) such an assumption has little effect of the result since Miner's hypothesis upon which these mechanistic models were based assumed a linear damage rate with traffic repetition. The sole aim of repeating the performance simulation for three traffic levels data was to assess the impact that bound/unbound drainage layer have on the predicted service life of the pavement under different traffic levels and axle load distributions since the MEPDG considered the interaction of environment, materials and traffic.

- $\quad$ Pavement Design Structures and Alternative Design Features: There is a plethora of pavement design categories described in the literature and with 
the impressive list of alternative design features that is available, developing an appropriate pavement section for use in the pavement performance simulations was a daunting task. This was also compounded by the fact that each highway agency has its own standard design crosssection. However, after reviewing the various JPCP sections contain in the LTPP online database, the following seven pavement sections were selected as being representative of JPCP sections across the United States:
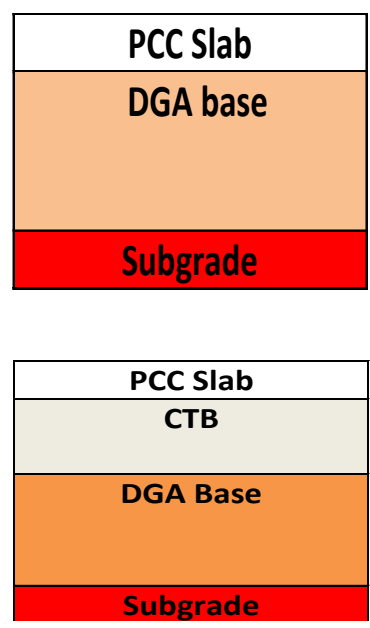
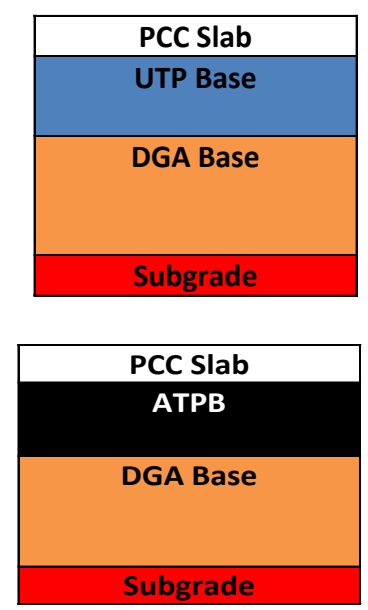
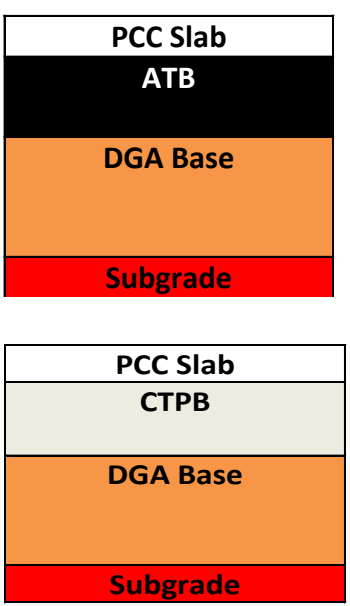

Figure 5.3: Pavement sections containing treated and untreated Permeable bases

\section{Legend:}

PCC - Portland cement Concrete Slab

DGA - Dense Graded Aggregate Base

UTP - Untreated Permeable Base

ATB - $\quad$ Asphalt Treated Base

CTB - $\quad$ Cement Treated Base

ATPB - $\quad$ Asphalt Treated Permeable Base

CTPB - $\quad$ Cement Treated Permeable Base

PS1: pavement section 1 consists of a PCC slab, DGA and a subgrade. PS2: pavement section 2 consists of a PCC slab,UTB, DGA base and a subgrade. 
PS3: pavement section 3 consists of a PCC slab, ATPB, DGA and a subgrade.

PS4: pavement section 4 consists of a PCC slab, CTPB, DGA and a subgrade.

PS5: pavement section 5 consists of a PCC slab,ATB, DGA and a subgrade.

PS6: pavement section 6 consists of a PCC slab,CTB, DGA and a subgrade.

According to the FHWA (2002) dowels represent the cheapest solution to the pumping problem affecting JPCP. As a result the FHWA is encouraging state highway agencies to incorporate dowels within their design and construction of concrete pavements. A field study conducted Schmitt et al. (2010) for the Wisconsin Department of Transportation (WisDOT), noted that there is very little difference in performance between pavements having both dowels and permeable bases to those having either a dowel or permeable base. As result therefore, the MEPDG simulations of pavement performance will be conducted with these two scenarios consisting of pavement sections outlined in Fig 5-3 with and without dowels bars. This is aim at testing the predictive accuracy of the MEPDG software and how its results compare to field results.

In order to facilitate performance and cost comparisons, standard pavement section was defined from the list of six pavements sections in Fig 5-3. Based on research work done by Hoerner et al. (2004), the following is the standard pavement cross-section used for this research project:

\footnotetext{
* 10" PCC slab thickness

* 6" Dense graded aggregate base

* An CH subgrade

* No dowels

* Concrete shoulders
} 


\subsection{Full Factorial Experimental Design for the Sensitivity Analysis}

A full factorial experimental program was designed to perform several runs of the MEPDG software in order to determine the performance of JPCP on various subsurface drainage features. In order to reduce the number of computational runs to a manageable size, not all the combinations mentioned in section 5.6 were used. However, since this research was focused on subsurface drainage features, the following three subsurface design features were utilized in the factorial design:

Open-Graded Aggregate (unbound)

Base plus underdrain system

- 4-in open-graded, nonstabilized granular drainage layer.

- 6-in dense-graded, crushed aggregate base layer.

Cement-Treated Permeable Base (CTPB)

plus underdrain system

- 4-in CTPB layer.

-6-in dense-graded, crushed aggregate base layer.

Asphalt-Treated Permeable Base (ATPB)

plus underdrain system

- 4-in ATPB layer.

-6-in dense-graded, crushed aggregate base layer.

CTPB/ATPB

Directly on Subgrade

Cement-Treated Permeable Base

- Eliminate 6-in dense-graded aggregate base course.

- Add 6-in of CTPB. 
Asphalt -Treated Permeable Base (ATPB)

- Eliminate 6-in dense-graded aggregate base course.

- Add 6-in of ATPB

In summary, the variables and factor levels in the full factorial design for the pavement prediction portion of the MEPDG simulations are as follows:

- $\quad$ Traffic levels: 3

- $\quad$ Axle load spectra: 1

- $\quad$ Base type: 6

- $\quad$ Climate regions: 4

- $\quad$ Dowels: 1 , with dowels.

- $\quad$ Joint spacing: 1

- $\quad$ Subgrade: 1-high plasticity clay.

- $\quad$ PCC flexural strength at 28 days:700 psi

- $\quad$ Shoulder type: 1

- $\quad$ Portland Cement Concrete (PCC) thickness: 8, 10, and 12 in.(3)

This factorial resulted in 216 runs. These simulations where run in batch mode wherein all the MEPDG iterations were run for one climatic region at a time. As far as possible, the inputs for all the variables used in these computer simulation runs were chosen to represent the practices and conditions of the climatic regions where the pavements are located. In cases where it was not possible to obtain representative inputs, default values found in the software were used to fill in the missing inputs.

There are several documented cases of rigid pavement sections wherein the bound permeable layers have been placed directly on the subgrade. This particular type of pavement section could not be simulated on the MEPDG since the climatic model within the MEPDG software can only do the analysis when the last two pavement bottom layers are granular. Attempts to evaluate the pavement section shown in Fig 5.4 was unsuccessful since the Enhanced Integrated Climatic Model (EICM) which is an integral 
part of the MEPDG design software could only run the climatic model on pavement section wherein the last two underlying pavement layers should be made up of granular materials. So when a pavement structure containing a stabilized permeable base placed directly on the subgrade is analyzed in the MEPDG software, the following "error" message shown in Fig 5.5 appeared. However, the MEPDG has an inbuilt capability of circumventing this problem by dividing the subgrade into basically two granular layers: an embankment layer and a "natural" or unprepared subgrade. The reason for this according to Quintero (2007) is to keep the stability of the program within a minimum required thickness.

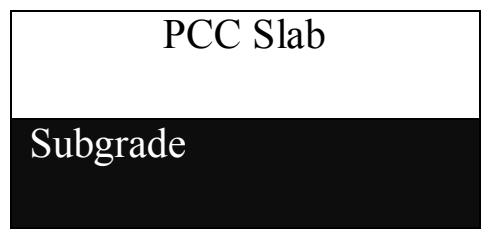

Figure 5.4: JPCP with bound permeable base place directly on the subgrade.

In order to determine how sensitive the MEPDG is to subsurface drainage variables like type of permeable base, a constant metric was used across the MEPDG simulations to compare the results. Even though some conclusions can be drawn with regards to the effects of subsurface drainage features from results of the performance criterion for each pavement structure considered in the sensitivity analyses, it was deemed not sufficient to make a life cycle cost analysis that will show the relative cost effectiveness of using permeable bases in rigid pavement. It was therefore decided that all of the comparison of the various pavement sections should be done on a common metric that was easily recognizable to a pavement design engineer and can also be used in life cycle cost analysis. One such variable that is easily recognizable to the pavement engineering community is the slab thickness. The thickness of the concrete slab is perhaps considered to be the most significant variable in determining the initial cost of rigid pavements and the primary design variable affecting slab thickness is traffic, notably truck traffic. As has been stated in earlier sections, the MEPDG does not provide as an output the thickness of the pavement as is the case with the AASHTO Design Guides. It however provides an iterative process whereby a given pavement structure with a set of traffic, climatic and 
material properties is analyzed to determine if the pavement structure is adequate for those set of input design conditions. If the pavement structure under analysis is found to be inadequate, the concrete slab thickness is then adjusted accordingly until a suitable slab thickness which satisfies the set performance criteria is reached.

Therefore a part of the sensitivity analysis was geared towards investigating the sensitivity of various subsurface drainage variables on the required pavement thickness. The iteration for this portion of the simulation began with a representative JPCP pavement section for each climatic region for a given AADTT value. The PCC thickness was varied incrementally by one-half of an inch until the minimum thickness that satisfies the all three performance criteria was reached. Once a pavement section has been found to be adequate for a specific AADTT, subsurface drainage design features were then varied and the pavement section subsequently reanalyzed to determine if in its new reconfigure state it meets design adequacy. If this subsequent analysis showed that pavement adequacy was increased, then the pavement thickness was decreased until a suitable minimum thickness was reached that make the pavement section just adequate for the given set of traffic and climatic conditions. If however the subsequent analysis resulted in a decreased pavement adequacy, then an increase in the thickness of the pavement was made. This technique provided a practical way of quantifying the effects of subsurface drainage features on pavement thickness which can be use in subsequent life cycle cost analysis. 


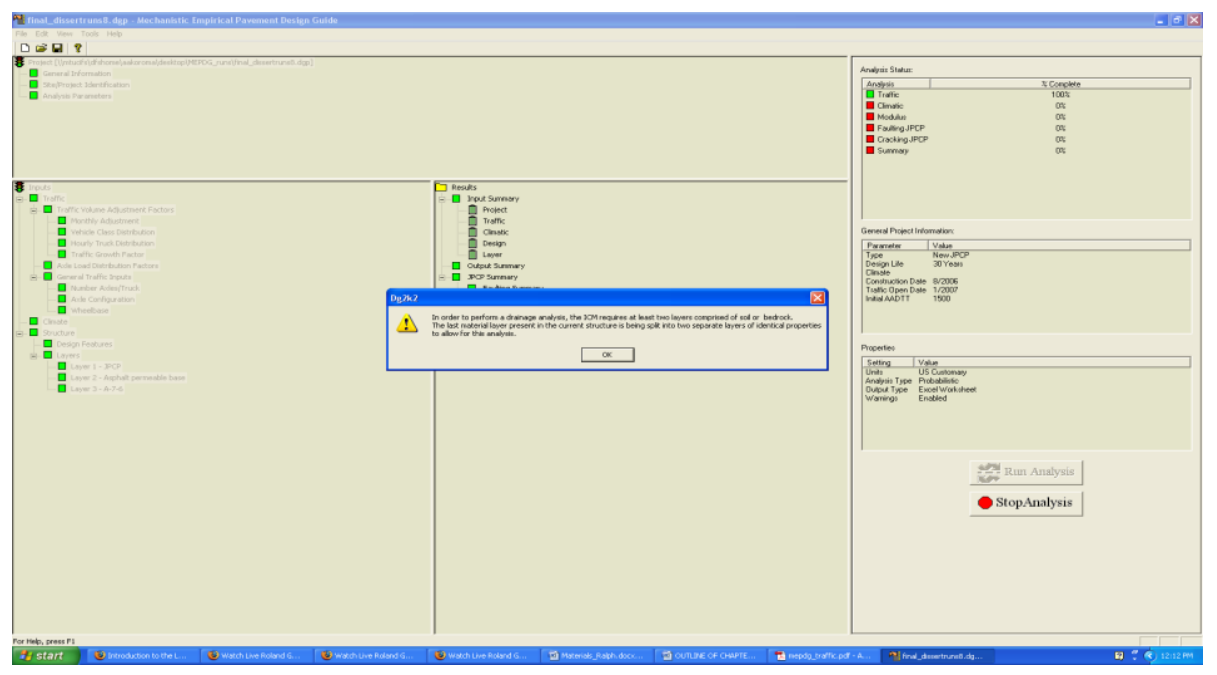

Fig 5.5 "Error" message for drainage analysis in the MEPDG.

\subsection{Results and Analysis}

The 216 combinations developed in the previous Section were run on the MEPDG software in batch mode. In running the simulations under the batch mode the cracking and faulting models need to be run separately. The sensitivity analysis was completed using a version 1.000 of the MEPDG Design Software. The default failure criteria established by the MEPDG was used in each analysis. These failure criteria were summarized n Table 5.4.

For this research project, the material properties for the entire pavement's layers used for the MEPDG simulations are the default values found in the software and summarized in Tables 5.6 through to Table 5.9: 
Table 5.6

\section{Portland cement Concrete Properties}

\begin{tabular}{|l|}
\hline \multicolumn{1}{|c|}{ General properties } \\
\hline Unit Weight (Pcf) \\
150 \\
\hline Poisson's ratio \\
0.20 \\
\hline Thermal Properties \\
\hline Coefficient of thermal expansion (perF0*10^(-6)) \\
5.5 \\
\hline Thermal conductivity (BTU/hr-Ft-F0) \\
1.25 \\
\hline Heat Capacity (BTU/lb-F0) \\
0.28 \\
\hline Mix properties \\
\hline Cement type Type 1 \\
\hline Cementitious material (pcy) \\
600 \\
\hline Water/Cement ratio \\
0.42 \\
\hline Aggregate type \\
Dolomite \\
\hline Ultimate reversible shrinkage \\
30 \\
\hline Time to develop $50 \%$ ultimate shrinkage (days) \\
35 \\
\hline Strength properties \\
\hline $28-$ day PCC modulus of rupture (psi) \\
690 \\
\hline
\end{tabular}


Table 5. 7

Granular aggregate base properties

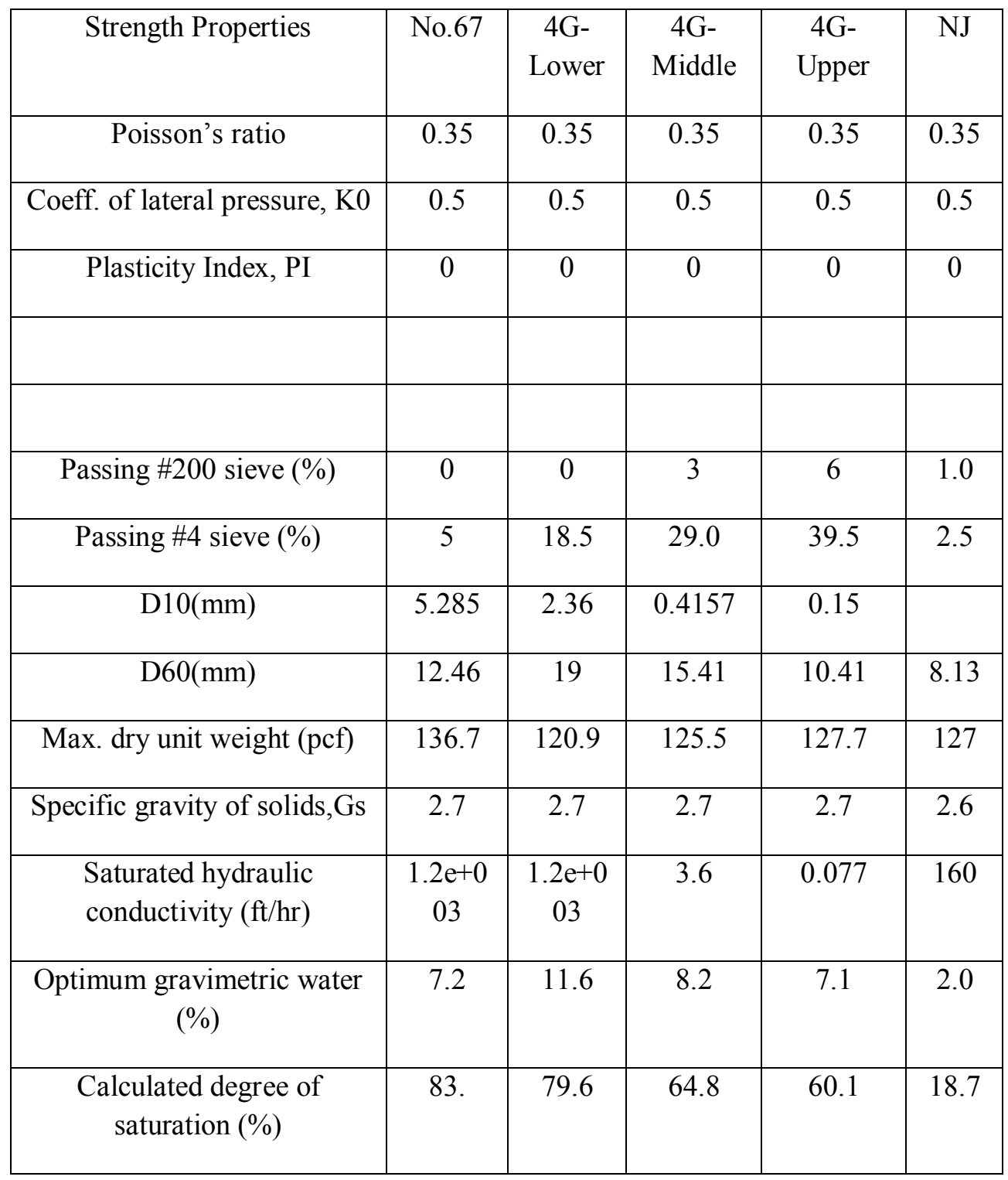


Table 5. 8

Asphalt Treated Permeable Base Properties

\begin{tabular}{|c|c|}
\hline \multicolumn{2}{|l|}{ GENERAL PROPERTIES } \\
\hline Reference temperature $(0 \mathrm{~F})$ & 70 \\
\hline Poisson's ratio & 0.35 \\
\hline \multicolumn{2}{|l|}{ Volumetrics } \\
\hline Effective binder content $(\%)$ & 3.0 \\
\hline Air Voids (\%) & 20 \\
\hline Total unit weight (pcf) & 120 \\
\hline \multicolumn{2}{|l|}{ Gradation } \\
\hline Cumulative $\%$ Retained $3 / 4$ inch sieve & 23 \\
\hline Cumulative $\%$ Retained $3 / 8$ inch sieve & 46 \\
\hline Cumulative \% Retained \#4 sieve & 60 \\
\hline$\%$ Passing \#200 sieve & 0 \\
\hline \multicolumn{2}{|l|}{ Thermal properties } \\
\hline Thermal conductivity asphalt (BTU/hr-ft-F0) & 0.67 \\
\hline Heat capacity asphalt (BTU/lb-F0) & 0.23 \\
\hline $\begin{array}{c}\text { Binder grade } \\
\text { PG 58-28 }\end{array}$ & \\
\hline
\end{tabular}


Table 5. 9:

Subgrade Material Properties

\begin{tabular}{|c|c|c|}
\hline AASHTO soil classification & A-2-4 & A-7-6 \\
\hline Poisson's ratio & 0.35 & 0.35 \\
\hline Coeff. of lateral pressure, K0 & 0.5 & 0.5 \\
\hline Resilient Modulus (psi) & 10000 & 5000 \\
\hline Plasticity Index, PI & 22 & \\
\hline Passing \#200 sieve (\%) & 8.6 & 96.4 \\
\hline Passing \#4 sieve (\%) & 54.3 & 100 \\
\hline D10 (mm) & 0.0112 & 0.0023 \\
\hline D60 (mm) & 0.1240 & 0.1024 \\
\hline Max. dry unit weight (psi) & 110 & 123 \\
\hline Specific gravity of solids, Gs & 2.7 & 2.65 \\
\hline Saturated hydraulic conductivity (ft/hr) & 0.138 & 0.0024 \\
\hline Optimum gravimetric water content (\%) & 6.5 & 9.3 \\
\hline Calculated degree of saturation (\%) & 87.5 & 92.3 \\
\hline
\end{tabular}

\subsubsection{Sensitivity of Pavement performance with Hydraulic Conductivity}

Since the hydraulic conductivity of the permeable material is an important design criterion in choosing appropriate subbase material for rigid pavement, a first step was to test the capabilities of MEPDG Design Guide to determine how sensitive pavement performance to the hydraulic conductivity value of the subbase/base layers. The FHWA recommended a minimum hydraulic conductivity value of $1000 \mathrm{ft} /$ day but analysis of pavement subsurface drainage using DRIP 2.0 microcomputer program have shown that 
hydraulic conductivity values in excess of $1000 \mathrm{ft} /$ day have no meaningful effect on the „time-to-drain' which is the criterion by which drainage efficiency is been measured. So the question always remain as to what effect on pavement performance does providing rigid pavements with permeable bases with very high coefficient of hydraulic conductivity?

In order to answer such a design question, MEPDG simulations of pavement performance was carried out on the following factorial:

i. Three base modulus values starting from a low of $10,000 \mathrm{psi}$, a medium value of $15,000 \mathrm{psi}$ and a high value of 20,000 psi for the permeable base material.

ii. One climatic region of Wet-freeze (WF).

iii. Three hydraulic conductivity values starting from a low of $500 \mathrm{ft} / \mathrm{day}$, a medium value of $1000 \mathrm{ft} /$ day and a high value of $5000 \mathrm{ft} /$ day.

iv. The pavement structure for this part of the simulation consists of a 10 inches PCC slab, a six inches granular base layer and A7-6 subgrade. A medium traffic level of 5000 AADTT and a 30 year design life were used for all the simulations.

This produced a total of 18 MEPDG runs. All other inputs parameters were held constant for these simulations. The results of the simulations are shown in Table 5.10. 
Table 5. 10

Sensitivity Analysis of Pavement Performance with K

\begin{tabular}{|c|c|c|}
\hline $\begin{array}{c}\text { Coefficient of } \\
\text { hydraulic conductivity }\end{array}$ & $\begin{array}{c}\text { Permeable base } \\
\text { modulus }\end{array}$ & $\begin{array}{c}\text { Faulting at the end } \\
\text { of design life }\end{array}$ \\
\hline Low K & $10 \mathrm{ksi}$ & $0.181^{\prime \prime}$ \\
$15 \mathrm{ksi}$ & $0.130^{\prime \prime}$ \\
$20 \mathrm{ksi}$ & 0.073 ” \\
\hline Middle K & $10 \mathrm{ksi}$ & 0.180 \\
& $15 \mathrm{ksi}$ & 0.129 \\
& $20 \mathrm{ksi}$ & 0.073 \\
& $10 \mathrm{ksi}$ & 0.179 \\
\hline Upper K & $15 \mathrm{ksi}$ & 0.129 \\
& $20 \mathrm{ksi}$ & 0.071 \\
\hline
\end{tabular}

It is quite apparent from the Table 5.10 that the predicted faulting is not sensitive to the coefficient of hydraulic conductivity of the base. Pavement sections with identical design features and site conditions but with different hydraulic conductivity values practically behave the same way in faulting. The only difference in performance that was noticeable between the two sections was when the resilient modulus values of the permeable base was altered but this can rightly be attributed to modulus change rather than due to changes in hydraulic conductivity of the permeable base. This further underlines the reason for the improved predicted performance of pavements containing treated permeable bases may not be due to their high coefficient of hydraulic conductivity values but rather due to their high resilient modulus of the base/subbase layer.

On the basis of these results therefore and the analysis of drainage efficiency of different permeable bases in chapter four, there is very little justification for the use of permeable bases with very high $\mathrm{K}$ values. One can make the argument therefore that if the only 
observed difference in predicted performance between two similar pavement sections is due only to difference in resilient modulus of the permeable bases and not due to differences in $\mathrm{K}$ value, then current pavement design practice of using treated permeable base may not be cost effective. However, in order to avoid such a hasty conclusion, it was considered appropriate to conduct a set of MEPDG simulation runs to determine the influence which the different types of permeable base have on the thickness design under identical conditions of traffic, climate and subgrade.

\subsubsection{Sensitivity Analysis of Permeable Bases to the Required Slab Thickness}

The PCC slab thickness is the critical design feature and also represents the most costly design component of rigid pavement. As was discussed in the literature review of this dissertation, the AASHTO Design Guides did provide as an output the thickness of a given rigid pavement section for a specific site condition of traffic, climate and subgrade. The MEPDG on the other hand does not produced thickness as an output but follows an iterative process to determine/predict the adequacy of a given pavement section under specific site condition of traffic, climate and subgrade. Pavement adequacy in this case is defined as the minimum slab thickness to satisfy a given set of performance criteria at a given reliability. Therefore, the objective for these series of MEPDG simulations was to test the capabilities of the MEPDG software to determine the adequacy of pavement sections having different permeable base types under varying site conditions. In this way the capabilities of the MEPDG to determine the adequacy of pavement sections containing different permeable bases under varying site conditions can be assessed. In this way one can determine the effect on PCC slab thickness associated with the use of different permeable bases.

Although many highway agencies do not considered the drainage layer as a structural layer due to its inherent weakness, the use of treated permeable bases have dispel such a notion and as result some highway agencies are now considering it as a structural layer (Forsyth 94). The prevailing design philosophy for concrete pavements is normally based on the notion that a thicker slab section is the perfect antidote for all the perceived design 
vulnerabilities for which a given concrete section can be exposed. As a result many highway agencies pay very little attention to the underlying layers but instead just focus on the concrete slab. This is understandably so since the mechanism of load transfer is completely different from that of asphalt pavement wherein the underlying pavement layers are designed to carry a significant portion of the applied traffic load. In concrete pavements however the slab is normally design to carry the entirety of the applied traffic load and the underlying pavement layers are design to merely provide uniform support for construction of the concrete slab and occasionally for drainage (Yoder et al. 1972). However, with recent research pointing to the importance of the underlying granular layers underneath rigid pavements in improving the performance of concrete pavement sections, more attention is now being given to these underlying pavement granular layers. Even though the quality of the materials used in the layers may be of lower quality in comparison to those use in flexible pavements, many research efforts are now been directed to find ways of designing appropriate and cost-effective subbase materials for use in concrete pavements.

With the structural improvement to the concrete pavement section that comes from the inclusion of treated permeable bases, some believe that this may lead to savings in slab thickness. There is little doubt that treated permeable base layers like ATPB and CTPB provided some structural contribution to the pavement system and as such many believed that their inclusion in the structural design may allow for a reduction in the concrete slab thickness by one-half of an inch under certain circumstances (MnDOT Pavement Manual, 2007). With the capabilities of a design software like the MEPDG that can predict the performance of a pavement section over its service life under various conditions of traffic, climate and material properties site, such a claim can be examined to very good effect. This is certainly not a hypothetical case but one that can be use to good measure in order to reduce the overtly conservatism that has characterized the design of concrete pavements and in the process design very cost-effective pavement sections that can still provide the desired performance. A set of MEPDG simulations were therefore carried out to determine how sensitive the required slab thickness for a given pavement section is 
to changes in the type of drainage layer included in the design. In order to do this, the following variables were included in the factorial design:

i. Three truck traffic levels i.e. low, medium and high traffic levels.

ii. Two climatic regions namely Wet/Freeze and Dry/No Freeze.

iii. One subgrade conditions i.e. a fine grain subgrade

The underlying objective in running these MEPDG simulations runs is to determine if there is any substantial effect on the slab thickness of rigid pavements by the inclusion of various types of drainage layers.

Results of the simulations are shown in Table 5.11

Table 5.11

Effects of base type on the slab thickness

\begin{tabular}{|c|c|c|c|c|}
\hline \multirow{3}{*}{$\begin{array}{c}\text { Climatic } \\
\text { region }\end{array}$} & \multirow{2}{*}{$\begin{array}{c}\text { Pavement } \\
\text { section }\end{array}$} & \multicolumn{3}{|c|}{$\begin{array}{c}\text { Slab thickness for various } \\
\text { traffic levels (in) }\end{array}$} \\
\cline { 2 - 5 } & Low & Medium & High \\
\hline \multirow{4}{*}{ Wet/Freeze } & PS1 & 12 & 15.5 & 20 \\
\cline { 2 - 5 } & PS2 & 12 & 15.5 & 20 \\
\cline { 2 - 5 } & PS3 & 10.5 & 13.0 & 17.5 \\
\cline { 2 - 5 } & PS4 & 8.5 & 13 & 16 \\
\cline { 2 - 5 } & PS5 & 8 & 12 & 14.5 \\
\cline { 2 - 5 } & PS6 & 8 & 11.5 & 14 \\
\hline \multirow{4}{*}{ Dry/No-Freeze } & PS1 & 11.5 & 15 & 18.5 \\
\cline { 2 - 5 } & PS2 & 11.5 & 14 & 18 \\
\cline { 2 - 5 } & PS3 & 8.5 & 12.5 & 16 \\
\cline { 2 - 5 } & PS4 & 8.5 & 12 & 15.5 \\
\cline { 2 - 5 } & PS5 & 8 & 10.5 & 13.5 \\
\cline { 2 - 5 } & PS6 & 8 & 10 & 13 \\
\hline
\end{tabular}

A closer examination of the result shown in Table 5.11 will show that the thickness trend is repetitive for all the six pavement sections for the various climatic and traffic scenarios 
under consideration. The Pavement section 2 (PS2) which is an addition of a 4" thick of untreated open-graded aggregate base layer to the standard pavement section PS1 does not showed any corresponding reduction in PCC slab thickness. This by implication means that the 4 " thick untreated permeable base does not offer significant structural contribution to the pavement since the same amount of slab thickness is required for pavement adequacy as PS1. However, both pavement sections PS3 and PS4 which have treated permeable aggregate bases did showed a reduction in the required PCC slab thickness needed for pavement adequacy. For instance, the addition of a 4" thick ATPB layer did lead to a reduction in slab thickness of about $12 \%, 13 \%$ and $13.5 \%$ for low, medium and high traffic conditions respectively. The pavement sections containing the highly stabilized bases ATB and CTB i.e. PS5 and PS6 did showed a greater reduction in slab thickness than their open-graded counterpart. This was an indication that the reduction in slab thickness that is associated with incorporating treated permeable layer was not as a result of the improved drainability of the pavement section but rather due to addition of stiffer underlying layers.

The same reduction in slab thickness trend was also observed for the Dry/No-Freeze climatic region which makes it difficult to attribute any reduction in PCC slab thickness to the positive effects of improved subsurface drainage. It is expected that moisture related distresses will not be prevalent or critical in a dry/no-freeze climatic environment. That being the case if the reduction in PC slabs thickness for pavement sections PS3 and PS4 can be attributed to the improved subsurface drainage, then a similar trend should not have been observed for the dry/no-freeze climatic region. Also if the reduction in slab thickness was due to improve drainability neither pavement sections PS5 or PS6 which basically comprised of impermeable base layers experienced greater slab reduction than their open-graded counterparts. These results are in stark contrast to the AASHTO 1993 Design Guide wherein drainage coefficients have a direct effect on the required slab thickness. In the AASHTO Design Guides, assigning a higher drainage coefficient to a pavement layer increases its structural number. As a result therefore a pavement having underlying layers with higher structural numbers will produced a reduced PCC slab thickness than one having underlying layers with low structural number. Even though the 
selection of these AASHTO drainage coefficients is based on assumptions and subjected to different interpretations, higher drainage coefficients always produced a considerable reduction in slab thickness. This result further point to the difficulty of using existing pavement design software to compute which portion of predicted pavement performance can be directly attributed to improved subsurface drainage. One probably reason for this is the structural section used by the MEPDG software to compute pavement performance.

The pavement structural model used in the MEPDG is that of a slab on grade i.e. a slab on a "subgrade". So whatever pavement section that is input into the design guide, the software will automatically convert that input section to an "equivalent section" containing just a PCC slab and underlying granular layer (Jung et al. 2009). One will therefore expect pavement section with stiffer underlying layers will have stiffer "equivalent sections" and consequently improved pavement performance. This probably explains why the untreated permeable base layer with its low modulus value did not make any significant structural contribution to that of dense-grade pavement section. For the same reason also highly stabilize bas like ATB and CTB even though they have very inferior drainage properties compare to those of ATPB, pavement sections containing these bases did show a greater slab reduction than their pervious counterparts due to their high stiffness values.

The Analysis of Results of MEPDG Prediction of Pavement Performance for pavement containing Permeable Base layers.

Detailed results for this portion of the MEPDG simulations can be found in Appendix 5A. Only graphical results of pavement performance in the Wet/Freeze and Dry/NoFreeze climatic regions under three traffic conditions and a 10" PCC slab will be displayed in this chapter in order to aid analysis of the results. Figs 5.6 through 5.11 showed the predicted pavement performance for these design conditions while Figures 5.12 through Figure 5.14 showed the effect of dowels on the predicted pavement performance for the Wet/Freeze regions only. 


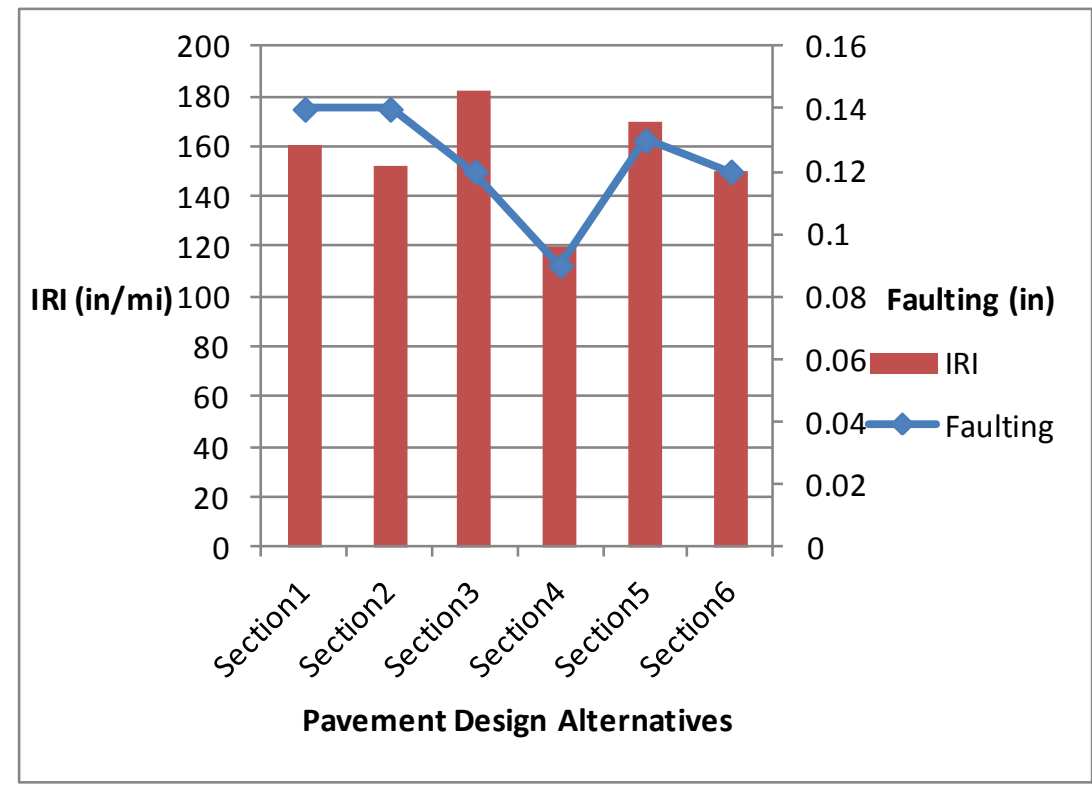

Figure 5.6: Predicted pavement performance for W/F Low traffic

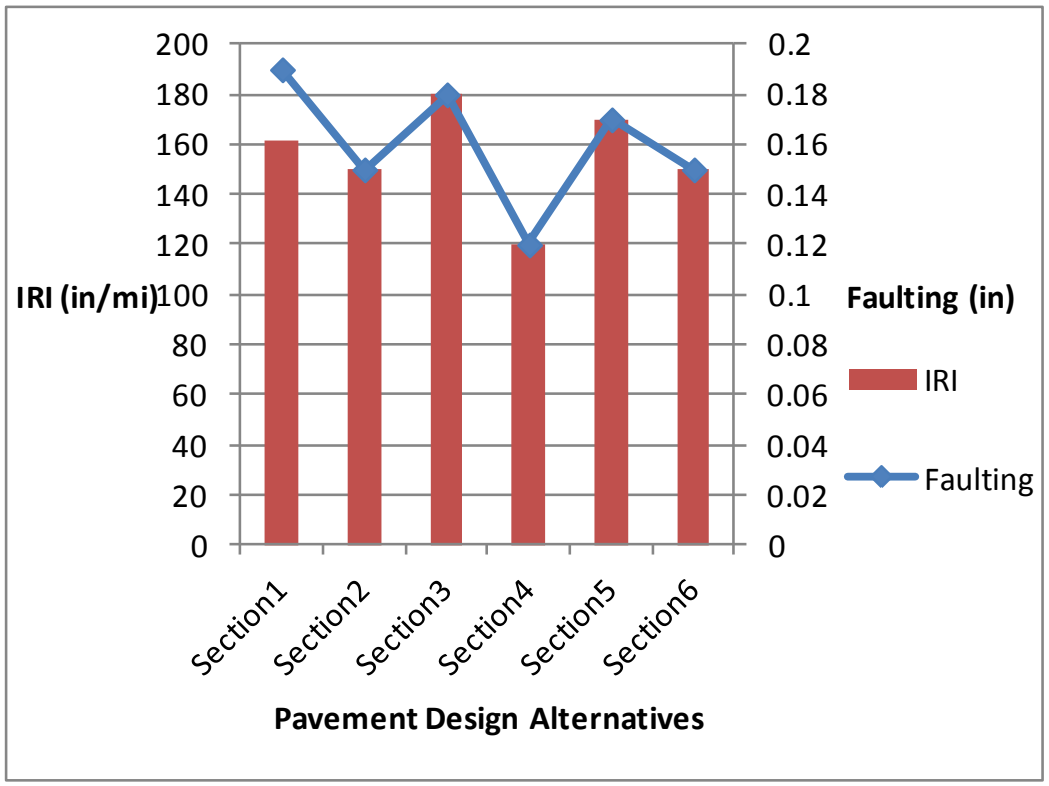

Figure 5.7: Predicted pavement performance for W/F Medium traffic 


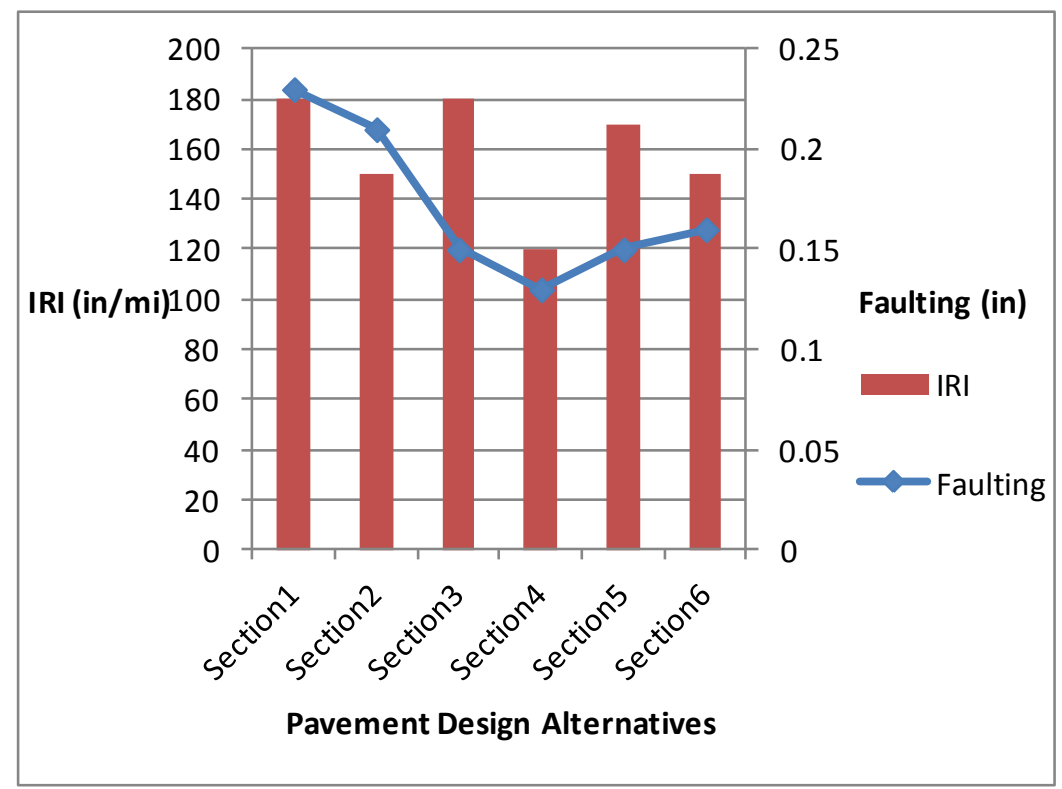

Figure 5.8: Predicted pavement performance for $W / F$ High traffic

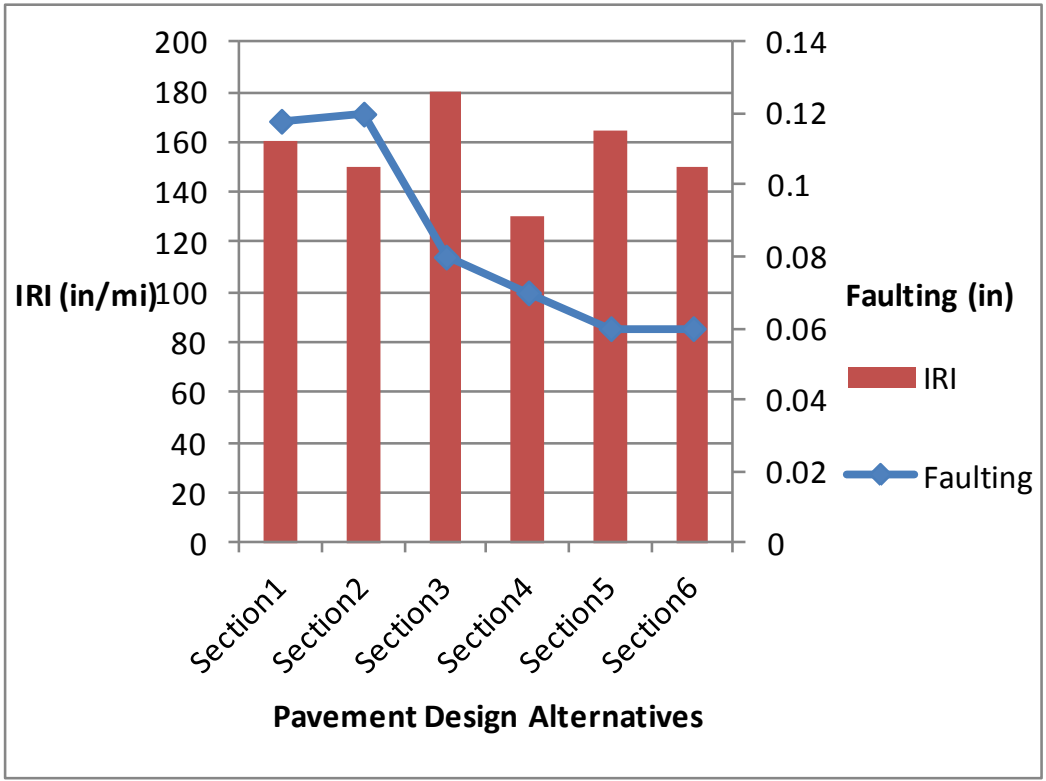

Figure 5.9: Predicted pavement performance for D /NF Low traffic 


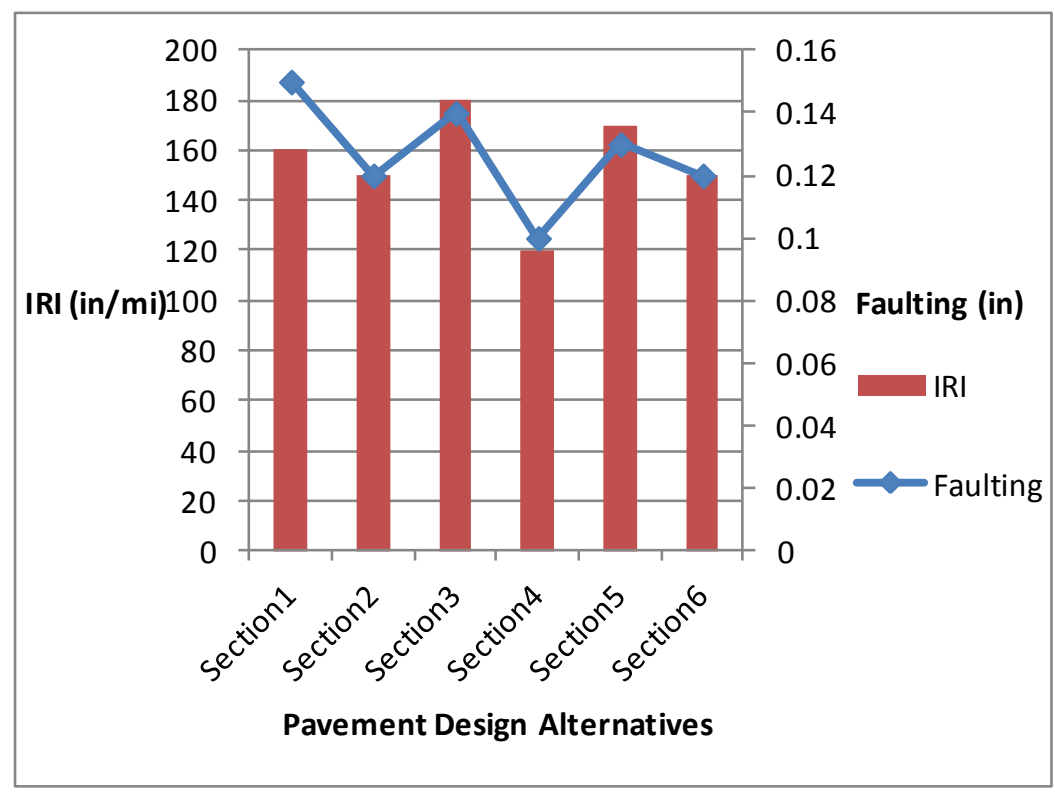

Figure 5.10: Predicted pavement performance for D/NF Medium traffic

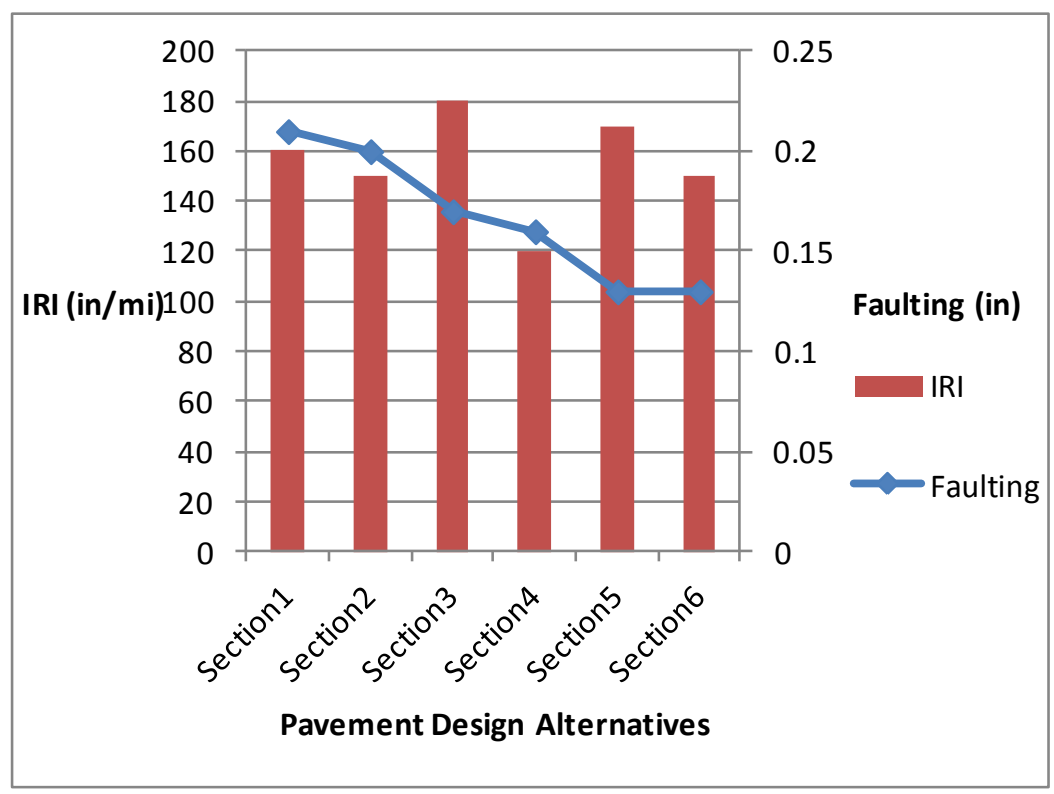

Figure 5.11: Predicted pavement performance for $\mathrm{D} / \mathrm{NF}$, High traffic 


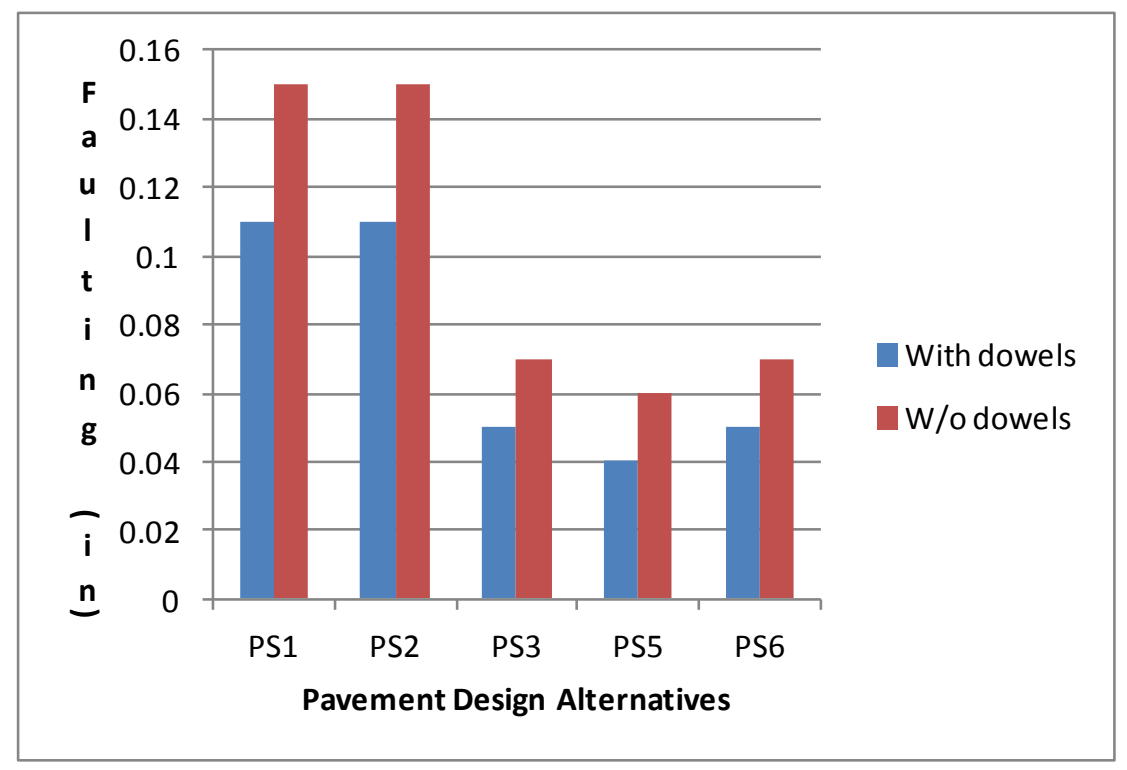

Figure 5.12: Differences in predicted faulting performance under

Wet/Freeze and Low traffic

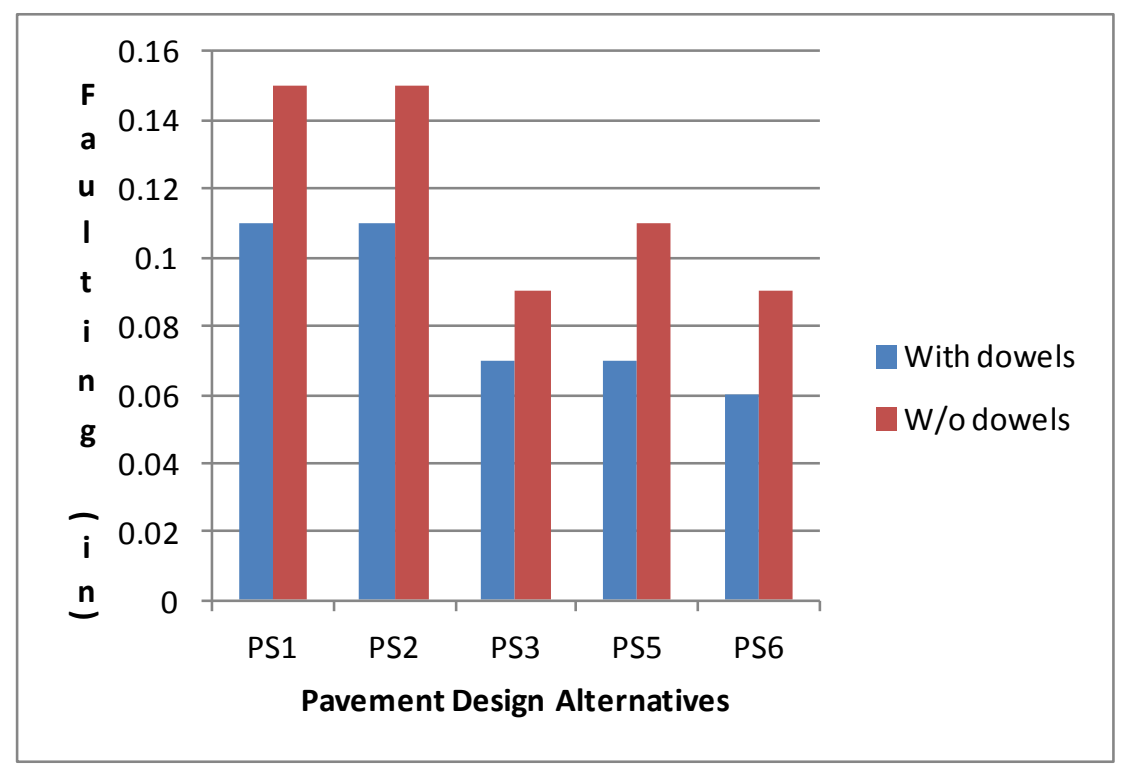

Figure 5.13: Differences in predicted faulting under Wet/Freeze and Medium traffic conditions 


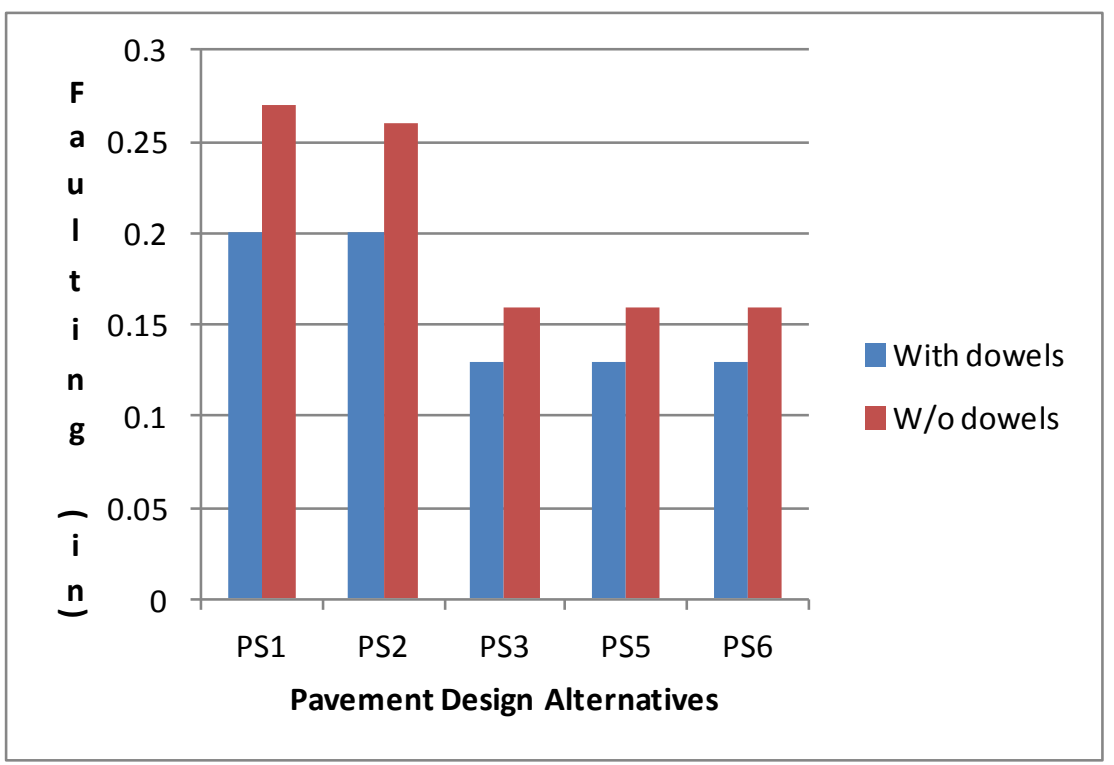

Figure 5.14: Differences in predicted faulting under Wet/Freeze and High traffic conditions

A summary of important findings pertaining to the effects of drainage layer on the predicted pavement performance is given below:

i. For PCC slab thickness above 8" thick, faulting is the critical distress that will dictate rehabilitations. Pavement section 1 containing the Densegraded Aggregate base failed in both faulting and IRI for the medium and high traffic conditions. Even though subsurface drainage features are nonexistent for this section, these failures cannot be entirely attributed to the absence of subsurface drainage features since the trend was repetitive for all the climatic regions under consideration.

ii. The addition of a 4" untreated permeable base to PS1 i.e. PS2 does not provide any improvement whatsoever to the predicted faulting and IRI values. Pavement section 2 failed in the same manner as PS1 which means that the improved subsurface drainage that comes with introducing the 4" untreated permeable layer does not translate to an increase in pavement performance. 
iii. Pavement sections containing treated permeable bases did showed significant improvement in both the predicted faulting and IRI. The question now is whether this increase in pavement performance can be attributed to the positive effects of subsurface drainage or some other factors.

iv. Pavement sections containing highly stabilized bases ATB and CTB did show the greatest increase in pavement performance. Since these bases are highly dense in nature and do not have the same level of drainage capacity compare to that of treated permeable bases, it is safe to assume that the increase in pavement performance for these sections can be attributed to their high stiffness and not due to improved drainability.

v. As is expected the Wet/Freeze region is the most critical climatic condition since the highest values of faulting and IRI are recorded there by all the pavement sections while results from the Dry/No-Freeze climatic region are the lowest. However one would expect that subsurface drainage to be critical in a Wet/Freeze climatic environment and less critical in a Dry/No-Freeze climatic region. But the performance trend for pavement sections with permeable bases is similar for both climatic regions which further make it difficult to quantify the degree of impact which improved subsurface drainage has on the predicted pavement performance.

vi. That the predicted pavement is largely a function of stiffness rather than the hydraulic capacity of the underlying pavement layers. This explains why the 4" open-graded aggregate with a resilient modulus of 15000 psi did not make any significant improvement in the predicted faulting. It is also the underlying reason why PS5 and PS6 have the highest predicted pavement performance. 
vii. As was expected the predicted faulting increases as the volume of truck traffic increases for all the pavement sections under consideration. This is more noticeable for pavement sections with untreated aggregate bases.

viii. As shown in Fig 5.12 through Fig 5.14, dowel sections showed a considerable increase in pavement performance compared to undowel sections. The average difference in faulting between a dowel and undowel pavement section was about $30 \%$. Both permeable bases and dowels are design features that serve identical purpose which is to minimize pumping and its associated faulting distress. One objective of this simulation was to determine if the combined use of the two design features can produced greater pavement performance than when they are use separately. Schmitt et al. (2010) did a field study in which they discovered that there is very little difference in pavement performance between pavement sections containing both a drainage layer and dowels to those containing either one of the two.

\subsection{Determining the Structural Adequacy of Drainage Layer Using MEPDG simulations}

As the results of the MEPDG simulations of pavement performance had shown, the use of treated permeable bases like ATPB and CTPB can lead to savings in the thickness of the PCC slab. These savings as expected are more pronounced for higher traffic conditions. However, most pavement designers would not incorporate such savings into actual designs owing to the conservative nature of civil engineering designs, which always err on the side of caution. A Federal Highway Administration 1997 TechBrief stated that "The AASHTO drainage coefficients are not recommended for use in structural design. Instead the design process should account for a reduction in the resilient modulus to account for saturated conditions through the use of relative damage factor for unbound material." (TechBrief, 1997: Improved Guidance of the 1993 AASHTO Flexible Design). This may be due to concern that the open-graded matrix of 
drainage layer introduces a weakened area within the pavement structure and as such many pavement designers thought it safe not to attach any structural value to it.

Structural adequacy of drainage layer has been of great concern even in the AASHTO Design Guides with some State Highway Agencies assigning structural layer coefficient to treated drainage layers while others don't assigned any structural contribution to the drainage layer. According to Forsyth (1991), five States assigned a structural coefficient for ATPB corresponding to a stabilized base course; eleven States give it no structural value, while ten assigned a value equivalent to an aggregate base. A report by Zhou et al. (1993) assigned a layer coefficient between 0.08 and 0.14 for untreated aggregate drainage layer and for the treated drainage layer, ATPB; a layer coefficient between 0.14 and 0.19 was assigned. Comparing these values to those you used in many pavement designs, the layer coefficients for the treated drainage layer are similar to the layer coefficients typically assigned to dense-graded aggregate bases and that of the ATPB is similar to layer coefficients assigned to stabilized bases. However, recent laboratory studies on the resilient modulus of both ATPB and CTPB have produced resilient modulus values within the range of stabilized bases like ATB and CTB (Zhou et al. 1993).

A recent NCHRP studied on pavement subsurface drainage found it difficult if not almost impossible to correlate pavement performance with the presence of subsurface drainage systems. Infact there are certain instances where the study found that the presence of subsurface drainage can be injurious to the overall health of the pavement. A notably case was the one that stated the presence of edge drains can reduce the faulting life of JPCP and that the fatigue life of asphalt pavement was significantly reduced due to the high air void content of the drainage layer (NHCRP 2007). However, Mallela et al. (2000) in their study noted that the conclusions of the NHCRP studies should be treated with caution since their study pointed out that many of the subsurface systems they investigated were not adequately designed. Some of the design inadequacies they mentioned were the drainage layer not thick enough for the expected infiltrations into the pavement and edge drains with lower capacity to receive the expected flows from the drainage layer. As a 
result any study on their contribution to pavement performance should first and foremost look at how well designed are the components of the subsurface drainage systems.

Therefore based on these observations and review of the literature on pavement subsurface drainage, a well-design drainage layer should meet the following characteristics if it is to make any significant contribution to pavement performance:

i. Hydraulic capacity: The drainage layer should have enough drainage capacity to discharge all moisture infiltrating the pavement's structural section within a reasonable period of time thereby keeping the pavement's underlying layers from reaching saturated conditions.

ii. Structural capacity: The drainage layer must be structurally stable to support not only construction traffic but also traffic and environmental loads throughout the pavement's design life. As a result the pavement design process should be able to provide the minimum structural thickness requirement to provide satisfactory load-bearing performances for the design traffic over the specified design life.

iii. Durability: The drainage layer must also be durable enough to resist not only the destructive effects of moisture and environmental constraints like freeze/thaw but also must have the ability to maintain high levels of drainage throughout the pavement's service life.

Existing drainage layer designs have often focused just on meeting the required hydraulic characteristics and in the process ignoring both the structural and durability aspects that are in themselves also very relevant to the overall performance of the drainage layer. Any rational design of a pavement drainage layer should therefore seek to meet these three critical features mentioned above. But such a rational design will be dependent on the type of pavement be it flexible or rigid due to differences in structural and durability requirement of the two types of pavement. The position of the drainage layer is typically below the surface course. Depending on the pavement type, this position poses quite 
some structural challenges to the drainage layer. Flexible and rigid pavements employed varying mechanisms to distribute traffic loads to the underlying pavement layers.

For rigid pavements, the rigid concrete slab is expected to carry the bulk of the traffic loads and as a result very little stress is been transmitted to the underlying layers. The main function of the underlying layers in rigid pavement is therefore to provide uniform support to the concrete slab and for drainage and less of a structural significance (Yoder et al. 1975). Flexible pavements however transmit substantial stress to the pavement underlying layers. Even though the asphalt surface carries the greater portion of the traffic load, the underlying layers are also expected to carry significant portion of the traffic loads. As a result therefore of this expected load-carrying capacity of pavement underlying layers in flexible pavements, higher quality materials are required in the underlying layers of flexible pavements than those in rigid pavements. From the foregoing, it is true to state that for flexible pavement the drainage layer can make up a significant portion of the pavement structural members. And even though it is not subjected to the same demand as the asphalt surface course in terms load-carrying capability, it may still be in the region of highest compressive stresses and wettest continuous condition than other granular layers underneath the pavement. Furthermore, this layer is positioned at the bottom of the HMA surface, a position wherein the fatigue resistance of the pavement can be truly impacted. One of the critical performance criteria of flexible pavement is that of the tensile strain at the bottom of the HMA layer which in large part governs the fatigue resistance of the asphalt pavement but in a flexible pavement structure having a treated drainage layer like ATPB, the MEPDG calculates the tensile strain at the bottom of the ATPB for use in predicting the alligator cracking. Research has shown that the fatigue life is greatly reduced in such a situation due to the high air void content of the drainage layer (NCHRP 2008).

For this portion of the MEPDG simulation, the factorial consisted of the following:

i. Climatic region- 1 (Wet/Freeze)

ii. Traffic level-3-High truck traffic

iii. Base layers-4 

iv. Subgrade-1
v. Slab thickness-1
vi. Design features-1: with dowels

This resulted in a total of 12 MEPDG runs for each pavement type. Before proceeding to perform MEPDG runs, the sensitivity of the design inputs for each of the base types was evaluated. Since the mix design for treated permeable bases varies quite extensively, the purpose of doing this sensitivity analyses was to determine which of the mix design variables have a profound effect on the predicted pavement performance. Results of the sensitivity analyses were then used to determine which of the mixed design parameters can be vary during the MEPDG simulations so as to improve the structural equivalency of the drainage layer without adversely affecting its drainage capacity.

The design inputs for both treated permeable bases and untreated permeable bases are shown in Figs 5.12 and 5.13 respectively:

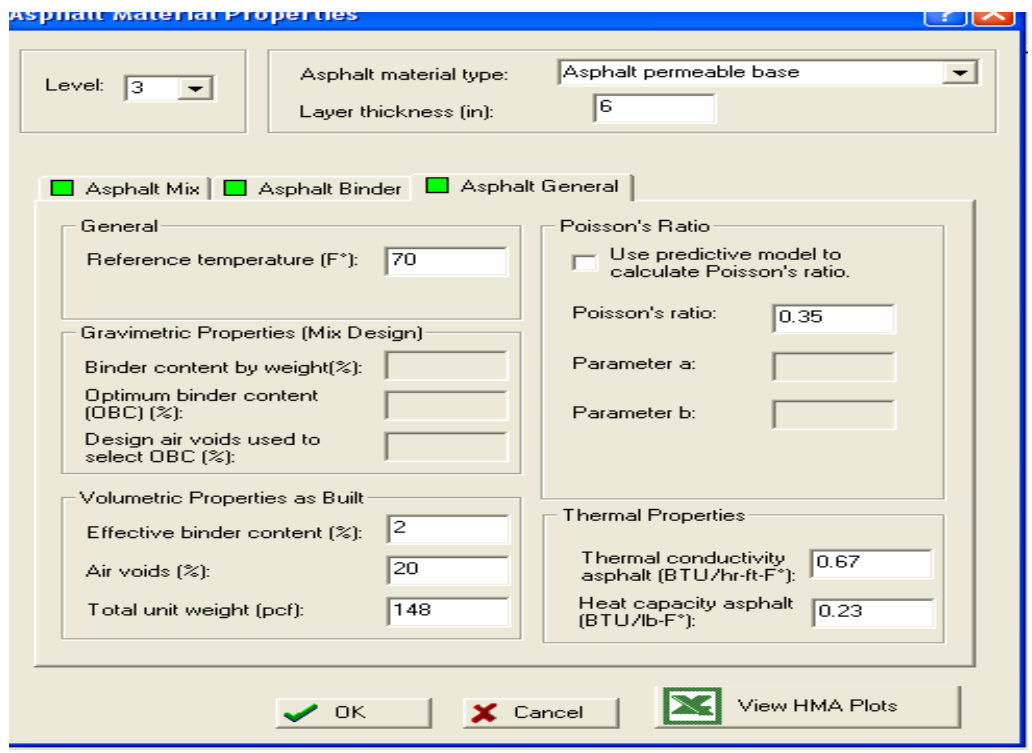

Figure 5.15: Material Properties for ATPB use in the MEPDG Analysis 


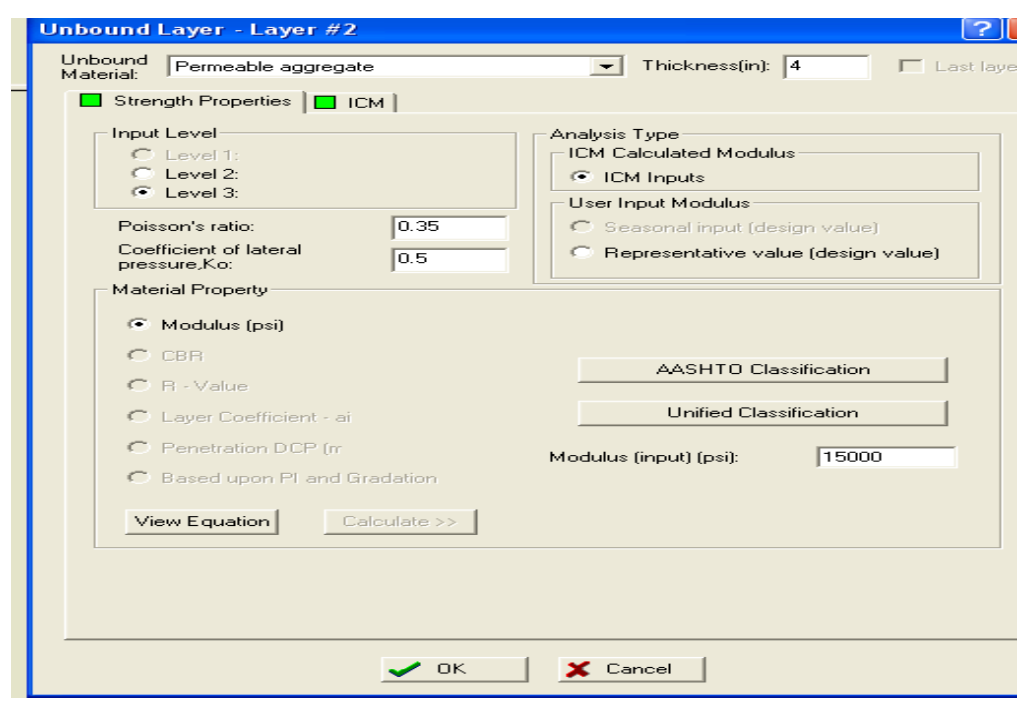

Figure 5.16: Material Properties for untreated permeable aggregate use in the MEPDG Analysis

Sensitivity Analyses Results for Rigid Pavement sections are shown in Fig 5.17 and Table 5.12 through Table 5.14

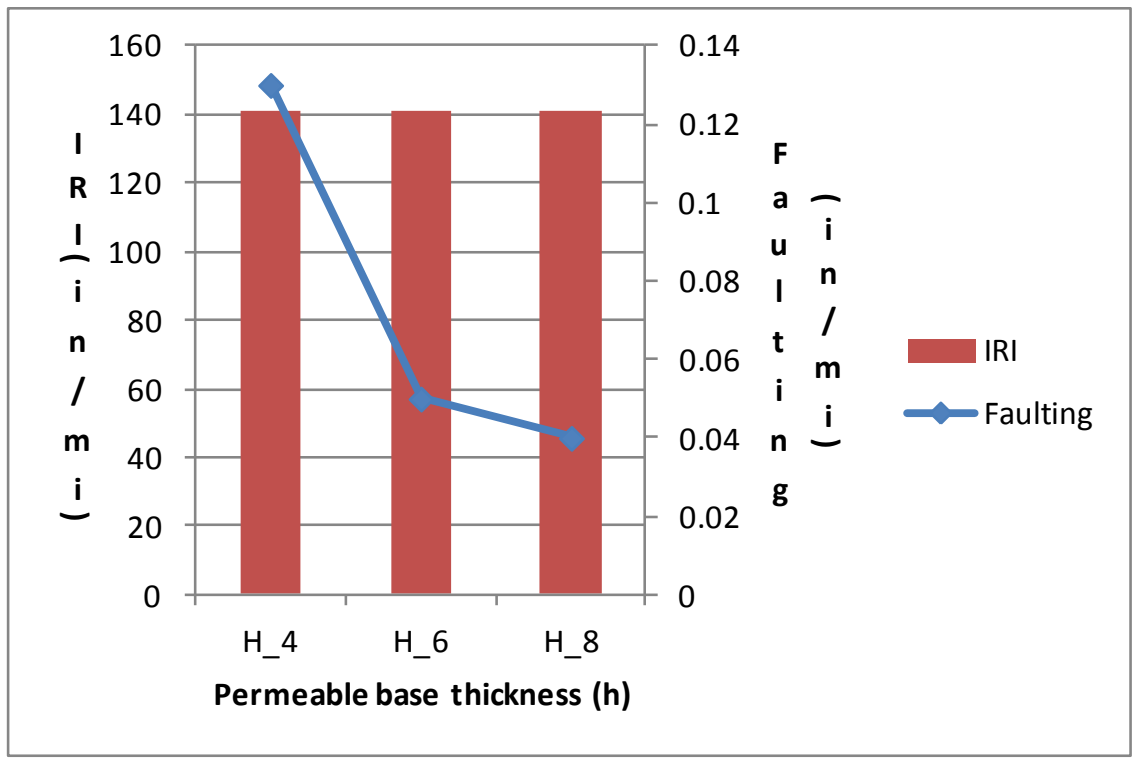


Figure 5.17: Variation of pavement performance with permeable base thickness

Table 5.12

Variation of pavement performance with percent air void content of permeable base

\begin{tabular}{|c|c|c|}
\hline $\begin{array}{c}\text { Air voids } \\
\text { content } \\
(\%)\end{array}$ & $\begin{array}{c}\text { Faulting } \\
\text { (in) }\end{array}$ & IRI (in/mi) \\
\hline 15 & 0.120 & 141.1 \\
\hline 25 & 0.124 & 141.3 \\
\hline 35 & 0.122 & 141.3 \\
\hline
\end{tabular}

Table 5.13:

Variation of pavement performance with \% binder content of treated permeable base

\begin{tabular}{|c|c|c|}
\hline Binder content (\%) & $\begin{array}{c}\text { Faulting } \\
\text { (in) }\end{array}$ & $\begin{array}{c}\text { IRI } \\
\text { (in/mi) }\end{array}$ \\
\hline 2 & 0.124 & 141.3 \\
\hline 3 & 0.124 & 141.3 \\
\hline 3 & 0.124 & 141.3 \\
\hline
\end{tabular}


Table 5.14:

Variation of pavement performance with binder type used to treat permeable base

\begin{tabular}{|c|c|c|}
\hline Binder type & $\begin{array}{c}\text { Faulting } \\
\text { (in) }\end{array}$ & $\begin{array}{c}\text { IRI } \\
\text { (in/mi }\end{array}$ \\
\hline $76 /-16$ & 0.115 & 143.4 \\
\hline $64 /-34$ & 0.120 & 142.1 \\
\hline $70 /-22$ & 0.122 & 140.4 \\
\hline
\end{tabular}

The results for flexible pavements are shown in Tables 5.15 through Table 5.18

Table 5.15

Variation of pavement performance with permeable base thickness

\begin{tabular}{|c|c|c|c|}
\hline $\begin{array}{c}\text { Thickness } \\
\text { (in) }\end{array}$ & Rutting (in) & $\begin{array}{c}\text { Alligator } \\
\text { cracking } \\
(\%)\end{array}$ & $\begin{array}{c}\text { IRI } \\
\text { (in/mi) }\end{array}$ \\
\hline 4 & 0.47 & 47.8 & 170.3 \\
\hline 6 & 0.38 & 33.8 & 150.1 \\
\hline 8 & 0.36 & 22.3 & 139.4 \\
\hline
\end{tabular}


Table 5.16

Variation of pavement performance with percent air void content of permeable base

\begin{tabular}{|c|c|c|c|}
\hline $\begin{array}{c}\text { Air voids } \\
\text { content } \\
(\%)\end{array}$ & $\begin{array}{c}\text { Rutting } \\
\text { (in) }\end{array}$ & $\begin{array}{c}\text { Alligator } \\
\text { cracking } \\
(\%)\end{array}$ & IR1 \\
$(\mathrm{in} / \mathrm{mi})$
\end{tabular}

Table 5.17

Variation of pavement performance with \% binder content of treated permeable base

\begin{tabular}{|c|c|c|c|}
\hline $\begin{array}{l}\text { Binder } \\
\text { content } \\
(\%)\end{array}$ & $\begin{array}{l}\text { Rutting } \\
\text { (in) }\end{array}$ & $\begin{array}{l}\text { Alligator } \\
\text { cracking (\%) }\end{array}$ & $\begin{array}{l}\text { IRI } \\
\text { (in/mi) }\end{array}$ \\
\hline 2.5 & 0.46 & 38.4 & 153.1 \\
\hline 3 & 0.46 & 52.3 & 124.2 \\
\hline 5 & 0.45 & 70.3 & 110.3 \\
\hline
\end{tabular}


Table 5.18

\section{Variation of pavement performance with binder type use to treat permeable base}

\begin{tabular}{|c|c|c|c|}
\hline $\begin{array}{c}\text { Binder } \\
\text { content } \\
(\%)\end{array}$ & $\begin{array}{c}\text { Rutting } \\
\text { (in) }\end{array}$ & $\begin{array}{c}\text { Alligator } \\
\text { cracking (\%) }\end{array}$ & $\begin{array}{c}\text { IRI } \\
\text { (in/mi) }\end{array}$ \\
\hline $76 /-16$ & 0.47 & 59.7 & 174.6 \\
\hline $64 /-34$ & 0.47 & 47.8 & 153.4 \\
\hline $70 /-22$ & 0.47 & 27.9 & 133 \\
\hline
\end{tabular}

From the results of MEPDG predicted performance of pavement, it can be seen that the sensitivity analysis of the treated base design inputs is dependent on the type of pavement. For the rigid pavement, it can be seen that increasing the thickness of the treated drainage layer has a marginal effect on the predicted pavement performance. A $100 \%$ increase in base thickness only resulted in less than a $7 \%$ increase in the predicted faulting life of the rigid pavement whereas for the case of the flexible pavement, a $100 \%$ increase in thickness of the drainage layer resulted in $20 \%$ and $15 \%$ for rutting and alligator cracking respectively. It should however be noted that such a correlation is not only restricted to treated permeable bases but overall the MEPDG predicting pavement performance is insensitive to the thickness of the base and/or subbase layers. Two conclusions that can be drawn from this sensitivity analyses are that:

1) The MEPDG prediction of faulting was surprisingly insensitive to the volumetric properties of the ATPB.

2) Even though the thickness of the ATPB has a non-negligible effect on pavement performance, the effect is not so significance as to warrant the use of thicker ATPB sections. 


\subsubsection{Defining an appropriate erodibility factor for treated open-graded bases}

A significant design feature use by the MEPDG to characterize the base layer of rigid pavement is the erodibility factor of the base layer (NCHRP, 2004). The erodibility of base/subbase is define as "The loss of base material due to hydraulic water, most often at the joints in rigid pavements, but also along the edges of both rigid and flexible pavements" (Jung et al. 2009) The erodibility is closely related to the durability of the base in relation to its potential to breakdown under traffic loads, climatic conditions and other environmental forces.

The subbase plays a very vital role in a concrete pavement and can perform a variety of functions. However beyond that of providing a stable construction platform, one critical function of the subbase layer in a rigid pavement is that of providing the concrete slab with uniform support.

The inclusion of a subbase in the structural design of concrete pavement is not justifiable for all site conditions and the use of one is not even recommended in areas of low traffic and high strength subgrade (Yoder et al. 1975). Many of the models that described the mechanical behavior of rigid pavements including such classics as the Westergaard equations are based on the concept of a slab on grade i.e. a concrete slab on a subgrade with no subbase. As was noted in earlier sections of this dissertation, the concrete slab is the principal load-carrying layer in a concrete pavement structure. As a result any good performing concrete pavements can still function well under a wide range of subbase support strength. This probably explains why structurally inferior materials can be used as subbase materials in concrete pavements as compared to the superior quality of subbase materials in flexible pavements where the strength of the subbase is a significant design factor. While the strength of the subbase should not negatively impact the performance of concrete pavement, the one thing that undermines its long lasting performance is that of variation in support conditions between any two segments within the pavement scetion. The concrete slab cannot tolerate to any great extent variation in support condition like that between the center and edge of the concrete slab. This 
variation in support conditions underneath a concrete slab has been identified as the principal cause for the development of such distresses as faulting in JPCP and punchout in CRCP (Jung et al. 2009).

The major factor that has been identified as being responsible for the variation of support condition underneath a concrete slab is the erosion of subbase caused by the combined action of heavy traffic wheel loads and porewater pressure from a highly saturated structural section. This makes erosion of subbase material a very critical factor in the design of concrete pavements especially for site conditions of heavy truck traffic and high precipitation. Therefore seeing the design significance of providing a concrete with a non-erodible subbase layer, the FHWA had recommended the use of stabilized bases which are deem non-erodible underneath concrete pavements (FHWA 2002). According to Youg et al. (2009) erosion of subbase material is as a result of high porewater pressure caused by high traffic loads which pump fine materials along the slab-subbase interface thereby creating voids underneath the slab that eventually leads to loss of support, joint deterioration, reduced stiffness of the subbase layer and ultimately faulting of the pavement section. As expected, the areas within the concrete pavements structure that are more susceptible to erosion are the sections where curling and warping along the edges and corners of the slab have separated the slab from the subbase. Under this kind of condition the slab will pump any water that is trapped underneath as the applied wheel loads move across the slab/subbase interface and this together with the highly pressurized water creates a shearing stress that carries eroded subbase material and in the process create a non-uniform support condition within the pavement structure.

Due to the significance of the potential of subbase erosion as it affects the performance of concrete pavements as highlighted in the previous discussion, many pavement design procedures have included it in their design specification for subbase materials.

However, only the MEPDG classification of subbase erosion levels will be considered in this section. The MEPDG characterization of the erosion potential of some common base materials is shown in Table 5.19. 
Table 5.19

Erodibility class of common Pavement bases (NHRCP 1-37A,2004)

\begin{tabular}{|c|c|}
\hline $\begin{array}{l}\text { ERODIBILITY } \\
\text { CLASS }\end{array}$ & MATERIAL DESCRIPTION AND TESTING \\
\hline 1 & $\begin{array}{l}\text { - Lean concrete with approximately } 8 \% \text { cement; or } \\
\text { with long-term compressive strength }>17.2 \mathrm{MPa} \\
(2,500 \mathrm{psi}) \text { [ }>13.8 \mathrm{MPa}(2,000 \mathrm{psi}) \text { at } 28 \text {-days] } \\
\text { and a granular subbase layer or a stabilized soil } \\
\text { layer or a geotextile fabric is placed between the } \\
\text { bound base and subgrade; otherwise Class } 2 \text {. } \\
\text { - Hot mixed asphalt concrete with } 6 \% \text { asphalt } \\
\text { cement that passes appropriate stripping tests and } \\
\text { aggregate tests and a granular subbase layer or a } \\
\text { stabilized soil layer; otherwise Class } 2 \text {. } \\
\text { Permeable drainage layer (asphalt-treated } \\
\text { aggregate or cement-treated aggregate) and with } \\
\text { an appropriate granular or geotextile separation } \\
\text { layer placed between the treated permeable base } \\
\text { and subgrade }\end{array}$ \\
\hline 2 & $\begin{array}{l}\text { 1. Cement-treated granular material with } 5 \% \\
\text { cement manufactured in-plant, or long-term } \\
\text { compressive strength } 13.8 \text { to } 17.2 \mathrm{MPa}(2,000 \text { to } \\
2,500 \mathrm{psi}) \text { [10.3 MPa to } 13.8 \mathrm{MPa}(1,500 \text { to } 2,000 \\
\text { psi) at } 28 \text {-days] and a granular subbase layer or a } \\
\text { stabilized soil layer or a geotextile fabric is placed } \\
\text { between the treated base \& subgrade; otherwise } \\
\text { Class } 3 \text {. } \\
\text { Asphalt-treated granular material with } 4 \% \text { asphalt } \\
\text { cement that passes appropriate stripping test and a } \\
\text { granular subbase layer or a treated soil layer or a } \\
\text { geotextile is placed between the treated base and } \\
\text { subgrade; otherwise Class } 3 \text {. }\end{array}$ \\
\hline 3 & $\begin{array}{l}\text { 1. Cement-treated granular material with } 3.5 \% \\
\text { cement manufactured in-plant, or with long-term } \\
\text { compressive strength } 6.9 \mathrm{MPa} \text { to } 13.8 \mathrm{MPa}(1,000 \\
\text { to } 2,000 \mathrm{psi}) \text { [5.2 } \mathrm{MPa} \text { to } 10.3 \mathrm{MPa} \text { ( } 750 \text { to } 1,500 \\
\text { psi) at } 28 \text {-days]. } \\
\text { Asphalt-treated granular material with } 3 \% \text { asphalt } \\
\text { cement that passes appropriate stripping test. }\end{array}$ \\
\hline 4 & $\begin{array}{l}\text { Unbound crushed granular material having dense } \\
\text { gradation and high quality aggregates. }\end{array}$ \\
\hline 5 & $\begin{array}{l}\text { Untreated soils (PCC slab placed on } \\
\text { prepared/compacted subgrade). }\end{array}$ \\
\hline
\end{tabular}


The criteria used to arrive at this erodibility factor are base material type, stabilizer type and content, and long term compressive strength. According to Jung et al. (2009) each level of erosion is assumed to offer five times the resistance to erosion than the next level. This by implication means that class two base/subbase materials are five times more erosion resistance than class 3 base/subbase materials. It can be seen from Table 510 that treated permeable bases are placed in the same category as stabilized bases on a class one erodibility level. This means that the guidelines for choosing the erodibility factor did not take into consideration some design issues especially considering the fact that treated permeable bases only consist of very small amount of stabilizer relative to more rigid stabilized bases like CTBs and ATBs. But such categorization seems contrary to field experiences that showed treated permeable bases like ATPBs have serious long term durability issues especially in the light of current mixed designs that utilizes small dosages of asphalt binder (Harvey et al. 1999). With the minimal asphalt or cement content use to treat these open graded bases, it is hard to see how their erosion resistance can parallel that of more rigid bases like stabilized cement or asphalt bases. It is however sufficed to not that the erodibility levels of Table 5.10 are simply qualitative description of erosion potential of certain material. They can at best be decribed as levl 3 input and as such should be treated with greater caution. According to the Christopher et al. (2004), there is currently no national test for base/subbase erosion potential from which level 1 input can be collected. Some of the tests that are currently under development to determine the erosion potential of base/subase materials are:

1. Rotational shear device for cohesive or stabilized materials

2. Jetting test

3. Linear and rotational brush tests

4. South African erosion test

The MEPDG incorporated the erodibility factor into its faulting model as shown in equation 5-1. It is quite obvious from equation 5.1 that the predicted faulting is sensitive to the erodibility factor (EROD). Base/subbase with higher EROD values have higher 
faulting values and those with low EROD values have lower faulting values. In other words, if the faulting values of two bases/subbases with erodibility levels of 1 and 2 were compared, the base/subbase with erodibillty level 1 which is five times more erosion resistant than the one with erodibility level 2 , will show a reduced faulting value. In order to determine the extent of the sensitivity of predicted faulting to the value of EROD, an MEPDG sensitivity analyses was run for the following conditions:

One climatic condition i.e. Wet/Freeze

Two traffic levels i.e. low and high truck traffic levels

3 EROD values of 1, 2 and 3 were assigned to the ATPB

The results of the simulation are shown in Figures 5.17 through 5.18.

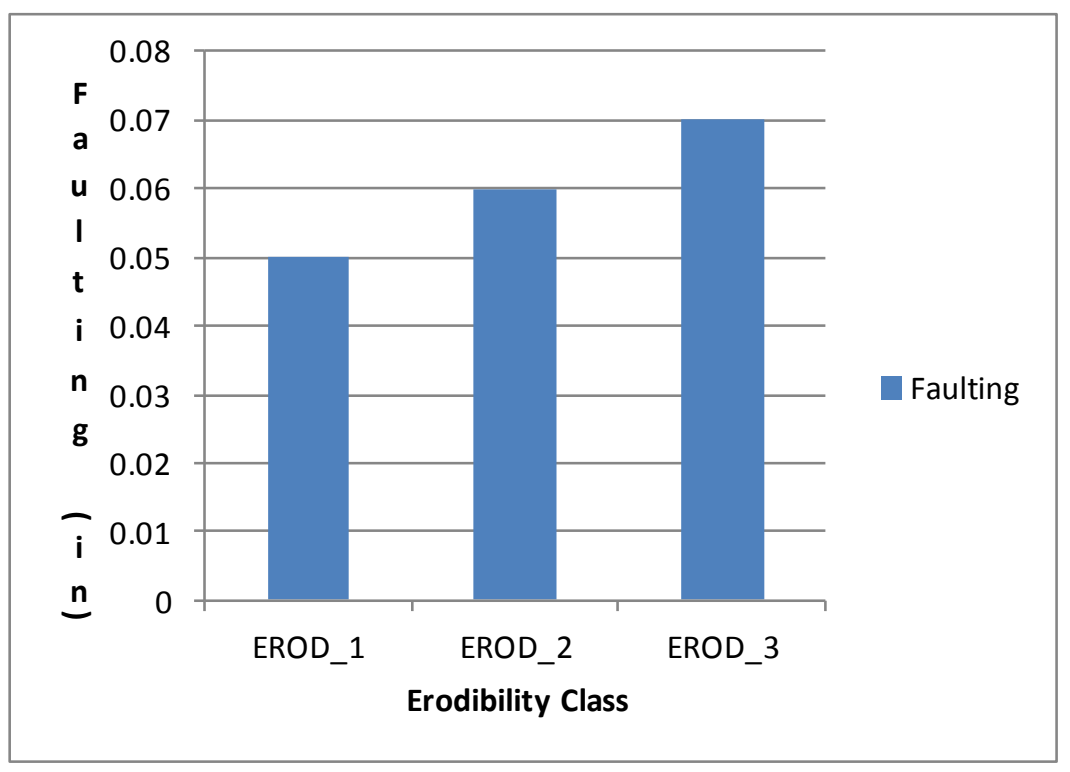

Figure 5.18: Predicted faulting using three erodibility levels for low traffic 


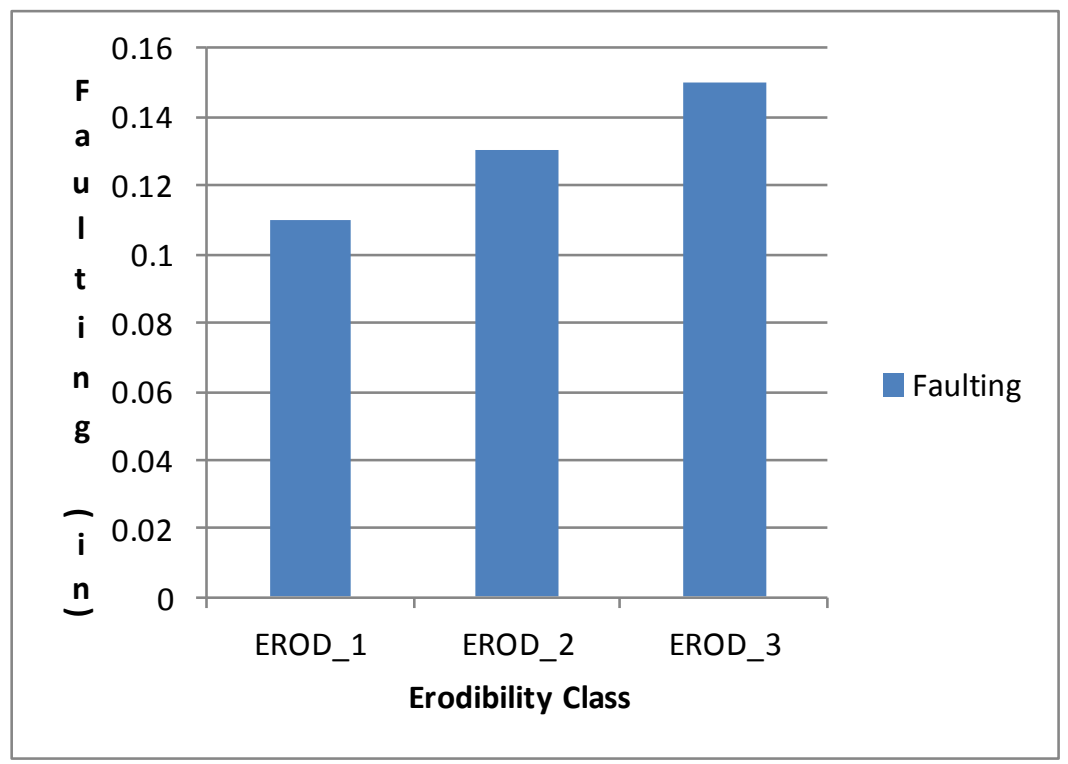

Figure 5.19: Predicted faulting using three erodibility levels for high traffic

Both graphs did show that the predicted faulting is highly dependent on the erodibility class of the base material. For the same traffic and environmental conditions, changing the erodibiltiy class of the base from a lower level to a higher level will produced on average a $12 \%$ increase in the faulting value. This is a significant percentage increase and as such if the MEPDG predicted performance is to be use to determine the structural contribution of the treated permeable bases, then an appropriate erodibility criteria has to be established from results of appropriate erosion susceptibility tests on base/subbase materials.

The foregoing results and discussions underline the need to modify existing mixed design for treated permeable bases if they are to function not only as a drainage layer but also a structurally and durable layer within the pavement structure. Experimental results listed and discussed in chapter 4 indicated the typical compressive and tensile strength values for these treated permeable bases. However, the AASHTO erodibility classification of Table 5.19 does not contain minimum values of compressive strength or tensile strength for these permeable base types. This makes it difficult to determine the erodibility class for these materials on the basis of the tests results in Chapter 4. In order to gets an 
understanding of the magnitude of the applied stresses acting on these layers under service conditions, a multi layer linear elastic analyses was conducted on pavement sections containing these treated permeable bases. Material properties use in this analysis was obtained from Michigan Department of Transportation (MDOT) Pavement Design and Selection Manual. The pavements structure used in the analysis is shown in Fig 5.17. A standard $9000 \mathrm{lbs}$ load with a contact pressure of 80 psi was used.

\subsection{MEPDG Prediction of Flexible Pavement sections containing different open-graded base layers.}

A limited number of MEPDG runs for flexible pavement sections containing open-graded bases were performed. For this portion of the MEPDG analysis, the following deign conditions were considered:

I. Two truck traffic: low and medium truck traffic

II. Two climatic regions: Wet/Freeze and Dry/No-Freeze

III. Three pavement sections: PS1, PS3 and PS5.

IV. The performance criteria of interest are: Alligator cracking (AC) and the International Roughness Index (IRI).

Results of the simulations are shown in Figs 5.19 through Fig 5.22. 


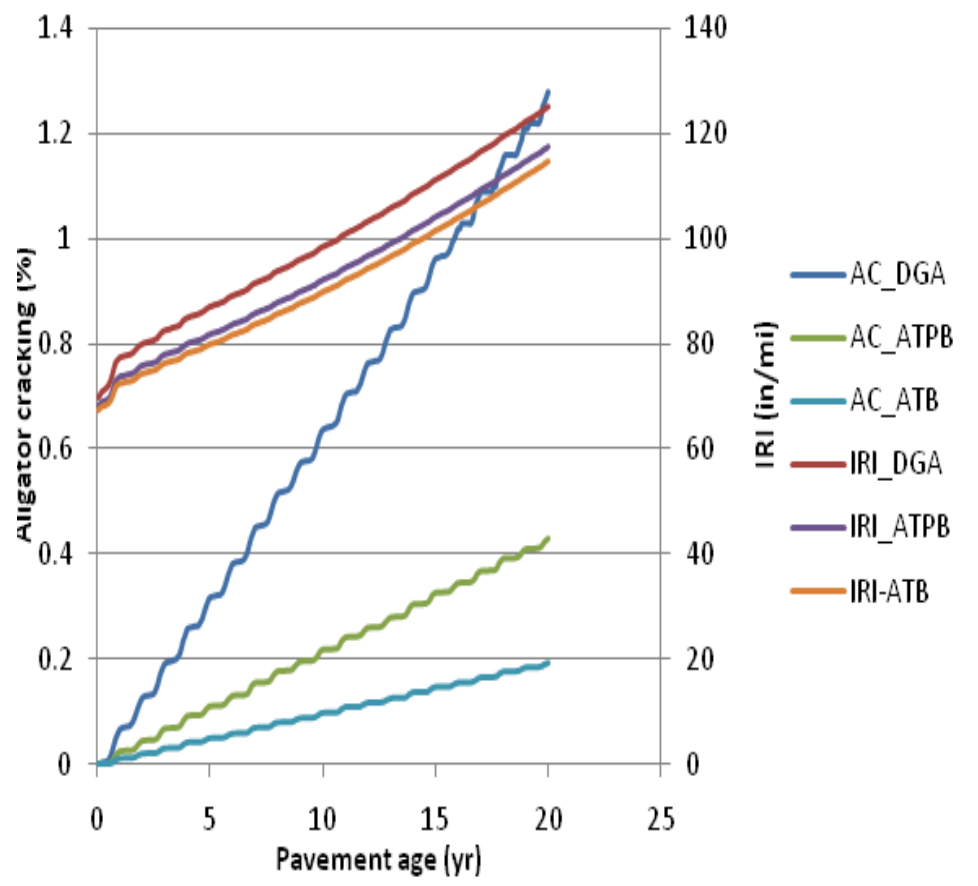

Figure 5.20. Predicted performance for low traffic, Wet/Freeze region

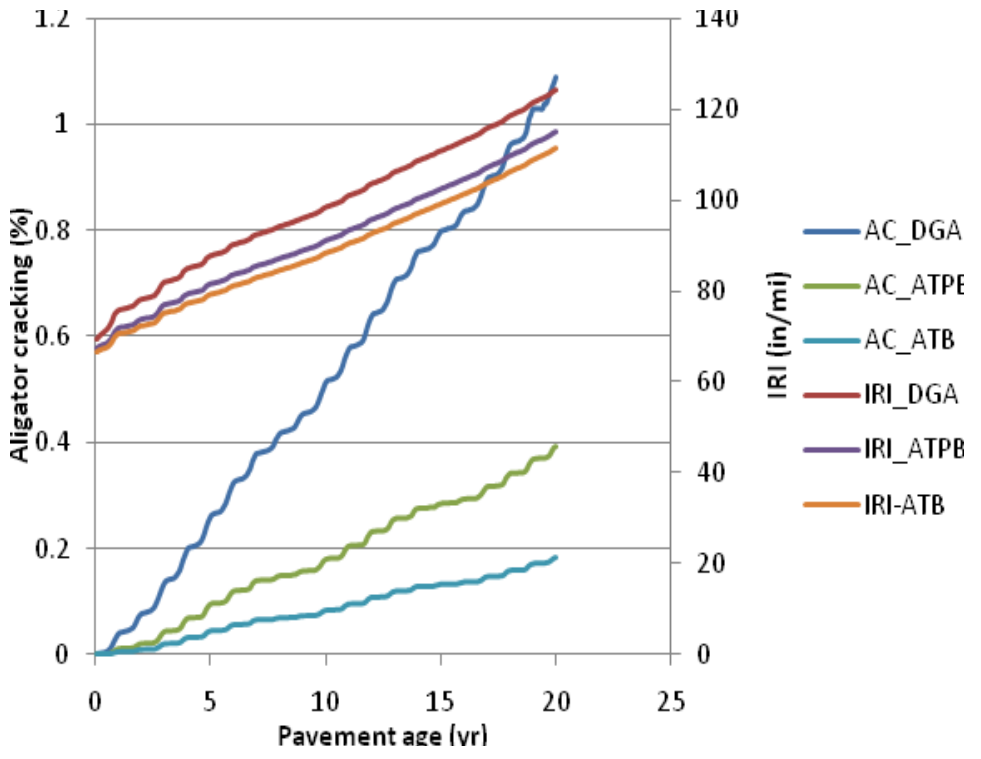

Figure 5.21. Predicted performance for low traffic, Dry/No-Freeze region 


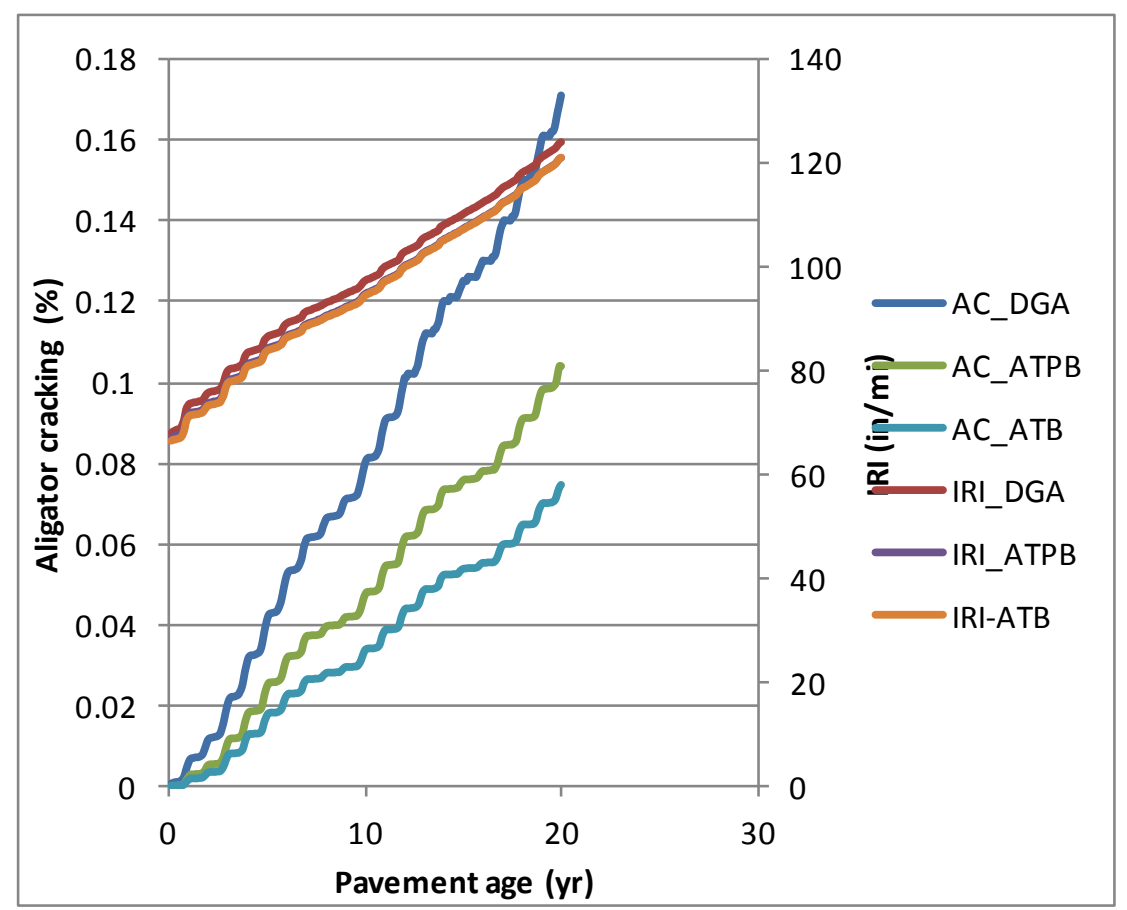

Figure 5.22: Predicted performance for medium traffic, Wet/Freeze region

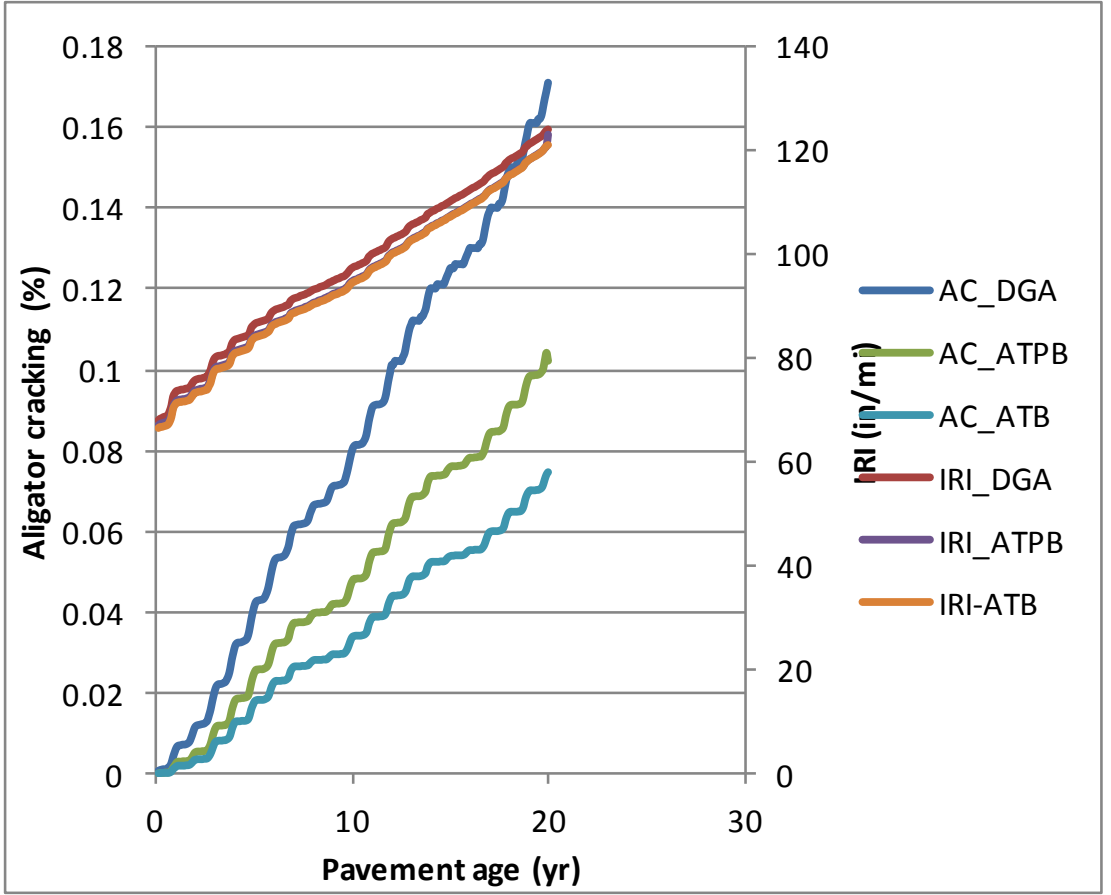

Figure 5.23. Predicted performance for medium traffic, Wet/Freeze region 
From the performance curves of Fig 5.19 through Fig 5.22 of three flexible pavement sections, the following can be deduced:

1) The performance trend was similar for both climatic regions. As was the case for the rigid pavement sections, PS3 with the ATB has the highest predicted performance i.e. low alligator cracking (AC) and international roughness index (IRI).

2) Even though PS2 with the ATPB shows a superior performance to that of PS1 with the DGA base, its performance was however still inferior to PS3. As with the analysis for rigid pavement sections, this again shows that improved performance of PS2 to that of PS1 may not be attributable to the presence of the drainage layer.

\subsection{Calibration/Validation of MEPDG Runs with LTPP Performance database}

The mechanistic-empirical pavement performance models contained in the MEPDG Design Guide were calibrated using performance data from the Long Term Performance Pavement (LTPP) database. The LTPP has been "described as the largest pavement performance research program ever undertaken, gathering data from 2000 pavement sections across the entire U.S. over a period of 20 years" (Elkins et al. 2003).

The LTPP test sections are to the MEPDG Design Guide as was the AASHO Road Test was to the AASHTO Design Guides. However, unlike the AASHO Road Test which was an accelerated loading case, located in one climatic region and subjected to identical traffic and material properties, the LTPP tests sections are in-service pavements, located in different climatic regions, subjected to a wide range of traffic, materials and design types. This makes the LTPP pavement database a versatile tool for developing realistic mechanistic-empirical models of pavement performance. This makes the MEPDG a much more robust design guide than the AASHTO Design Guides in its capability to handle the complex interactive nature of traffic, material and environment as they affect pavement performance. 
The LTPP data are being collected in a database known as LTPP National Information Management and it contains data characterizing the pavement structure, materials, and performance are being collected for test sections on in-service highways throughout the United States and Canada. The data collection exercise is still ongoing since it is expected that as more and more performance data becomes available, mechanisticempirical analyses would be conducted to provide better performance prediction models for use in pavement design and management, better understanding of the effects of the many complex variables on pavement performance, and to furnish new tools and techniques for pavement design, construction and rehabilitation (Elkins et al. 2003). Since this research project does not have a field component, no field performance data of the pavement sections simulated in the MEPDG sensitivity analyses were collected. As a result extensive use of the LTPP pavement performance database was made to validate the results of the MEPDG analyses. In order to make the validation/calibration process yields appropriate result, the pavement locations selected in the MEPDG sensitivity analyses are the same locations from where identical LTPP pavement sections were selected. Even at that it was still difficult to validate the results of the simulated pavement performance due to the wide difference in pavement design philosophies of pavement sections within the LTPP database. Furthermore, level 3 input material properties assumed in the computer simulations may be quite different from material properties of identical pavement sections within the LTPP database. 


\section{CHAPTER 6}

\section{ECONOMIC ANALYSIS OF PAVEMENT SUBSURFACE DRAINAGE SYSTEMS}

\subsection{Introduction}

Subsurface drainage systems have now become a regular pavement design feature (Hagen et al. 1996). The general consensus is that the inclusion of subsurface drainage systems/features has a significant effect on pavement performance by considerably mitigating the damaging effect of moisture on the pavement structural sections. Free moisture within the pavement structural section has been identified as one of the principal causes of distresses in pavements. Empirical evidence over the years have shown that undrained pavement sections wherein free moisture is trapped within the structural section for a considerable length of time, suffered premature failure due to moisture related distresses. These sections are also known to have high life cycle costs. On the other hand, experiences have also shown the increased in pavement service life and subsequent lower cycle costs associated with pavement sections equipped with subsurface drainage systems (Cedergren 1989). As a result of these empirical findings from in-service drained and undrained pavement sections, pavement design philosophy over the last two decades have seen the growing adoption of subsurface drainage features for both flexible and rigid pavements. The availability of improved and relatively cheap materials that can be utilized in the various components of subsurface drainage systems has also been an influencing factor to this rapid adoption of drainage layer within the pavement structure.

However, while it is true that the mere inclusion of a subsurface drainage features into a pavement system has the potential to increase the service life of a pavement, it can also be argue that their inclusion also increases the initial construction cost of a pavement by a significant amount. Cole and Hall (1997) cited in that the inclusion of a drainage layer in 
pavement systems can increase the construction by as much as $15 \%$ when stabilized drainage layers are used. Furthermore, there is the additional cost of maintaining subsurface drainage components like edge drains and outlet pipes over the design life of the pavement. This increased cost associated with the inclusion of subsurface drainage features calls for detail guidelines as to what site conditions does warrant their inclusion. As a result, many state highway agencies have developed a set of design guidelines that can help pavement designers determine the conditions under which the inclusion of subsurface drainage systems is engineering feasible and cost-effective. Some of these criteria include traffic volume, subgrade permeability and climate. Christopher et al. (1997) stated that for locations that received less than 15 inches precipitation per year subsurface drainage may not be critical and hence should not be included in the design. Bejarno et al. (2004) on the other hand noted that the use of drainage layers within the pavement structural system may not be required in locations where annual rainfall is less than $125 \mathrm{~mm} / \mathrm{yr}$ or the permeability of the subgrade exceeds $0.35 \mathrm{~mm} / \mathrm{s}$. As a result of these findings that point to the fact that the inclusion of subsurface drainage may not provide any meaningful contribution to the pavement in certain locations, many researchers are of the view that such features must only be included if their life-cycle costs outweigh the cost of installing and maintaining them. The challenge however faced by many pavement engineers in using some of these guidelines is how to obtain realistic performance data for the various types of subsurface drainage systems (Mallela et al. 2000).

Quantifying the economic impacts of subsurface drainage systems on pavement performance is a difficult exercise. This is primarily due to the scarce availability of performance data from controlled pavement sections that can adequately show the effects of including subsurface drainage systems on the pavement structural performance. Even some of the available performance data that are available in the literature are too limited in terms of variations in environmental conditions and design structural sections, thus making them unsuitable to draw generalized inferences about the economic impacts of subsurface drainage systems (Forsyth et al. 1987). 
Some of the references in literature often used to estimate inputs for use in the economic analysis of subsurface drainage are the works done by pioneer researchers like Cedergren (1974) and Markov (1982). A general review of the above cited literature references indicated that the inclusion of subsurface drainage system can extend the service life of flexible pavement by a minimum of four years and can extend the service life of a concrete pavement by $50 \%$. Most of the economic estimates for the positive effects of subsurface drainage systems have been based upon the above estimates of the increase in pavement service life for both flexible and rigid pavements. Based on these estimates, other researchers have developed simplify cost estimates for pavements sections with and without subsurface drainage systems. It is however quite obvious that these estimates are base on conservative assumptions. Therefore attempts to extrapolate results of these studies which are admittedly from a narrow scope of field studies to encompass all categories of subsurface drainage systems will lead to misleading estimates of the economic effects of positive drainage. Even recent studies by NCHRP 1-34 (NCHRP 2002) presented very limited findings on the cost effectiveness of subsurface drainage systems in both concrete and flexible pavements. The only conclusion of note from that study in this regard was that if subsurface drainage systems are properly designed and constructed, the performance of the pavement will be improved as a result of the reduction in the occurrence of moisture related distresses. It was however noted in that study that the inclusion of a drainage layer and associated edge drains can increase the cost of a highway project significantly and recommended that a detailed cost analysis be performed to determine the cost effectiveness of the subsurface drainage system. From the results of the experimental program of this research project, it was quite evident that the materials and gradations that make up a subsurface drainage component like the drainage layer have different hydraulic, mechanical and durability properties. This scenario therefore has lead to the design and construction of different kinds of drainage with various degrees of effectiveness and consequently different impacts on pavement performance.

A pavement can be drained in a variety of ways. This has led to the development of different kinds of pavement subsurface drainage systems. Pavement subsurface drainage 
systems have evolved over the years from simple unbound open-graded drainage bases to more structurally advanced stabilized drainage layers, separator layers, edge drains and outlet pipes (Hall and Correa 2003). The drainage layer consists of different aggregates types of varying gradation than can result in varying degrees of drainage.

Based upon conditions of traffic, climate and material availability, pavement designers have the options of selecting a wide range of base types that can function as a drainage layer. The pavement designer would however want to base his/her decision on a very sound engineering and economic basis. For instance, a pavement designer would want to base his/her selection of an Asphalt Treated Permeable Base (ATPB) over a Cement Treated Permeable Base (CTPB) based upon reliable estimates of how each will affect pavement service life. Rather than just applying the 50\% increment in pavement service life which a pavement section containing each of the two alternatives will experienced, the pavement designer would be better serve to make sound engineering judgment by the availability of mechanistic tools that can determine the relative contribution to pavement performance for each of these alternative drainage layers. Kazmierowski et al. (1994) conducted a study to compare the permeability and deflections of drainage systems consisting of CTPB, ATPB and an untreated permeable aggregate. Their conclusion was that while the permeability of all the drainage layers was sufficient to quickly drain out any moisture infiltrating the pavement within the acceptable time frame, the strength of the treated layers was superior to that of the untreated drainage layer. It was also found that the deflection on CTPB was about $17 \%$ less than that of the ATPB. Results of this nature are very helpful to pavement designers since they can be useful in the selection process of which types of materials should be used for a drainage layer for a particular pavement section based on conditions of traffic, environmental factors and cost.

A rational way to approach the economics of subsurface drainage systems would be to employ analytical tools that can realistically evaluate the performance of rigid pavement sections containing various subsurface drainage alternatives and then make comparisons to a "standard' undrained pavement section. In this way a reliable comparison can be made not only between drained and undrained pavement section but also between 
pavement sections having different types of drainage layer. Since pavement design is now shifting from a completely empirical base design to a more mechanistic one, it is fitting if pavement designers have at their disposal a set of mechanistic-empirical guidelines through which they can make realistic determination of the economic effects of positive drainage. These mechanistic tools should be able for instance give a reasonable estimates by how much percentage he faulting life of a pavement section is been increased by the inclusion of a particular subsurface drainage feature. This information can then be input into a life cycle cost analysis for rigid pavements section containing these alternative subsurface drainage systems.

In conducting a life cycle cost analysis for any given pavement section, both the performance and cost parameters for the section must be known (Rangaraj et al. 2008). The performance of the pavement section will in large part determine the cost estimation for that particular pavement section. As a result therefore, an efficient cost estimation of pavement subsurface drainage systems is therefore dependent upon the performance models use to predict pavement performance. The focus of this chapter therefore was to present a methodology that was developed to determine the relative differences in expected performance and expected costs of the various alternative subsurface drainage systems considered in this research project. The methodology was based on laboratory results of Chapter 4 and the computer simulations of pavement performance of Chapter 5 .

\subsection{Life Cycle Cost Analysis for Highway Infrastructure}

The ultimate purpose of pavement design is to produce an economic pavement section that meets conditions of traffic, climate and material properties. Pavements are typically designed for longer service lives and low maintenance facilities. In order to optimized these two basic design functions, pavement designers have at their disposal a variety of design features from which to choose from. Examples of these design features include widened lanes, tied concrete shoulder, doweled joints and subsurface drainage. To produce an economic pavement section, the cost of each of these design features must be carefully considered in terms of initial cost and established long term performance benefits (Cole and Hall 1997). Take for instance the case of using design features to 
minimize joint faulting in a concrete pavement section. The pavement designer can choose any of the three alternatives:

i. $\quad$ Doweled joint bars

ii. Unbound/bound drainage layer

iii. A combination of (i) and (ii) above

Each of the above alternatives has its own recurring cost and affects the initial construction cost of the project in different ways. Based upon the design specifications of the project, the pavement designer will choose which of these three alternatives can best produce an economic section which will meet all the performance criteria of the project. Highway pavements are an expensive part of a nation's infrastructure and the cost to maintain them annually is a huge financial burden on most highway agencies. In order therefore to build low life cycle cost pavements, it is imperative that pavement designers are provided with better decision support systems that will aid them to make sound decisions that are based not only on initial construction phase of the highway project but on its whole life cycle. This is now possible due to the availability of advanced and reliable pavement predictions models that are well suited to predict how a pavement will perform under conditions of design traffic and prevailing environmental conditions during its service life (Hagan and Cochran 1996).

Life cycle cost analysis is an analytical decision making procedure that helps pavement designer to evaluate the long term alternative investment options by taking into account all of the related costs that would occur throughout the life of the each alternative (Caltrans 2007). The end goal of conducting a life cycle cost analysis is the identification of the lowest cost alternative to carry out the projects consistent with the project's requirements. Even though it is not a federal mandate to conduct a LCCA for highway transportation infrastructure, the FHWA encourages States to however do likewise. As a result there has been a growing interest by many SHA to conduct LCCA and some States have even developed guidelines as to when the application of LCCA is appropriate for the various highway transportation projects. Some State DOTs like Michigan use LCCA for highway projects in excess of $\$ 40$ million while others like Caltrans uses a more 
detailed guideline that identifies situations where a LCCA may be needed to assist in determining the most appropriate and cost-effective alternative by comparing the life cycle cost of the following alternatives (Caltrans 2007):

$* \quad$ Different pavement types i.e. flexible, rigid or composite
$* \quad$ Different rehabilitation strategies
$* \quad$ Different pavement lives e.g. 5 years versus 10 years
$* \quad$ Different design features e.g. dowels or subsurface drainage
* Different construction strategies

\subsection{Components of a Life Cycle Cost Analysis}

A comprehensive life cycle cost analysis should be able to take into consideration all aspects of pavement performance, rehabilitation, social and economic impacts and public safety (Wilde et al. 1999). The challenge therefore in developing a framework for conducting a comprehensive LCCA is the development of new and reliable ways to quantify all the costs the pavement can incur during its life cycle. While the agency costs i.e. initial construction costs and future maintenance can be reliably be quantify due to the availability of improved pavement performance prediction models, the user cost however are difficult to quantify. This makes it quite difficult and tasking to conduct LCCA for all highway projects and this has lead to a scenario where LCCA varies from across the highway spectrum depending on what aspects of users' costs an agency choose to include in the LCCA.

The four major components of that comprise of any comprehensive LCCA are discussed below (Wilde et al. 1999):

\subsubsection{Pavement Performance}

How a pavement performs during its design life is a very critical component of any LCCA. A first step therefore in developing a comprehensive LCCA scheme is to accurately evaluate the pavement design and the environment conditions under which it is expected to operate throughout its service life. A crucial part of the LCCA is to be able to predict when a given pavement section is in need of maintenance or rehabilitation and 
which distress type will control the rehabilitation/maintenance needs for that particular section. A comprehensive LCCA should therefore be able to simulate both traffic and environmental loads on the pavements for each year of the analysis period and then employ realistic pavement performance models to predict the distress levels in the pavement section.

Since pavement design is now shifting from a largely empirical domain to a more mechanistic realm, the need to develop accurate and reliable pavement performance models cannot be overemphasized. Two considerations when developing appropriate prediction models are the establishment of acceptable distress levels in the design stage and the level of reliability used. A failure criterion should be established for each known distress that will occur in the pavement and the level of reliability at which the distress will occur should also be specified. Each highway agency can establish their own failure criteria and reliability levels depending on their design and construction practices. An illustration of the working of a pavement performance model is shown in Fig 6.1. Fig 6.1 shows the level of faulting and cracking that may become manifested in the pavement and it is obvious from the figure that both the faulting and cracking distresses have different failure criterion. The distress which first reaches its failure criterion is the one that will control the rehabilitation needs for the project. For the particular pavement section, taking performance criterion for faulting to be level 1 and that of cracking to be level 2, it can be seen that under application of both traffic and environmental loads, faulting reaches its terminal level much sooner than slab cracking. With faulting reaching its acceptable level, this will trigger some type of maintenance so as to keep the pavement section in acceptable riding condition. In general, anytime one of the designed distresses reaches its failure criterion, the LCCA enters a maintenance and rehabilitation mode. In its handling of the maintenance need and rehabilitation needs of this particular pavement section, LCCA assumes that all distresses regardless of their existing condition in the pavement are repaired while the work zone is in place for the maintenance activity related to the distress that triggers the maintenance and rehabilitation module(Wilde et al. 1999). This therefore calls for detail and accurate evaluation methods to determine which distress type is critical for a particular pavement section an then taking appropriate steps 
during design to make this distress type the governing failure criterion of that pavement section. Furthermore, the level of reliability use for each distress criterion should be choosing based on the type of pavement. It is advisable that for interstate highways since they represent the highest functional class higher reliability levels should be used when doing LCCA so as to ensure that the design pavement section will have a high probability of meeting or exceeding the anticipated service life.

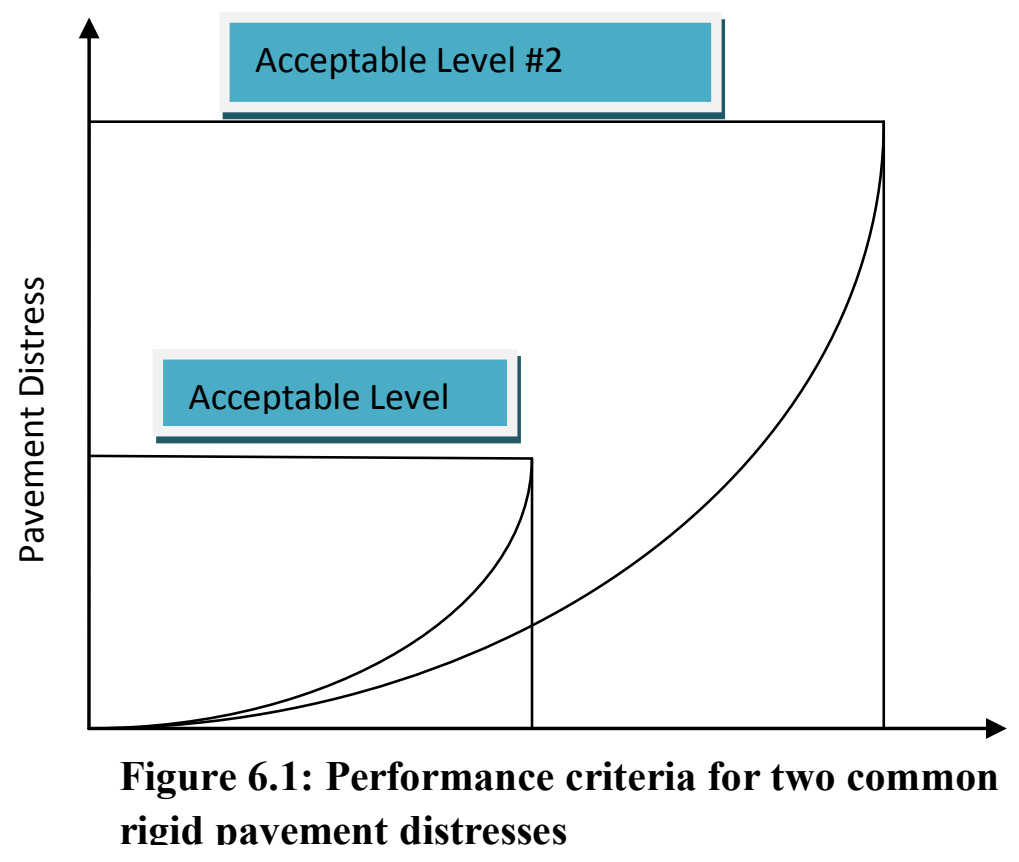

\subsubsection{Maintenance and Rehabilitation Strategy}

As has been previously mentioned in the previous section, the maintenance and rehabilitation comes into operation when the pavement section has failed with respect to any of the design distresses. The maintenance and rehabilitation used for inputs the predicted distress levels in the pavement performance module and then determine appropriate maintenance and rehabilitation strategies. The maintenance and rehabilitation module is built to reflect an agency's maintenance practices and as such the maintenance strategy recommended should always be based on individual transportation agency's preferences. The challenge always in the setting up of a maintenance and rehabilitation module is to develop maintenance and rehabilitation strategies that are consistent with an agency's budget, local soils, and environment and drainage conditions. 
There are basically two ways of conducting a maintenance and rehabilitation module. One way as previously mentioned is to use pavement distress levels predicted by the pavement performance module. For this method the performance models are used to predict when maintenance, rehabilitation or some form of major reconstruction must take place. The advantage of this method is that it helps the agency in resource allocation and in planning for future expenditures with respect to the highway facility. Another method besides pavement distress levels would be to carry out annual maintenance on the pavement section each year without having to resort any form of major rehabilitation. While this has the potential benefits of helping the agency to annually upgrade the pavement section, it also present the possibility of increased cumulative cost of maintenance over the life of the pavement particularly when the distress levels becomes higher with time. It should be expected that as the distresses on the pavement increase with pavement age, annual maintenance expenditures will also increased and as result the pavement section will reached a point when major rehabilitation may be the costeffective and reasonable decision (Wilde et al.1999).

\subsubsection{Users Costs}

User costs have been define as costs borne by the users of the transportation facility that are caused and attributable to the condition of the pavement, the presence of work zones and construction obstructions by the highway agency (Caltrans 2007). Unlike agency costs which can be valued and computed with a high degree of accuracy and reliability, users costs are difficult to measure and valued. Because of this many LCCA do not include any consideration for user costs. However, there are now reliable models that are available to predict the following user costs with sufficient degree of accuracy:

Travel time delay costs incurred while travelling at slower speeds through a work zone

Vehicle operating costs incurred while travelling at slower speeds through the work zone.

Presently other types of user costs like accidents which have economic impacts and are not directly tangible are calculated using other methods and are reported in non-monetary units. However travel time delay represents the single greatest components of user costs 
and as such is an important consideration in the design of highway facilities. User costs associated with a highway transportation facility can be very substantial and in some cases especially in urban settings they can exceed the agency costs by significant amount. Rangaraj et al. (2008) reported a case in El Paso Texas where the user costs associated with the construction of a bonded concrete overlay amount to over $\$ 1$ million per day which greatly exceed the construction cost of $\$ 4$ million. Since the essence of a LCCA is to compute all predictable costs that may have an impact on the highway facility, it is important that a comprehensive LCCA should attempt to quantify as much user costs as possible during the whole life cycle of the facility. Other types of user costs that related to highway construction and operation but there are currently no methods for measuring their economic effects are:

Excess vehicle emissions that are produced by vehicles in congested traffic

Increased in highway noise caused by the construction of a new highway or a particular pavement surface.

Vehicle accidents occurring at work zones

\subsection{Economic Components of LCCA}

There are various economic indicators available for the economic evaluation of highway projects. Prior to conducting a LCCA, a transportation agency needs to select an appropriate economic indicator for use in computing both present and future costs of the highway facility. Some of the more common economic indicators use in the transportation industry is benefit/cost ratio (B/C), Net Present Worth (NPW), Equivalent Uniform Annual Cost (EUAC) and Internal Rate of Return (IRR) (Rangaraju et al. 2008). The choice of an economic indicator however depends on several factors such as the economic environment in which the LCCA is being conducted. Ozbay et al. (2004) cited that in cases where the discount rate is highly uncertain like in the case of developing countries, the IRR methods seems to be the preferred economic indicator but according to 
Zimmerman (2000) the most commonly use economic indicators are the NPV and EUAC. A brief description of these economic indicators is given below:

B/C Ratio: This is ratio of net discounted benefits of an alternative to the net discounted costs. A B/C ratio greater than 1.0 indicates that the benefits of the investment outweigh the cost of that investment. Usually the alternative with the highest $\mathrm{B} / \mathrm{C}$ ratio is selected as the design alternative. The $\mathrm{B} / \mathrm{C}$ ratio economic indicator however is not widely use to evaluate highway infrastructural facilities due to the complexity in computing the various benefits and costs associated with the highway facility.

Internal Rate of Return: In cases where uncertainties about the discount rate exist or where budgets are constrained as in the case with developing economies, the IRR represent the best economic evaluation tool for highway infrastructural projects. The IRR is the discounted rate necessary to make discounted costs and benefits equalized. But according to Ozbay et al. (2003) the IRR does not generally provide the acceptable decision criteria but it does provide useful economic information in the cases mentioned above.

Net Present Worth (NPW): NPV is the presented discounted monetary value of net benefits. In order to compute the NPV for a particular alternative, monetary values are assigned to both the costs and benefits of the alternative and then discount these values to existing costs using an appropriate discount rate. The difference between the sum total of discounted benefits and discounted costs is the Net Present Value of that alternative. An alternative with a positive NPV is considered to increase social resources and is generally preferred whereas those with a negative NPV value are not economically feasible alternatives.

Equivalent Uniform Annual Cost (EUAC): This represents the net present worth of all discounted costs and benefits of an alternative and is treated as though they occur uniformly throughout the analysis period. This involves converting all the present and future costs of an alternative to a uniform annual cost. 


\subsection{Developing a Life Cycle Cost Analysis for Subsurface Drainage Systems: Previous Research}

The Federal Highway Administration (FHWA) in a report titled "LCCA for highway infrastructure" identified the following as basics steps in conducting a comprehensive life cycle cost (FHWA 2002):

i. Predict the expected performance of the pavement

ii. Develop rehabilitation and maintenance strategies for the analysis period

iii. Establish the expected life of the various rehabilitation and maintenance strategies

iv. Estimate the agency costs for construction, rehabilitation, and maintenance.

v. Estimate user and expected costs of the transportation facility

vi. Develop expenditure stream for each alternative

vii. Compute the present worth value for each alternative

viii. Analyze the results using either a deterministic or probabilistic approach

ix. Re-evaluate the strategies and developments

Fig 7.2 shows a flowchart for conducting a comprehensive LCCA. It can be seen from the flowchart that the two main activities that have profound impacts on the successful outcome of the LCCA are performance periods and activity timing as they both affect not only the agency costs but also the user costs. This just further underlines the significance of using sound mechanistic based pavement performance prediction models. Based upon the events and their respective timing as predicted by these two modules, the LCC framework basically assigns a cost i.e. both agency and user for each applicable component of each elements based on the agency's design and construction practices. The costs for each event are then sum up and discounted to the present time in order to obtain its present value which can then be use to compare with other alternatives (Hagen Cochran1996).

Cost estimation of the various components of a highway facility is of great significant and also how they affect the overall life cycle costs of the facility. The inclusion of 
subsurface drainage system can now be described as a critical component of most highway transportation facility and as such must be run through the LCCA framework in order to justify their inclusion in pavement design. There are two ways this can done. Firstly by considering the cost of subsurface drainage systems as an integral part of the total cost of the pavement or the estimation of the cost of subsurface drainage can be done separately from that of the pavement structure. The problem with the first approach is how the performance of a particular subsurface drainage can be truly related to its cost when all the various subcomponents of the pavement system have been integrated as a whole. The second approach offers a better way of isolating the subsurface drainage components and in so doing would be in position to better relate performance and cost indices for these measures. The difficulty in using the second approach however is how to get reliable relative performance estimates of subsurface drainage features within the overall context of pavement performance. 


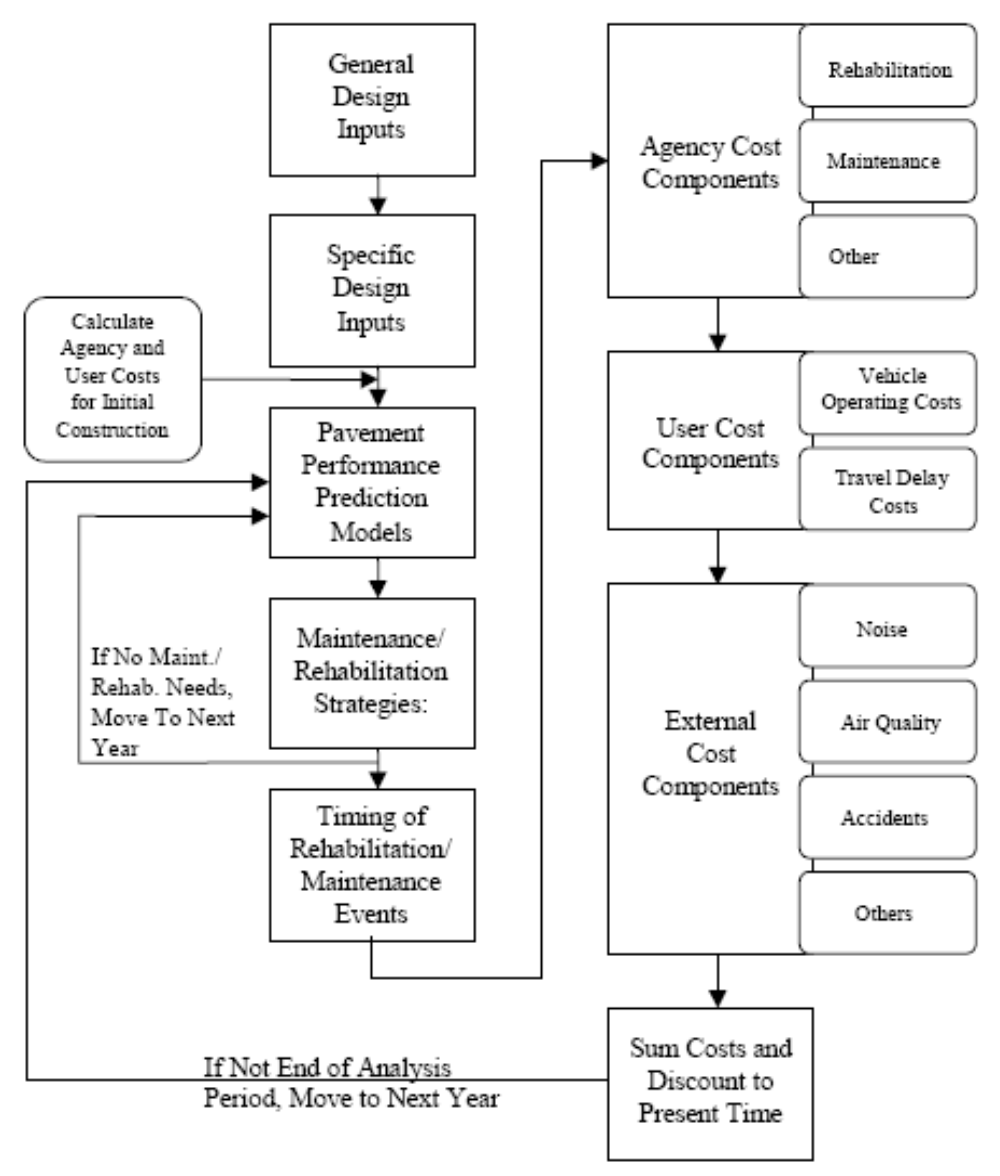

\section{Figure 6.2: $\quad$ Flowchart showing Comprehensive Life Cycle Cost Analysis Framework (Wilde et al. 99).}

From the foregoing it can be seen that the key to performing LCCA for subsurface drainage systems is to establish a relationship between performance and cost for the various subsurface drainage features. It is however difficult to establish such a relationship between performance and cost considering the limited data available. While many research efforts have been directed towards determining the performance of subsurface drainage features, not much has gone in terms of research on the costing aspect of these features (Cole and Hall 1997). The challenge always for the pavement design engineer is to select subsurface drainage features that not only meet the desired performance criteria but are also very cost-effective. But in the absence of well established and proven relationship between performance and cost of subsurface drainage features, the selection has been purely empirical tempered with engineering judgment. This further emphasized the importance of mechanistic performance prediction models in 
conducting appropriate LCCA of pavement alternatives. The new MEPDG with its pavement performance prediction capabilities offers a real practical help in this regard by enabling performance comparison to be made between two different pavement sections with different subsurface drainage features. Part of the goal of this study was to use the MEPDG software not only as a pavement performance prediction tool but also as a cost analysis tool. One area that the MEPDG software can be put into good effects is to determine the time maintenance and rehabilitation $(M \& R)$ strategies are needed on any given pavements. Since the MEPDG software has the capability to predict on a monthly basis the values of the critical pavement responses like cracking, faulting and IRI for rigid pavement sections, it becomes easier to determine the time when a particular pavement response falls below the accepted value. For instance, if a highway agency set up a predefined M\&R strategy for a certain level of faulting, then the MEPDG software is capable to predict what exact time in the pavement life that that particular M\&R strategy can be implemented.

\subsection{Previous Research on the economic impact of subsurface drainage}

The leading proponents of subsurface drainage system like Cedergren, and Lovergren have made very consistent efforts to make a case for the economic returns of providing subsurface drainage. Cedergern et al. (1974) estimated that providing subsurface drainage systems can increase the service life of flexible pavement by a minimum of 4 years and that of rigid pavement by $50 \%$ of their useful life. According to their estimates, this can amount to annual savings of $\$ 5,000,000$ per year. These estimates were based on the estimated time a pavement is exposed to saturated conditions.

Forsyth et al. (1987) conducted a study in which they reviewed the impact of positive drainage on the performance of selected pavements in California with the sole purpose of establishing cost-benefit relationship. They however indicated the difficulty in establishing such a relationship due to a lack of abundant controlled experimental data on the effects of subsurface drainage on pavement service life. The very few data available on the subject is very limited in terms of variation in subgrade and environmental 
conditions and structural design sections. Forsyth et al (1987) believed that a ,traditional' life cycle cost analysis was not appropriate in the case of subsurface drainage due to the following reasons:

- Conducting a life cycle cost analysis whose results can be attributed to the presence of subsurface drainage components is hard to establish and quantify

- Times during which specific maintenance and rehabilitation strategies should be undertaken are difficult to predict.

- It is difficult to establish and quantify which portion of the user costs can be attributed to subsurface drainage.

Because of the foregoing, their economic estimate of the impact of subsurface drainage was based on extremely conservative assumption about the increase in pavement service. These assumptions are:

1. Flexible pavements experienced a minimum increase of 4 years of service life with a drained system.

2. Rigid pavements likewise could experience a minimum of $50 \%$ extension of service life.

The pavement sections that were selected for this cost analysis were identical in loadcarrying capacity but different only by the inclusion of subsurface drainage system in each of the two basic pavement types. Using cost per square yard per year from construction to first rehabilitation as the cost indicator, they computed the following pavement costs:

A. Rigid Pavement

a) Pavement cost for Undrained section (assuming a design life of 20 years) is $\$ 1.47 / \mathrm{SY} / \mathrm{yr}$

b) Pavement cost for drained section (assuming a 30 year service life) is $\$ 0.87 / \mathrm{SY} / \mathrm{yr}$ 


\section{B. Flexible Pavement}

a) Pavement cost for the undrain section (assuming a design life of 12 years) is $\$ 2.12 / \mathrm{SY} / \mathrm{yr}$

b) Pavement cost for drained section (assuming a 16 year service life) is $\$ 1.67 / \mathrm{SY} / \mathrm{yr}$

From the above figures, an annual saving of $41 \%$ can be realized for a concrete pavement section due to the addition of subsurface drainage features while an annual saving of $21 \%$ was realized for the flexible pavement. Forsyth et al. (1987) extrapolated these annual savings to the number of lane miles constructed annually in California. At the time of the report, California was constructing 200 lane miles of new pavement annually of which $20 \%$ are rigid and $80 \%$ flexible. Using the cost savings calculated above the total amount of annual savings of $\$ 5 \mathrm{M}$ and $\$ 8 \mathrm{M}$ for rigid and flexible pavements respectively can be realized. A total annual savings of $\$ 13 \mathrm{M}$ is therefore realized throughout the service life of the pavement constructed in any given year due to the addition of subsurface drainage features in the design. This figure of course excludes the savings due to increased service life from the retrofit edge drains installed on in-service pavements or maintenance and uses costs. While these figures look very impressive from an economics standpoint, they are however based on very flaw assumptions of the increase of pavement life due to subsurface drainage features. In the light of recent research that has shown the durability issues associated with both treated and untreated permeable bases coupled with a malfunctioning of many edge drain systems, it is almost impossible to validate the assumptions made by Forsyth et al. (1987).

The FHWA sponsored research that culminated in a report whose end product is a software analysis that can be used by pavement designers to evaluate the relative performance benefits and costs associated with adding different design features to a rigid pavement design. This software tool was aim at helping the pavement design process by comparing costs versus performance associated with the selection of design features in PCC pavement design process. The design features selected for this study are listed below in order of importance: 


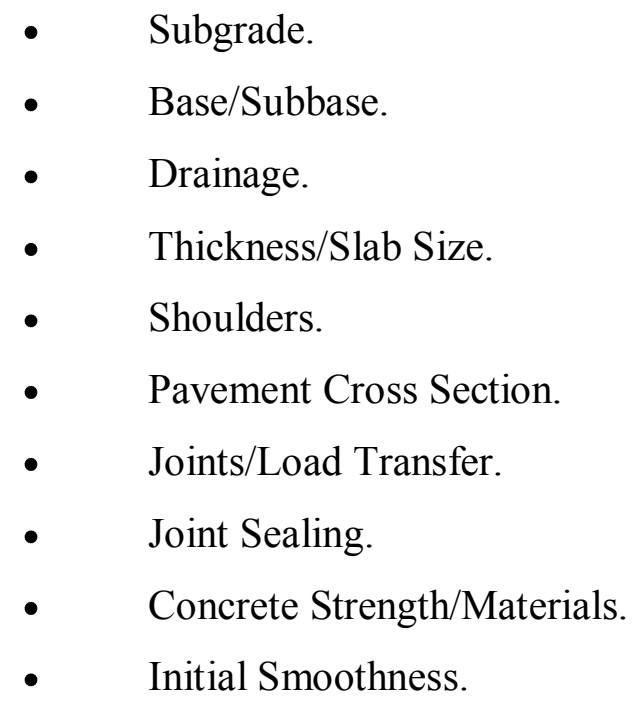

The study was based on relative cost to determine the effects of the above design features on the overall performance and cost of concrete pavements. A standard pavement section was defined and assigned a relative cost value of 100 . The standard reference section was then modified by changing a specific design feature and contractors were then asked by means of a survey to determine the relative cost of the modified section. Fourteen U.S. concrete paving contractors took part in the survey. Using this approach therefore one can determine the cost effectiveness of various subsurface drainage features albeit in relative costs and not in real dollars. The problem though with this approach is trying to two parameters with completely different units of measurements. As noted by Cole and Hall (1997) whereas costs can be measured in a single unit of measurement i.e. in terms of dollars, performance on the other hand is more difficult to quantify in a single unit of measurement. Such a scenario makes it difficult to make direct comparison between performance and cost since they have different units of measurements. As a result any changes in cost and performance as a result of changes in other design features cannot be directly compared because the units of measurements are dissimilar.

Another study that attempted to quantify the economic impact of subsurface drainage was that carried out by Zaghloul et al. (2004) in which they investigated the effect of positive drainage on flexible pavement life cycle cost using two case studies. Their study was based on evaluating the effect of higher base course saturation on the insitu structural 
capacity of pavement. They conducted deflection testing on a number of pavements using the Falling Weight Deflectometer (FWD). Using a Structural Adequacy Index (SAI) to assess the structural service life of the pavement, they were able to show the reduction in SAI due to high base course saturation. This change in SAI due to moisture content levels in the base layer was then use as input data in a life cycle cost analysis model to determine the effect of higher moisture content on the pavement life cycle cost. The study concluded that a moisture content increase of 16-45\% in the base course resulted in the reduction of pavement service life from 13-7 years for a design period of 40 years that translated to a threefold increase in life cycle cost for a $250 \mathrm{ft}$ long flexible pavement section. The conclusion from this study was that reducing the base course saturation through various subsurface drainage features can extend the service life of a pavement that can lead to substantial long term savings.

One other study that also investigated the economics of pavement subsurface drainage which is similar to that of Zaghoul et al. (2004) was carried by the Minnesota Department of Transportation (MnDOT). This study by Arika et al. (2009) was based on the hypothesis that excess water in a pavement structural section will reduced the pavement's longetivity and increase the associated maintenance cost that are put in place to keep the pavement in a serviceable conditions throughout its design life. This increase in maintenance cost was then considered as a fraction of the total initial construction cost of the pavement. Rather than developing a SAI as was done by Zaghoul et al. (2004), Arika et al. (2005) developed a relationship between the pavement's fatigue life and the increase in subgrade moisture content due to poor internal drainage of the pavement's structural section. Using the Equivalent Uniform Annual Cost (EUAC) economic indicator, they were able to apply this relationship to determine that an increase of $5 \%$ in the moisture content of the subgrade will decrease the fatigue life of the pavement by $12 \%$ and hence a reduction in its life cycle cost by $20 \%$. This means that assuming a design life of a rigid pavement to be 30 years, a 5\% increase in the subgrade moisture content will reduce the useful life to 24 years. Using a discount ratio of $7 \%$, the increase in the initial construction cost of the pavement was computed at $12.5 \%$. 
While these two approaches to determine the cost-effectiveness of using pavement subsurface drainage features are simplistic in nature, they can only be carried out on inservice pavements. They can't be use in the design process since appropriate analytical methods are needed to predict the moisture regime within the pavement structure over the design life of the pavement.

\subsection{Calculation of Life Cycle Cost from performance prediction data}

The two LCCA approaches used in this research closely mirrored those of Forsyth et al. (1997) and that of Gharaibeh et al. (2001) with some significant modifications.

The methodology used by Gharabeil et al. (2001) is outlined below:

○ Define project site condition

- Establish future performance based Maintenance and Rehabilitation (M/R) policy.

- Develop a reference design pavement section whose relative intial construction cost is $100 \%$.

- Predict the performance of the pavement section for the given site conditions

- Apply M/R policy and calculate total net present worth value.

- Modify the design by replacing one type of drainage layer with another and compute the relative initial construction costs (RICCi).

- Predict performance for this modified section and then calculate the relative NPW value for the modified design(i) expressed in percentage of NPW of the referenced section as shown in Equation 6.1:

$$
R L C C i=L C C i * 100 / \text { LCCref } \quad \text { Equation } 6.1
$$


The key difference between the approach adopted in this study and the one outline above lies in the differences in pavement performance prediction software used. Whereas the study by Ghabriel et al. (2001) used PaveSpec 3.0 PRS software as the pavement performance prediction tool, this study however used the MEPDG software as the pavement performance prediction software. The reason for this is because the MEPDG software represents the new transition from a purely empirical approach to pavement design to a mechanistic one and as such it contains the most recent distress models that have been developed and validated using the extensive LTPP databases. Furthermore, due to the limitations of relative cost as effective index to compare the cost-effectiveness of pavement sections as discussed earlier, the LCCA approach used in this research was not based on relative cost but rather on actual costs computed for each pavement section.

The first step in the LCCA approach employed in this research was to define a reference section based upon existing design philosophy for rigid pavements. This referenced section is one that basically lacks any subsurface drainage components and is assumed to have reduced service life and consequently a higher life cycle cost. Once this reference has been so define, alternative pavement sections were then developed by modifying this referenced pavement section. Since the thrust of this research is on subsurface drainage, the only modification that was made to the referenced section was replacing base. Users' costs were not included in the life cycle cost analysis. The difficult though for a research of this nature is to determine appropriate $M \& R$ policies since most highway agencies adopt different M\&R policies based on the individual agency's design and maintenance philosophy and available resources. However, the capability of the MEPDG software to

predict the performance of the pavement on a monthly basis over the entire design life makes it easier to set trigger values for the different types of M\&R strategies.

\subsection{Pavement Performance prediction for LCCA}

In order to facilitate the computation of life cycle cost analysis, only three pavement sections from the six sections considered in Chapter 5 will be utilized. These three sections are shown in Fig 6.3: 


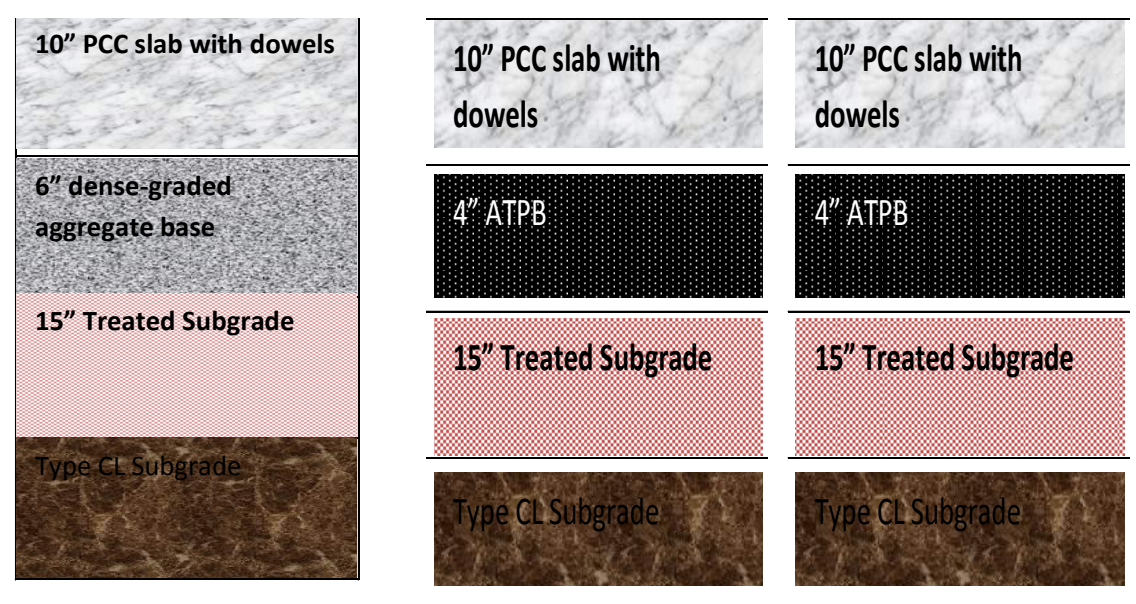

Figure 6.3: Pavement sections used in LCCA

The three pavement section selected contain three categories of bases normally use in rigid pavement. Pavement section 1 with the 6" dense graded is considered the standard section since it symbolizes a typical pavement with little or no drainage. Pavement section 2 contains the ATPB, which was designed to offer greater drainage to the pavement section than the standard section. Pavement section 3 contains the highly stabilized and non-erodible Asphalt Treated Base (ATB). All three pavement sections have dowel bars and pavement section 2 have additional design features namely edge drains and outlet pipes which are necessary to help in the removal of moisture from the pavement structural sections.

Two approaches of predicting pavement performance as predicted by the MEPDG software was used in this LCC analysis. The aim here was to determine how effective the predictive capabilities of the MEPDG can be put into practical effect in evaluating the life cycle costs of various rigid pavement sections. These two methods are the extended service life and slab reduction methods: 


\section{Extended Service Life Method}

In this approach a minimum slab thickness for pavement section 1 was found based on traffic, environmental and material input data using MEPDG iterations. This minimum thickness is the minimum required thickness to satisfy all three performance criteria of IRI, mean joint faulting and thermal cracking at the designated reliability. Using the same minimum slab thickness obtained for PS1, the MEPDG software was then used to predict the pavement performance of both pavement sections 2 and 3. Since cracking is not a controlling pavement response for thicker slabs, the mean joint faulting was selected as the pavement criterion that controls M\&R events. Once a value of mean joint faulting has been predicted for both PS2 and PS3, the extended life of these two sections was then determined. The extended life in this case is defined as the additional years it will take for both pavement sections 2 and 3 to reach the same mean joint faulting value as that of predicted for pavement section 1. In order to determine the extended life for pavement sections 2 and 3, the predicted performance of these sections were simulated using the MEPDG software by incrementally increasing the design life by a period of one year. The simulation was continued until a predicted mean joint faulting value that is very close to the faulting value of PS I was reached. The extended life was simply the difference between this new design life and the original design life. This difference was then taking to mean the additional benefits in years that can gain by the use of the treated permeable base like ATPB. This extended service life was then used in the subsequent life cycle cost calculations.

\section{2. $\quad$ Slab Reduction Method}

In this method, rather than maintaining the same minimum slab thickness for all three pavement sections, a minimum slab thickness was obtained for each of the three pavement sections for the conditions of traffic, climate and material inputs. The difference in minimum slab thickness between PS2 and PS1 was taking to mean the positive effects or benefits gained by using the treated permeable bases ATPB. This approach is more meaningful with regards to initial cost since it considerably lowers the 
initial construction cost of the PS2 and PS3 and in the process make them not only competitive in terms of life cycle costs but also in terms of initial construction cost.

In order to make this LCCA as practicable as possible, the three performance criterions selected were based on the level of truck traffic and the ASSHTO functional classification of highways. Table 6.1 shows the values of the performance criteria and reliability levels used in the pavement prediction phase of the LCCA calculations.

\section{Table 6.1}

Performance criteria and reliability levels used in LCCA

\begin{tabular}{|l|l|l|l|}
\hline Truck traffic level & $\begin{array}{l}\text { Mean joint faulting } \\
\text { (in) }\end{array}$ & Cracking (\%) & $\begin{array}{l}\text { IRI } \\
\text { (in/mi) }\end{array}$ \\
\hline Low & 0.25 & 20 & 200 \\
\hline Medium & 0.20 & 15 & 200 \\
\hline High & 0.15 & 10 & 160 \\
\hline
\end{tabular}

Tables 6.2 and 6.3 show the results of the simulations for the extended life and slab reduction methods respectively: Tables $6.4,6.5$ and 6.6 give the summary of the predicted pavement responses for the three truck traffic levels for three pavement sections. It can be seen from the values of the predicted pavement response that for low traffic, the mean joint faulting for the three sections is $0.060,0.036$ and 0.035 for PS1, PS2 and PS3 respectively. From these results it can be seen that both pavement sections 2 and 3 did experienced a reduction in faulting by $43 \%$ to that pavement section 1 . This reduction in faulting can be rightly attributed to the use of ATPB and ATB in pavement section 2 and 3 respectively. From Table 6.5 showing the extended design life of the pavements, it can be seen that it will take PS 2 an additional 12 years to have the same value of faulting as PS1. This additional 12 years was credited to mean the increase in pavement life as a result of using the treated open-graded base, ATPB. 
Table 6. 2

MEPDG predicted design life for the three pavement section

\begin{tabular}{|c|c|c|c|}
\hline \multirow{2}{*}{ Traffic level } & \multicolumn{3}{|c|}{ Predicted design life (Years) } \\
\cline { 2 - 4 } & PS1 & PS2 & PS3 \\
\hline Low & 30 & 42 & 42 \\
\hline Medium & 30 & 59 & 59 \\
\hline High & 30 & 72 & 72 \\
\hline
\end{tabular}

Table 6.3

MEPDG predicted slab thickness for the three pavement sections

\begin{tabular}{|c|c|c|c|}
\hline \multirow[b]{2}{*}{ Traffic level } & \multicolumn{3}{|c|}{$\begin{array}{c}\text { Minimum slab thickness } \\
\text { (in) }\end{array}$} \\
\hline & PS1 & PS2 & PS3 \\
\hline Low & 7.5 & 7.5 & 7.5 \\
\hline Medium & 14.5 & 11.5 & 11 \\
\hline High & 20 & 17 & 16.5 \\
\hline
\end{tabular}




\subsection{Computation of the Economic Benefits of using a Drainage Layer.}

Based on the MEPDG output of the previous sections, the following indices were computed:

1. Cost per square yard per year from construction to first rehabilitation. This index used only the extended design life of Table 6.2. The pavement section with the lowest cost per square yard per year is considered the most cost-effective.

2. Life cycle cost. This index used both the predicted extended design life of Table 6.2 and the minimum slab thicknesses of Table 6.3 to compute the life cycle cost of each pavement. The life cycle costs were calculated for a 90 year design period. The following construction cost data used in the LCC analysis were taken from MDOT LCCA unit prices for 2005 shown in Appendix A:

○ Conc Pavt, nonreinforced, 8”@\$19.32/SY

○ Conc Pavt, nonrinforced, 12"@\$21.16/SY

○ Conc Pavt, nonreinforced, 15”@27.26/SY

○ Aggregate Base, 6”@\$3.78/SY

○ ATPB, 4”@\$23.43/SY

○_ATB, 6”@\$30/SY

○_Embankment, earth @\$3.36/CY

○ $\quad$ Edge drains, @\$10.75/SY

○_Outlet, @\$17.50/LF

A 1 mile 2-lane highway pavement with a standard pavement width of 12' was used for the analysis. The following M\&R strategies were assumed for pavement section1:

i. $\quad$ Patch and diamond grinding at year 30 and $40 @ \$ 3.85$

iii. 3" AC overlay at year $40 @ \$ 16.45 / \mathrm{SY}$ 
iv. 3" Mills/3" AC overlay at years 50, 60, 70, $80 \& 90 @ \$ 21.23 / \mathrm{SY}$

For pavement sections 2 and 3, a highly improbable M\&R strategy was assumed that the two sections do not require any maintenance of any kind until the $80^{\text {th }}$ and $90^{\text {th }}$ year:. This is a highly unlike scenario but was chosen as the best case scenario that the use of drainage layer will bring to the pavement. The aim here was to assess how the life cycle costs of the referenced pavement section compare to life cycle costs to the best performed of pavement sections 2 and 2. The following M\&R strategy was therefore adopted: Patch and Diamond Grinding at years $80 \& 90 @ \$ 6.185 / \mathrm{SY}$.

Based on these assumed M \& R strategies, the following life cycle costs were computed based on the Present Worth given in Equation 6.2 using a discount rate of 5\% and a $0 \%$ inflation rate.

$$
P V=F V^{*}(1 /(1+i) n) \text { Equation } 6.2
$$

Where

$\mathrm{PV}=$ present value of the future M\&R activity

$\mathrm{FV}=$ future value of M\&R activity

$\mathrm{i}=$ discount rate

$\mathrm{n}=$ year in which $M \& \mathrm{R}$ cost was applied

Once the present value for each M\&R activity has been calculated, the Net Present Value for the pavement section for each traffic level is then computed from the following equation 6.3:

$$
N P V=\text { InitialCost }+\sum P V \text { Equation } 6.3
$$

Where

$\mathrm{NPV}=$ total net present value of a given pavement section

The pavement section with the lowest NPV is considered the most cost-effective 
Table 6.4 through Table 6.7 showed the computed cost per square yard per year for the three pavement sections. Table 6.7 and Table 6.8 showed the computed initial cost and life cycle costs for the three pavement sections.

Table 6.4

Pavement cost for three pavement sections for the low truck traffic scenario

\begin{tabular}{|c|c|c|c|}
\hline Pavement Section & Layer & $\begin{array}{c}\text { Cost } \\
(\$ / y d 2)\end{array}$ & $\begin{array}{l}\text { Pavement Cost } \\
\quad \$ / \mathrm{yd} 2 / \mathrm{yr}\end{array}$ \\
\hline \multirow[b]{3}{*}{ PS1 } & $7.5^{\prime \prime} \mathrm{PCC}$ & 18.11 & \multirow[b]{3}{*}{0.85} \\
\hline & 6" DGA & 4.29 & \\
\hline & $15^{\prime \prime} \mathrm{TS}$ & 3.09 & \\
\hline \multirow[b]{3}{*}{ PS2 } & $7.5^{\prime \prime} \mathrm{PCC}$ & 18.11 & \multirow[b]{3}{*}{1.26} \\
\hline & 4" ATPB & 23.66 & \\
\hline & $15^{\prime \prime} \mathrm{TS}$ & 11.25 & \\
\hline \multirow[b]{3}{*}{ PS3 } & $7.5 " \mathrm{PCC}$ & 18.11 & \multirow[b]{3}{*}{1.22} \\
\hline & 4" ATB & 30 & \\
\hline & $15^{\prime \prime} \mathrm{TS}$ & 3.09 & \\
\hline
\end{tabular}


Table 6. 5

Pavement cost for three pavement sections for the medium truck traffic level

\begin{tabular}{|c|c|c|c|}
\hline \multirow{4}{*}{ Pavement section } & Layer & Cost $(\$ / S Y)$ & Pavement cost \\
\hline \multirow{2}{*}{ PS1 1 (SY/YR) }
\end{tabular}


Table 6. 6

Pavement cost for three pavement sections for the high truck traffic level

\begin{tabular}{|c|c|c|c|}
\hline Pavement section & Layer & Cost $(\$ / S Y)$ & $\begin{array}{c}\text { Pavement cost } \\
(\$ / S Y / Y R)\end{array}$ \\
\hline \multirow[b]{3}{*}{ PS1 } & $14.5^{\prime \prime} \mathrm{PCC}$ & 46.28 & \multirow[b]{3}{*}{2.68} \\
\hline & 6" DGA & 4.29 & \\
\hline & $15^{\prime \prime} \mathrm{TS}$ & 3.09 & \\
\hline \multirow[b]{3}{*}{ PS2 } & $14.5^{\prime \prime} \mathrm{PCC}$ & 46.28 & \multirow[b]{3}{*}{1.25} \\
\hline & 4" ATPB & 23.66 & \\
\hline & $15^{\prime \prime} \mathrm{TS}$ & 11.25 & \\
\hline \multirow[b]{3}{*}{ PS3 } & $14.5^{\prime \prime} \mathrm{PCC}$ & 46.28 & \multirow[b]{3}{*}{1.22} \\
\hline & 4" ATB & 30 & \\
\hline & $15^{\prime \prime} \mathrm{TS}$ & 3.09 & \\
\hline
\end{tabular}


Table 6.7

Initial construction cost of the three pavement sections.

\begin{tabular}{|c|c|c|c|c|}
\hline \multirow{2}{*}{$\begin{array}{l}\text { Truck } \\
\text { Traffic } \\
\text { level }\end{array}$} & \multicolumn{3}{|c|}{ Pavement structural section } & \multirow{2}{*}{$\begin{array}{l}\text { Initial construction cost } \\
(\$)\end{array}$} \\
\hline & $\begin{array}{l}\text { Pavement } \\
\text { section1 }\end{array}$ & $\begin{array}{l}\text { Pavement } \\
\text { section2 }\end{array}$ & $\begin{array}{l}\text { Pavement } \\
\text { section } 3\end{array}$ & \\
\hline & 8" PCC & $8 " \mathrm{PCC}$ & 8" PCC & 640,000 \\
\hline & 6" DGA & 4" ATPB & 4" ATB & $1,123,000$ \\
\hline Low & $\begin{array}{c}15 " \text { Treated } \\
\text { Subgrade }\end{array}$ & $\begin{array}{c}\text { 15" Treated } \\
\text { Subgrade }\end{array}$ & $\begin{array}{l}\text { 15" Treated } \\
\text { Subgrade }\end{array}$ & $1,140,000$ \\
\hline \multirow{3}{*}{ Medium } & $12 " \mathrm{PCC}$ & $12^{\prime \prime} \mathrm{PCC}$ & 8" PCC & \multirow{3}{*}{$\begin{array}{c}930,000 \\
1,421,000 \\
1,438,000\end{array}$} \\
\hline & 6" DGA & 4" DGA & 4" ATB & \\
\hline & $\begin{array}{l}\text { 15" Treated } \\
\text { Subgrade }\end{array}$ & $\begin{array}{l}\text { 15" Treated } \\
\text { Subgrade }\end{array}$ & $\begin{array}{l}\text { 15" Treated } \\
\text { Subgrade }\end{array}$ & \\
\hline \multirow{3}{*}{ High } & $15 " \mathrm{PCC}$ & $15^{\prime \prime} \mathrm{PCC}$ & $8 " \mathrm{PCC}$ & \multirow{2}{*}{$1,161,000$} \\
\hline & 6" DGA & 4" ATPB & 6" ATB & \\
\hline & $\begin{array}{l}15 " \text { Treated } \\
\text { Subgrade }\end{array}$ & $\begin{array}{l}15 " \text { Treated } \\
\text { Subgrade }\end{array}$ & $\begin{array}{l}15^{\prime \prime} \text { Treated } \\
\text { Subgrade }\end{array}$ & $1,644,000$ \\
\hline
\end{tabular}




\section{Table 6.8:}

\section{Computed Life cycle costs for the three pavement sections}

\begin{tabular}{|l|c|c|c|}
\hline \multirow{2}{*}{\multicolumn{1}{|c|}{ Traffic level }} & \multicolumn{3}{c|}{ Computed life cycle costs (\$) } \\
\cline { 2 - 4 } & PS 1 & PS 2 & PS 3 \\
\hline Low & $1,186,000$ & $1,200,000$ & $1,206,000$ \\
\hline Medium & $1,445,000$ & $1,465,000$ & $1,467,000$ \\
\hline High & $1,720,180$ & $1,721,240$ & $1,723,650$ \\
\hline
\end{tabular}

It can be seen from the values on Table 6.8 that the PS1 has the lowest life cycle cost for all three traffic levels.

The MEPDG predicted that for high traffic conditions, both pavement sections 2 and 3 will have an additional 40 years of useful life than PS1. However, even when the life cycle cost analysis was based on this projected design life for pavement sections 2 and 3 design life, the standard pavement section still turn out to be the section with the lowest life cycle cost.. The only possible way the pavements sections 2 and 3 can be made to have a lower life cycle costs than PS1 is a reduction in initial cost that may arise from a reduction in slab thickness. This was the approach used in the first cost analysis where the index used to compare the pavement sections was the cost per square yard per year from construction to first rehabilitation. It can be seen that for low traffic, the standard section PS1 has the lowest cost per square yard per year of the three sections. This by interpretation means that for low truck traffic conditions, incorporation a treated drainage layer like ATPB is not a cost-effective design option. However, for the middle and high truck traffic levels, both pavement sections 2 and 3 have lower cost per square yard per year than that of the standard section. Based on these results, it is more cost-effective to use a pavement section with a drainage layer for medium-high traffic conditions. On the basis of these results, the use of PS2 can lead of cost savings of 34\% and 53\% for medium and high traffic conditions respectively. A closer examination of Table 6.2 shows that the extended service life methods yielded the same predicted design life for 
PS2 and PS3. The simulation was rerun again to cross-check for possible errors since the ATB and ATPB bases have different thicknesses and mechanical properties but the rerun gave the same results as earlier predicted. However, looking at the results of the slab reduction method, there is a noticeable difference in required slab thickness for PS2 and PS3. This difference in the result of the two methods shows that the slab reduction method may be more sensitive to the drainage characteristics of the base layer than is the extended service life method.

\subsection{Discussion of Results from Life Cycle Costs Analysis}

This chapter attempts to quantify the economic benefits if there are any that comes from the use of permeable bases like ATPB in rigid pavement sections compared to pavement sections with traditional bases like DGA and ATB bases. The LCCA was based on pavement performance as predicted by the MEPDG software and various M\&R policies were also assumed. The results show that the pavement section 1 with the traditional dense-grade aggregate base was the most cost-effective pavement section of the three. Even when conservative assumptions like taking the design life of pavement section 1 to be 20 years instead of 30 years and future maintenance costs of edge drains and outlet pipes were excluded included from life cycle cost analysis of pavement section 2, the referenced pavement section still turns out to be the most cost-effective pavement section by having the lowest cycle cost for all three traffic levels. However, cost analysis using the cost per square yard per year from construction to first rehabilitation showed that both PS2 and PS3 are cost-effective design options to PS1 for both medium and high traffic site conditions. The difference in the outcomes between the two methods used to carry out the cost analysis may be largely due to the assumptions made with regards to the M\&R strategies used in calculating the life cycle costs.

\subsection{Importance of Limitations and Assumptions}

It should however be noted that the life cycle cost analysis made several assumptions with regard to cost and performance of the three pavement sections under consideration. As a result therefore, these results are not intended to prove that the use of permeable bases like ATPB is not cost-effective. Furthermore, the MEPDG analysis of Chapter 5 
was based in large part on level 3 design inputs which makes the predicted pavement performance questionable to certain extent. Another limitation also was that user costs were not included in the analysis, and their inclusion could have made a very big difference in life cycle cost especially considering the fact that pavement section 1 was assumed to undergo more M\&R activities than pavement sections 2 and 3. It has been shown that in certain cases users costs associated with M\&R activities can be higher than initial construction costs and a such if holistic LCCA is conducted that incorporates user costs, the results of the LCCA will be different. Despite these limitations, what these results do indicate is the potential of pavement analysis tools like the MEPDG can be put into good effects in determining cost-effective pavement sections. With the use of higher level of inputs, the predictive accuracy of the MEPDG can be improved upon and more realistic life cycle costs can be obtained. In summary therefore, what this limited life cycle cost analysis revealed is that even though rigid pavement design features like treated permeable bases are known to significantly improve pavement performance, justifying their inclusion on cost-benefit basis using current LCCA tools is difficult. Since the initial cost of pavement sections containing these permeable bases can be very high compared to those with dense graded bases, it is important that existing analytical tools be improved upon so as to better be able to determine the cost-effectiveness of design features like ATPB. However, judging from the result of this limited LCCA analysis and other results contained in the literature of the economic benefits of pavement subsurface drainage systems; it is quite evident that the decision to include subsurface drainage components like treated and untreated permeable bases will continue to be largely an empirical process. 


\section{CHAPTER 7}

\section{RESEARCH SUMMARY, CONCLUSIONS, RECOMMENDATIONS AND TECHNOLOGY TRANSFER.}

\subsection{Research Summary}

The focus of this research project was to determine the performance and costeffectiveness of pavement sections containing treated and untreated drainage layer using a combined experimental and analytical approach. A detailed review of the literature on the evolution of pavement subsurface drainage and its impact on pavement performance was carried out. In order to achieve this stated objective, an experimental program was designed that involves conducting a series of laboratory tests to investigate the hydraulic, mechanical and durability characteristics of three common aggregates use in Michigan as pavement bases. The three aggregates were natural gravel, dolomite and recycled concrete aggregate. Laboratory tests were carried out on both treated and untreated samples of these three aggregates. In an effort to capture the wide variability in material properties of both treated and untreated drainage layers comprising of these three aggregates, a wide range of samples were designed and tested. Based on the results of the laboratory tests, the hydraulic capacity, structural stability and durability of drainage layers comprising of these three aggregates was assessed.

Using the new Mechanistic-Empirical Design Guide (MEPDG) software several simulations of pavement performance was carried out on pavement sections containing both treated and untreated drainage layers made from these three aggregates. In an effort to capture the range of traffic and environmental conditions under which the use of these drainage layers is of practical necessity and economical, four climatic regions and three truck traffic levels were used in the MEPDG simulations of pavement performance. The four climatic regions were Wet-Freeze, Wet/No-Freeze, Dry-Freeze and Dry/No-freeze. 
Average Annual Daily Truck Traffic (AADTT) representing low, medium and high truck traffic volume of 500, 5000 and 10,000 respectively were use in the simulation process.

As part of the computer simulations of pavement performance on rigid pavement sections containing treated and untreated drainage layers, a sensitivity analysis of critical subsurface drainage material properties like the coefficient of hydraulic conductivity, mixed design properties and erodibility level was also carried out. A total of six rigid pavement sections were used in the computer simulations and the performance of these sections in terms of both faulting and International Roughness Index (IRI) was predicted using the MEPDG software. Due to the lengthy time require to run one simulation for a flexible pavement section and considering the high numbers of iterations involved, the MEPDG simulations of pavement performance does not included any flexible pavement sections.

Based on the predicted performance of the pavement sections under consideration and an assumed Maintenance and Rehabilitation (M\&R) policy, a life cycle cost analysis was carried out to determine the most cost-effective pavement section. Deviating from traditional methodologies used to assess the economic impact of positive drainage on pavement performance; this research provided a realistic way of assessing the costeffectiveness of pavement sections having a drainage layer assuming the predictive capabilities of the MEPDG software can be relied upon.

\subsection{Conclusions}

The following conclusions which are based on the research work performed are a summary of the conclusions contained in earlier chapters:

1. The effectiveness of a pavement subsurface drainage layer is strongly related to the hydraulic, mechanical and durability characteristics of its constituent materials. Due to the wide variability in material properties of these layers, it is hard to predict the level of performance they can bring to a given pavement section with their inclusion.

2. The quality of aggregate plays a critical role in defining the hydraulic, mechanical and durability characteristics of both treated and untreated drainage layers. Dolomite 
which is the superior aggregate of the three aggregates under investigation did produced open-graded samples with better material properties than the other two aggregates. The other two aggregates even though they are have inferior material properties to that of dolomite did produce some samples with acceptable material properties required of a drainage layer. However, as important as the quality of aggregate is to effective functioning of the drainage, this research shows that a combination of other factors like gradation, mix design and method of compaction play a critical role in producing a drainage layer that meets the requirement of drainability, stability and durability.

3. That current mix designs for both treated and untreated open-graded pavement layers that are geared towards providing a more porous matrix will provide drainage layers that have long term stability and durability problems. This research showed that an optimal mix for both treated and untreated open-graded base course that meets the three critical requirements of drainability, stability and durability is attainable. Even when they are treated with small amount of cement or asphalt binder, the use of gradations like the MDOT 5G which are too "open" produced open-graded samples that are extremely difficult to prepare and test in the laboratory and in the field.

4. Untreated open-graded samples even though they are of inferior stability and durability to those of treated open-graded samples, produced acceptable coefficient of hydraulic conductivity and resilient modulus values. This makes them suitable to effectively perform both the traditional role of a load-carrying layer whilst at same time meeting the drainage needs of the pavement. Depending on the mix design and degree of compaction, both the cement and asphalt treated open-graded samples have superior material properties needed to act as a drainage layer. The durability tests used in this research project may not fully capture the long term environmental conditions to which these samples may be exposed to in the field.

5. The MEDPG software, while it is a useful tool of pavement analysis, does not quite capture the effect of various degree of drainability offer by various types of drainage layer on the predicted performance. It was found that pavement sections with high drainage efficiency almost have identical predicted performance to a similar 
pavement with lower drainage efficiency. The MEPDG predicted performance is largely a function of the stiffness of the drainage layer rather than its hydraulic properties. Depending on the type of pavement, the MEPDG predicted pavement performance is not sensitive to the mix design of treated open-graded drainage layer.

6. Besides the stiffness of the base, the erodibility of the base layer appeared to be the only base material property that has a significant effect on the predicted performance of rigid pavement sections. In the absence of standardized tests to measure the erodbility level of base materials thus excluding the use of level 1 input for that material property, the predicted pavement performance based on level 3 erodibility levels should be treated with great caution. As a result therefore, analysis based on results of predicted performance that shows that the use of treated open-graded bases can lead to a reduction in slab thickness needs to be further assessed with higher level of MEPDG inputs.

7. Life cycle cost analysis based on the predicted MEPDG performance showed that pavement sections containing treated open-graded bases have higher life cycle cost than pavement sections containing traditional dense-graded bases. Even when the MEPDG predicted pavement performance between these two sections containing were doubled, the pavement sections with treated drainage layer will have to go an extra 30 years without maintenance in order to have identical life cycle costs as with those with densegrade bases.

\subsection{Recommendations for Future Research}

The results from this limited experimental program can be improved upon if the following tasks can be undertaken in the near future:

- A more detailed experimental program to determine an optimal mix design for treated drainage layer needs to be undertaken. This will entail the use of different asphalt binder types, cementing agents and also test mixes with different binder contents. This will help furnish Level 1 inputs for use in the MEPDG simulations. This additional testing will help provide data this is needed to assess the potential of using treated open-graded base 
layers like ATPB as a structural layer in addition to it being a drainage layer. The use of additives like cementitious materials and anti-stripping agents to improve the performance of both cement and asphalt treated open-graded mixes should also be explored.

- The need to build test sections containing drainage layers that are made from these open-graded mixes will furnish much needed information on the effects of these layers on the performance of the pavement and help in providing a more realistic life cycle cost analysis for these pavement sections.

- Appropriate durability tests for treated open-graded base course have to be developed or existing durability tests significantly modified for these types of materials.

- More MEPDG trial simulations of pavement containing these drainage layers should be carried out using higher levels of inputs. The use of level 3 inputs may have been a contributing factor to some of the unusual trends in the results of this research project.

- There is a need to establish appropriate acceptance criteria for opengraded bases. Since traditional acceptance criterion for bases are not applicable in the case of open-graded layers, a more realistic acceptance criterion that is easily measurable in the field and can be related to performance should be developed.

- The variation of coefficient of hydraulic conductivity of the drainage layer with age of the pavement needs to be investigated. Even though most pavement sections with a drainage layer are required by specification to provide either an aggregate or a geosythentic separator layer, it will be helpful to determine the changes in effective porosity of these layers as a result of internal compression of aggregate particles from the combined action of traffic and environmental forces. 
- Another area that needs further research is with regards to finding an optimal position of the drainage layer within the pavement structure. Currently specifications required that it be located just below the surface course. This is understandably so since the majority of moisture infiltrating the pavement structural section comes from precipitation. As a result locating it just below the pavement surface course is assume to provide the maximum effect of minimizing the pavement underlying layers from reaching saturated conditions. Recent research finding have indicated that these drainage layers can be in the zone of high stresses and that certain distresses like fatigue cracking in asphalt pavement can actually start in that layer. Bearing this in mind and with the knowledge that other sources of moisture entering the pavement besides precipitation like moisture coming from high water table and freeze/thaw cycle can also be significant, finding an optimal position for the drainage layer for a particular set of site conditions will have a positive effect on the effectiveness of subsurface drainage systems. A preliminary MEPDG simulation was run during this research in which the position of the ATPB was interchanged with that if the dense-graded aggregate base in PS2. Results of that analysis however showed that the predicted pavement performance is not sensitive to the position of the drainage layer.

○ The open-graded mixes investigated in this research have varying degrees of hydraulic, compressibility and durability properties. It will be helpful to use finite element software to determine how the combined effects of these properties affect pore-pressure generation and dissipation due to a transient load on saturated pavement sections containing these open-grade layers. Analytical studies of this nature based on experimental results of this research project can provide additional information needed in mix design selection. 


\subsection{Technology Transfer: Putting Research into Practice}

The motivation for this research came as a result of the three years work experience this researcher had with the Sierra Leone Roads Authority (SLRA), which is the government agency responsible for the National Highway System (NHS). Moisture induced distresses are widely prevalent in most of the roads within the NHS making moisture damage the principal factor responsible for the deteriorating conditions of the roads in that country. This came as no surprised due to the Sierra Leone's climate which boasts of very heavy rainfall. Sierra Leone has a tropical climate with heavy rains in the wet season which spans from May-October. The average annual rainfall can vary from a high of 230 inches on the coast to a minimum of 86 inches moving inland. However annual rainfall averages more than 125 inches a year in most of the country with Freetown the capital having average annual rainfall intensity of 144 inches.

Surprisingly, the pavement design process has not evolved fast enough to address this prevalent moisture related damages on many of the country's major highways. Sierra Leone got most of the money for road infrastructural development from donor agencies like the World Bank, International Monetary Fund (IMF), European Union (EU) and others. While these donor agencies provide the monies for the building of new and rehabilitated pavements, maintenance of these roads comes from local funds derived from a fuel levy tax. As a result therefore, the persistent premature failures of these new and rehabilitated pavements are putting an extreme maintenance burden on the NHS.

As a former British colony, most of the specifications for roads come from Oversea Road Notes, which are technical bulletins prepared by the Department for International Development (DFID), a British based organization providing technical assistance to former British colonies. Even though specifications contain in these technical bulletins were developed form road tests in other tropical regions, there is no record of any testing program conducted in Sierra Leone. One very important lesson learned during this research program is that durable and cost-effective pavement sections can be designed and constructed if all design is treated as local i.e. taking cognizance of local roadway materials properties, climate and traffic. Even in a small country like Sierra Leone there 
are clearly distinct climatic differences between coastal and inland regions and as such design and construction of pavement in these two regions should reflect the climatic differences if the objective of designing and constructing low life cycle cost pavements sections is to be realized.

Currently Sierra Leone uses dense graded aggregate base with high percentage of fines in the range of $10-15 \%$ for most Class A highways. As permeability results from this research study have shown the presence of such a high percentage of fines significantly reduces the value of the coefficient of hydraulic conductivity which makes the pavement practically impervious. Considering the country's high rainfall intensity, such a design scenario will caused the pavement structural sections to remain in saturated conditions for very long periods of time, hence the prevalence of moisture related distresses. There is no record of the use of treated bases like asphalt or cement stabilized bases. As was evident from the results of this research results, the aggregate and gradations under consideration produced pavement drainage bases with a very wide variability in hydraulic, mechanical and durability characteristics.

The fundamental lesson that a country like Sierra Leone could learn from results of this research study is the engineering reasons of why pavement behave the way they do in that the life of a pavement is an integral function of material properties, environmental factors, traffic and design philosophies. Potential areas wherein the results of this result can be put into practice in Sierra Leone setting in an effort to provide mitigating measures against moisture induced distresses and in the process improving the service life of pavement will be the development of a subsurface drainage manual for highways in Sierra Leone. The manual will address among other design issues the following:

1. Detailed material characterization of the common roadway aggregates for both coastal and inland regions. Pavement design in that region of the world is $100 \%$ empirical and as a result very little or no work has been done in trying to determine how the properties of these roadway aggregates affect pavement performance in these climatic regions. 
2. Development of appropriate gradation types for both coastal and inland regions that meet the drainage requirement of pavement in those two regions.

3. Determination of infiltration rates for pavement sections in both coastal and inland regions that will help in design of appropriate pavement sections for these two regions.

4. Development of material specifications for the use of both asphalt and cement treated open-graded bases. With the wide availability of both asphalt and cement binders, development of these base types will offer sound base alternatives for the design and construction of long lasting pavement sections.

5. Pavement design in that region of the world is $100 \%$ empirical, but it is hoped that this technology transfer will provide the basis for a transition to a more mechanical-empirical design framework. The MEPDG simulation runs carried out in this research project can lead to substantial economic benefits and Sierra Leone can develop its own version of the MEPDG. 


\section{REFERENCES.}

Abdallah I, Yuan D, Nazarian S. 2004. Validation of Software Developed for detrmining design modulus from Seismic Testing. The Center of Transportation Infrastructure Systems, University of Texas at El Paso. Texas Department of Transportation Research Report 1780-3.

Ahmed Z, White TD, Kuczek T. 1997. Comparative Field Performance of Subdrainage Systems. Journal of Irrigation and Drainage Engineering, 123:194-201

Alam M, Mjed M, Fekpe E. 2007. Freight Traffic Analysis. Office of Freight Management and Operations (HOFM) Federal Highway Administration Washington, D.C.

American Association of State Highways Transportation Officers (AASHTO). 1993. Guide for the Design of Pavement Structures. American Association of State Highway Transportation Officers, Washington D.C.

American Association of State Highways Transportation Officers (AASHTO) T209 2007. Standard Method of Test for Theoretical Maximum Specific Gravity and Density of Hot Mix Asphalt.

American Association of State Highways Transportation Officers (AASHTO ) T283 2007. Standard Method of Test for Resistance of Compacted Hot Mix Asphalt (HMA) to Moisture-Induced Damage.

American Association of State Highways Transportation Officers (AASHTO) provisional procedure P-125 .Determination of Saturated Hydraulic Conductivity using a Flexwall Permeameter.

American Association of State Highways Transportation Officers (AASHTO) T85 2010. Standard Method of Test for Specific Gravity and Absorption of Coarse Aggregate.

American Association of State Highways Transportation Officers (AASHTO) T99 2010.Standard Method of Test for Moisture-Density Relationship. 
American Society for Testing and Materials (ASTM ) D559 .Standard Test Methods for Wetting and Drying Compacted Soil-Cement Mixtures. Annual Book of ASTM Standards, Vol.12.09.

American Society for Testing and Materials (ASTM )D560 .Standard Test Methods for Freezing and Thawing of Compacted Soil-Cement Mixtures. Annual Book of ASTM Standards, Vol.08.12.09.

American Society for Testing and Materials (ASTM) D5084. Standard Test Methods for Measurement of Hydraulic Conductivity of Saturated Porous Materials Using a Flexwall Permeameter. Annual Book of ASTM Standards, Vol.08.12 2007.

American Society for Testing and Materials (ASTM) D6572. Standard Test Method for Bulk Specific Gravity and Density of Compacted Bituminous Mixtures Using Automatics Vacuum Sealing. Annual Book of ASTM Standards, Vol.08.12 2009.

ARA Inc 2004. Guide for Mechanistic-Empirical Design Guide of New and Rehabilitated pavement structures. Final Report for Project No. 1-37A. National Cooperative Highway Research Project (NCHRP), Washington, D.C.

Arika, CN, Carmelon DJ, Niebar J.L. 2009. Subsurface Drainage Manual for Pavement in Minnesota. Minnesota Department of Transportation (MDOT), St. Paul, Minnesota.

Ashford N, Wright PH. 2007. Drainage and Pavement design. In. Airport Engineering. p. 369-418. John Wiley and Sons, NY

Atchison GD, Richards BG.1965. A Broad Scale Study of Moisture Conditions in Pavement Systems throughout Australia. Butter worth, Australia. $56 \mathrm{p}$

Barksdale RD. 1978: Practical Application of Fatigue and Rutting Tests on Bituminous Base Mixes. Journal of the Association of Asphalt Paving Technologists, 47:161-174.

Barksdale RD, Hicks RG. 1997. Drainage Considerations to Minimize Distress at the pavement shoulder joint. Proceedings of the International Conference on Concrete Pavement Design, Purdue: 383-398. 
Baumgardner R H. 1992. Overview of permeable bases. Proceedings of International Conference on Performance and Prevention of Deficiencies and Failure, ASCE, New York.: 275-287.

Bear J. 1979. Hydraulics of Groundwater. McGraw-Hill Book Company, NY. 211 p.

Bejarno MO, Harvey JT. 2004. Analysis of Asphalt Concrete Pavements with and without Permeable Base Layers. Presented at the Transportation Research Board's 83rd Annual Meeting, Washington, D.C.

Benkelmann AC. 1959. Analysis of Flexible Pavement Deflection and Behavior Data. Highway Research Board, Synthesis 210:39-48.

Benkelmann AC. 1962. Structural Deterioration of Test Pavement: Flexible. Special Report 73, pp. 173-185, HRB, NRC, Washington D.C.

Bennet A, Hansen W, Smiley D. 2007. Performance of Michigan's Stabilized Base Projects. Michigan Department of Transportation (MDOT) Publications.

Bouchedid M. 2001. Permeability of Base Materials for Maine Roads. Master's Thesis, University of Maine, Maine.

Buchanan SM, TD White. 2005. Hot mix asphalt mix design evaluation using the Corelok vacuum-sealing device. Journal of Materials in Civil Engineering, 17:137 - 142.

California Department of Transportation (CalTrans). 2007. Life Cycle Cost Analysis Procedures Manual. CalTrans Pavement Standards Team and Division of Design, Sacramento, Ca.

Carpenter SH. 1990. Highway Subdrainage design by Microcomputer: DAMP: Drainage Analysis and Modeling Programs. Final Report, FHWA, Washington D.C.

Casagrande A, Shannon WL. 1951. Strength of soils under dynamic loads. Transaction of ASCE 114:755-772. 
Cedergren HR. 1960. Seepage requirements of Filters and Pervious Bases . ASCE Journal of Soil Mechanics and Foundation Division. 86: 21-30.

Cedergren HR. 1974. Drainage of Highway and Airfield Pavements. John Wiley, New York 1974.

Cedergren HR. 1989. Roads, Airfields and other Surface Facilities. In: Seepage, Drainage and Flow Nets. John Wiley New York pp. 337-341

Cedergren HR, Godfrey K.A. 1974. Water: Key cause of Pavement Failure. ASCE Journal of Civil Engineering. 44:78-82.

Ceran T, Newman RB. 1992. Maintenance Consideration in Highway Design. NCHRP Report 349, TRB, Washington, D.C.

Chen C, Ge L, Zhang J .2010. Modeling Permanent Deformation of Unbound Granular Materials under Repeated Loads. International Journal of Geomechanics. 10:236-242.

Christopher BR, VC McGuffey .1990. Pavement Subsurface Drainage. TRB, NRC, Washington D.C, Sixth International Conference on Concrete Roads.

Christopher BR, McGuffey VC. 1997. Pavement Subsurface Drainage System. NHCRP Synthesis 239.National Research Council, Transportation Research Board (TRB), Washington D.C.

Christopher BR, McGuffey VC .1997. Pavement Subsurface Drainage Systems. Journal of Transportation Research Record, 239: 1-10.

Christopher BC, Zhao A. 2001) Water in Pavement Systems. Christopher Consultants and Tenax Corporation, Georgia.

Christopher BR, Schwartz C, Boudren, R. 2006. Geotechnical Aspect of Pavement. FHWA, Washington D.C. 
Chu TY, Humphis WR. 1971. Investigation of Subgrade Moisture condition in connection with design of Flexible pavement structures. Research Project No.523, University of South Carolina.

Cole LW, Hall, MJ. 1997. Relative Costs of Various Concrete Pavement Features. Journal of Transportation Research Record. 1574:99-102.

Cooley LA, Jr., Prowell BD, ER Brown.2002. Issues Pertaining to the Permeability Characterisitcs of Coarse-Graded Superpave Mixes. National Center for Asphalt Technology, Auburn, AL.

Coree B. 2005. Implementing the M-E Pavement Design Guide in Iowa. Iowa Highway Research Board, Report No. TR-509, Center for Transportation Research and Education (CTRE) Iowa State University.

Crouch L, Cates M, Dotson V, Honeycutt K, Badoe D. 2003. Measuring the Effective Air Void Content of Portland Cement Pervious Pavements. Journal of Cement, Concrete, and Aggregates. 25: 23-30.

CSSA .Chemical Stabilization Pavement Moisture. MUD history, < http://www.haroconsulting.com/project_appl/pavements/PAVEMENT_MOISTURECONCERNS.pdf> (Aug 4, 2009).

Darter MI, Carpenter SH .1987. Techniques for pavement Rehabilitation- a Training Course, Report FHWAS-HI-90-022, Federal Highway Administration, Washginton D.C.

Delatte NJ. 2007. Subgrade, Subbase and Drainage. In: Concrete Pavement Design, Construction and Performance. Routledge Taylor and Francis Group, NY.

Dempsey BJ. 1972. Durability Testing of Stabilized Bases. Interim Report

Dempsey BJ and Elzeftay AA. 1975. Moisture movement and Moisture Equilibria in Pavement Systems. Illinois Cooperative Highway Research Program, Project IHR-604, Illinois. 
Eigenbrid KD, Knuttson S. 1992. Measurement of pore pressures at the interface of asphalt cement concrete pavement and soil. Proceedings of the Canadian Permafrost Conference, Canadian Geotechnical Society, Edmonton, Canada: p. 44.1-44.10

Elfino MK, Shabbier HM. 2007. Subsurface Drainage and Premature distresses in concrete pavements: A case study in Virginia. Journal of Transportation Research Record, 2004:141-149.

Elsayed AS, Lindly JK. 1996. Estimating Permeability of untreated Roadway Bases. Journal of Transportation Research, 1519:11-28.

ERES Consultants .1996. Performance of Subsurface Drainage. Interim Report. TRB, NRC, Washington D.C.

ERES Consultants .1999. Pavement Subsurface Drainage Design- Reference Manual. U.S. Department of Transportation, FHWA, Washington D.C.

Faghri M, Martin HD. 2002. Performance Improvement of Open-graded Asphalt Mixes. Report No. URITC 00-44.Transportation Research Center, University of Rhode Island,

Fang H. 1990. Soil Stabilization and Grouting. In: Foundation Engineering Handbook. 'Kluwer Academic Publishing, Massachusetts, U.S.A.

Feng A, Hua J, White TD. 1999. Flexible Pavement Drainage Monitoring, Performance and Stability. Purdue University, West Lafayette, IN.

Federal Highway Administration. 1990. FHWA Technical Guide Paper 90-01: Subsurface Pavement Drainage. Federal Highway Administration Publication No. FHWA-SA-92-008, Washington, D.C.

Federal Highway Administration.1992.Drainable Pavement Systems: Participant Handbook, Demonstration Project, U.S. DOT, Washington D.C.

Federal Highway Administration. 1992. Reference Manual Construction of Pavement Subsurface Drainage Systems. U.S. DOT, Washington D.C. 
Federal Highway Administration.1997. Improved Guidance for users of the 1993 AASHTO Flexible pavement Design Procedures". TechBrief publications, FHWA, Washington D.C.

Forsyth R.A., Wells G.K., and Woodstrom J.H. (1987).”Economic Impact of Pavement Subsurface Drainage”. Journal of Transportation Research Record, 1121:77-85.

Forsyth RA .1994. Asphalt Treated Permeable Base: Its evolution and Application. National Asphalt Pavement Association, Report Number Q117:23-30, Lanham, MD.

Gharaibeh NG, Darter MI 2001. Benefits and Costs of Jointed Plain Concrete Pavement Design Features. Journal of Transportation Research Record, 1778:1- 8.

Grogan WP. 1994. Evaluation of Drainable Base Courses for Pavements. Proceedings of the Materials Engineering Conference. Issue No: 804:693-700.

Guclu A, Ceylan H. 2009. Sensitivity Analysis of Rigid Pavements Using MechanisticEmpirical Design Guide Software. Journal of Transportation Engineering, 135, No.8:555562.

Guinee JW, Thomas CE. 1955. Subgrade Moisture Condition under an Experimental Pavement. Bulletin 111, HRB, NRC, Washington D.C.

Guthrie WS, Hermanssen A, Woffinden KH. 2006. Saturation of Granular Base Material Due to Water Vapor Flow during Freezing: Laboratory Experimentation and Numerical modeling. Current Practices in Cold Regions Engineering Proceedings of 13th International Conference on Cold Regions Engineering.

Hagen MG, Cochran GR .1996. Comparison of Pavement Drainage Systems. Journal of Transportation Research Record, Volume 1519:1-10

Hall JW, Mallela J, Smith KL. 2005. Stabilized and Drainable Bases for Rigid Pavement. Research Report IPRF-01-G-002-021(G).Innovative Pavement Research Foundation (IPRF), IL. 
Hall KT, Correa, CE. 2003. Effects of Subsurface Drainage on Performance of Asphalt and Concrete Pavement. NCHRP Report 499, TRB, Washington D.C.

Hansen W, Smiley DL, Bennet A, Krom B. 2009. Performance Evaluation of JRCP with Stabilized Open-graded Drainage Courses. MDOT Research report RC-1523, Lansing, MI.

Harvey J, Tsai B, Long F, Hung D. 1999. Asphalt Treated Permeable Base: Laboratory Testing, Performance, Prediction, and Evaluation of the Experience of Caltrans and Other Agencies. California Department of Transportation (CalTrans), Sacramento, CA.

Head KH.1986. Effective Stress Testing. In: Manual of Soil Laboratory Testing. Pentech Press, London, England.

Hicks LD. 1948. Observation of Moisture Contents and Densities of Soil Type Bases and their Subgrades. Highway Research Board, 28:10-18.

Hindley G. 1972. A History of Roads. Lyle Stuart, New York, NY.

Hoerner TD, Smith KD, Bruinsma JE. 2004. Incremental Costs and Performance Benefits of Various Features of Concrete Pavement. Federal Highway Administration, Washington D.C.

Hoffman GL. 1982. Subbase Permeability and Pavement Performance. Journal of Transportation Research Record. 849:12-18.

Holtz RD, Kovacs WD. 1981. Compaction. In: An Introduction to Geotechnical Engineering. Prentice Hall Inc, Englewood Cliffs, N.J.

Hoppe EJ. 2000. Frost action consideration in Roadway Construction. Virginia Transportation Research Council, VA.

Jung Y, Zollinger DG, Won M, Wimsatt AJ. 2009. Subbase and Subgrade Performance Investigation for Concrete Pavements. Texas Transportation Institute, The Texas A\&M University System. TxDot, Austin, TX. 
Kannekanti V, Harvey J. 2006. Sensitivity Analyses of 2002 Design Guide Rigid Pavement Distress Prediction Models. Final Report No. UCPRC-DG-2006-0 California Department of Transportation. Sacramento, CA.

Kazmierowski TJ, Bradbury A, Hajek J. 1994. Field Evaluation of Various Types of Open-Graded Drainage Layers. Journal of Transportation Research Record 1434: 29-36.

Kersten MS. 1945. Subgrade Moisture Conditions beneath Airport Pavements. Journal of Transportation Research Board, 25:450-463.

Kohn SD, Tayabji S, Okanoto P .2003. Base and Subbase Construction. In: Best Practices for airport Portland cement concrete pavement construction. Innovative Pavement Research Foundation, IL.

Kubler G. 1963. Influence of Meteorological Factor on Frost Damage in Roads. HRB Synthesis 33:217-255.

Li J, Pierce L, Hallenbeck M, Uhlmeyer, J. 2009. Sensitivity of Axle Load Spectra in MEPDG for WsDOT. Journal of Transportation Research Record, 2093:50-56.

Lindy JK, A.S. Elsayed. 1995. Estimating Permeability of Asphalt-Treated Bases.” Journal of Transportation Research Record, 1504:103 - 111.

Low PF, Lovell C.W. Jr. 1959. The Factor of Moisture in Frost Action. Highway Research Board, Bulletin 225:23-24.

Macari EJ, Wright TR.2007. Effectiveness Analysis of Subsurface Drainage Features based on Design Adequacy. Journal of Transportation Research Record, 1709: 69-77.

Mallela J, Titus-Glover L, Darter MI.2000. Considerations for providing Subsurface Drainage in Jointed Concrete Pavements. Journal of Transportation Research Record, 1709: 1-9.

Mallela J, Larson G, Wyatt T, Hall J, Barker W.2002. User Guide for Drainage requirement in pavements, DRIP 2.0 Microcomputer program. FHWA, Washington D.C. 
Markow MJ .1982. Simulating Pavement Performance under Various Moisture Conditions. Journal of Transportation Research Record, 849:24-29.

Marks A. 2008. Pervious Concrete Pavement- How Important is Compressive Strength. Journal of Green Building, 3:36-43.

Mayrberger T, Hodek RJ. 2007. Resilient Modulus at the Limits of Gradation and Varying Degrees of Saturation. Final Report Research Report RC-1497. Michigan Department of Transportation, Lansing, MI.

McCracken JK, Vandenbossche JM, Asbahan RA .2008. Effect of the MEPDG Hierarchal Levels on the Predicted Performance of a Jointed Plain Concrete Pavement. Proceedings of 9th International Conference on Concrete Pavement, San Francisco, California, U.S.A., 2008:153-169.

McEnroe BM. 2006. Drainability of granular bases for highway pavements. Journal of Transportation Research Record, 1434:23-28.

McEnroe BM, Zon S.1993. Simulation of Subsurface Drainage of Highway Pavements. Journal of Hydraulic Engineering, 1:483-488.

Minnesota Department of Transportation Pavement Manual .2007. Chapter 5 Design Section. Minnesota Department of Transportation publication:http://www.dot.state.mn.us/materials/pvmtdesign/docs/Chapter_5-3.pdf.

Moulton LK. 1980. Highway Subdrainage Design. Office of Research and Development, FHWA, Washington D.C.

Moulton LK, Dubbe EC.1966. A Study of the Relationship between Air temperatures and Depth of Frost Penetration as related to pavement performance of West Virginia Highways. West Virginia Department of Transportation.

Nagi MA, Okamoto PA, Kozikowski, RL, Hover KC. 2007. Evaluating Air-Entraining Admixtures for Highway Concrete. NCHRP Report No. 578, Transportation Research Board, Washington D.C. 
National Cooperative Highway Research Project. 1998. Pavement Subsurface Drainage Systems. Road Management and Engineering Journal, Synthesis of Highway Practice. 239:23-42.

National Cooperative Highway Research Project. 2002. Performance of Pavement Subsurface Drainage. Research Results Digest, Number 268.

National Cooperative Highway Research Project. 2007. Hydraulic Design, Maintenance, and Construction Details of Subsurface Drainage Systems. NRC, Washington D.C.

National Ready Mixed Concrete Association. 2004. Freeze-Thaw Resistance of Pervious Concrete. NRMAC Publications, Silver Spring, Maryland.

Gupta J, Heydinger A, Randolph B. 1999. Permeability \& Stability of Base and Subbase Materials. Ohio Department of Transportation (ODOT) Research report.

Ozbay K, Jawad D, Parker A, Hussein S .2004. Life Cycle Cost Analysis: State-of-thePractice vs. State-of-the-Art. Journal of Transportation Research Record, 1864:62-70.

Quintero NM. 2007. Validation of Enhanced Integrated Climatic Model (EICM) for the Ohio Test Road at U.S. 23. Master of Science Thesis, Civil Engineering. Ohio University.

Rabab'ah SR.2007. Integrated Assessment of Free Draining Base and Subbase Materials. Phd Dissertation, University of Akron, $\mathrm{OH}$.

Rangaraj PR, Amirkhania S, Guven, Z. 2008. Life Cycle Cost Analysis for Pavement Type Selection. Final Report, South Carolina Department of Transportation.

Reddi LN. 2003. Principles and applications of Subsurface Drainage in Pavement Systems. In: Seepage in Soils. p. 316-320.John Wiley and Sons, NY.

Redus JF. 1952. Moisture Conditions under Flexible Airfield Pavements. ASCE Journal of Soil Mechanics and Foundation Division. 83:20-26 
Ridgeway H H.1982. Pavement Subsurface Drainage Systems. NCHRP Synthesis 96. Transportation Research Board, Washington, D. C.

Rodden R . 2010. Drainable Base Layers Revisited. Proceedings from the Tennessee Concrete Pavement Conference. American Concrete Pavement Association (ACPA).

Russam K. 1967. Subsoil Drainage and Structural Design of Roads. Road Research Laboratory, Report No. LRF 110, London, U.K.

Sargand SM, Wu S, Ludwig-Figueroa J. 2006. Rational Approach for Base Type Selection. Journal of Transportation Engineering, 132:753-762.

Schmitt R, Owusu-Ababio S, Crovetti J. 2010. Performance Evaluation of Open Graded Base Course with Doweled and Non-doweled Transverse Joints on USH 18/151, STH 29, and USH 15. Wisconsin Department of Transportation, Division of Business Services. Research Coordination Section, Madison, WI.

Smith N .2004. Permeability of Pervious Portland Cement Pavement. Master of Science Thesis, Tennessee Technological University.

Smith BC, Diefenderfer .2010. Analysis of Virginia Specific Traffic Data for Inputs for use with MEPDG. Final Report VTRC 10-R19. Virginia Transportation Research Council, Charlottesville, VA.

Stevens TC, Maner AW, Shelburne TE. 1949. Pavement Performance Correlated with Soil Areas. Highway Research Board Proceedings, 29:445-466.

Straub AL, Dudden PF, Moorhead FT. 1969. Frost Penetration and Moisture Changes related to Highway Pavement Shoulders". HRB Synthesis 276:39-49.

Tangpithakkul R.1997. Study of Permeability of Base Materials. Master's Thesis, Ohio University, $\mathrm{OH}$.

Taamneh MM. 2009. Long Term Monitoring and Evaluation of Drainable Bases at I-90 Test Road. PhD Dissertation, University of Akron, $\mathrm{OH}$. 
Thom N H, Brown S F.1987. Effect of moisture on the structural performance of a crushed-limestone road base.' Journal of Transportation Research Record, 1121:50-56.

Toan DV. 1975. Effects of Base course Saturation of Flexible Pavement Performance. PhD Thesis, University of Auckland.

Turner KA jr, Jumikis AR. 1956. Subsurface Temperatures and Moisture Contents in Six New Jersey Soils. HRB Synthesis $135: 77-109$

U.S. Department of Transportation .2002. Life-Cycle Cost Analysis Primer. Office of Asset Management, U.S. DOT, Washington, D.C.

Van Sambeek RJ. 1989. Synthesis on Subsurface Drainage of Water infiltration on a pavement structure. Minnesota Local Roads Research Board, Materials and Research Laboratory, Maplewood, MN.

Vaswani NK. 1974. Subgrade Moisture and Temperature Variations under Road Pavements in Virginia. Virginia Highway Research Council, Charlotte, Virginia.

Velasquez R, Hoegh K, Yut I, Cochran G, Marasteanu M, Khazanovic L. 2009. Implementation of the MEPDG for New and Rehabilitated Pavement Structures for Design of Concrete and Asphalt Pavements in Minnesota". Final Report, Minnesota Department of Transportation, St. Paul, Minnesota.

Von Quintus HL, Darter MI, Mallalela J. 2009. Recommended Practice for Local Calibration of MEPDG. NCHRP, Program Report, Washington D.C.

Webb D, Sholar G, Musselman J, Upshaw P, Page J. 2007. An Evaluation of Asphalt Treated Permeable Base". Research Report FL/DOT/SMO/07-511. Florida Department of Transportation.

Wielinski JC. 2007. Investigation of Permeable Asphalt Treated Bases in Alabama. Master's thesis, Auburn University, AL. 
Wilde WJ, Waakles S, Harrison R .1999. Life Cycle Cost Analysis of Portland Cement Concrete Pavements. Final Report No. 0-1739-1, Texas Department of Transportation Research and Technology Transfer Section/Construction Division.

Wyatt TR, Macari EJ. 2000. Effectiveness Analysis of Subsurface Drainage Features Based on Design Adequacy. Journal of Transportation Research Record, Volume 1709: 69-77.

Yoder EJ, Witczak MW. 1975. Subgrades. In: Principles of Pavement Design. John Wiley and Sons, New York. p. 100-143

You Z, Goh SW, Williams CR. 2009. Development of Specifications for the Superpave Simple Performance Tests. Michigan Technology University. MDOT Publications, Lansing, MI.

Yu HT, Khazanovich L, Shremah PR, Dater MI, Von Quinton H. 2006. Guidelines for Subsurface Drainage Based on Performance. NCHRP Report 1-34, TRB, Washington D.C.

Zaghloul S, Ayed A, Ahmed Z, Henderson B, Springer J, Vitillo N. 2004. Effect of Positive Drainage on Flexible Pavement Life-Cycle Cost. Journal of Transportation Research Record, 1868:135-141.

Zaniewski JP, Srinivasan G. 2004. Evaluation of Indirect Tensile Strength to Identify Asphalt Concrete Rutting Potential. Asphalt Technology Program, Department of Civil and Environmental Engineering, West Virginia University, Morgantown, West Virginia.

Zapata CE, Houston, W.N. 2008. Calibration and Validation of Enhanced Integrated Climatic Model for Pavement Design. NCHRP Report 602, Transportation Research Board, Washington D.C.

Zhou H, Moore L, Huddleston J, Grower, J.1993. Determination of free-draining base materials properties. Journal of Transportation Research Record, 1425:54-63. 
Zimmerman KA, Smith KD, Grogg M.G. 2000. Applying Economic Concepts from LifeCycle Cost Analysis to Pavement Management Analysis. Journal of Transportation Research Record, 1699:58-65. 


\section{APPENDIX A}

2005 Construction Cost Index of various pavement materials taken from Michigan Engineers' Resource Library (MERL): http://merl.michiganltap.org/

\section{LCCA Unit Prices}

2/10/05 NEW 2/10/0 5 NEW 2/10/0 5 NEW

Price Updates: 07-06-2005

$1 \& 21 \& 23,4 \& 53,4 \& 56 \& 76 \& 7$

2050010 Cyd Embankment, CIP \$3.36 \$3.08 \$9.88 \$5.70\$3.38\$3.14

2050011 Cyd Embankment, LM \$7.80 \$7.36\$2.93 \$3.36\$12.17\$9.93

2050016 Cyd Excavation, Earth $\$ 4.28 \$ 4.59 \$ 1.79 \$ 2.04 \$ 4.16 \$ 4.85$

2050023 Cyd Granular Material, Cl II - \$6.64 - \$6.64 - \$6.64

2050024 Cyd Granular Material, Cl III $\$ 10.00 \$ 10.00 \$ 10.00 \$ 10.00 \$ 10.00 \$ 10.00$

2050040 Cyd Subgrade Undercutting, Type I \$5.34 \$5.33 \$5.34 \$7.39\$5.34 \$5.30

2050041 Cyd Subgrade Undercutting, Type II \$3.91 \$6.70 \$12.46 \$12.52 \$16.35 \$16.17

3010002 Cyd Subbase, CIP \$6.45 \$6.77 \$4.31 \$5.32 \$10.05\$10.00

3020008 Syd Aggregate Base, 3 inch $\$ 2.50 \$ 5.00 \$ 2.50 \$ 5.00 \$ 2.50 \$ 5.00$

3020010 Syd Aggregate Base, 4 inch $\$ 3.35 \$ 5.00 \$ 6.26 \$ 2.52 \$ 3.17 \$ 3.45$

3020012 Syd Aggregate Base, 5 inch $\$ 3.66 \$ 4.70 \$ 5.71 \$ 3.32 \$ 3.56 \$ 3.76$

3020016 Syd Aggregate Base, 6 inch $\$ 3.75 \$ 3.78 \$ 4.29 \$ 4.19 \$ 3.79 \$ 3.85$

3020018 Syd Aggregate Base, 7 inch $\$ 4.48 \$ 4.48 \$ 4.48 \$ 4.48 \$ 4.48 \$ 4.48$

3020020 Syd Aggregate Base, 8 inch $\$ 4.32 \$ 4.45 \$ 2.62 \$ 3.20 \$ 5.84 \$ 5.82$

3020022 Syd Aggregate Base, 9 inch $\$ 6.48 \$ 4.94 \$ 5.53 \$ 4.24 \$ 7.34 \$ 5.71$

3020026 Syd Aggregate Base, 10 inch $\$ 9.00 \$ 5.41 \$ 9.00 \$ 5.41 \$ 9.00 \$ 5.41$

3020028 Syd Aggregate Base, 11 inch $\$ 7.38 \$ 11.00 \$ 7.38 \$ 11.00 \$ 7.38 \$ 11.00$

3020030 Syd Aggregate Base, 12 inch \$4.41 \$5.24 \$4.41 \$5.24\$4.41 \$5.24

3020050 Syd Aggregate Base, Conditioning $\$ 1.84 \$ 1.84 \$ 1.37 \$ 0.65 \$ 0.75 \$ 0.75$

3030001 Syd Open-Graded Dr Cse, 4 inch $\$ 3.36 \$ 2.15 \$ 4.39 \$ 2.47 \$ 2.20 \$ 1.54$

3037011 Syd Open-Graded Dr Cse, 6 inch $\$ 3.93 \$ 3.93 \$ 3.93 \$ 6.06 \$ 3.93 \$ 6.03$

3037011 Syd Open-Graded Dr Cse, 16 inch $\$ 6.11 \$ 8.27 \$ 6.11 \$ 8.27 \$ 6.11 \$ 8.27$ 
3030020 Syd Geotextile Separator $\$ 0.81 \$ 0.86 \$ 0.78 \$ 0.78 \$ 0.83 \$ 0.91$

3040001 Syd Rubblized Pavt Operation \$4.51 \$4.44 \$3.15 \$1.93 \$2.88 \$2.64

3050002 Syd HMA Base Crushing and Shaping $\$ 0.87 \$ 0.90 \$ 0.87 \$ 0.97 \$ 0.87 \$ 0.90$

$4040021 \mathrm{Ft}$ Underdrain, Edge of Pavt, 12 inch $\$ 3.30 \$ 3.30 \$ 3.30 \$ 3.30 \$ 3.30 \$ 3.30$

$4040025 \mathrm{Ft}$ Underdrain, Edge of Pavt, 18 inch $\$ 3.05 \$ 3.05 \$ 3.05 \$ 3.05 \$ 3.05 \$ 3.05$

4040041 Ft Underdrain, Pipe, Open-Graded, 4 inch - \$3.10 - \$3.10 - \$6.44

4040043 Ft Underdrain, Pipe, Open-Graded, 6 inch $\$ 7.13 \$ 3.67 \$ 3.27 \$ 3.29 \$ 10.78$

$\$ 4.08$

$4040061 \mathrm{Ft}$ Underdrain, Subbase, 4 inch $\$ 2.63 \$ 2.63 \$ 3.52 \$ 3.48 \$ 3.73 \$ 5.69$

$4040063 \mathrm{Ft}$ Underdrain, Subbase, 6 inch $\$ 3.10 \$ 2.47 \$ 3.56 \$ 3.78 \$ 4.13 \$ 5.75$

4040081 Ft Underdrain, Subgrade, Open-Graded, 4 inch - - - - -

4040083 Ft Underdrain, Subgrade, Open-Graded, 6 inch \$4.27 \$4.27\$7.87\$6.24 \$12.25

$\$ 7.13$

5020003 Syd Cold Milling HMA Surface $\$ 0.77 \$ 0.79 \$ 0.77 \$ 0.76 \$ 0.77 \$ 1.40$

5020004 Syd Cold Milling Conc Pavt \$3.23 \$2.38 \$5.92 \$4.52 \$6.35 \$4.81

5020015 Ft Joint and Crack, Cleanout \$1.66 \$0.86 \$1.00\$1.47\$1.71 \$1.52

5020020 Ft Pavt Joint and Crack Repr, Det 7 \$6.44 \$4.77 \$9.47 \$8.81 \$5.11 \$4.48

5020021 Ft Pavt Joint and Crack Repr, Det 8 \$9.35 \$5.75 \$8.02 \$10.73 \$3.90 \$3.84

5020025 Ton Hand Patching \$46.07 \$64.05 \$36.13 \$34.82 \$49.44 \$51.35

5020030 Ton HMA, 2 C $\$ 34.50 \$ 33.47 \$ 34.50 \$ 34.50 \$ 34.50 \$ 31.05$

5020031 Ton HMA, 3C \$33.00\$33.00\$36.50\$40.44\$31.79\$34.08

5020032 Ton HMA, 4C \$30.04\$30.91 \$34.33\$37.73 \$32.36\$35.24

5020033 Ton HMA, 11A $\$ 29.16 \$ 31.73 \$ 33.22 \$ 30.59 \$ 29.16 \$ 31.36$

5020034 Ton HMA, 13A \$29.16 \$31.73\$33.22 \$30.59\$29.16\$31.36

5020035 Ton HMA, 36A $\$ 29.16 \$ 31.73 \$ 33.22 \$ 30.59 \$ 29.16 \$ 31.36$

5020036 Ton HMA, 36B $\$ 29.16 \$ 31.73 \$ 33.22 \$ 30.59 \$ 29.16 \$ 31.36$

5020037 Ton HMA, 2 E03 \$29.16 \$31.73\$33.22 \$30.59\$29.16\$31.36

5020038 Ton HMA, 2 E1 $\$ 24.90 \$ 24.90 \$ 24.90 \$ 29.34 \$ 34.18 \$ 34.18$

5020039 Ton HMA, 2 E3 $\$ 32.94 \$ 36.00 \$ 39.65 \$ 36.00 \$ 35.54 \$ 36.00$

5020040 Ton HMA, 2 E10 $\$ 37.60 \$ 37.60 \$ 37.60 \$ 37.60 \$ 37.60 \$ 37.60$ 
5020041 Ton HMA, 2 E30 $\$ 33.50 \$ 34.00 \$ 33.50 \$ 34.00 \$ 33.50 \$ 34.00$

5020042 Ton HMA, 2E50 $\$ 40.55 \$ 43.64 \$ 40.55 \$ 43.64 \$ 40.55 \$ 43.64$

5020043 Ton HMA, $3 \mathrm{E} 03 \$ 29.16 \$ 31.73 \$ 33.22 \$ 30.59 \$ 29.16 \$ 31.36$

5020044 Ton HMA, 3E1 \$24.90\$24.90\$24.90\$29.34\$34.18\$34.18

Re gi o $n$

These are the unit construction prices of the various pavement materials i.e. subgrade, subbase and base, used in the Life Cycle Cost Analysis (LCCA). The unit prices were used to compute the pavement trial sections containing the various permeable aggregates under investigation. 


\section{APPENDIX B:}

\section{COPYRIGHT}

1. Received permission to reproduced Fig 5.1 The email granting the permission is hereby included:

\section{Re: Pemission to use Fig 3.14 in} your report

From: dianeh@mail.utexas.edu

To: aakoroma@mtu.edu
Fri Apr 082011 10:51:13 GMT-0400 (Eastern Daylight Time)

3. Abdul,

The director of the center gives you permission. He stated to be sure to site the reference.

Thank you for seeking permission.

Diane

Diane L. Higginbotham, Executive Assistant

The University of Texas at Austin

Center for Transportation Research

1616 Guadalupe, Suite 4.202, Austin, TX 78701-1255

Campus Mail code: D9300

http://www.utexas.edu/research/ctr

Ph: 512.232.3125 Fax: 512.232.3153

What starts here changes the world...

On 4/8/11 8:46 AM, "Abdul Koroma" <aakoroma@mtu.edu> wrote:

4. Dear Diane,

I'm a Abdul Koroma, a student reading for his $\mathrm{PhD}$ at Michigan Technological

University. I'm in the process of finalizing my dissertation and as a result I'm asking your permission to use Fig 3.14 in the report titled "LIFE CYCLE COST ANALYSIS OF PORTLAND

CEMENT CONCRETE PAVEMENTS". It's a 1999 TxDot publication that was done by your research center. My dissertation is on pavement subsurface drainage and I would like to use that figure as an illustration the various stages of a life cycle cost analysis. I contact TxDOT a couple of days ago and was duly informed that Center for Transportation Research has the licensing right to the report. Thanks and hope to hear from you at your earliest convenience.

$--$

Ph.D Candidate

Department of Civil Engineering

Michigan Technological University 
Houghton, Michigan.

Office Tel: 906-487-2100

2. Fig 4.1 is a material that is in the public domain. It first appeared in a publication dated 1957 which is well within the stipulated time for a material to part of the public domain repository.

3. Figure 2.1, Figure 5.2. Figure 5.15 and Figure 5.16 fall under the doctrine of ,fair use' since they met the following conditions:

1. The purpose and character of the use, including whether such use is of commercial nature or is for nonprofit educational purposes

2. The nature of the copyrighted work

3. The amount and substantiality of the portion used in relation to the copyrighted work as a whole

4. The effect of the use upon the potential market for, or value of, the copyrighted work

Figure 2.2 and Figure 6.2 have been adapted so extensively that no permission was needed to reproduce them. 